Fernando Stancato

\title{
ANÁLISE DO AMBIENTE TÉRMICO DE CABINE DE AERONAVE
}

São Paulo 


\section{Fernando Stancato}

\section{ANÁLISE DO AMBIENTE TÉRMICO DE CABINE DE AERONAVE}

Tese apresentada à Escola Politécnica da Universidade de São Paulo para obtenção do título de Doutor em Engenharia

Área de Concentração:

Engenharia Mecânica

Orientador:

Arlindo Tribess

São Paulo 
Este exemplar foi revisado e alterado em relação à versão original, sob responsabilidade única do autor e com anuência de seu orientador

São Paulo, 06 de maio de 2009.

Assinatura do Autor

Assinatura do Orientador

\section{FICHA CATALOGRÁFICA}

Stancato, Fernando

Análise do ambiente térmico de cabine de aeronave / Fernando Stancato - ed. rev. - São Paulo, 2009.

$154 \mathrm{p}$.

Tese (Doutorado) - Escola Politécnica da Universidade de São Paulo. Departamento de Engenharia Mecânica.

1. Conforto térmico 2. Troca de calor 3. Cabine 4. Aeronave I. Universidade de São Paulo. Escola Politécnica. Departamento de Engenharia Mecânica II. t 
A meus pais 


\section{AGRADECIMENTOS}

Ao Prof. Dr. Arlindo Tribess pela inestimável orientação, sugestões e estímulo para consecução desta tese.

Aos Profs. Drs. Cláudia Regina de Andrade e Jurandir Itizo Yanagihara pela contribuição no aprimoramento do trabalho.

A todos os colegas que de uma forma ou de outra contribuíram para a realização deste trabalho. 


\section{RESUMO}

Uma das maiores dificuldades que enfrentam os engenheiros responsáveis pelo conforto aeronáutico é proporcionar um bom nível de conforto térmico nas aeronaves. $\mathrm{O}$ espaço restrito entre os ocupantes, a pequena distância entre as fileiras de bancos, a grande variação de fontes térmicas e os campos de velocidade e temperatura de ar assimétricos, são alguns dos obstáculos que prejudicam as condições térmicas. Estes fatos têm levado a uma série de iniciativas em centros de pesquisa internacionais e no Brasil para melhor caracterizar a complexidade desse ambiente térmico e melhorar as condições de conforto térmico. No presente trabalho foram realizados estudos que lançam a base para a construção de uma metodologia numérica de análise do ambiente térmico de cabine e de avaliação de condições de conforto térmico em aeronaves. Os estudos compreendem a realização de trabalho experimental e de simulação utilizando CFD em seção de cabine de aeronave. Foram realizadas simulações e medições de temperaturas e velocidades do ar e de temperaturas equivalentes em seção de cabine de 12 passageiros, utilizando manequim térmico digital e experimental com 17 segmentos. As pessoas foram simuladas utilizando manequins com fontes de calor. Resultados do trabalho mostram que o modelo de turbulência k-E realizável apresentou os melhores resultados com refinamento de malha que permita atingir $y+$ próximo de 4. Resultados numéricos e experimentais apresentaram uma boa correlação, tanto nos campos de velocidade e temperatura do ar, quanto nas temperaturas equivalentes. Finalmente, a utilização de manequins térmicos digitas e experimentais mostra ser uma boa ferramenta para análise do ambiente térmico em cabine de aeronave. 


\begin{abstract}
One of the most difficult tasks for the aerospace interior comfort engineers is to promote a good thermal environment inside the aircraft cabin. The restricted space, asymmetric air velocity and temperature fields and the great variation of thermal environment conditions are some of the obstacles to get good cabin thermal comfort conditions. These facts led to a significant number of international and national research initiatives to understand this complex thermal environment and improve the cabin thermal comfort. In this work some CFD and experimental studies were carried out to form the basis of a numerical cabin thermal comfort analysis methodology. Experimental and CFD analysis of the equivalent temperatures and air velocities and temperatures in a 12 seat cabin mock-up using an experimental and a digital 17 segments thermal manikin were performed. Occupancy was simulated with heated manikins. The results showed that the realizable k- $\varepsilon$ turbulent model gave good results with a $y+$ around 4 at the manikin surface. Good correlation between numerical and experimental results led to an increased confidence in the use of experimental and digital thermal manikins to evaluate the aircraft cabin thermal ambient.
\end{abstract}




\section{LISTA DE ILUSTRAÇÕES}

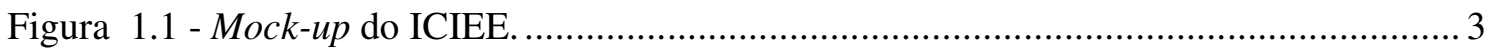

Figura 1.2 - Detalhe do mock-up mostrando os manequins térmicos e cilindros aquecidos

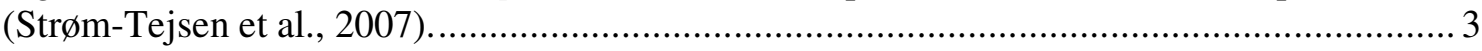

Figura 1.3 - Mock-up da Universidade de Purdue............................................................ 4

Figura 2.1 - Modelo cilíndrico da interação térmica: corpo humano - meio envolvente

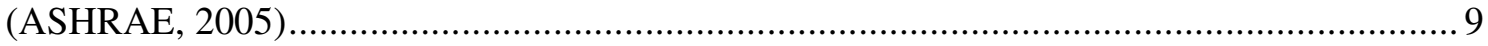

Figura 2.2 Zonas de conforto da ASHRAE para atividade sedentária ............................... 15

Figura 2.3 - Relação entre PMV e PPD .................................................................. 16

Figura 3.1 - Ilustração da definição de temperatura equivalente (adapt. de Nilsson, 2004).. 19

Figura 3.2 - Variação do PMV e do PPD com a umidade relativa

considerando condição de conforto. ....................................................................... 24

Figura 3.3 Os manequins comparados com as suas respectivas divisões de zonas.

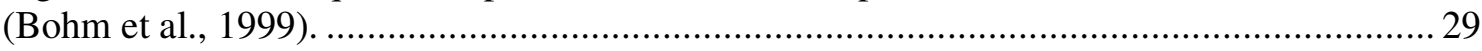

Figura 3.4 - Faixas de conforto e perfil de temperaturas equivalentes ideais para inverno

(esquerda) e verão (direita) (Wyon et al, 1989)............................................................... 37

Figura 3.5 - Faixas de conforto obtidas para condições de verão e inverno (Nilsson, 2004). 37

Figura 4.1 - Pontos de medição e valores das velocidades do ar para o primeiro caso

(esquerda) e segundo caso (direita). .............................................................................. 40

Figura 4.2 - Pontos de medição de velocidade (intensidade média e direção), índice de turbulência e temperatura do ar (Loomans et al., 2004).................................................... 41

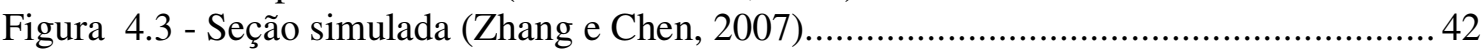

Figura 4.4 - Geometria utilizada por Manzumdar e Chen ( 2007). ................................... 43

Figura 4.5 - Distribuição do escoamento numérico (rosa) e experimental (preto) em uma

secção vertical da cabine (Chen e Chen, 2007)............................................................. 43

Figura 4.6 - Geometria da cabine utilizada por Zhang T. et al (2007a)............................... 44

Figura 4.7 - Assimetrias nas temperaturas equivalentes em cada segmento........................ 45

Figura 4.8 - Interior do mock-up com os manequins e os simuladores térmicos

(Strom-Tejsen et al, 2007)..................................................................................... 45

Figura 4.9 - Perfis de temperatura nos segmentos para os três grupos de assentos nas três

temperaturas do teste (Strom-Tejsen et al., 2007)......................................................... 46

Figura 5.1 Vista esquemática do interior do mock-up (Moura, 2009) .................................... 48

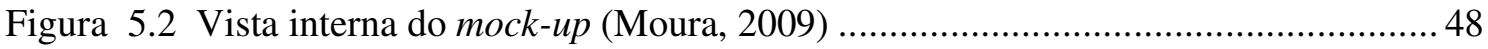

Figura 5.3 Detalhes do bin e de entradas de ar do mock-up - três em cada lado. (Moura

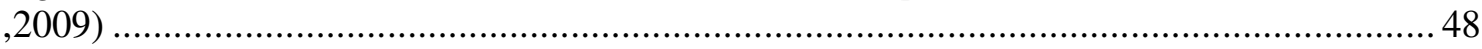

Figura 5.4 Detalhes do retorno do ar (Moura, 2009) …............................................... 49

Figura 5.5 Fluxograma do ar da cabine do mock-up (Moura, 2009) .................................. 49

Figura 5.6 Vistas, com dimensões, dos manequins aquecidos..................................... 50

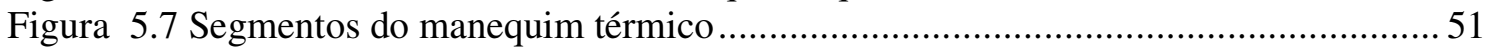

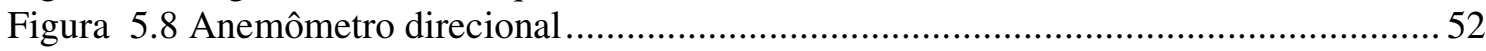

Figura 5.9 - Medidor de temperatura superficial ...................................................... 53

Figura 5.10 Painel de lâmpadas simulando radiação solar em uma das laterais do mock-up. 54

Figura 5.11 Plano de medições das velocidades e temperaturas do ar. ............................. 55

Figura 5.12 Posições de medições no plano vertical. ....................................................... 56

Figura 5.13 Manequim sentado para a calibração na cabine ............................................ 57

Figura 5.14 Manequim sentado em poltrona próxima ao corredor. ...................................59

Figura 5.15 Manequim sentado em poltrona próxima à fuselagem...................................6 60

Figura 6.1 Detalhes da seção de uma fileira de bancos com manequins simples.................. 66 


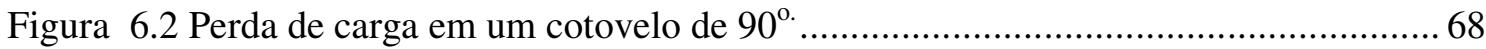

Figura 6.3 Malha superficial tetraédrica no retorno do ar e sobre os passageiros

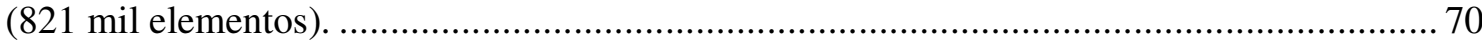

Figura 6.4 Malha superficial tetraédrica com prismas sobre os passageiros

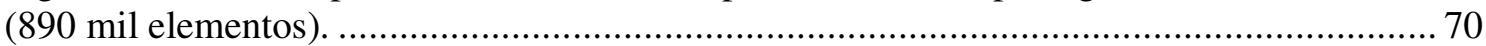

Figura 6.5 Corte na malha sobre os passageiros mostrando a camada de seis prismas

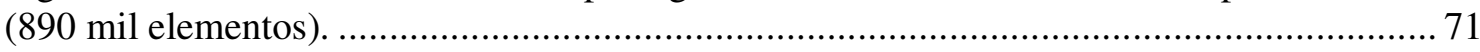

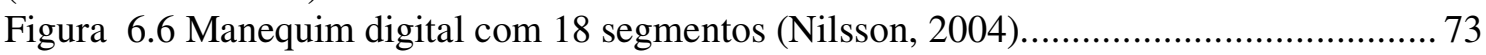

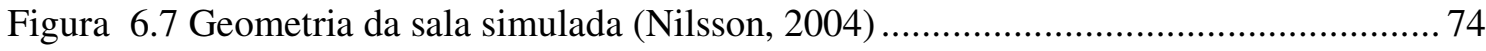

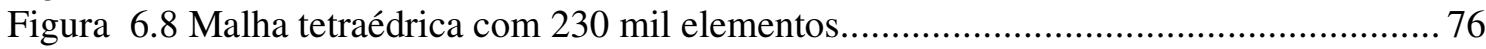

Figura 6.9 Malha de 230 mil elementos utilizada no estudo dos modelos de turbulência....... 77

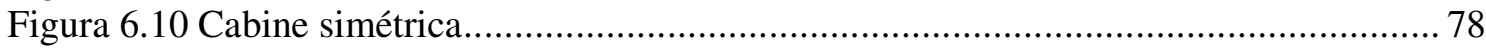

Figura 6.11 Superfícies da cabine virtual sem simuladores térmicos............................... 80

Figura 6.12 Geometria e superfícies da cabine virtual com simuladores térmicos ................ 81

Figura 6.13 Detalhe da malha superficial nas entradas de ar sobre os bins........................ 81

Figura 6.14 Malha gerada para a análise numérica de cabine sem ocupação........................ 82

Figura 6.15 Seção da malha da cabine sem ocupação na posição da seção das avaliações

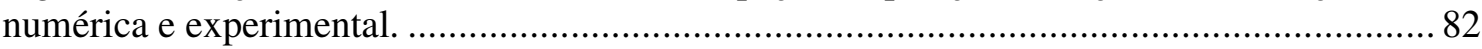

Figura 6.16 Malha superficial na cabine com os simuladores térmicos. ............................. 82

Figura 6.17 Geometria e malha utilizada nas simulações da cabine com os simuladores

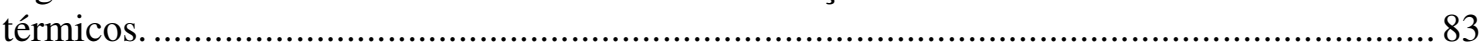

Figura 6.18 Corte horizontal na malha volumétrica de cabine com ocupação na altura dos

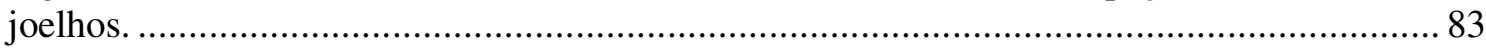

Figura 6.19 Corte vertical na altura dos joelhos em malha de cabine com ocupação. ............ 83

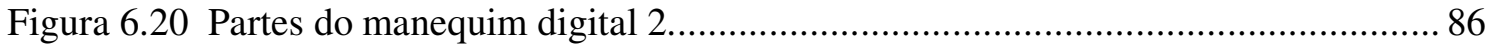

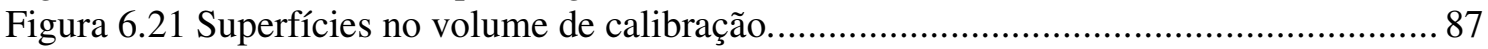

Figura 6.22 . Manequim térmico sentado junto à fuselagem. ........................................ 88

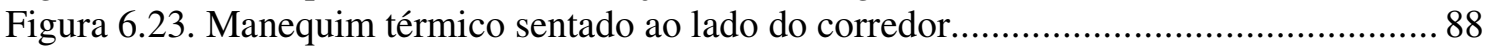

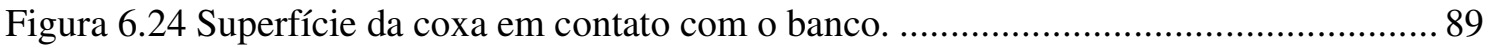

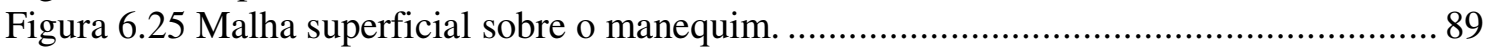

Figura 6.26 Malha superficial nas superfícies do mock-up ............................................ 90

Figura 7.1 Distribuição de temperaturas do ar em corte transversal da cabine ................... 93

Figura 7.2 Camadas térmicas junto aos manequins.................................................. 93

Figura 7.3 Zonas de recirculação do ar junto às cabeças dos manequins. .......................... 94

Figura 7.4 Detalhe da recirculação do ar sobre a cabeça do manequim. .............................. 94

Figura 7.5 Crescimento da camada térmica na lateral do manequim junto à parede. ......... 95

Figura 7.6 Recirculação do ar entre as coxas dos manequins contíguos. A visualização é

feita considerando a frente dos manequins. ................................................................. 95

Figura 7.7 Fluxos de calor dos passageiros para malhas tetraédricas e tetraédricas com

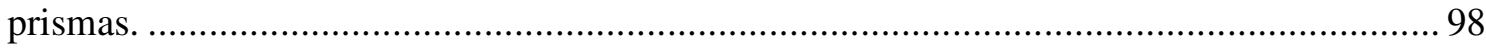

Figura 7.8 Distribuição de temperaturas do ar e dos manequins (corte transversal).............99

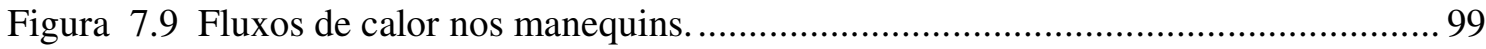

Figura 7.10 Diagrama de sensação térmica com temperaturas equivalentes na situação de

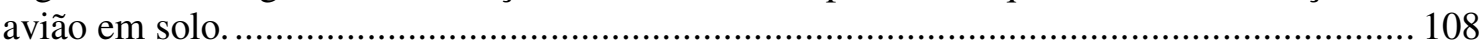

Figura 7.11 Distribuições das temperaturas equivalentes no caso do avião em solo. .......... 109

Figura 7.12 Distribuição das temperaturas equivalentes nas regiões de contato com o banco.

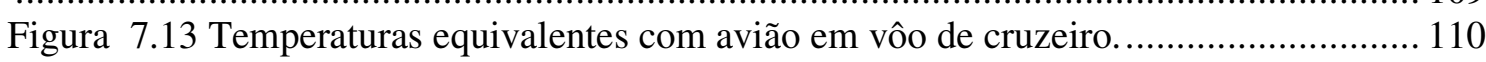

Figura 7.14 Temperaturas equivalentes com vista pela fuselagem. ................................ 111

Figura 7.15 Temperaturas equivalentes vistas pelo lado do corredor............................. 111 
Figura 7.16 Temperaturas Equivalentes para situação de emergência.

112

Figura 7.17 Distribuição das temperaturas equivalentes nos manequins no caso de situação de emergência

Figura 7.18 Campo de velocidades escalares.

Figura 7.19 Campo vetorial das velocidades mostrando duas áreas de recirculação. ......... 117

Figura 7.20 Campo de temperaturas do ar.

Figura 7.21 Campos de velocidades vetoriais e de temperaturas do ar na seção de medição com posição do ponto de estagnação dos jatos.

Figura 7.22 Campos de velocidades vetoriais e de temperaturas do ar na seção mediana dos simuladores térmicos.

Figura 7.23 Campos calculados de velocidades vetoriais e de temperaturas do ar na seção de medição.

Figura 7.24 Campo de vetores de velocidades calculadas (preto) e medidas (azul).

Figura 7.25 Temperaturas equivalentes experimentais e numéricas com manequim posicionado na janela com simuladores com dissipação de $70 \mathrm{~W} / \mathrm{m}^{2}$.

Figura 7.26 Temperaturas equivalentes experimentais e numéricas com manequim posicionado na janela com simuladores com dissipação de $50 \mathrm{~W} / \mathrm{m}^{2}$.

Figura 7.27 Temperaturas equivalente experimentais e numérica com manequim posicionado

na janela com simuladores com dissipação de $0 \mathrm{~W} / \mathrm{m}^{2}$.

Figura 7.28 Valores de $t_{\text {eqs }}$ experimentais para os lados esquerdo e direito (caso com dissipação térmica de $70 \mathrm{~W} / \mathrm{m}^{2}$ ).

Figura 7.29 Fluxos de radiação do manequim no caso com dissipação de $70 \mathrm{~W} / \mathrm{m}^{2}$.

Figura 7.30 Fluxos de calor por convecção do manequim no caso com dissipação de 70

$\mathrm{W} / \mathrm{m}^{2}$.

Figura 7.31 Mão do manequim apoiada no braço da poltrona e pés apoiados no piso. ...... 135

Figura 7.32 Temperaturas equivalentes experimentais e numéricas com manequim posicionado no corredor com simuladores com dissipação de $70 \mathrm{~W} / \mathrm{m}^{2}$.

Figura 7.33 Temperaturas equivalentes experimentais e numéricas com manequim posicionado na janela com simuladores com dissipação de $50 \mathrm{~W} / \mathrm{m}^{2}$.

Figura 7.34 Temperaturas equivalente experimentais e numéricas com manequim posicionado na janela com simuladores com dissipação de $70 \mathrm{~W} / \mathrm{m}^{2}$.

Figura 7.35 Valores de $t_{\mathrm{eq}} \mathrm{s}$ experimentais para o lado esquerdo e direito (caso com

dissipação térmica de $70 \mathrm{~W} / \mathrm{m}^{2}$ )

Figura 7.36 Fluxos de calor por radiação na posição próxima ao corredor.

Figura 7.37 Fluxos de calor por convecção na posição próxima ao corredor. 


\section{LISTA DE TABELAS}

Tabela 2.1 Metabolismos para diferentes atividades (www.hku.hk/bse/bbse3004/).............. 12

Tabela 2.2 Escala de sensação térmica da ASHRAE (ASHRAE, 2005) .............................. 13

Tabela 2.3 Determinação do voto médio estimado - PMV (ISO 7730, 2005) ....................... 14

Tabela 3.1 Valores de PMV calculados para 9 situações com diferentes umidades relativas*23

Tabela 3.2 Temperaturas equivalentes calculadas pelas equações de PMV ........................ 23

Tabela 3.3 Modelos, códigos e resultados dos manequins digitais. .................................... 33

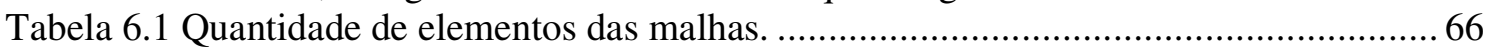

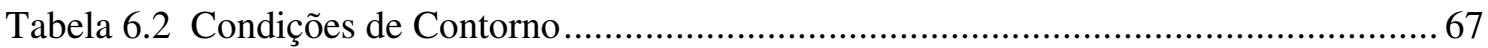

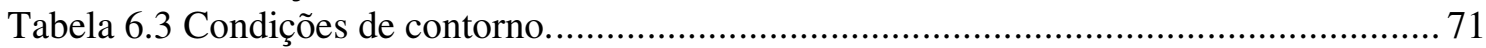

Tabela 6.4 Condições de contorno utilizadas nas simulações de calibração do manequim

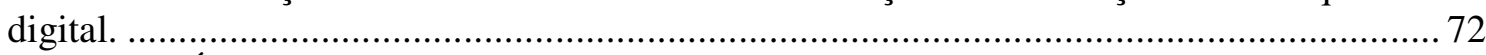

Tabela 6.5 Áreas de troca de calor dos segmentos do manequim digital (Nilsson, 2004) ...... 73

Tabela 6.6 Espessura da roupa para cada segmento do manequim .................................. 75

Tabela 6.7 Condições de contorno medidas e adotadas numericamente. ............................ 85

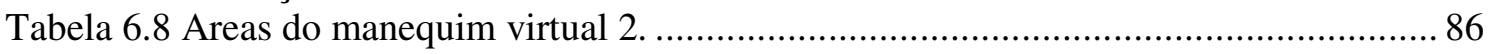

Tabela 6.9 Condições de contorno medidas e adotadas numericamente. ............................. 91

Tabela 7.1 Fluxos de calor por convecção dos manequins para as diversas malhas e ordens de

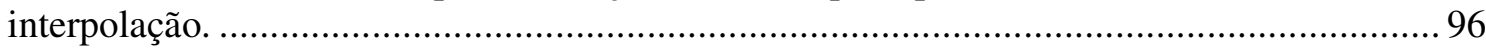

Tabela 7.2 Fluxos de calor dos passageiros para malhas tetraédricas. ............................... 97

Tabela 7.3 Fluxos de calor dos passageiros para malhas tetraedicas com prismas. ............... 97

Tabela 7.4 Resultados de $\mathrm{h}_{\text {cal }}$ para a condição de verão.................................................... 101

Tabela 7.5 Módulo da diferença entre os resultados experimentais e os obtidos numericamente

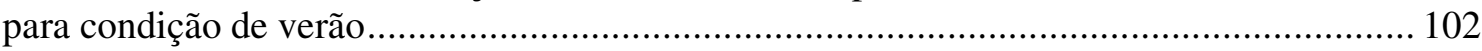

Tabela 7.6 Resultados de $\mathrm{h}_{\text {cal }}$ para a condição de inverno ............................................ 103

Tabela 7.7 Módulo da diferença entre os resultados experimentais e os obtidos numericamente

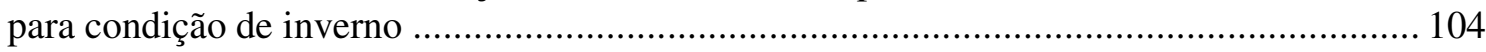

Tabela 7.8 Valores de coeficientes de troca de calor de calibração dos segmentos do

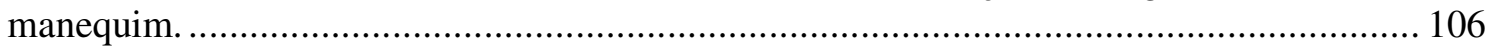

Tabela 7.9 Valores médios medidos experimentalmente na cabine do mock-up ................ 115

Tabela 7.10 Velocidades do ar: horizontais e verticais a diferentes alturas......................... 115

Tabela 7.11 Temperaturas do ar medidas e calculadas nas diversas alturas e posições da

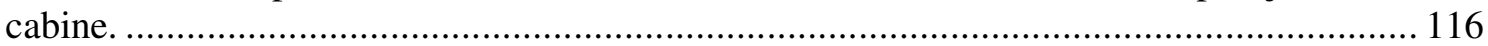

Tabela 7.12 Condições de contorno medidas e adotadas numericamente. ........................... 118

Tabela 7.13 Velocidades do ar horizontais e verticais a diferentes alturas e posições.......... 119

Tabela 7.14 Temperaturas do ar a diversas alturas e posições da cabine. ........................... 119

Tabela 7.15 Condições de contorno medidas ................................................................. 122

Tabela 7.16 Velocidades do ar horizontais e verticais a diferentes alturas e posições.......... 122

Tabela 7.17 Temperaturas do ar a diversas alturas e posições da cabine. ............................ 123

Tabela 7.18 Coeficientes de troca de calor de calibração nos diversos segmentos do manequim térmico experimental. ............................................................................... 125

Tabela 7.19 Coeficientes de troca de calor de calibração médios em dois experimentos .... 126

Tabela 7.20 Coeficientes de troca de calor de calibração do manequim digital 2. .............. 127

Tabela 7.21 Temperaturas médias medidas nas avaliações de temperaturas equivalentes.... 128 Tabela 7.22 Temperaturas equivalentes experimentais e numéricas do manequim junto à

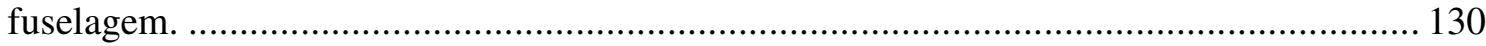

Tabela 7.23 Média das diferenças entre as teqs experimentas e numéricas ......................... 132 
Tabela 7.24 Temperaturas equivalentes experimentais e numéricas do manequim junto ao

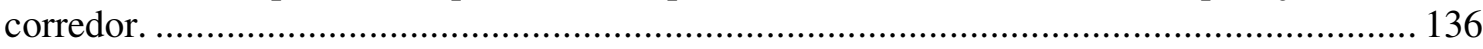

Tabela 7.25 Média das diferenças entre as teqs experimentas e numéricas. .......................... 138 Tabela 7.26 Módulos das diferenças numérico-experimentais de cada segmento nas seis avaliações. 


\section{LISTA DE SIGLAS}

$\begin{array}{ll}\text { ASHRAE } & \begin{array}{l}\text { American Society of Heating, Refrigerating and Air-Conditioning } \\ \text { Engineers }\end{array} \\ \text { CFD } & \text { Computational Fluid Dynamics } \\ \text { EMBRAER } & \text { Empresa Brasileira de Aeronáutica } \\ \text { FAPESP } & \text { Fundação de Amparo à Pesquisa do Estado de São Paulo } \\ \text { ISO } & \text { International Organization for Standardization } \\ \text { SAE } & \text { Society of Automotive Engineers }\end{array}$




\section{LISTA DE SÍMBOLOS}

A

$\mathrm{A}_{\mathrm{cl}}$

ASET

$\mathrm{A}_{\mathrm{u}}$

C

$\mathrm{C}_{\text {res }}$

$\mathrm{E}_{\text {res }}$

Esk

Esp._s

Esp._w

$\mathrm{F}_{\mathrm{cl}}$

$\mathrm{f}_{\mathrm{cl}}$

$\mathrm{h}_{\mathrm{c}}$

$\mathrm{h}_{\mathrm{cal}}$

$\mathrm{h}_{\mathrm{r}}$

$\mathrm{h}_{\text {tot }}$

$\mathrm{I}_{\mathrm{cl}}$

$\mathrm{k}$

$\mathrm{k}_{\text {eff }}$

M

OSTI

$\mathrm{p}$

$p_{a}$

PD

PMV

PPD

Q

Q"

$\mathrm{Q}_{\text {limite }}$

Qres
Área de parte do corpo humano, $\mathrm{m}^{2}$

Área do corpo com roupa, $\mathrm{m}^{2}$

Asymmetry in the segmental equivalent temperature, $\left({ }^{\circ} \mathrm{C}\right)$, Melikov e Irgens (2004)

Área do corpo nu, $\mathrm{m}^{2}$

Troca de calor de convenção entre a superfície externa da roupa e o ar externo por unidade de área, $\left(\mathrm{W} / \mathrm{m}^{2}\right)$

Calor convectivo perdido pela respiração, $\left(\mathrm{W} / \mathrm{m}^{2}\right)$

Calor evaporativo perdido pela respiração, $\left(\mathrm{W} / \mathrm{m}^{2}\right)$

Calor perdido pela pele por evaporação de suor, $\left(\mathrm{W} / \mathrm{m}^{2}\right)$

Espessura da roupa no verão, $(\mathrm{m})$

Espessura da roupa no inverno, (m)

Fator redutor de troca térmica, devido à roupa

Fator de área de roupa $\left(\mathrm{A}_{\mathrm{cl}} / \mathrm{A}_{\mathrm{u}}\right)$

Coeficiente de troca de calor por convecção, $\left(\mathrm{W} / \mathrm{m}^{2} . \mathrm{K}\right)$

Coeficiente de troca de calor de calibração, $\left(\mathrm{W} / \mathrm{m}^{2} . \mathrm{K}\right)$

Coeficiente de troca de calor linerizado por radiação entre a superfície externa da roupa e o ambiente, $\left(\mathrm{W} / \mathrm{m}^{2} . \mathrm{K}\right)$

Coeficiente de troca de calor total entre a pele e o ambiente exterior, $\mathrm{W} / \mathrm{m}^{2}{ }^{\circ} \mathrm{C}$.

Resistência térmica da roupa, (clo)

Energia cinética turbulenta $(\mathrm{J})$

Condutividade térmica efetiva

Metabolismo $\left(\mathrm{W} / \mathrm{m}^{2}\right)$

Objective thermal stress index, Alfahaid et al. (1999)

Pressão $(\mathrm{Pa})$

pressão parcial do vapor d'água no ambiente $(\mathrm{kPa})$

Draught risk index

Predicted Mean Vote

Predicted Percentage of Dissatisfied

Fluxo de calor por convecção e radiação, $\left(\mathrm{W} / \mathrm{m}^{2} . \mathrm{K}\right)$

Fluxo de calor em uma parte do manequim térmico $\left(\mathrm{W} / \mathrm{m}^{2}\right)$

Fluxo de calor médio em função do limite do VTM, (W/m²)

Calor total perdido pela respiração $\left(\mathrm{W} / \mathrm{m}^{2}\right)$ 


\begin{tabular}{|c|c|}
\hline Qsk & Calor total perdido pela pele $\left(\mathrm{W} / \mathrm{m}^{2}\right)$ \\
\hline $\mathrm{R}$ & Troca de calor por radiação por unidade de área, $\left(\mathrm{W} / \mathrm{m}^{2}\right)$ \\
\hline Rcl_s & Resistência térmica da roupa no inverno, $\left.\left(\mathrm{m}^{2} . \mathrm{K} / \mathrm{W}\right)\right)$ \\
\hline Rcl_W & Resistência térmica da roupa no inverno \\
\hline $\mathrm{R}_{\mathrm{t}}$ & $\begin{array}{l}\text { Resistência térmica total entre a superfície e a temperatura equivalente, } \\
\text { previamente estabelecida em calibração, }\left(\mathrm{m}^{2} . \mathrm{K} / \mathrm{W}\right)\end{array}$ \\
\hline $\mathrm{t}$ & Tempo (s) \\
\hline $\mathrm{t}_{\mathrm{a}}$ & Temperatura do ar, $(\mathrm{K})$ \\
\hline$t_{\text {eq }}$ & Temperatura equivalente, $(\mathrm{K})$ \\
\hline $\mathrm{t}_{\mathrm{r}}$ & Temperatura média radiante, $(\mathrm{K})$ \\
\hline$t_{\mathrm{s}}$ & Temperatura superficial de pele, $(\mathrm{K})$ \\
\hline $\mathrm{v}_{\mathrm{a}}$ & Velocidade do ar, $(\mathrm{m} / \mathrm{s})$ \\
\hline VST & Voto de Sensação Térmica \\
\hline$y+$ & $\begin{array}{l}\text { Relação entre a distância do centróide da célula da malha à parede e à } \\
\text { espessura da camada limite dinâmica. }\end{array}$ \\
\hline$W$ & trabalho externo $\left(\mathrm{W} / \mathrm{m}^{2}\right)$ \\
\hline$\dot{\mathrm{U}}$ & Taxa de variação de energia interna por unidade de área $\left(\mathrm{W} / \mathrm{m}^{2}\right)$ \\
\hline$\vec{u}$ & Vetor de velocidade, $(\mathrm{m} / \mathrm{s})$ \\
\hline$\vec{g}$ & Aceleração gravitacional $\left(\mathrm{m} / \mathrm{s}^{2}\right)$ \\
\hline$\vec{F}$ & Forças externas, $(\mathrm{N})$ \\
\hline$\phi$ & Umidade relativa \\
\hline$\rho$ & Massa específica $\left(\mathrm{kg} / \mathrm{m}^{3}\right)$ \\
\hline$\varepsilon$ & Taxa de dissipação da energia cinética turbulenta, $\mathrm{k}(\mathrm{J})$ \\
\hline$\mu \mathrm{t}$ & Viscosidade turbulenta $(\mathrm{kg} / \mathrm{m} . \mathrm{s})$ \\
\hline$v$ & Viscosidade cinemática $\left(\mathrm{m}^{2} / \mathrm{s}\right)$ \\
\hline$\tau$ & Tensão de cisalhamento $\left(\mathrm{N} / \mathrm{m}^{2}\right)$ \\
\hline
\end{tabular}




\section{SUMARIO}

1 Introdução ........................................................................................................................... 1

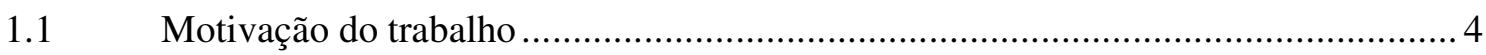

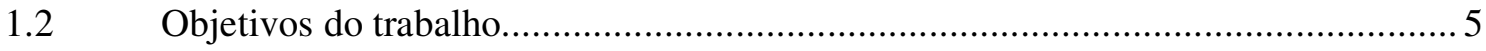

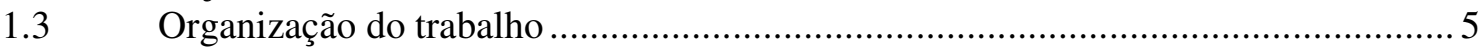

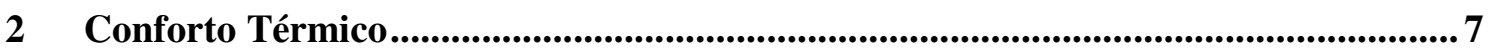

2.1 O sistema termorregulador humano ............................................................. 7

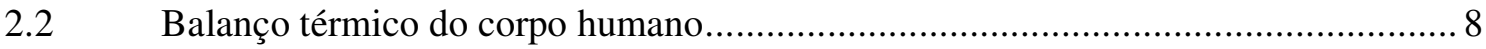

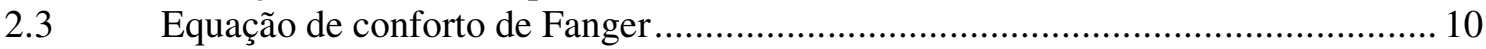

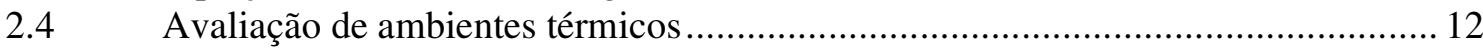

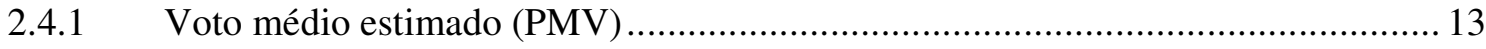

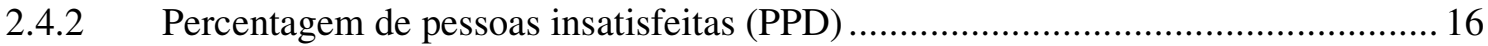

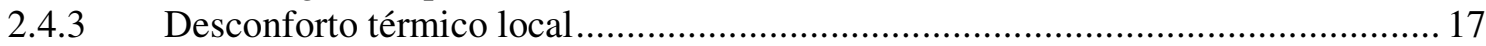

3 Avaliação de conforto térmico em ambientes não homogêneos............................... 18

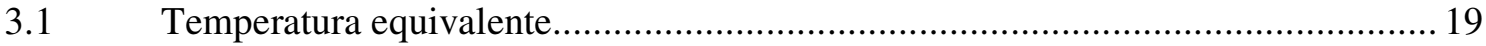

3.2 Influência da não-avaliação das trocas evaporativas na temperatura equivalente ... 23

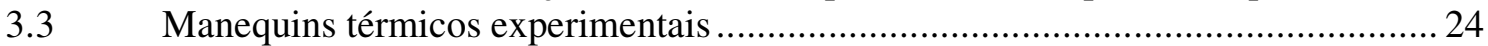

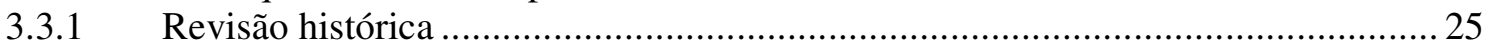

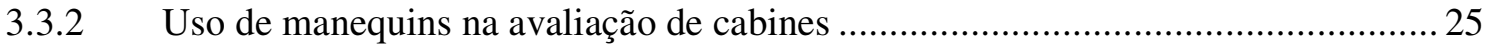

3.3.3 Precisão nas medições das temperaturas equivalentes ......................................2 27

3.3.4 Impacto de temperaturas medidas com manequim nu ou vestido............................ 30

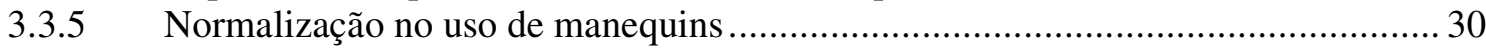

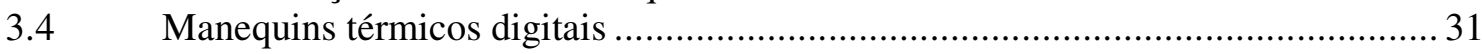

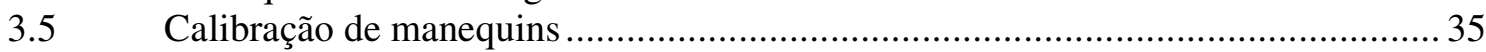

3.6 Método de temperatura equivalente e faixas de conforto .................................... 36

4 Avaliação do ambiente térmico em cabines de aeronaves ....................................... 39

4.1 Avaliação experimental dos campos de temperatura e velocidades do ar em

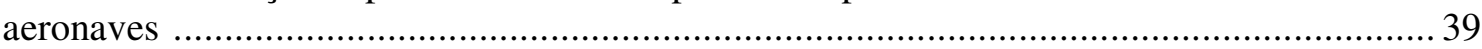

4.2 Avaliação experimental de temperaturas equivalentes em aeronaves.................... 44

5 Avaliação experimental do ambiente térmico em aeronave ...................................... 47

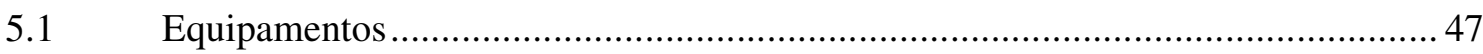

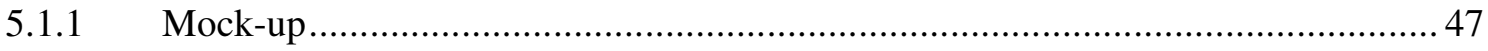

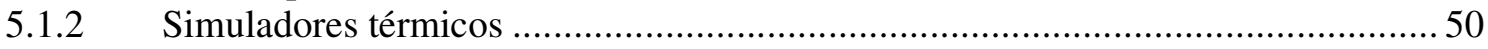

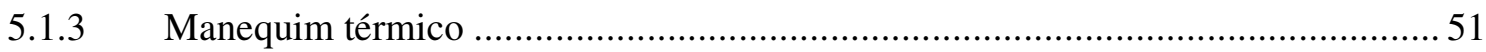

5.1.4 Medição de velocidades e temperaturas do ar ............................................... 52

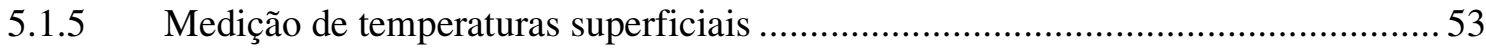

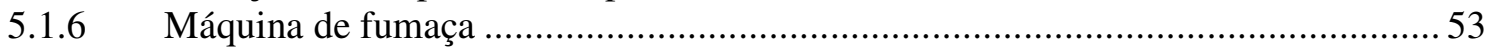

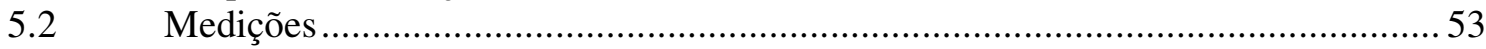

5.2.1 Medições dos campos de temperatura e velocidade de ar .................................. 54

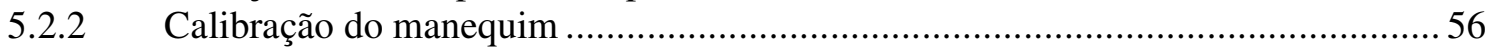

5.2.3 Determinação das temperaturas equivalentes ................................................ 59 
6 Avaliação numérica do ambiente térmico em aeronave ........................................... 62

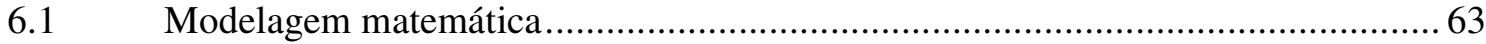

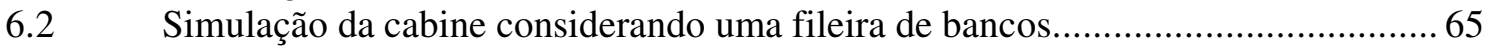

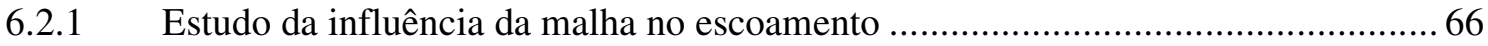

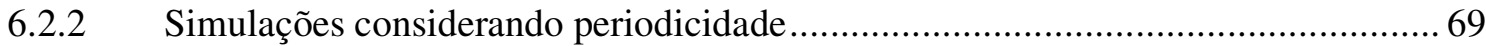

6.2.3 Simulações considerando manequim digital 1 para determinação de temperaturas

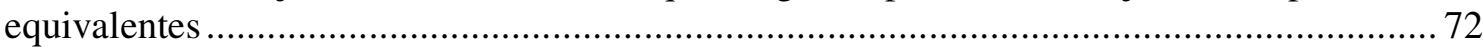

6.2.4 Avaliação de conforto térmico em aeronave com manequim digital 1 .................. 77

6.3 Simulação da cabine considerando mock-up inteiro .......................................... 80

6.3.1 Geometrias, malhas e condições de contorno para cabine....................................... 80

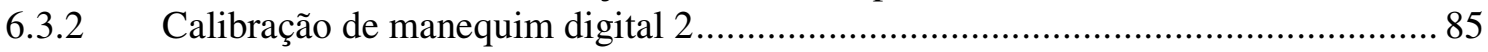

6.4 Simulação das temperaturas equivalentes com manequim digital 2 .................... 87

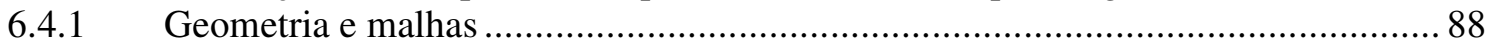

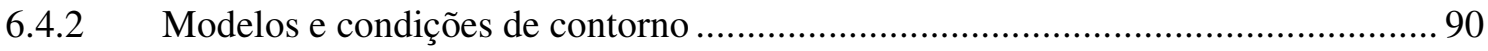

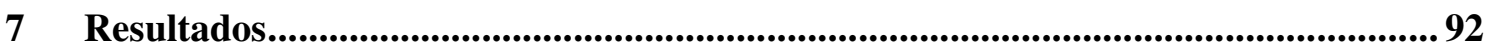

7.1 Resultados das avaliações considerando uma fileira de bancos............................. 92

7.1.1 Resultados do estudo de influência de malha no escoamento ............................. 92

7.1.2 Resultados da simulação considerando periodicidade....................................... 97

7.1.3 Resultados da avaliação do manequim digital 1 - efeito de malha....................... 100

7.1.4 Resultado da avaliação de manequim digital 1 - efeito dos modelos de turbulência

7.1.5 Resultado da avaliação de conforto térmico em aeronave com manequim digital 1. 107

7.2 Resultados de avaliações considerando cabine completa ................................... 114

7.2.1 Resultados da avaliação do campo de velocidades e temperaturas do ar.............. 114

7.2.2 Resultados da calibração do manequim..................................................... 125

7.2.3 Resultados das temperaturas equivalentes ...................................................... 128

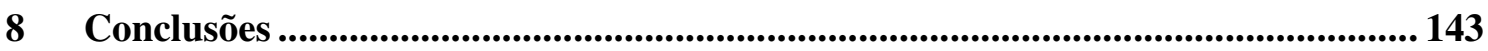

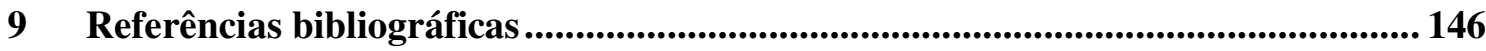




\section{Capítulo 1}

\section{Introdução}

É possível notar, atualmente, uma crescente preocupação da indústria aeronáutica, de órgãos governamentais e não-governamentais e, principalmente, dos passageiros, com o conforto e bem-estar em aeronaves. Na aviação comercial, fabricantes de grandes aviões têm chamado a atenção para as iniciativas relativas ao conforto dos passageiros (Forbes, 2006). Esta questão também ganhou espaço na mídia nacional e levou a agência reguladora a fazer exigências semelhantes das companhias aéreas que operam no Brasil (Globo, 2007). Os passageiros esperam um nível de conforto satisfatório, principalmente em viagens longas. As companhias aéreas nacionais, motivadas por tais exigências, ficaram mais sensíveis à questão do bem-estar interno da aeronave. Em nível internacional, as empresas têm encontrado, nesta expectativa, uma oportunidade de aumentarem as suas vendas. As grandes companhias pressionam os fabricantes de aeronaves para que assegurem aos passageiros níveis de conforto térmico superior. Para atender a essas solicitações, os fabricantes têm incorporado soluções sofisticadas, como pisos e interiores aquecidos.

$\mathrm{Na}$ aviação executiva, este item ganha importância especial. Geralmente, o comprador desse tipo de avião é o próprio usuário, e os níveis de conforto exigidos são bastante elevados, devido ao alto padrão de vida destes clientes. Assim, estas exigências, muitas vezes, orientam a opção de compra. Itens como design, baixo nível de ruído, controle de temperatura do ar, adequada umidificação do ambiente, ausência de correntes de ar e estratificação de temperaturas são mais relevantes do que baixo consumo de combustível e grande autonomia de vôo. Este cliente espera usufruir o mesmo nível de conforto que tem em sua casa ou automóvel.

Uma das áreas de conforto que tem recebido maior atenção é o conforto térmico e a caracterização do ambiente térmico em aeronaves. Esta atenção é devida a limitações especiais dos sistemas de climatização e das características do ambiente térmico de uma cabine de aeronave. Tradicionalmente, os sistemas apresentam baixas vazões para não se comprometer o desempenho dos motores, que comprimem o ar a ser inserido na cabine. Isto causa grandes diferenças de temperatura entre o ar da cabine e o ar insuflado. $\mathrm{O}$ pouco espaço 
para se colocar os difusores de ar impede uma boa distribuição para os passageiros. O retorno do ar localizado próximo aos pés, cria desconforto nesta região.

As variações das condições térmicas externas também criam ambientes térmicos internos complexos e assimétricos. A temperatura de fuselagem pode ir de $80{ }^{\circ} \mathrm{C} \mathrm{em} \mathrm{solo} \mathrm{à} \mathrm{-}$ $40{ }^{\circ} \mathrm{C}$ em menos de uma hora. Em vôo, temperaturas frias dos acabamentos juntos à fuselagem podem criar assimetrias térmicas para os passageiros. Em função destas mudanças bruscas de carga térmica, o sistema de climatização do avião pode mudar de uma situação de alta refrigeração a uma situação de aquecimento. Assim, gradientes de temperatura de ar na cabine são facilmente observáveis. Em função destas grandes diferenças térmicas, correntes de ar localizadas são geradas próximas a superfícies pouco isoladas como portas de serviço, de passageiros e de emergência.

$\mathrm{Na}$ aviação comercial, este complexo ambiente se intensifica em função da alta densidade de ocupação com pouco espaço entre as poltronas e espaço tomado por grandes bagageiros na parte superior da cabine.

As limitações de adaptação dos passageiros a este complexo ambiente térmico causam uma dificuldade ainda maior para se atingir o conforto, como o acesso limitado à mudança da vestimenta e controle das variáveis térmicas do ambiente.

Estes fatos têm levado a uma série de iniciativas, tanto de associações de engenheiros, quanto dos órgãos de fomento que, por meio de pesquisas e avaliações, têm procurado entender e caracterizar a complexidade do ambiente térmico. Vários centros de pesquisa tem se dedicado à análise numérica e experimental do ambiente térmico de aeronaves.

$\mathrm{Na}$ Europa o ICIEE, Internacional Centre for Indoor Environment and Energy, da Dinamarca, tem se destacado por estudos experimentais em mock-up com 21 assentos (Fig. 1.1) com simulação de paredes "realisticamente" frias e capacidade de simulação de umidades baixas. Nos ensaios realizados no ICIEE foram medidas temperaturas e velocidades do ar, temperaturas superficiais das paredes e temperaturas equivalentes com manequins térmicos. A simulação da troca de calor das pessoas foi feita com cilindros aquecidos (fontes de calor) e manequins térmicos para determinação de temperaturas equivalentes (Fig. 1.2). Os resultados obtidos mostram uma grande assimetria térmica com diferenças significativas de temperaturas equivalentes em diferentes partes do corpo dos passageiros, principalmente na posição próxima da janela (Irgens e Melikov, 2004; Strom-Tejsen et al., 2005; Strom-Tejsen et al., 2007). 


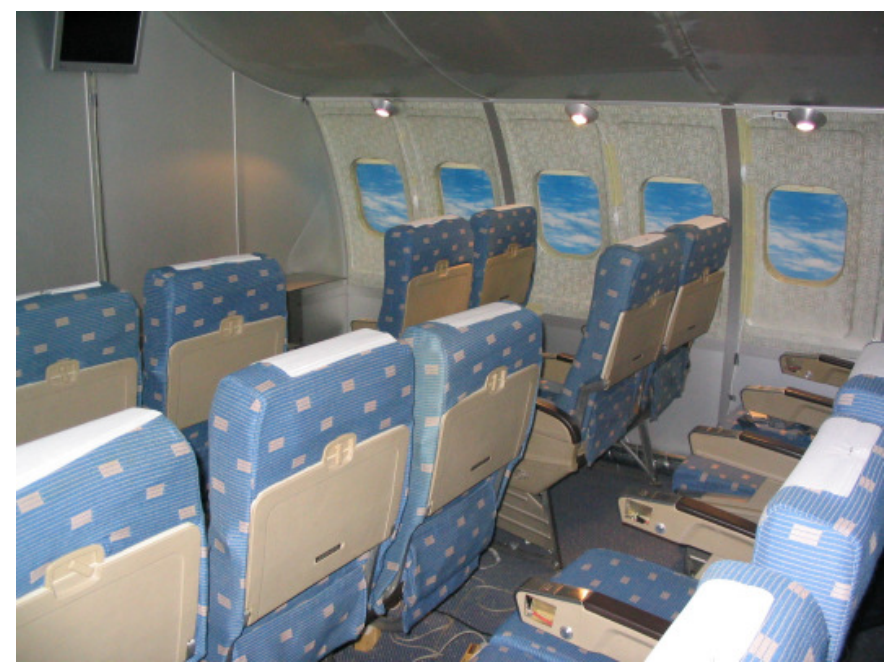

Figura 1.1 - Mock-up do ICIEE.

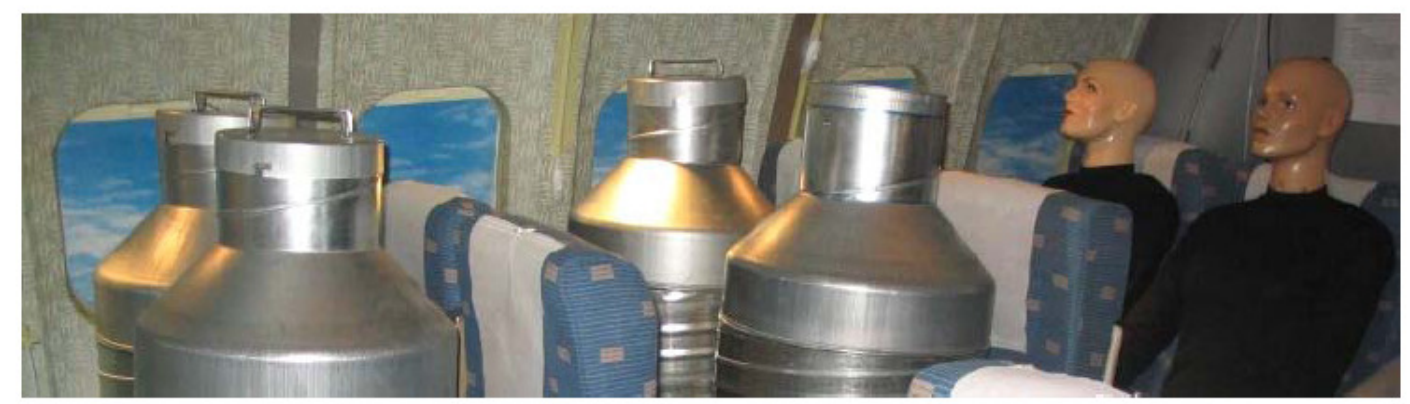

Figura 1.2 - Detalhe do mock-up mostrando os manequins térmicos e cilindros aquecidos (Strøm-Tejsen et al., 2007).

Avaliações experimentais do ambiente térmico em vôo real são muito caras. Por isso não são comuns de serem realizadas e poucos são os artigos publicados. Em um artigo de 2004 é apresentado estudo comparativo entre medições realizadas em vôo cruzeiro e resultados de simulação (CFD) em aeronave com sete poltronas por fileira, sem passageiros a bordo (Loomans et al., 2004). Também é verificada grande assimetria de temperaturas de ar em diversas posições na cabine.

Nos EUA, os trabalhos experimentais se concentram em duas universidades americanas: Universidade de Urbana-Champaign e da Universidade de Purdue (Fig. 1.3). Ambas possuem um mock-up com 4 fileiras de assentos. 


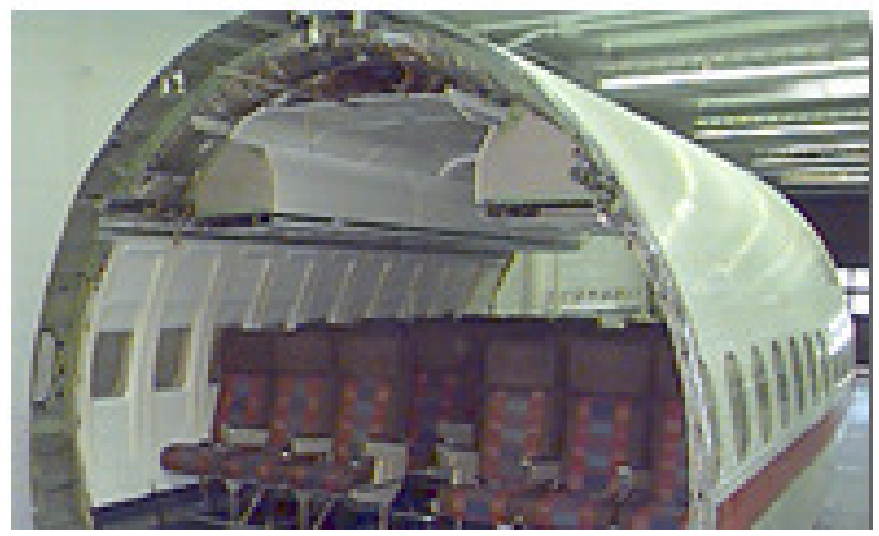

Figura 1.3 - Mock-up da Universidade de Purdue.

Os últimos trabalhos publicados pelas equipes de ambas universidades tiveram o foco em avaliação de dispersão de contaminantes. Os pesquisadores também fizeram medições de campo de velocidades e temperaturas do ar.

Paralelamente, tem se observado, na literatura mundial, um número maior de trabalhos dedicados a estudar, de modo mais efetivo, a distribuição de ar em aeronaves (Singh et al., 2002; Hailong et. al., 2003; Lin et al., 2005a,b; Sun et. al., 2005a,b).

\subsection{MOTIVAÇÃO DO TRABALHO}

No Brasil a questão do conforto térmico em aeronaves também tem merecido atenção da indústria aeronáutica, universidades e órgãos de fomento. Um trabalho pioneiro foi realizado por pesquisadores da EMBRAER e da Universidade de São Paulo, com a participação do presente autor. Nesse trabalho o foco foi a simulação numérica das condições ambientais no interior da cabine e o desenvolvimento de uma ferramenta computacional de avaliação de condições de conforto térmico utilizando dinâmica dos fluidos computacional (CFD). No desenvolvimento da ferramenta computacional foram construídos manequins térmicos digitais e utilizada técnica das temperaturas equivalentes e diagramas de sensação térmica na análise de condições de conforto térmico. Artigo com apresentação de resultados desse trabalho no Congresso da SAE Brasil 2006 (Stancato et al., 2006), foi considerado o melhor dentre os trabalhos nacionais apresentados.

Em continuação às atividades conjuntas entre a Embraer e Universidades, com o apoio da FAPESP, recentemente foi aprovado um novo projeto de "Conforto e design de cabine". 
Neste projeto serão estudados diversos aspectos de conforto como ergonomia, vibração, pressão e sensação térmica e a influência deste conjunto de fatores na sensação de conforto.

Paralelamente, ao se realizar a pesquisa bibliográfica sobre metodologias numéricas e experimentais para avaliação do ambiente térmico e de condições de conforto em aeronaves constatou-se que ainda existem poucos trabalhos publicados na literatura aberta. Também se verificou a inexistência de uma metodologia consolidada, como se vê na área de conforto térmico predial.

Assim, verificou-se a importância da continuidade do trabalho iniciado, fundamentando e discutindo mais profundamente as avaliações e teorias aplicáveis, e de focar o trabalho na análise numérica e experimental do ambiente térmico em mock-up de cabine de aeronave comercial.

\subsection{OBJETIVOS DO TRABALHO}

O trabalho teve como objetivo a realização de análise experimental e numérica do ambiente térmico em aeronave com a medição e simulação do campo de velocidades e temperaturas do ar e das temperaturas equivalentes para diversos segmentos do corpo humano. Paralelamente, os objetivos específicos foram:

- Estudar quais os níveis de refinamento de malha e modelo de turbulência adequado à avaliação do ambiente térmico em programa de CFD de uma cabine de aeronave comercial.

- Analisar os campos de temperatura e velocidade de ar e temperaturas equivalentes em um mock up experimental para algumas situações típicas em cabines.

- Simular as condições testadas experimentalmente em programa de CFD e comparar os resultados experimentais das variáveis ambientais citadas no item acima com valores simulados.

- Analisar em programa de CFD o conforto térmico em uma cabine utilizando um manequim térmico numérico simplificado.

\subsection{ORGANIZAÇÃO DO TRABALHO}

No capítulo 2 são apresentados os principais aspectos relacionados ao conforto térmico. 
No capítulo 3 é comentada a teoria sobre a avaliação de conforto térmico em ambientes não homogêneos. É apresentado o conceito de temperatura equivalente e sua determinação com manequins experimentais ou numéricos. Finalmente, é explicada a avaliação de conforto local com o uso das cartas de conforto.

O capítulo 4 é uma revisão da literatura referente à avaliação do ambiente térmico e de conforto térmico em aeronaves. São discutidas as avaliações numéricas e experimentais dos campos de temperatura e velocidade do ar e de temperaturas equivalentes.

As avaliações experimentais efetuadas estão descritas no capítulo 5. São comentados os instrumentos de medição, as medições realizadas e o mock-up experimental utilizado.

As avaliações numéricas realizadas no presente trabalho estão descritas no capítulo 6. São apresentadas as geometrias, malhas, modelos e condições de contorno utilizadas.

Os resultados numéricos e experimentais são apresentados e analisados no capítulo 7. As conclusões finais e sugestões para trabalhos futuros são apresentadas no capítulo 8. 


\section{Capítulo 2}

\section{Conforto Térmico}

Define-se conforto térmico como o "estado de espírito que expressa satisfação com o ambiente térmico" (ASHRAE 55, 2004). A sensação local de frio ou calor é basicamente produzida por termoreceptores localizados na pele e no hipotálamo. Por sua vez, a temperatura da pele e a do interior do corpo depende, fundamentalmente, das trocas térmicas com o ambiente, que estão associadas a seis parâmetros: temperatura e velocidade do ar, umidade relativa, temperatura média radiante, resistência térmica da roupa e metabolismo.

Para avaliar as condições de conforto térmico é necessário, também, analisar as condições de desconforto local, porque o ambiente pode proporcionar condições de conforto para o corpo como um todo e, mesmo assim, causar desconforto local.

\subsection{O SISTEMA TERMORREGULADOR HUMANO}

Sistema termorregulador refere-se aos órgãos do corpo humano que controlam a perda de calor. Do ponto de vista termodinâmico, o corpo humano pode ser considerado uma máquina térmica. Para que as células desempenhem bem as suas funções, a temperatura dos tecidos deve estar em torno de $37{ }^{\circ} \mathrm{C}$ e, para tal, o corpo deve perder uma quantidade de calor equivalente ao metabolismo. Devido ao metabolismo das células, esse calor pode ser maior ou menor, dependendo da atividade muscular humana. Quanto maior o trabalho muscular, maior será o metabolismo. Esta energia deve ser dissipada para o meio externo, por meio de dois processos, comandados pelo sistema termorregulador. $\mathrm{O}$ sistema termorregulador vai ser responsável por controlar o excesso, tanto para o frio quanto para o calor. Em ambientes quentes o ajuste se dará pelo aumento da perda de calor por meio de vasodilatação na pele e suor. As glândulas sudoríparas transferem água para a superfície da pele. A água, por sua vez, rouba calor da pele para evaporar. Se o corpo estiver perdendo mais calor do que produz, entrará em ação outro mecanismo, a contração das veias periféricas, e, se essa atividade ainda não for suficiente, o corpo aumentará a produção de energia por meio de trabalho muscular involuntário - os tremores. 
Este controle é feito pelo hipotálamo, região do cérebro que consiste de diversas divisões, duas das quais são responsáveis pela termo-regulação: o núcleo anterior e posterior. Benzinger et al. (1961) descrevem estas áreas como centros de termo-regulação.

O hipotálamo anterior, definido como centro de perda de calor, provê a termoregulação quando o corpo está muito quente, combinando as funções de sensor de temperatura e controlador. Qualquer aumento na temperatura acima de $37{ }^{\circ} \mathrm{C}$ resulta no envio de impulsos nervosos, que iniciam os mecanismos para aumentar a troca de calor, a vasodilatação e a transpiração. A temperatura pode subir durante exercícios físicos ou em caso de febre.

O hipotálamo posterior, ou centro de manutenção de calor, proporciona a defesa do organismo, em caso de frio. Existe uma independência entre este centro e o núcleo posterior, segundo Keller e Hare (1932 apud Zhang 2003). Estes autores verificaram que, mesmo após a destruição do centro de manutenção de calor, as funções de controle de perda de calor

permaneceram intactas. Os centros de manutenção de calor recebem informação dos sensores de pele e sua função é provocar vasoconstrição e tremores.

McIntyre (1980 apud Zhang 2003) sugere que os dois centros se inibem mutuamente, ou seja, a pessoa cuja temperatura central está alta irá transpirar por causa da ação do centro de perda de calor. Se a temperatura da pele for diminuída por resfriamento, o hipotálamo posterior será ativado e inibirá o hipotálamo anterior, interrompendo assim a transpiração. Dessa forma, os respectivos centros somente percebem o gradiente de temperatura de aumento ou diminuição da temperatura.

Uma revisão muito boa do assunto pode ser encontrada em Ferreira (1997) e Ferreira (2001).

\subsection{BALANÇO TÉRMICO DO CORPO HUMANO}

A temperatura interna do corpo humano é mantida constante somente se ocorrer um equilíbrio entre a energia produzida pelo corpo e o calor perdido para o ambiente. $\mathrm{O}$ homem interage termicamente com o ambiente trocando calor pelos mecanismos da condução, convecção, radiação e evaporação pela pele e por meio da respiração. Esta interação do corpo humano com o meio envolvente é apresentada na Figura 2.1.

Do balanço térmico do corpo humano ( $1^{\mathrm{a}}$. lei da termodinâmica), tem-se que:

$$
\dot{U}=M-W-Q_{s k}-Q_{\text {res }}
$$




$$
\dot{U}=M-W-\left(R+C+E_{s k}\right)+\left(C_{r e s}+E_{r e s}\right)
$$

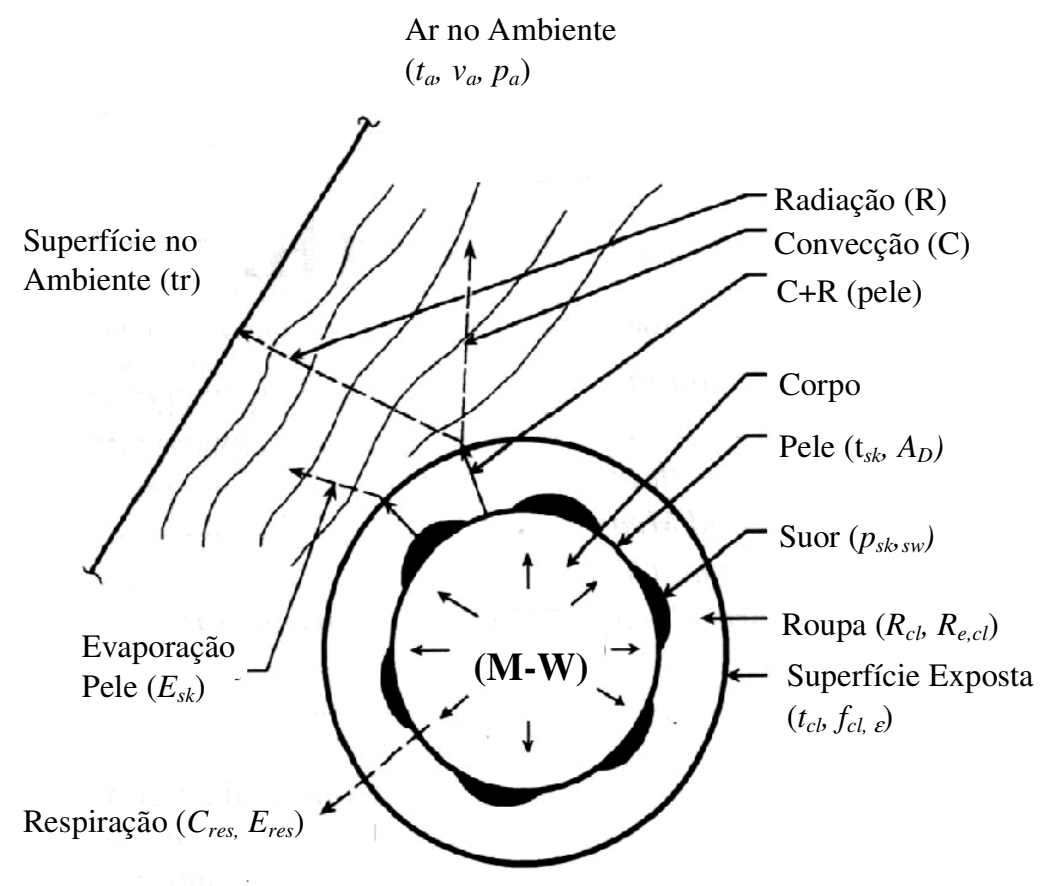

Figura 2.1 - Modelo cilíndrico da interação térmica: corpo humano - meio envolvente

(ASHRAE, 2005)

onde:

Ù Taxa de variação de energia interna por unidade de área $\left[\mathrm{W} / \mathrm{m}^{2}\right]$

M Metabolismo

W Trabalho externo por unidade de tempo e área

Q $\quad$ Calor total perdido pela pele por unidade de tempo e área

Q $\quad$ Calor total perdido pela respiração por unidade de tempo e área

C Calor perdido pela pele por convecção por unidade de tempo e área

$\mathrm{R} \quad$ Calor perdido pela pele por radiação por unidade de tempo e área

$\mathrm{E}_{\mathrm{sk}} \quad$ Calor perdido pela pele por evaporação de suor por unidade de tempo e área

$\mathrm{E}_{\mathrm{res}} \quad$ Calor perdido por evaporação na respiração por unidade de tempo e área

$\mathrm{C}_{\mathrm{res}} \quad$ Calor perdido por convecção na respiração por unidade de tempo e área

Do balanço térmico do corpo humano e aplicando-se as equações que descrevem os mecanismos de transferência de calor, são obtidas as variáveis de conforto térmico (Fanger, 1972): 
a) Parâmetros individuais: o tipo de atividade $(\mathrm{M}, \mathrm{W})$ e a isolação da vestimenta $\left(\mathrm{I}_{\mathrm{cl}}\right)$; b) Parâmetros do ambiente: a temperatura do ar ambiente $\left(\mathrm{t}_{\mathrm{a}}\right)$; a temperatura radiante média $\left(\mathrm{t}_{\mathrm{r}}\right)$; a velocidade do ar $\left(\mathrm{v}_{\mathrm{a}}\right)$ e a umidade relativa do ar $(\phi)$.

\subsection{EQUAÇÃO DE CONFORTO DE FANGER}

Fanger (1972) estabeleceu três condições para que uma pessoa estivesse em condição de conforto térmico exposta a um dado ambiente por um período longo:

a) A primeira condição é que haja equilíbrio das trocas de calor entre o corpo e o ambiente, isto é,

$$
\dot{\mathrm{U}}=0
$$

b) A segunda condição é que a temperatura média da pele $\left(t_{s}\right)$ seja dada pela equação:

$$
\mathrm{t}_{\mathrm{sk}}=35,7-0,0275(\mathrm{M}-\mathrm{W})
$$

c) A terceira condição é que a produção de suor $\left(\mathrm{E}_{\mathrm{sw}}\right)$ seja igual a:

$$
E_{s w}=0,42(M-W-58,2)
$$

onde $58,2 \mathrm{~W} / \mathrm{m}^{2}$ correspondem à atividade sedentária.

Das condições de conforto de Fanger, tem-se que uma pessoa em atividade sedentária em condição de conforto térmico não produzirá suor, pois $\mathrm{E}_{\mathrm{sw}}$ será igual a zero (Eq. 2.4) e a

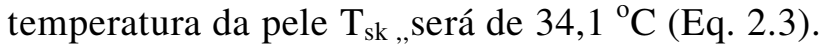

As equações (2.3) e (2.4) foram obtidas a partir de dados experimentais levantados em ensaios realizados com estudantes do sexo feminino e masculino em diferentes níveis de atividade. Inserindo as Eqs. 2.3 e 2.4, juntamente com as equações de transferência de calor, na Eq. (2.2), obtém-se a equação de conforto de Fanger (1972), dada por:

$$
\begin{aligned}
&(\mathrm{M}-\mathrm{W})=3,96.10^{-8} \mathrm{f}_{\mathrm{cl}}\left[\left(\mathrm{t}_{\mathrm{cl}}+273\right)^{4}+\left(\mathrm{t}_{\mathrm{r}}+273\right)^{4}\right] \\
&+ f_{c l} \cdot h_{c}\left(t_{c l}-t_{a}\right)+3,05\left[5.73-0,007(M-W)-p_{a}\right] \\
&+0,42[(M-W)-58,15]+0,0173 M\left(5.87-p_{a}\right)+0,0014 M\left(34-t_{a}\right)
\end{aligned}
$$

com: 


$$
\begin{aligned}
& t_{c l}=35,7-0,028(M-W)-0,155 I_{c l}\left\{\begin{array}{l}
(M-W)-3,05\left[5,73-0,007(M-W)-p_{a}\right] \\
-0,42[(M-W)-58,15]-0,0173 M\left(5,87-p_{a}\right) \\
-0,0014 M\left(34-t_{a}\right)
\end{array}\right\}
\end{aligned}
$$

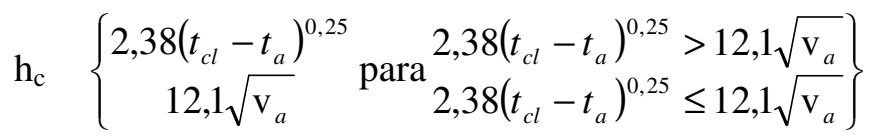

$$
\begin{aligned}
& f_{c l}\left\{\begin{array}{l}
1,00+0,2 I_{c l} \text { para } I_{c l} \leq 0,5 \\
1,05+0,1 I_{c l} \quad I_{c l}>0,5
\end{array}\right\} \text { clo }
\end{aligned}
$$

onde:

$$
\begin{aligned}
& M=\text { metabolismo }\left(\mathrm{W} / \mathrm{m}^{2}\right) \\
& W=\text { trabalho externo }\left(\mathrm{W} / \mathrm{m}^{2}\right) \\
& I_{c l}=\text { índice de isolamento da roupa }(\mathrm{clo}) \\
& t_{a}=\text { temperatura do ar }\left({ }^{\circ} \mathrm{C}\right) \\
& t_{c l}=\text { temperatura da roupa }\left({ }^{\circ} \mathrm{C}\right) \\
& v_{a}=\text { velocidade média do ar }(\mathrm{m} / \mathrm{s}) \\
& p_{a}=\text { pressão parcial do vapor d'água no ambiente }(\mathrm{kPa}) \\
& \mathrm{t}_{\mathrm{r}}=\text { temperatura radiante média }\left({ }^{\circ} \mathrm{C}\right) \\
& \mathrm{f}_{\mathrm{cl}}=\text { fator de área de roupa }\left(\mathrm{A}_{\mathrm{cl}} / \mathrm{A}_{\mathrm{u}}\right)
\end{aligned}
$$

A equação 2.5 relaciona os fatores pessoais $\left(\mathrm{M}, \mathrm{W}, \mathrm{I}_{\mathrm{cl}}\right)$ e ambientais $\left(\mathrm{t}_{\mathrm{a}}, \mathrm{v}_{\mathrm{a}}, \mathrm{p}_{\mathrm{a}}, \mathrm{t}_{\mathrm{r}}\right)$ para conforto térmico. O metabolismo, função da atividade, normalmente é expresso em termos de unidades de metabolismo met ${ }^{1}$. Na Tabela 2.1 são apresentados valores de metabolismo para diferentes atividades.

A vestimenta representa uma resistência à troca de calor entre o corpo e o meio, e, portanto, afeta o equilíbrio térmico. A resistência térmica da roupa $\left(I_{R}\right)$ é normalmente representada pela unidade $\mathrm{clo}^{2}$.

\footnotetext{
11 met $=58,2 \mathrm{~W} / \mathrm{m}^{2}$ (atividade sedentária)

$21 \mathrm{clo}=0,155 \mathrm{~m}^{2} \mathrm{C} / \mathrm{W}$ (vestimenta típica de inverno, pesada)
} 
Tabela 2.1 Metabolismos para diferentes atividades (www.hku.hk/bse/bbse3004/)

\begin{tabular}{lcc}
\hline \multicolumn{1}{c}{ Atividade } & \multicolumn{2}{c}{ Taxa metabólica } \\
\hline Sentado reclinado & $46 \mathrm{~W} / \mathrm{m}^{2}$ & $0,8 \mathrm{met}$ \\
Sentado relaxado & $58 \mathrm{~W} / \mathrm{m}^{2}$ & $1,0 \mathrm{met}$ \\
Sentado em trabalho de escritório & $70 \mathrm{~W} / \mathrm{m}^{2}$ & $1,2 \mathrm{met}$ \\
Dirigindo carro & $80 \mathrm{~W} / \mathrm{m}^{2}$ & $1,4 \mathrm{met}$ \\
Em pé, atividade leve & $93 \mathrm{~W} / \mathrm{m}^{2}$ & 1,6 met \\
Caminhando horizontalmente $(2 \mathrm{~km} / \mathrm{h})$ & $110 \mathrm{~W} / \mathrm{m}^{2}$ & 1,9 met \\
Em pé, atividades moderadas (trabalho doméstico) & $116 \mathrm{~W} / \mathrm{m}^{2}$ & 2,0 met \\
Caminhando horizontalmente, $5 \mathrm{~km} / \mathrm{h}$ & $200 \mathrm{~W} / \mathrm{m}^{2}$ & 3,4 met \\
Trabalhadores da construção civil & $275 \mathrm{~W} / \mathrm{m}^{2}$ & $4,7 \mathrm{met}$ \\
Esportes - correndo a $15 \mathrm{~km} / \mathrm{h}$ & $550 \mathrm{~W} / \mathrm{m}^{2}$ & $9,5 \mathrm{met}$ \\
\hline
\end{tabular}

Uma vestimenta leve (calça comprida, camisa de manga curta, sapato e meia), apresenta um clo em torno de 0,5. Já uma vestimenta mais pesada, de inverno, com calça comprida, camisa de manga comprida, gravata, sapato, meia e paletó assumem valores em torno de 1,0 clo.

Para a obtenção das variáveis ambientais: velocidade média do ar, $\mathrm{v}_{\mathrm{a}}$, temperatura média radiante, $\mathrm{t}_{\mathrm{r}}$, temperatura do ar, $\mathrm{t}_{\mathrm{a}}$ e umidade do ar: umidade absoluta, $\omega$, e umidade relativa, $\phi$, são realizadas medições no ambiente. A norma ISO 7726 (1998) apresenta procedimentos de medição e métodos para a determinação destas variáveis ambientais.

\subsection{AVALIAÇÃO DE AMBIENTES TÉRMICOS}

No item anterior foi apresentada a equação de conforto de Fanger (Eq. 2.5). que trata de situações de conforto térmico, isto é, das combinações dos parâmetros $\left(\mathrm{M}, \mathrm{W}, \mathrm{I}_{\mathrm{cl}}, \mathrm{t}_{\mathrm{a}}, \mathrm{v}_{\mathrm{a}}\right.$, $\left.\mathrm{p}_{\mathrm{a}}, \mathrm{t}_{\mathrm{r}}\right)$ que causam conforto térmico. A sensação de conforto em um ambiente térmico, contudo, depende da percepção das pessoas.

Assim, há a necessidade de uma avaliação das pessoas quanto às condições de conforto que o ambiente térmico proporciona. Esta avaliação subjetiva, normalmente, é realizada por meio do voto das pessoas segundo critérios definidos na escala de sensação térmica da ASHRAE, apresentada na Tabela 2.2. 
Tabela 2.2 Escala de sensação térmica da ASHRAE (2005)

\begin{tabular}{cc}
\hline Escala & Sensação \\
\hline+3 & muito quente \\
+2 & quente \\
+1 & ligeiramente quente \\
0 & neutro \\
-1 & ligeiramente frio \\
-2 & frio \\
-3 & muito frio \\
\hline
\end{tabular}

\subsubsection{Voto médio estimado (PMV)}

Nos ensaios realizados por Fanger (1972), as pessoas, desempenhando uma certa atividade (metabolismo, M) e vestindo uma certa roupa (clo), eram colocadas em câmaras climatizadas (com determinadas condições ambientais) e davam os seus votos quanto à sensação que percebiam. Destes votos resultou a equação do voto médio estimado (PMV Predicted Mean Vote) que correlaciona as variáveis pessoais $\left(\left(\mathrm{M}, \mathrm{W}, \mathrm{I}_{\mathrm{cl}}\right)\right.$, as variáveis ambientais $\left(\mathrm{t}_{\mathrm{a}}, \mathrm{v}_{\mathrm{a}}, \mathrm{p}_{\mathrm{a}}, \mathrm{t}_{\mathrm{r}}\right)$ e o voto (sensação) das pessoas.

O trabalho de Fanger (1972) é a base da norma ISO 7730 (2005) de conforto térmico. Nesta norma são apresentadas tabelas, como a Tabela 2.3, e uma rotina para utilização em microcomputador, que permitem determinar o PMV para diferentes atividades, tipos de vestimenta e condições ambientais.

Considerando a abrangência do estudo realizado por Fanger (1972), o uso de PMV para a avaliação do conforto térmico deve se restringir à faixa $-2 \leq \mathrm{PMV} \leq+2$ e os principais parâmetros devem estar dentro dos seguintes intervalos:

$$
\begin{aligned}
& M=46 \text { a } 232 \mathrm{~W} / \mathrm{m}^{2}(0,8 \text { a } 4 \text { met }) \\
& I_{c l}=0 \text { a } 0,310 \mathrm{~m}^{2}{ }^{\circ} \mathrm{C} / \mathrm{W}(0 \text { a } 2 \text { clo }) \\
& t_{a}=10 \text { a } 30^{\circ} \mathrm{C} \\
& t_{r}=10 \text { a } 40^{\circ} \mathrm{C} \\
& \mathrm{v}_{a}=0 \text { a } 1 \mathrm{~m} / \mathrm{s} \\
& p_{a}=0 \text { a } 2700 \mathrm{~Pa} \\
& \phi=30 \text { a } 70 \%
\end{aligned}
$$


Tabela 2.3 Determinação do voto médio estimado - PMV (ISO 7730, 2005)

Atividade sedentária (met=1,0) e umidade relativa do ar de $50 \%$

\begin{tabular}{|c|c|c|c|c|c|c|c|c|c|c|}
\hline \multicolumn{2}{|c|}{ Vestimenta } & \multirow{2}{*}{$\begin{array}{c}\text { Temperatu } \\
\text { ra } \\
\begin{array}{c}\text { Operativa } \\
{ }^{\circ} \mathrm{C}\end{array}\end{array}$} & \multicolumn{8}{|c|}{ Velocidade Relativa do ar - m/s } \\
\hline $\mathrm{CLO}$ & $\begin{array}{l}{ }^{\circ} \mathrm{C} \cdot \mathrm{m}^{2} / \\
\mathrm{W}\end{array}$ & & $<0.10$ & 0.10 & 0.15 & 0.20 & 0.30 & 0.40 & 0.50 & 1.00 \\
\hline 0 & 0 & $\begin{array}{l}26 \\
27 \\
28 \\
29 \\
30 \\
31 \\
32 \\
33\end{array}$ & $\begin{array}{r}-1.62 \\
-1.00 \\
-0.39 \\
0.21 \\
0.80 \\
1.39 \\
1.96 \\
2.50\end{array}$ & $\begin{array}{r}-1.62 \\
-1.00 \\
-0.42 \\
0.13 \\
0.68 \\
1.25 \\
1.83 \\
2.41\end{array}$ & $\begin{array}{r}-1.96 \\
-1.36 \\
-0.76 \\
-0.15 \\
0.45 \\
1.08 \\
1.71 \\
2.34\end{array}$ & $\begin{array}{r}-2.34 \\
-1.69 \\
-1.05 \\
-0.39 \\
0.26 \\
0.94 \\
1.61 \\
2.29\end{array}$ & & & & \\
\hline 0.25 & 0.039 & $\begin{array}{l}24 \\
25 \\
26 \\
27 \\
28 \\
29 \\
30 \\
31\end{array}$ & $\begin{array}{r}-1.52 \\
-1.05 \\
-0.58 \\
-0.12 \\
0.34 \\
0.80 \\
1.25 \\
1.71\end{array}$ & $\begin{array}{r}-1.52 \\
-1.05 \\
-0.61 \\
-0.17 \\
0.27 \\
0.71 \\
1.15 \\
1.61\end{array}$ & $\begin{array}{r}-1.80 \\
-1.33 \\
-0.87 \\
-0.40 \\
0.07 \\
0.54 \\
1.02 \\
1.51\end{array}$ & $\begin{array}{r}-2.06 \\
-1.57 \\
-1.08 \\
-0.58 \\
-0.09 \\
0.41 \\
0.91 \\
1.43\end{array}$ & $\begin{array}{r}-2.47 \\
-1.94 \\
-1.41 \\
-0.87 \\
-0.34 \\
0.20 \\
0.74 \\
1.30\end{array}$ & $\begin{array}{r}-2.24 \\
-1.67 \\
-1.10 \\
-0.53 \\
0.04 \\
0.61 \\
1.20\end{array}$ & $\begin{array}{r}-2.48 \\
-1.89 \\
-1.29 \\
-0.70 \\
-0.10 \\
0.50 \\
1.12\end{array}$ & $\begin{array}{r}-2.66 \\
-1.97 \\
-1.28 \\
-0.58 \\
0.11 \\
0.83\end{array}$ \\
\hline 0.50 & 0.078 & $\begin{array}{l}23 \\
24 \\
25 \\
26 \\
27 \\
28 \\
29 \\
30\end{array}$ & $\begin{array}{r}-1.10 \\
-0.72 \\
-0.34 \\
0.04 \\
0.42 \\
0.80 \\
1.17 \\
1.54\end{array}$ & $\begin{array}{r}-1.10 \\
-0.74 \\
-0.38 \\
-0.01 \\
0.35 \\
0.72 \\
1.08 \\
1.45\end{array}$ & $\begin{array}{r}-1.33 \\
-0.95 \\
-0.56 \\
-0.18 \\
0.20 \\
0.59 \\
0.98 \\
1.37\end{array}$ & $\begin{array}{r}-1.51 \\
-1.11 \\
-0.71 \\
-0.31 \\
0.09 \\
0.49 \\
0.90 \\
1.30\end{array}$ & $\begin{array}{r}-1.78 \\
-1.36 \\
-0.94 \\
-0.51 \\
-0.08 \\
0.34 \\
0.77 \\
1.20\end{array}$ & $\begin{array}{r}-1.99 \\
-1.55 \\
-1.11 \\
-0.66 \\
-0.22 \\
0.23 \\
0.68 \\
1.13\end{array}$ & $\begin{array}{r}-2.16 \\
-1.70 \\
-1.25 \\
-0.79 \\
-0.33 \\
0.14 \\
0.60 \\
1.06\end{array}$ & $\begin{array}{r}-2.22 \\
-1.71 \\
-1.19 \\
-0.68 \\
-0.17 \\
0.34 \\
0.86\end{array}$ \\
\hline 0.75 & 0.118 & $\begin{array}{l}21 \\
22 \\
23 \\
24 \\
25 \\
26 \\
27 \\
28\end{array}$ & $\begin{array}{r}-1.11 \\
-0.79 \\
-0.47 \\
-0.15 \\
0.17 \\
0.49 \\
0.81 \\
1.12\end{array}$ & $\begin{array}{r}-1.11 \\
-0.81 \\
-0.50 \\
-0.19 \\
0.12 \\
0.43 \\
0.74 \\
1.05\end{array}$ & $\begin{array}{r}-1.30 \\
-0.96 \\
-0.66 \\
-0.33 \\
-0.01 \\
0.31 \\
0.64 \\
0.96\end{array}$ & $\begin{array}{r}-1.44 \\
-1.11 \\
-0.78 \\
-0.44 \\
-0.11 \\
0.23 \\
0.56 \\
0.90\end{array}$ & $\begin{array}{r}-1.66 \\
-1.31 \\
-0.96 \\
-0.61 \\
-0.28 \\
0.09 \\
0.45 \\
0.80\end{array}$ & $\begin{array}{r}-1.82 \\
-1.46 \\
-1.09 \\
-0.73 \\
-0.37 \\
0.00 \\
0.36 \\
0.73\end{array}$ & $\begin{array}{r}-1.95 \\
-1.58 \\
-1.20 \\
-0.83 \\
-0.46 \\
-0.08 \\
0.29 \\
0.67\end{array}$ & $\begin{array}{r}-2.36 \\
-1.95 \\
-1.55 \\
-1.14 \\
-0.74 \\
-0.33 \\
0.08 \\
0.48\end{array}$ \\
\hline 1.00 & 0.155 & $\begin{array}{l}20 \\
21 \\
22 \\
23 \\
24 \\
25 \\
26 \\
27\end{array}$ & $\begin{array}{r}-\mathbf{0 . 8 5} \\
-\mathbf{0 . 5 7} \\
-\mathbf{0 . 3 0} \\
-\mathbf{0 . 0 2} \\
\mathbf{0 . 2 6} \\
\mathbf{0 . 5 3} \\
\mathbf{0 . 8 1} \\
\mathbf{1 . 0 8}\end{array}$ & $\begin{array}{r}-0.87 \\
-0.60 \\
-0.33 \\
-0.07 \\
0.20 \\
0.48 \\
0.75 \\
1.02\end{array}$ & $\begin{array}{r}-1.02 \\
-0.74 \\
-0.46 \\
-0.18 \\
0.10 \\
0.38 \\
0.66 \\
0.95\end{array}$ & $\begin{array}{r}-1.13 \\
-0.84 \\
-0.55 \\
-0.27 \\
0.02 \\
0.31 \\
0.60 \\
0.89\end{array}$ & $\begin{array}{r}-1.29 \\
-0.99 \\
-0.69 \\
-0.39 \\
-0.09 \\
0.21 \\
0.51 \\
0.81\end{array}$ & $\begin{array}{r}-1.41 \\
-1.11 \\
-0.80 \\
-0.49 \\
-0.18 \\
0.13 \\
0.44 \\
0.75\end{array}$ & $\begin{array}{r}-1.51 \\
-1.19 \\
-0.88 \\
-0.56 \\
-0.25 \\
0.07 \\
0.39 \\
0.71\end{array}$ & $\begin{array}{r}-1.81 \\
-1.47 \\
-1.13 \\
-0.79 \\
-0.46 \\
-0.12 \\
0.22 \\
0.56\end{array}$ \\
\hline 1.50 & 0.233 & $\begin{array}{l}14 \\
16 \\
18 \\
20 \\
22 \\
24 \\
26 \\
28\end{array}$ & $\begin{array}{r}-1.36 \\
-0.94 \\
-0.52 \\
-0.09 \\
0.35 \\
0.79 \\
1.23 \\
1.67\end{array}$ & $\begin{array}{r}-1.36 \\
-0.95 \\
-0.54 \\
-0.13 \\
0.30 \\
0.74 \\
1.18 \\
1.62\end{array}$ & $\begin{array}{r}-1.48 \\
-1.07 \\
-0.64 \\
-0.22 \\
0.23 \\
0.68 \\
1.13 \\
1.56\end{array}$ & $\begin{array}{r}-1.58 \\
-1.15 \\
-0.72 \\
-0.28 \\
0.18 \\
0.63 \\
1.09 \\
1.56\end{array}$ & $\begin{array}{r}-1.72 \\
-1.27 \\
-0.82 \\
-0.37 \\
0.10 \\
0.57 \\
1.04 \\
1.52\end{array}$ & $\begin{array}{r}-1.82 \\
-1.36 \\
-0.90 \\
-0.44 \\
0.04 \\
0.52 \\
1.01 \\
1.48\end{array}$ & $\begin{array}{r}-1.89 \\
-1.43 \\
-0.96 \\
-0.49 \\
0.00 \\
0.49 \\
0.98 \\
1.47\end{array}$ & $\begin{array}{r}-2.12 \\
-1.63 \\
-1.14 \\
-0.65 \\
-0.14 \\
0.37 \\
0.89 \\
1.40\end{array}$ \\
\hline 2.00 & 0.310 & $\begin{array}{l}10 \\
12 \\
14 \\
16 \\
18 \\
20 \\
22 \\
24\end{array}$ & $\begin{array}{r}-1.38 \\
-1.03 \\
-0.68 \\
-0.32 \\
0.03 \\
0.40 \\
0.76 \\
1.13\end{array}$ & $\begin{array}{r}-1.39 \\
-1.05 \\
-0.70 \\
-0.35 \\
-0.00 \\
0.36 \\
0.72 \\
1.09\end{array}$ & $\begin{array}{r}-1.49 \\
-1.14 \\
-0.79 \\
-0.43 \\
-0.07 \\
0.30 \\
0.67 \\
1.05\end{array}$ & $\begin{array}{r}-1.56 \\
-1.21 \\
-0.85 \\
-0.48 \\
-0.11 \\
0.26 \\
0.54 \\
1.02\end{array}$ & $\begin{array}{r}-1.67 \\
-1.30 \\
-0.93 \\
-0.56 \\
-0.18 \\
0.20 \\
0.59 \\
0.98\end{array}$ & $\begin{array}{r}-1.74 \\
-1.37 \\
-0.99 \\
-0.61 \\
-0.23 \\
0.16 \\
0.55 \\
0.95\end{array}$ & $\begin{array}{r}-1.80 \\
-1.42 \\
-1.04 \\
-0.65 \\
-0.26 \\
0.13 \\
0.53 \\
0.93\end{array}$ & $\begin{array}{r}-\mathbf{1 . 9 6} \\
-\mathbf{1 . 5 7} \\
-\mathbf{1 . 1 7} \\
-\mathbf{0 . 7 7} \\
-\mathbf{0 . 3 7} \\
\mathbf{0 . 0 4} \\
\mathbf{0 . 4 5} \\
\mathbf{0 . 8 7}\end{array}$ \\
\hline
\end{tabular}

OBS: 1) Valores de PMV em torno de zero indicam condições de conforto térmico.

2) Valores de clo igual a 0,5 representam uma vestimenta leve de verão (calça comprida com camisa de mangas curtas), enquanto valores de clo igual a 1,0 representam uma vestimenta pesada de inverno. 
A ASHRAE também apresenta gráficos para a determinação das condições de conforto térmico em ambientes climatizados - as Cartas de Conforto da ASHRAE. A Figura 2.2 mostra uma carta psicrométrica com as zonas de conforto representadas por áreas hachuradas (ASHRAE 55, 2004; ASHRAE, 2005).

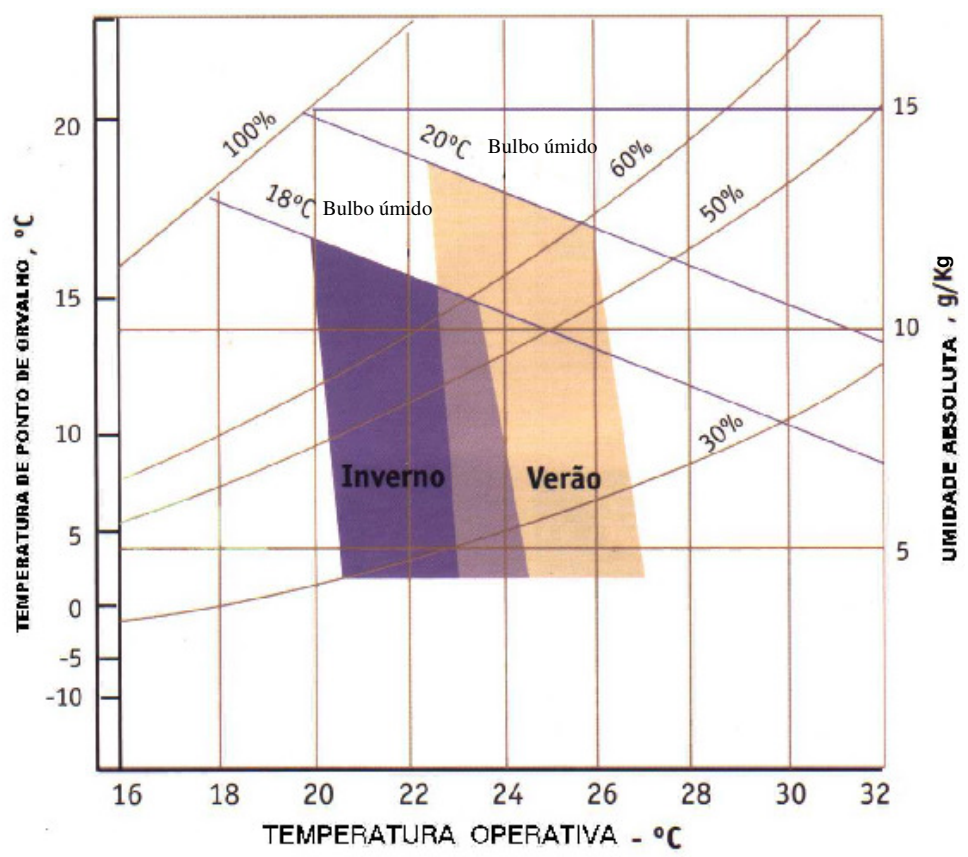

Figura 2.2 Zonas de conforto da ASHRAE para atividade sedentária (ASHRAE 55, 2004; ASHRAE, 2005).

As cartas de conforto da ASHRAE são de aplicação limitada, pois foram obtidas para condições ambientais e pessoais específicas. A carta da Figura 2.2, por exemplo, é válida somente para atividade sedentária, roupa leve, temperatura radiante média, $\mathrm{t}_{\mathrm{r}} \approx \mathrm{t}_{\mathrm{a}}$, temperatura do ar (temperatura de bulbo seco), velocidade relativa, $\mathrm{v}_{\mathrm{a}}<0,2 \mathrm{~m} / \mathrm{s}$ e umidade relativa do ar, $\phi$, em torno de $50 \%$.

Verifica-se na Tabela 2.3 e na Figura 2.2 que os resultados são apresentados em função da temperatura operativa, to ${ }^{3}$, que é função da temperatura média radiante, $\mathrm{t}_{\mathrm{r}}$, e da temperatura do ar, $t_{\mathrm{a}}$, dado pela Equação $(2.9)^{4}$ :

\footnotetext{
${ }^{3} \mathrm{t}_{\mathrm{o}}=$ temperatura operativa $\left({ }^{\circ} \mathrm{C}\right)$ : temperatura de um meio imaginário (envolvendo ar e superfícies) com o qual a pessoa troca a mesma quantidade de calor por convecção e radiação que aquela trocada com o meio real.

4 ASHRAE 55 (2004) e ISO 7730 (2005).
} 


$$
\mathrm{t}_{\mathrm{o}}=\mathrm{a} \cdot \mathrm{t}_{\mathrm{a}}+(1-\mathrm{a}) \cdot \mathrm{t}_{\mathrm{r}}
$$

onde a constante $\boldsymbol{a}$ varia de acordo com a velocidade do ar $\left(\mathrm{v}_{a}\right)$ :

\begin{tabular}{cccc}
\hline $\mathrm{v}_{\mathrm{a}}(\mathrm{m} / \mathrm{s})$ & $0-0,2$ & $0,2-0,6$ & $0,6-1,0$ \\
\hline$a$ & 0,5 & 0,6 & 0,7
\end{tabular}

\subsubsection{Percentagem de pessoas insatisfeitas (PPD)}

Os valores de PMV não são suficientes para definir a sensação de desconforto, pois, "ligeiramente frio ou quente" ou qualquer outro valor da escala, não indicam o quão insatisfeitas as pessoas estão. Para isto, Fanger (1972), associou aos índices de voto médio estimado (PMV) com a percentagem de pessoas insatisfeitas (PPD - Predicted Percentage of Dissatisfied).

Na Figura 2.3 é mostrada a relação entre PMV e PPD. Verifica-se nesta figura que, mesmo com PMV igual a zero (neutralidade térmica), 5\% estão insatisfeitos.

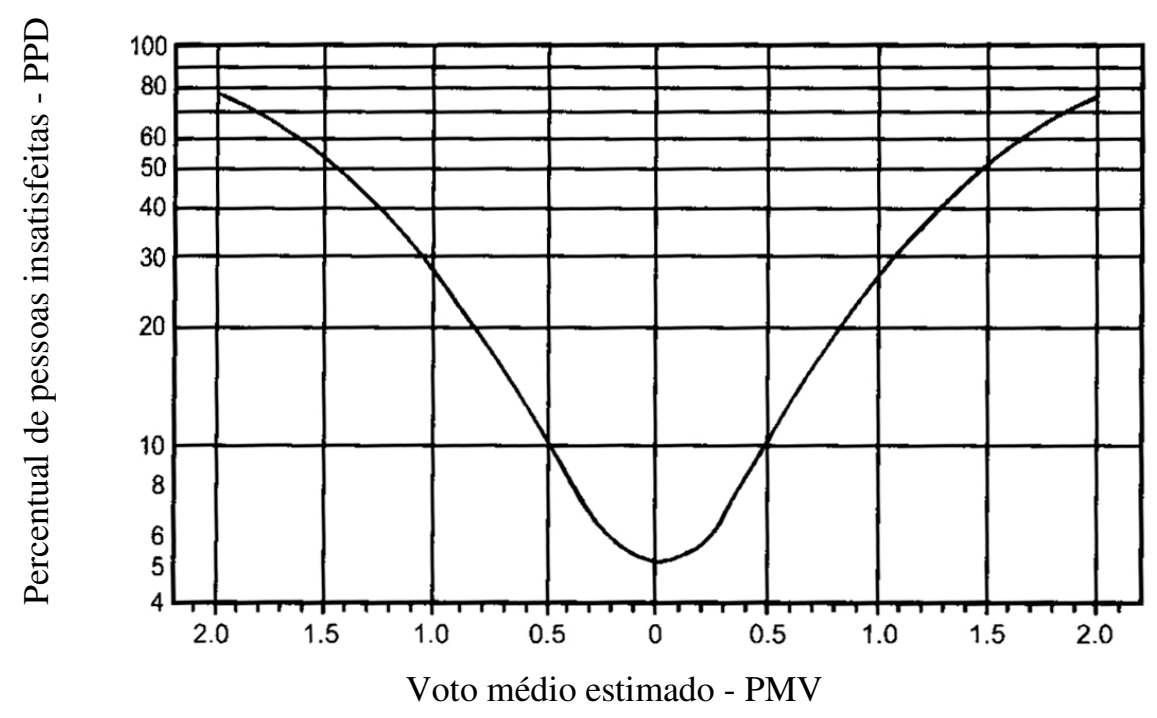

Figura 2.3 - Relação entre PMV e PPD 


\subsubsection{Desconforto térmico local}

As condições de conforto térmico de Fanger foram obtidas para o corpo como um todo. Contudo, uma pessoa pode estar em condições de neutralidade térmica $(\mathrm{PMV}=0)$, mas pode não estar confortável se uma parte do corpo estiver "quente" e uma outra "fria". Portanto, para se ter condições de conforto é necessário também que não haja desconforto local (quente ou frio) em diferentes partes do corpo.

Este desconforto térmico local pode ser causado por:

Correntes de ar (draft);

Assimetria de radiação;

$>$ Diferença de temperatura vertical do ar entre os pés e a cabeça;

$>$ Diferença de temperatura entre os pés e o piso.

Limites máximos previstos para cada uma das causas de desconforto térmico local são apresentados nas normas ASHRAE 55 (2004) e ISO 7730 (2005). 
Capítulo 3

\section{Avaliação de conforto térmico em ambientes não homogêneos}

Os índices PMV e PPD e as zonas de conforto da ASHRAE, vistos no Capítulo 2, podem ser utilizados com boa aproximação em ambientes de edificações onde, normalmente, ocorrem condições relativamente homogêneas de temperatura e velocidade do ar.

Por não permitir a verificação de desconforto em regiões localizadas do corpo humano, uma vez que o PMV e PPD foram obtidos a partir do balanço de energia para uma pessoa como um todo, Fanger et al. (1988) estabeleceram um índice complementar que leva em consideração o risco de desconforto por correntes de ar (risco de draft), denominado PD (Percentage of Dissatisfied). Além disso, as normas ISO 7730 (2005), baseada no trabalho de Fanger, e ASHRAE 55 (2004) estabelecem condições de conforto térmico e condições complementares com relação à diferença de temperatura entre os pés e a cabeça, assimetria de radiação e velocidades máximas do ar.

Essas especificações, porém, não são suficientes e adequadas para a avaliação de conforto térmico em ambientes não homogêneos, como aqueles que ocorrem em veículos automotivos e cabines aeronáuticas. Principalmente em função de se tratar de espaços confinados, nesses tipos de ambientes podem ocorrer gradientes de temperatura e velocidade do ar significativos, com assimetrias de temperatura, velocidade do ar e temperaturas radiantes.

Para a avaliação de ambientes não homogêneos o índice de temperatura equivalente, sua medição com manequins térmicos e a avaliação do conforto com cartas de conforto são os métodos mais utilizados. A seguir são comentados estes conceitos que serão utilizados nesta tese para avaliação do ambiente térmico em uma cabine de aeronave, visando condições de conforto térmico. 


\subsection{TEMPERATURA EQUIVALENTE}

\section{Definição geral}

“Temperatura de um invólucro imaginário onde, em ar parado e ambiente uniforme, a pessoa troca o mesma quantidade de calor por convecção e radiação que no ambiente real não uniforme (Fig.3.1).” (ISO 14505-2, 2006)

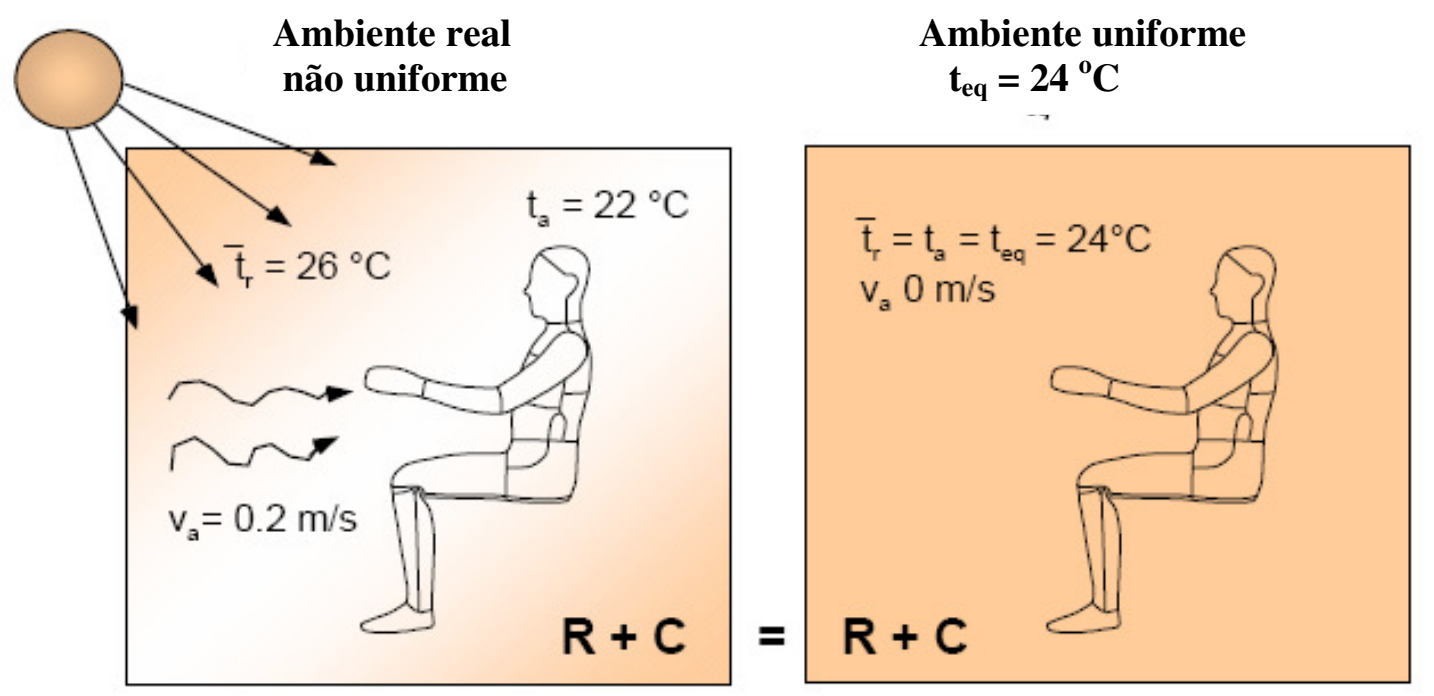

Figura 3.1 - Ilustração da definição de temperatura equivalente (adapt. de Nilsson, 2004)

Esta definição baseia-se em:

1) O corpo humano é exposto a dois ambientes diferentes: um, real, em que as condições climáticas não são homogêneas; e outro, ideal, com condições homogêneas que significam, principalmente, temperaturas do ar e temperaturas radiantes iguais. Considera-se, aqui, que a postura, a atividade, o metabolismo e as roupas são os mesmos, em ambos os ambientes. A aplicação da definição demonstra uma forte dependência dos fatores pessoais. Assim, ao aplicá-la, é necessário avaliar, sempre, o isolamento térmico e a atividade física.

2) O calor sensível trocado pelo corpo humano é o mesmo, em ambos os ambientes. A troca térmica pode ser negativa, ou seja, o corpo ganha calor, caso esteja em um ambiente com temperatura superior a $34{ }^{\circ} \mathrm{C}$ (atividade sedentária).

É importante observar que a temperatura equivalente é derivada da temperatura operativa, to, com a inclusão do efeito da velocidade do ar sobre um corpo aquecido. A temperatura operativa somente considera a temperatura do ar e a temperatura radiante média, 
e é definida para a velocidade real do ar, enquanto a temperatura equivalente é definida para uma velocidade padronizada, próximo de zero.

Em alguns trabalhos da literatura aparecem algumas variações com relação à denominação da temperatura equivalente, tais como ELT - equivalent living-room temperature (temperatura equivalente do “ambiente") e EHT - equivalent homogeneous temperature (temperatura equivalente homogênea), mas o conceito é o mesmo.

\section{Cálculo geral}

A determinação da temperatura equivalente baseia-se nas equações de transferência de calor por convecção e radiação em pessoas vestidas, com:

$$
\begin{array}{ll}
\mathrm{R}=\mathrm{F}_{\mathrm{cl}} \cdot \mathrm{f}_{\mathrm{cl}} \cdot \mathrm{h}_{\mathrm{r}} \cdot\left(\mathrm{t}_{\mathrm{s}}-\mathrm{t}_{\mathrm{r}}\right) & \left(\mathrm{W} / \mathrm{m}^{2}\right) \\
\mathrm{C}=\mathrm{F}_{\mathrm{cl}} \cdot \mathrm{f}_{\mathrm{cl}} \cdot \mathrm{h}_{\mathrm{c}} \cdot\left(\mathrm{t}_{\mathrm{s}}-\mathrm{t}_{\mathrm{a}}\right) & \left(\mathrm{W} / \mathrm{m}^{2}\right)
\end{array}
$$

em que:

$\mathrm{R}=$ Troca de calor por radiação por unidade de área $\left(\mathrm{W} / \mathrm{m}^{2}\right)$;

$\mathrm{C}=$ Troca de calor de convenção entre a superfície externa da roupa e o ar externo por unidade de área $\left(\mathrm{W} / \mathrm{m}^{2}\right)$;

$\mathrm{h}_{\mathrm{r}}=$ Coeficiente de troca de calor linearizado por radiação entre a superfície externa da roupa e o ambiente $\left(\mathrm{W} / \mathrm{m}^{2} .{ }^{\circ} \mathrm{C}\right)$;

$\mathrm{t}_{\mathrm{s}}=$ Temperatura da pele $\left({ }^{\mathrm{O}} \mathrm{C}\right)$;

$\mathrm{h}_{\mathrm{c}}=$ Coeficiente de troca de calor por convecção $\left(\mathrm{W} / \mathrm{m}^{2} .{ }^{\circ} \mathrm{C}\right)$;

$\mathrm{t}_{\mathrm{a}}=$ Temperatura do ar $\left({ }^{\circ} \mathrm{C}\right)$;

$\mathrm{t}_{\mathrm{r}}=$ Temperatura média radiante $\left({ }^{\circ} \mathrm{C}\right)$;

$\mathrm{F}_{\mathrm{cl}}=$ Fator redutor de troca térmica, devido à roupa, adimensional;

$\mathrm{f}_{\mathrm{cl}}=$ Fator de área de roupa $\left(\mathrm{A}_{\mathrm{cl}} / \mathrm{A}_{\mathrm{u}}\right)$, adimensional.

A resistência térmica da roupa está ligada ao fator $\mathrm{F}_{\mathrm{cl}}$. Roupas com maior resistência térmica têm $\mathrm{F}_{\mathrm{cl}}$ menor. $\mathrm{O}$ aumento de área de troca de calor resultante do acréscimo de roupa 
está ligado ao fator $\mathrm{f}_{\mathrm{cl}}$. Roupas que aumentam muito a área externa, que está em contato com o ar, ampliam o fator $\mathrm{f}_{\mathrm{cl}}$.

Os coeficientes $h_{r}$ e $h_{c}$ dependem da temperatura da parte externa da roupa, da temperatura das superfícies próximas, da temperatura do ar, da velocidade do ar, da posição do corpo e das respectivas partes do corpo humano ao campo do escoamento.

A troca total de calor será dada por:

$$
\mathrm{R}+\mathrm{C}=\mathrm{F}_{\mathrm{clr}} \cdot \mathrm{f}_{\mathrm{cl}} \cdot \mathrm{h}_{\mathrm{r}} \cdot\left(\mathrm{t}_{\mathrm{s}}-\mathrm{t}_{\mathrm{r}}\right)+\mathrm{F}_{\mathrm{clc}} \cdot \mathrm{f}_{\mathrm{cl}} \cdot \mathrm{h}_{\mathrm{c}} \cdot\left(\mathrm{t}_{\mathrm{s}}-\mathrm{t}_{\mathrm{a}}\right) \quad\left(\mathrm{W} / \mathrm{m}^{2}\right)
$$

Usando a definição de temperatura equivalente, com a temperatura do ar e da temperatura radiante média com o mesmo valor, tem-se:

$$
\mathrm{R}+\mathrm{C}=\mathrm{F}_{\mathrm{clr}} \cdot \mathrm{f}_{\mathrm{cl}} \cdot \mathrm{h}_{\mathrm{r}} \cdot\left(\mathrm{t}_{\mathrm{s}}-\mathrm{t}_{\mathrm{eq}}\right)+\mathrm{F}_{\mathrm{clc}} \cdot \mathrm{f}_{\mathrm{cl}} \cdot \mathrm{h}_{\mathrm{c}} \cdot\left(\mathrm{t}_{\mathrm{s}}-\mathrm{t}_{\mathrm{eq}}\right) \quad\left(\mathrm{W} / \mathrm{m}^{2}\right)
$$

Assim

$$
\mathrm{t}_{\mathrm{eq}}=\mathrm{t}_{\mathrm{s}}-\mathrm{R}+\mathrm{C} /\left(\mathrm{F}_{\mathrm{clr}} \cdot \mathrm{f}_{\mathrm{cl}} \cdot \mathrm{h}_{\mathrm{r}}+\mathrm{F}_{\mathrm{clc}} \cdot \mathrm{f}_{\mathrm{cl}} \cdot \mathrm{h}_{\mathrm{c}}\right)
$$

Denominando:

$\mathrm{h}_{\text {tot }}=$ Coeficiente de troca de calor total entre a pele e o ambiente exterior

em que

$$
h_{\text {tot }}=F_{\text {clr }} \cdot f_{\text {cl }} \cdot h_{r}+F_{\text {clc }} \cdot f_{\text {cl }} \cdot h_{c} \quad\left(W / m^{2} \cdot{ }^{\circ} \mathrm{C}\right)
$$

tem-se

$$
\mathrm{t}_{\mathrm{eq}}=\mathrm{t}_{\mathrm{s}}-\mathrm{Q} / \mathrm{h}_{\mathrm{tot}} \quad\left(\mathrm{W} / \mathrm{m}^{2} .{ }^{\circ} \mathrm{C}\right)
$$

em que

$$
\mathrm{Q}=\mathrm{R}+\mathrm{C} \quad\left(\mathrm{W} / \mathrm{m}^{2} \cdot{ }^{\circ} \mathrm{C}\right)
$$

$\mathrm{R}+\mathrm{C}=$ troca de calor total de convecção e radiação. 


\section{Evolução Histórica}

Há muito tempo procura-se um índice que integre as condições térmicas de um ambiente. Ao estudar trabalhadores em um ambiente industrial, Bedford (1936 apud Nisson 2004) usou um conceito chamado "temperatura equivalente", diferente da definição mencionada, que tentava incorporar parâmetros externos (velocidade, temperatura do ar e temperatura radiante média).

Yaglou (1947 apud Nilsson, 2004) foi um dos primeiros a utilizar um índice de temperatura efetiva para integrar velocidade e temperatura do ar, e temperatura radiante média. Nota-se, nestas definições, a falta de parâmetros importantes, como aqueles relacionados à pessoa (roupa e metabolismo). Fanger foi o primeiro a unir todas as variáveis em um só índice. Fazendo um balanço térmico para o corpo humano, correlacionou tanto as variáveis ambientais quanto às relativas à pessoa em um só índice, o PMV. Utilizada em normas de avaliação de conforto térmico para o corpo como um todo (ISO 7730; ASHRAE, 55), a sua metodologia continua sendo largamente aplicada.

Madsen et al. (1984) incluíram a resistência térmica da roupa em uma correlação empírica:

$$
\begin{gathered}
\mathrm{t}_{\mathrm{eq}}=\mathrm{t}_{\mathrm{o}}=0,5 \cdot\left(\mathrm{t}_{\mathrm{a}}+\mathrm{t}_{\mathrm{r}}\right) \quad \text { para } \mathrm{v}_{\mathrm{a}} \leq 0,1 \mathrm{~m} / \mathrm{s} \\
\mathrm{t}_{\text {eq }}=0,55 \cdot \mathrm{t}_{\mathrm{a}}+0,45 \cdot \mathrm{t}_{\mathrm{r}}+\frac{0,24-0,75 \cdot \sqrt{\mathrm{va}_{\mathrm{a}}}}{1+\mathrm{I}_{\mathrm{cl}}}\left(36,5-\mathrm{t}_{\mathrm{a}}\right) \quad \text { para } \mathrm{v}_{\mathrm{a}}>0,1 \mathrm{~m} / \mathrm{s}
\end{gathered}
$$

em que

$\mathrm{v}_{\mathrm{a}}=$ Velocidade do ar, $(\mathrm{m} / \mathrm{s}) ;$

$\mathrm{t}_{\mathrm{a}}=$ Temperatura do ar, $\left({ }^{\circ} \mathrm{C}\right)$;

$\mathrm{t}_{\mathrm{r}}=$ Temperatura média radiante, $\left({ }^{\circ} \mathrm{C}\right)$;

$\mathrm{I}_{\mathrm{cl}}=$ Resistência térmica da roupa, clo. 


\subsection{INFLUÊNCIA DA NÃO-AVALIAÇÃO DAS TROCAS EVAPORATIVAS NA TEMPERATURA EQUIVALENTE}

Como se pode observar, os diversos conceitos de temperatura equivalente sempre fazem referência às trocas térmicas de convecção e radiação, mas não às trocas de calor evaporativas. A questão é: uma definição de temperatura equivalente, que leve em conta as trocas térmicas por evaporação do corpo, não poderia auxiliar em análises em que as alterações de umidade absoluta são importantes, como nos aviões? Para responder a esta pergunta, fez-se as seguintes análises:

Utilizando-se as equações de conforto de Fanger, que levam em conta as trocas térmicas por evaporação, calculou-se o PMV para 9 situações (Tabela 3.1):

Tabela 3.1 Valores de PMV calculados para 9 situações com diferentes umidades relativas*

\begin{tabular}{|c|c|c|c|}
\hline & \multicolumn{3}{|c|}{ Temperaturas de Bulbo Seco $\left({ }^{\circ} \mathrm{C}\right)$} \\
\hline Umidade Relativa (\%) & 15 & 24 & 29 \\
\hline 5 & $-3,16$ & $-1,59$ & $-0,87$ \\
\hline 30 & $-3,05$ & $-1,39$ & $-0,60$ \\
\hline 60 & $-2,91$ & $-1,15$ & $-0,29$ \\
\hline
\end{tabular}

* Metabolismo de 58,2 W/m², velocidade do ar de $0,1 \mathrm{~m} / \mathrm{s}$, temperatura radiante média de $20{ }^{\circ} \mathrm{C}, \mathrm{I}_{\mathrm{cl}}=0,5$.

A seguir, foram calculadas as temperaturas equivalentes, considerando temperaturas do ar e a temperaturas radiantes médias iguais, que forneçam o mesmo PMV da tabela anterior, cujos resultados são apresentados na Tabela 3.2.

Tabela 3.2 Temperaturas equivalentes calculadas pelas equações de PMV

\begin{tabular}{|c|c|c|c|}
\hline & \multicolumn{3}{|c|}{ Temperaturas de Bulbo Seco $\left({ }^{\circ} \mathrm{C}\right)$} \\
\hline Umidade Relativa (\%) & 15 & 24 & 29 \\
\hline 5 & 17,4 & 22,0 & 24,1 \\
\hline 30 & 17,3 & 22,0 & 24,3 \\
\hline 60 & 17,2 & 22,1 & 24,5 \\
\hline
\end{tabular}


Percebe-se, na Tabela 3.2, que não houve variações significativas quando se alterou a umidade relativa. Assim, não deve haver muito impacto na percepção do conforto quando se varia a umidade relativa.

Utilizando-se as equações de conforto de Fanger (1972), verificou-se o impacto no voto médio estimado, PMV, e a porcentagem de pessoas insatisfeitas, PPD. Para uma situação de conforto (igual à anterior, com temperatura do ar e temperatura radiante média iguais a $26{ }^{\circ} \mathrm{C}$ ) variou-se a umidade relativa entre 5 e $90 \%$, cujos resultados são apresentados na Figura 3.2

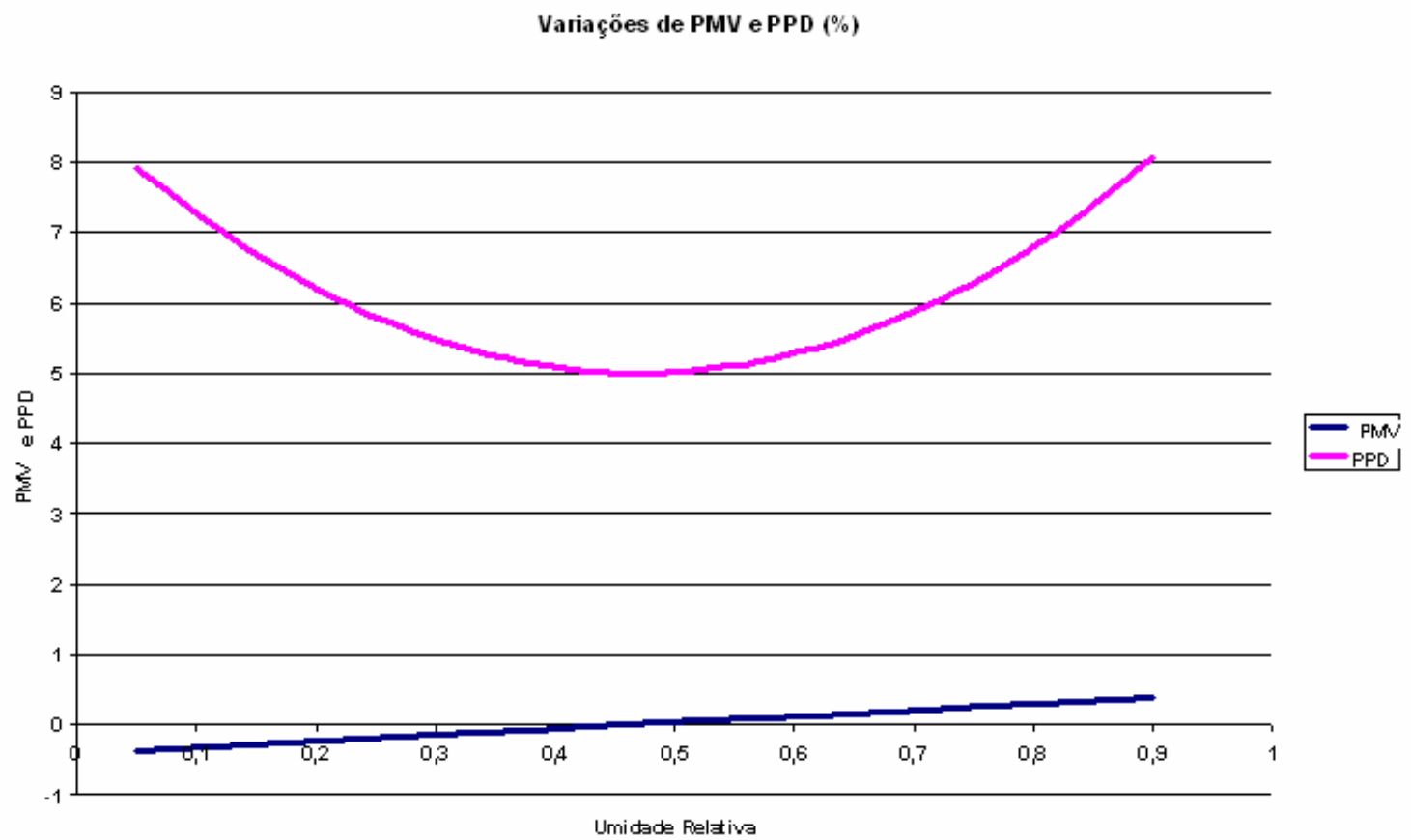

Figura 3.2 - Variação do PMV e do PPD com a umidade relativa considerando condição de conforto.

Pode-se notar na Figura 3.2 que o PPD cresce somente 2\% quando a umidade relativa varia. Analogamente, o PMV não saiu da faixa de $\pm 0,5$, o que está na faixa de conforto. Assim, o conceito de temperatura equivalente é adequado para avaliar situações de grandes alterações na umidade absoluta (Strom-Tejsen et al., 2005; Grun et al.2008).

\subsection{MANEQUINS TÉRMICOS EXPERIMENTAIS}

Vários equipamentos foram construídos para medição da temperatura equivalente. Uma solução largamente difundida para medição de temperaturas equivalentes é o manequim 
térmico. Embora em uso desde meados do século passado, somente agora o seu uso ganhou impulso maior na avaliação de ambientes térmicos não homogêneos. Necessitando de alguns cuidados no seu uso e interpretação de seus dados, os manequins podem fornecer informações importantes para a correta avaliação do conforto e sua melhoria.

\subsubsection{Revisão histórica}

Os manequins térmicos apareceram nos anos 1940. O primeiro, feito de cobre, sem cabeça nem braços, tinha um aquecedor e ventilador para homogeneizar as temperaturas (Belding, 1949 apud Nilsson 2004). Ao longo do tempo foram aperfeiçoados para simular melhor o desempenho térmico do corpo humano. Em 1942, Belding e os engenheiros da General Eletric Co. desenvolveram um novo modelo com placas de circuito impresso com corrente elétrica, que aqueciam uniformemente as superfícies. Os pés e mãos tinham controle independente para proporcionar temperaturas diferentes das temperaturas do resto do corpo.

A necessidade de informações mais detalhadas fez com que os manequins tivessem mais zonas com controle independente. Hoje, quase todos têm mais de 15 zonas térmicas. Para reduzir o custo e o peso, a maioria tem sido construída em alumínio e com material isolante interno. Um último passo importante foi acrescentar controle e um sistema de aquisição digital, que propiciou mais flexibilidade nos diversos modos de controle e exatidão nas leituras.

A grande utilização dos manequins térmicos, atualmente, é na avaliação de roupas e ambientes térmicos assimétricos e não homogêneos. Para avaliação em climas quentes, o processo de transpiração é um mecanismo importante na termo-regulação do corpo humano e alguns manequins têm esta característica.

\subsubsection{Uso de manequins na avaliação de cabines}

O desenvolvimento dos manequins térmicos para avaliar ambientes assimétricos teve grande influência da indústria automotiva. Wyon et al. (1985) foram os primeiros a utilizar um manequim para avaliar o ambiente em cabines de veículos. Madsen et al. (1986) utilizaram um manequim desenvolvido na Universidade Técnica da Dinamarca, com 16 segmentos, para comparar os diversos métodos de medição de conforto térmico em veículos. Os autores empregaram o método de temperatura superficial constante para avaliar as 
temperaturas equivalentes. Comparando os diversos métodos de avaliação de conforto, os autores concluiram que o uso de manequins térmicos é o melhor.

De Dear et al. (1997) usaram um manequim térmico para avaliar os coeficientes de convecção para o ar nos diversos segmentos do corpo humano. Empregaram o método de temperatura de superfície constante, embora não especifiquem qual. $\mathrm{O}$ manequim tem formato feminino e 16 segmentos e, para aquecimento, possui um fio de níquel de 0,3 $\mathrm{mm}$ de espessura com espaçamento de $2 \mathrm{~mm}$, e uma cobertura protetora de 0,1 a $1 \mathrm{~mm}$ de espessura. Sua estrutura é de fibra de vidro com poliéster com $4 \mathrm{~mm}$ de espessura.

Conceição et al. (1997) estudaram a movimentação do ar em uma cabine de ônibus. Utilizaram um manequim da Universidade Técnica da Dinamarca com temperatura de pele constante, regulada entre $32{ }^{\circ} \mathrm{C}$ e $37{ }^{\circ} \mathrm{C}$.

Nilsson (2004) apresenta um manequim térmico que não tem articulação e está sempre sentado. Possui 36 zonas de controle independentes e é construído com espuma de poliuretano rígida, recoberta por fios de níquel com espaçamento de $5 \mathrm{~mm}$. Está ligado a uma caixa com conversores analógico-digitais que, por sua vez, está conectada a um computador que permite regulagem por três métodos: temperatura de superfície constante, fluxo de calor constante e equação de conforto. Em estudo sobre a repetição dos coeficientes de convecção, chegou a um desvio padrão de $8 \%$ para cada membro dos manequins. Isto tem um impacto de incerteza no cálculo das temperaturas equivalentes de \pm 1 a $\pm 3,3{ }^{\circ} \mathrm{C}$. Utilizou-se, como método de controle, temperatura de superfície constante de $34{ }^{\circ} \mathrm{C}$.

Martinho et al. (2004) apresentam estudo comparativo de dois métodos de medição de temperatura equivalente em um mock-up de um veículo. O primeiro usa um modelo feminino da Universidade Técnica da Dinamarca com temperatura de pele constante. O segundo utiliza equações empíricas com medidas de temperatura de ar e velocidades. Os autores verificaram que houve diferenças razoáveis, como já tinha sido verificado por Madsen et al. (1986).

Lebbin e Hosni (2005) apresentaram a seqüência de um trabalho que estava sendo desenvolvido na Universidade de Kansas em que foram testados, basicamente, dois métodos de avaliar o transiente de resfriamento em um carro aquecido. O manequim TOM (Thermal Observation Manikin) tem transdutores de fluxo de calor, medidores de temperatura de pele e aquecedores. Está ligado a um computador que possui um modelo fisiológico que, em função das informações dos fluxímetros e dos sensores de temperatura, modifica as potências dos aquecedores locais.

A tendência de se adicionar um modelo fisiológico e psicológico ao manequim, visando controlar a temperatura da pele, pode ser observada também em artigo de Rugh e 
Baharatan (2005). O manequim ADAM - Advanced Automotive Manikin - é composto por 120 zonas que, além dos sensores e atuadores, têm a capacidade de transpirar sob calor excessivo. Assim como o TOM, o ADAM tem um modelo fisiológico tridimensional do corpo humano, modelado em um programa de elementos finitos ANSYS ${ }^{\circledR}$, com uma rede de veias e artérias em cada parte do corpo. Outra rede de dutos simula a traquéia e os pulmões. O programa recebe as informações das temperaturas e fluxos de calor de cada parte do manequim e demora 2 minutos para calcular as novas temperaturas de pele. $\mathrm{O}$ modelo de conforto utilizado é o da Universidade de Berkley (Zhang, 2003). O artigo apresenta a validação do manequim com dados de literatura. Os maiores desvios das temperaturas de pele estão nas mãos e pés $\left(2^{\circ} \mathrm{C}\right)$. Nas outras partes, os dados apresentam melhor correlação.

\subsubsection{Precisão nas medições das temperaturas equivalentes}

Embora o uso de manequins para obter temperaturas equivalentes esteja normalizado, pode-se questionar se modelos diferentes alcançariam as mesmas temperaturas equivalentes, em um mesmo ambiente. Isto foi discutido em um Seminário - Consortium Assessment of Thermal Climate in Operator's Cabs - CABCLI, realizado em Florença em 1999, em que foram discutidos resultados de um projeto envolvendo pesquisadores da Comunidade Européia, denominado EQUIV (CABCLI, 1999).

Melikov e Zhou (1999), apresentaram artigo no Seminário CABCLI onde mostraram existir variações decorrentes da diferença de tamanho, do modo de regulagem e do número de zonas, nas temperaturas equivalentes medidas por diferentes instrumentos e métodos de controle. Para isto foram empregados três manequins térmicos com diversos números de zonas e quatro medidores integrativos. Por meio de medidas de temperaturas equivalentes de ambientes assimétricos, os autores concluíram que para a temperatura equivalente de corpo inteiro houve uma diferença de $2{ }^{\circ} \mathrm{C}$ para instrumentos integrativos (confortímetro) e $0,5{ }^{\circ} \mathrm{C}$ para medições com manequins. Esta diferença diminui quando se reduz o número de zonas medidas. A repetitividade dos instrumentos integrativos foi melhor do que 1\%; e para manequins nus, melhor do que $10 \%$. As temperaturas equivalentes medidas com manequins vestidos foram maiores do que as medidas com manequins nus. Um aumento no isolamento da roupa de 0,6 clo para 1 clo não teve impacto significativo nas temperaturas equivalentes. Os maiores desvios (até $1{ }^{\circ} \mathrm{C}$ ) foram obtidos com método de fluxo de calor constante.

Melikov e Zhou (1999) ainda fizeram um estudo para verificar como os coeficientes globais de troca de calor $\left(\mathrm{h}_{\text {cal }}\right)$ variavam com as temperaturas médias do ar nas calibrações. Os 
coeficientes globais de troca de calor decresceram um pouco, com um máximo de $1,2 \mathrm{~W} / \mathrm{m}^{2} . \mathrm{K}$ quando a temperatura média do ar decresceu em $10{ }^{\circ} \mathrm{C}$. Isto mostra que uma calibração é suficiente para uma faixa de medição de $10{ }^{\circ} \mathrm{C}$ caso se espere uma exatidão menor de $2 \%$ neste coeficiente de troca de calor. Também a diferença entre os modos de regulagem mostram pouca diferença na faixa de calibração feita $\left(19{ }^{\circ} \mathrm{C}\right.$ à $\left.30{ }^{\circ} \mathrm{C}\right)$. Assim, pode ser utilizado um ou outro modo de regulagem caso seja desejada exatidão maior que $3 \%$.

Quanto à diferença das temperaturas equivalentes de corpo inteiro, houve diferenças médias de $0,5{ }^{\circ} \mathrm{C}$. Isto mostra que, para medidas de temperaturas equivalentes de corpo inteiro, é possível comparar resultados com manequins diferentes, caso se queira exatidão maior do que $0,5^{\circ} \mathrm{C}$. As diferenças maiores referiram-se à comparação entre as temperaturas equivalentes dos equipamentos integrativos e os manequins $\left(4{ }^{\circ} \mathrm{C}\right.$ para situações assimétricas e $1,5{ }^{\circ} \mathrm{C}$ para condições mais homogêneas). Isto ocorre, principalmente, porque a troca de calor do corpo humano é tridimensional, enquanto os sensores planos têm uma diretividade muito grande. Outras razões são as diferenças nas formas, tamanhos e temperaturas de superfície dos sensores.

Ao comparar as temperaturas equivalentes dos três manequins, os dados mostraram que a variação média é de $1,0{ }^{\circ} \mathrm{C}$, mas chegando a $4{ }^{\circ} \mathrm{C}$ em algumas zonas, como coxas. É comentado que este resultado não era esperado.

A explicação destas diferenças está em um artigo apresentado no mesmo Seminário CABCLI por Bohm et al. (1999), onde são comparadas médias de temperaturas equivalentes medidas em segmentos de manequins com mais de uma zona, manequins HEATMAN e AIMAN, e de uma só zona, o manequim NILLE (Figura 3.3). No caso das coxas, por exemplo, a parte inferior, que sofre o isolamento do banco, apresentou uma temperatura equivalente maior do que a parte superior. Nos manequins cujas coxas estão separadas por zonas diferentes, estas temperaturas são, respectivamente, $33,4{ }^{\circ} \mathrm{C}$ e $24{ }^{\circ} \mathrm{C}$, resultando em uma temperatura média de $28,7^{\circ} \mathrm{C}$. No manequim NILLE, que tem apenas uma zona, a resistência térmica ficará submetida a duas temperaturas e terá um fluxo de calor $\left(9,4 \mathrm{~W} / \mathrm{m}^{2}\right)$, tal que a temperatura será $32,8{ }^{\circ} \mathrm{C}$, ou seja, $4,1{ }^{\circ} \mathrm{C}$ maior. 


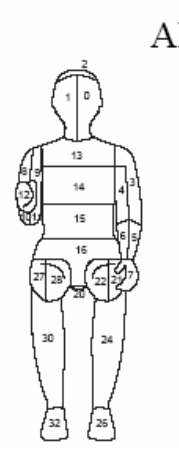

AIMAN

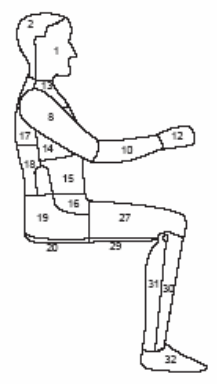

HEATMAN

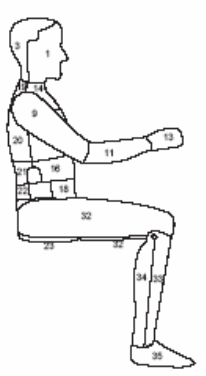

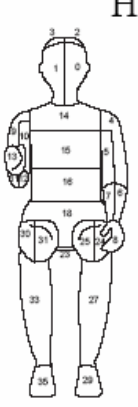

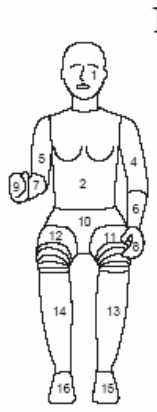

NILLE

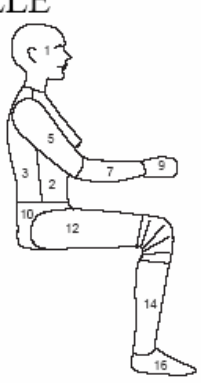

Figura 3.3 Os manequins comparados com as suas respectivas divisões de zonas.

(Bohm et al., 1999).

Existem três métodos de regulagem dos segmentos do manequim, Cada um dos métodos têm vantagens e desvantagens apresentadas a seguir:

Temperatura de superfície constante: $\mathrm{O}$ método utiliza uma temperatura constante em todas as zonas, ou diferentes, mas constantes, em ambientes térmicos diversos, como no caso da coxa, com uma só zona para manequins sentados.

Um tempo de resposta pequeno é a principal vantagem, porque a temperatura na superfície é sempre a mesma. Isto faz com que todo o volume interno seja adiabático, sem alteração na energia térmica interna do manequim. Também não há fluxo interno entre os segmentos.

Uma ligeira instabilidade na regulagem é a principal desvantagem. Além disso, não se consegue medir temperaturas equivalentes maiores do que as reguladas - na maioria dos casos, $34{ }^{\circ} \mathrm{C}$.

Fluxo de calor constante: regula-se uma potência térmica por área dissipativa constante em cada zona, que pode ter um só valor ou valores diferentes. Vantagens desta forma de regulagem: ilimitadas faixas de medição e estabilidade, isto é, não existe uma malha de controle. Pode-se medir um transiente sem instabilidades do controle.

As desvantagens são que as temperaturas das superfícies podem não ser realistas. Além disso, pode haver fluxo de calor de uma parte para outra, ou transientes térmicos que demoram a atingir estabilidade, devido à variação no fluxo interno.

A temperatura do corpo do manequim irá variar de modo bastante semelhante ao que ocorre com o ser humano, caso se utilize regulagem baseada na equação de conforto. Vantagens: as superfícies terão as temperaturas mais próximas daquelas que ocorrem com o ser humano em uma faixa de medição maior do que as de temperatura constante. $\mathrm{O}$ controle mais lento do que o método de temperatura constante é a principal desvantagem. Além disso, 
existe fluxo interno, e não se pode garantir que todo o fluxo medido esteja sendo trocado com o ambiente.

\subsubsection{Impacto de temperaturas medidas com manequim nu ou vestido}

Os manequins podem ser usados nus ou vestidos. Ambas as utilizações têm vantagens e desvantagens - os vestidos estão mais próximos da realidade, mas têm menor resolução e são mais difíceis de se mover sem alterar o isolamento. O manequim nu é mais sensível ao efeito convectivo e mais fácil de calibrar. No entanto, a temperatura da superfície que está trocando calor com o ambiente não é igual. Isto explica a diferença entre as medidas no mesmo ambiente entre um manequim vestido, e outro, nu (Bohm et al., 1999). Neste mesmo artigo, os autores calculam, teoricamente, a influência da velocidade de ar e da temperatura para um manequim nu e outro vestido, clo=1. Para velocidades baixas e temperatura do ar de $24{ }^{\circ} \mathrm{C}$, não há diferença. Para temperatura do ar com $10^{\circ} \mathrm{C}$, a mais ou a menos, a diferença é de $1{ }^{\circ} \mathrm{C}$.

\subsubsection{Normalização no uso de manequins}

O principal emprego de manequins está na medição da resistência térmica de roupas. Um exemplo pode ser encontrado nos trabalhos apresentados em recentes congressos sobre o tema (IMM, 1997), (3IMM, 1999), (4IMM, 2001), (5I3M, 2003), (6I3M, 2006). Existem diversas normas que estabelecem procedimentos para realizar tal medição:

- ISO 7929 - Estimation of the thermal characteristics of clothing;

- ASTM F1291 - Standard method for measuring the thermal insulation of clothing using a heated thermal mankin;

- ISO NP - Measurement of thermal insulation with a thermal manikin (ISO TC92 WG17).

O uso de manequins para avaliar ambientes térmicos em veículos automotivos está normalizado na ISO 14505 - Ergonomic of the thermal environment - Evaluation of thermal environment in vehicles, que está dividida em três partes:

Parte1 - Principles and methods for assessment of thermal stress;

Parte 2 - Determination of equivalent temperature;

Parte 3 - Evaluation of thermal comfort using human subjects. 
Esta norma foi resultado de um projeto da Comissão Européia (Commission of the European Communities, Directorate General XII, Science, Research and Development) no desenvolvimento do projeto EQUIV - (Development of standard test methods for evaluation of thermal climate in vehicles), formado por 14 membros - 6 centros de pesquisa, 5 montadoras automotivas (Scania, Volvo, BMW, Daimler e Renault) e três indústrias (Innova, Behr GmbH e Volvo Car Corporation), conforme descrito em Nilsson e Holmér (2002).

Pode-se aplicar as boas práticas resultantes de diversas experiências, como conservar o manequim aquecido para evitar o resfriamento do seu núcleo e utilizar roupas apertadas para impedir variações nas avaliações (Zhihua e Yuhang, 1999; Nilsson, 2004).

Dos resultados apresentados no Seminário CABCLI (1999), pode-se concluir:

a) Manequins conseguem captar as nuances dos diferentes ambientes térmicos e suas diferentes fontes e trocas de calor;

b) Têm boa repetibilidade;

c) Deve-se conhecer bem as divisões das zonas antes de comparar temperaturas entre manequins térmicos diferentes. Se possível, comparar manequins com as mesmas divisões de zonas. Aqueles que têm zonas únicas submetidas a ambientes térmicos diferentes maximizam as temperaturas;

d) As diferenças nas temperaturas equivalentes ocorrem, principalmente, devido à mudança na temperatura da superfície que está trocando calor, seja ela causada pela regulagem ou isolamento, seja pela divisão de zonas;

e) Outras fontes de diferenças são o tamanho e a postura do manequim. As cabines são pequenas e têm condições assimétricas. Portanto, tamanho e postura influenciam:

e.1) a presença do manequim trará impacto nas condições ambientais de cabine;

e.2) uma pequena mudança de posição mudará a posição do sensor, que captará uma outra condição ambiental.

\subsection{MANEQUINS TÉRMICOS DIGITAIS}

Com o crescente uso de análises computacionais de CFD em escoamentos em ambientes interiores (Murakami et al., 2001, 2004), é possível verificar a atenção que tem recebido atualmente a utilização de manequins digitais para se avaliar o conforto térmico 
global e local. Este fato é demonstrado tanto pelo número de artigos publicados sobre o tema, quanto pela quantidade de congressos internacionais voltados a esta área.

Um dos primeiros estudos sobre o emprego de manequins para analisar o conforto é de Gan (1994). O manequim é um paralelepípedo com dissipação de $70 \mathrm{~W} / \mathrm{m}^{2}$, distribuído em toda a superfície, na qual $30 \%$ é calor latente.

Posteriormente, Brohus e Nielsen (Brohus et al., 1996) apresentaram três modelos de manequins digitais de forma cubóide, que são comparados a um manequim térmico, em pé, em um túnel com velocidade constante na entrada. Como condição de contorno no manequim, utiliza-se o fluxo de calor prescrito de $25 \mathrm{~W} / \mathrm{m}^{2}$. Nesse mesmo ano, utilizando um manequim térmico, Kato (1996) apresentou um estudo de renovação de ar em uma sala onde o manequim tem fluxo de calor constante de $20 \mathrm{~W} / \mathrm{m}^{2}$ distribuído na sua superfície.

Matsunaga et al. (1997) apud Nilsson (2004) descrevem três modelos de avaliação de conforto térmico local e global. O manequim digital tem 16 segmentos com o modelo fisiológico de Stolwijk de 65 nós.

Um manequim térmico digital foi desenvolvido por Murakami et al. (1997; 1998) para predizer o conforto humano. Os autores modelaram diferentes modos de transferência de calor de forma acoplada, simulando o efeito combinado de campo de velocidades, radiação e transferência de massa.

Alfahaid et al. (1999) desenvolveram um manequim digital para regime permanente e transitório. Não utiliza troca de calor por radiação e não há troca de massa na pele (evaporação). O manequim tem temperatura de pele constante.

Han et al. (2001; 2004 e 2005) empregaram um manequim com um modelo fisiológico de 16 segmentos de Stowijk e simularam o escoamento do ar, e da radiação solar e infravermelha no programa Fluent. Han e Huang (2004) apresentam o modelo fisiológico e a forma de se obter as temperaturas equivalentes. Avaliam a sensação térmica por meio dos gráficos de conforto de Bohm et al. (1990), embora na literatura já houvesse diagramas de conforto mais elaborados, como os diagramas independentes de roupa de Nilsson (2004) ou o modelo da Universidade de Berkeley (Zhang, 2003). Han e Huang (2005) mostram a validação de seu modelo, aplicando-o em 6 manequins dentro de um utilitário, e comparam as temperaturas do ar e os votos de conforto experimentais. A correlação alcançada é muito boa. Eles fornecem também as temperaturas equivalentes para 16 partes do corpo, sem validação.

Tanabe et al. (2002) desenvolveram um modelo fisiológico de Stowijk com 65 nós e 16 segmentos. As trocas convectivas, de radiação e as características de roupa resultam de experiências com manequins térmicos. Roy et al. (2003) apresentam um manequim digital 
com temperatura de superfície constante $\left(34^{\circ} \mathrm{C}\right)$ e calculam as temperaturas equivalentes para 15 segmentos. O manequim não tem um modelo fisiológico para interagir com o código de CFD, o que simplifica significativamente a solução numérica. As trocas térmicas de convecção são calculadas por relações empíricas em função das velocidades do ar próximo da célula. No caso de convecção natural, o coeficiente é constante. As trocas de calor por radiação são feitas por um código pessoal, em que se calcula os fatores de forma de superfície para superfície. Os autores não informam qual código de CFD ou modelos de turbulência foram utilizados. Um estudo da influência das diversas trocas térmicas de radiação das partes aquecidas de uma cabine no cálculo da temperatura equivalente da face também é realizado.

Em sua tese, Nilsson (2004) apresenta um manequim digital com geometria simplificada para avaliar as temperaturas equivalentes em uma série de avaliações experimentais. Não possui um modelo fisiológico e utiliza a temperatura de pele constante de $34{ }^{\circ} \mathrm{C}$ para todos os 17 segmentos. O autor calcula a transferência de calor por convecção e radiação utilizando correlações empíricas e valida o manequim com dados experimentais obtendo diferenças médias em torno de $2{ }^{\circ} \mathrm{C}$ entre os valores calculados e os medidos.

Gao et al. (2006) utilizam um manequim digital com modelo fisiológico e psicológico de Berkley. O acoplamento do modelo fisiológico e o código de CFD ocorre por meio de fluxos de calor, calculados e utilizados como entrada no modelo fisiológico, cuja resposta é uma temperatura de pele. O cálculo é iterativo até a convergência da temperatura de pele. A forma no manequim foi obtida por escaneamento a laser do manequim feminino usado na Universidade Técnica da Dinamarca. A Tabela 3.3 mostra um resumo dos diversos modelos, códigos e resultados dos manequins digitais pesquisados na literatura.

Tabela 3.3 Modelos, códigos e resultados dos manequins digitais.

\begin{tabular}{|c|c|c|c|}
\hline Autor & Modelos fisiológicos e resultados & $\begin{array}{c}\text { Modelos } \\
\text { psicológicos }\end{array}$ & $\begin{array}{c}\text { Modelos de turbulência, } \\
\text { códigos }\end{array}$ \\
\hline \multirow[t]{3}{*}{ Gan (1994) } & Fluxo de calor constante $(70$ & Iso-linhas $\mathrm{de}$ & Modelo k- $\varepsilon$ standard \\
\hline & $\left.\mathrm{W} / \mathrm{m}^{2}\right)$ & PMV, PPD e & Regime permanente \\
\hline & Predição de campo de escoamento & PD & Código próprio \\
\hline \multirow{4}{*}{$\begin{array}{l}\text { Brohus et al. } \\
\text { (1996) }\end{array}$} & Fluxo de calor constante $(25$ & & Modelo k- $\varepsilon$ standard \\
\hline & $\left.\mathrm{W} / \mathrm{m}^{2}\right)$ & & Regime permanente \\
\hline & Predição de & & Programa \\
\hline & escoamento & & FLOVENT $^{\circledR}$ \\
\hline
\end{tabular}




\begin{tabular}{|c|c|c|c|}
\hline Autor & Modelos fisiológicos e resultados & $\begin{array}{c}\text { Modelos } \\
\text { psicológicos }\end{array}$ & $\begin{array}{l}\text { Modelos de turbulência, } \\
\text { códigos }\end{array}$ \\
\hline $\begin{array}{l}\text { Kato et al. } \\
(1996)\end{array}$ & $\begin{array}{l}\text { Aquecimento passivo }\left(20 \mathrm{~W} / \mathrm{m}^{2}\right) \\
\text { Análise de campos de fluxo de } \\
\text { contaminantes }\end{array}$ & & Modelo de Baixo Re k- $\varepsilon$ \\
\hline $\begin{array}{l}\text { Matsunaga et } \\
\text { al. (1997) }\end{array}$ & $\begin{array}{l}\text { Stolwijk, } 65 \text { nós } \\
\text { Calcula SET** }\end{array}$ & & \\
\hline $\begin{array}{l}\text { Maué et al. } \\
\text { (1997) }\end{array}$ & $\begin{array}{l}\text { Modelo fisiológico da Daimler- } \\
\text { Benz, SWF }\end{array}$ & $\begin{array}{l}\text { PMV e } t_{\text {eq }} \text { para } \\
8 \text { zonas }\end{array}$ & $\begin{array}{l}\text { Modelo k- } \varepsilon \text { para baixos } \\
\text { números de Reynolds. } \\
\text { Regime permanente } \\
\text { Três programas: Star } \text { CD }^{\circledR} \text {, } \\
\text { SWF, e programa de CFD } \\
\text { TIM. }\end{array}$ \\
\hline $\begin{array}{l}\text { Murakami et al. } \\
(1997,1998)\end{array}$ & $\begin{array}{l}\text { Gagge de dois nós } \\
\text { Temperatura do ar, umidade e } \\
\text { radiação }\end{array}$ & & $\begin{array}{l}\text { Modelo k- } \varepsilon \text { para baixos } \\
\text { números de Reynolds. } \\
\text { Regime permanente } \\
\text { Vários códigos }\end{array}$ \\
\hline $\begin{array}{l}\text { Alfahaid et al. } \\
\text { (1999) }\end{array}$ & $\begin{array}{l}\text { Modelo fisiológico referenciado. } \\
\text { Campo de velocidade, } \\
\text { temperatura e pressão }\end{array}$ & $\begin{array}{l}\text { OSTI (objective } \\
\text { thermal stress } \\
\text { index) }\end{array}$ & $\begin{array}{l}\text { Modelo k- } \varepsilon \text { para baixos } \\
\text { números de Reynolds. } \\
\text { Regime transitório }\end{array}$ \\
\hline $\begin{array}{l}\text { Bjørn et al. } \\
(2000)\end{array}$ & $\begin{array}{l}\text { Fluxo de calor constante }(34,7 \\
\text { W/m2). Efeitos de respiração }\end{array}$ & & $\begin{array}{l}\text { Modelo k- } \varepsilon \text { RNG } \\
\text { Regime permanente }\end{array}$ \\
\hline $\begin{array}{l}\text { Huizenga et al. } \\
\text { (2001) }\end{array}$ & $\begin{array}{l}\text { Stowijk, } 25 \text { nós } \\
\text { PMV e EHT (16 zonas) }\end{array}$ & $\begin{array}{ll}\text { Modelo do } & \text { de } \\
\text { conforto } & \text { de } \\
\text { Berkley } & \end{array}$ & $\begin{array}{l}\text { Vários códigos } \\
\text { Simulações acopladas }\end{array}$ \\
\hline $\begin{array}{l}\text { Han et al. } \\
(2001, \quad 2004, \\
2005)\end{array}$ & $\begin{array}{l}\text { Stowijk } \\
\text { PMV e EHT }\end{array}$ & $\begin{array}{ll}\text { Zonas } & \text { de } \\
\text { conforto } & \text { de } \\
\text { Bohm } & \end{array}$ & FLUENT $^{\circledR}$ \\
\hline $\begin{array}{l}\text { Kang et al. } \\
(2002)\end{array}$ & Stowijk 61 nós & & $\begin{array}{l}\text { Modelo k- } \varepsilon \text { para alto número } \\
\text { de Reynolds com função de } \\
\text { parede. } \\
\text { Regime permanente } \\
\text { Simulação acoplada }\end{array}$ \\
\hline $\begin{array}{l}\text { Tanabe et al. } \\
\text { (2002) }\end{array}$ & Stowijk 65 nós (16 zonas) & & $\begin{array}{l}\text { Modelo fisiológico acoplado } \\
\text { com troca de calor por } \\
\text { radiação com código de CFD. }\end{array}$ \\
\hline
\end{tabular}




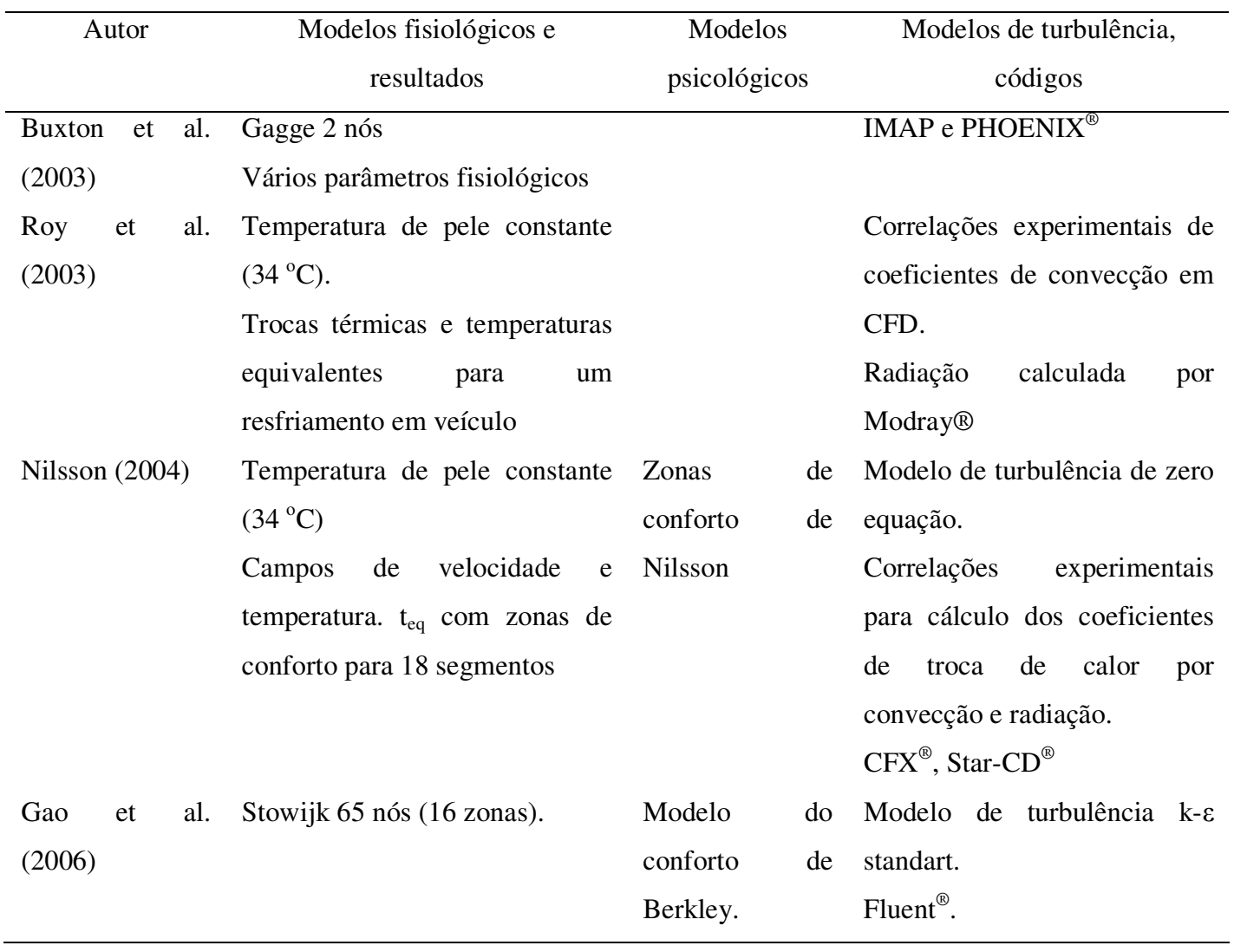

\subsection{CALIBRAÇÃO DE MANEQUINS}

Para se aplicar o conceito de temperatura equivalente, os manequins térmicos precisam ser calibrados em um ambiente térmico padrão para determinação de coeficientes de transferência de calor, $\mathrm{h}_{\text {tot }}$, da Equação (3.7), para os diversos segmentos do corpo.

Para satisfazer o conceito de temperatura equivalente, o ambiente padrão é um ambiente homogêneo com temperatura de bulbo seco igual à temperatura radiante média, $\mathrm{t}_{\mathrm{a}}=\mathrm{t}_{\mathrm{r}}$, e com velocidade do ar próximo de zero $\left(\mathrm{v}_{\mathrm{a}}<0,1 \mathrm{~m} / \mathrm{s}\right)$. Nestas condições tem-se: $\mathrm{t}_{\mathrm{a}}=\mathrm{t}_{\mathrm{r}}=\mathrm{t}_{\mathrm{eq}}$.

Uma vez satisfeitas estas condições, em ensaio realizado em câmara climatizada e condições de regime permanente nas trocas de calor do manequim com o ambiente, são realizadas leituras de temperaturas superficiais, $\mathrm{t}_{\mathrm{s}}$, e de fluxo de calor, Q", para cada segmento do corpo e calculados valores de coeficientes de troca de calor, $\mathrm{h}_{\mathrm{cal}}$, que são os coeficientes de troca de calor da calibração, dados pela equação:

$$
h_{c a l}=\frac{Q^{\prime \prime}}{t_{s}-t_{e q}}
$$


Os valores de coeficientes de transferência de calor da calibração, $h_{\text {cal }}$, serão os valores de coeficiente de troca de calor, $h$, da Equação (3.7) no cálculo das temperaturas equivalentes no ambiente real.

Uma vez calibrado o manequim para a posição e vestimenta do ensaio real, o método de avaliação consiste em posicionar o manequim no ambiente real e medir os fluxos de calor e as temperaturas superficiais de cada segmento. Por meio da Equação 3.7 é possível determinar a $t_{\text {eq }}$ para cada segmento ou para o corpo todo utilizando os valores de $h_{\text {cal }}$ da calibração e os novos valores de Q" e $t_{s}$.

$$
t_{e q}=t_{s}-\frac{Q^{\prime \prime}}{h_{c a l}}
$$

As temperaturas equivalentes assim determinadas são indicadores do nível de afastamento entre as condições do ambiente e as condições correspondentes a uma sensação térmica de neutralidade.

\subsection{MÉTODO DE TEMPERATURA EQUIVALENTE E FAIXAS DE CONFORTO}

O uso do conceito de temperatura equivalente tem sido apontado, na literatura atual, como o mais indicado para avaliar o conforto e a sensação térmica.

Wyon et al. (1989) foram os primeiros a correlacionar a temperatura equivalente com avaliação subjetiva. Com o objetivo de avaliar o conforto térmico para a indústria automotiva sueca, fez-se uma avaliação com pessoas, que davam seus votos em uma escala de 7 valores, denominada de Voto Térmico Médio, VTM. Estes votos foram correlacionados com a temperatura equivalente e foram definidas faixas de conforto. 

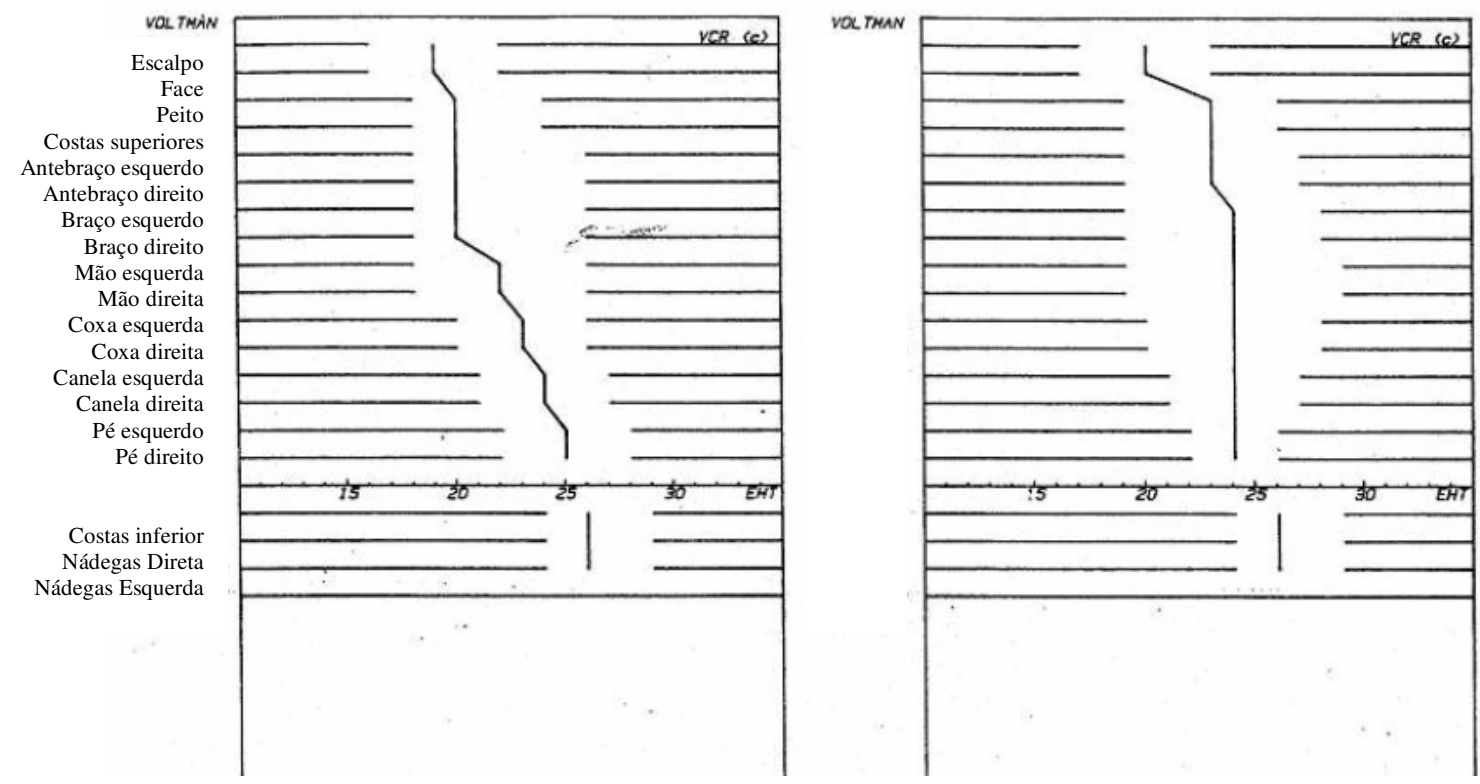

Figura 3.4 - Faixas de conforto e perfil de temperaturas equivalentes ideais para inverno (esquerda) e verão (direita) (Wyon et al, 1989).

Posteriormente, outros estudos (Bohm et al., 1990; Wahl, 1995 apud Nilsson, 2004; Nilsson e Holmér, 2002; Nilsson, 2004, 2005; Strom-Tsejsen et al., 2005 e Nilsson et al. 2007) basearam-se no conceito de temperatura equivalente e nas faixas de conforto.

Nilsson (2004) fez dois tipos de testes com dez pessoas em 30 condições climáticas diversas, com simulação solar e temperaturas de insuflamento diferentes (Holmér et al, 1992 apud Nilsson, 2004; Nilsson et al, 1997) em uma cabine de automóvel. Esses testes permitiram determinar também faixas de conforto para condições de verão e inverno.
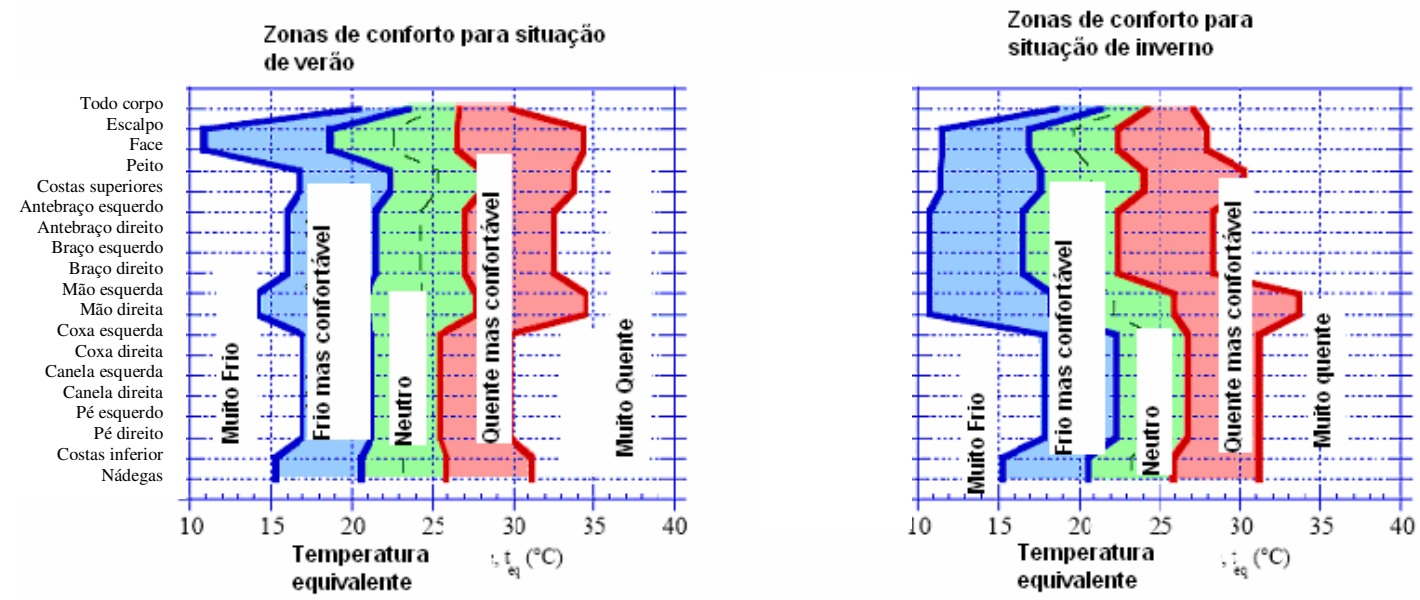

Figura 3.5 - Faixas de conforto obtidas para condições de verão e inverno (Nilsson, 2004). 
Nilsson (2004) incorporou não somente um perfil de temperatura ideal para 18 segmentos do corpo, mas também as faixas limites de conforto (faixa verde) que correspondem à VTM entre $+0,5$ e $-0,5$, relativos a $10 \%$ de pessoas insatisfeitas. Os limites seguintes, faixas azul e vermelha, correspondem a áreas com VTMs entre $+0,8$ e - 0,8 (até 20 $\%$ de insatisfeitos). Acima dos limites +2 e -2 correspondem os limites de muito frio e muito quente (inaceitável), com mais de $80 \%$ de insatisfeitos. 
Capítulo 4

\section{$4 \quad$ Avaliação do ambiente térmico em cabines de aeronaves}

Recentemente é possível notar uma crescente preocupação por parte da indústria da mobilidade e da academia pela questão de se melhorar o ambiente térmico de cabines. A indústria aeronáutica não é exceção. O crescimento do número de empresas operadoras de linhas aéreas fez com que houvesse uma salutar concorrência para se oferecer melhores vantagens aos passageiros. Isto fez com que houvesse uma maior exigência aos fabricantes de aviões dos níveis de conforto interno. Estes, por sua vez, começaram a desenvolver estudos com centros de pesquisa para levar um melhor nível de conforto aos passageiros. Um dos requisitos que tem recebido mais atenção são os itens referidos ao ambiente térmico. Neste capítulo são discutidas algumas iniciativas neste campo e os resultados obtidos.

\subsection{AVALIAÇÃO EXPERIMENTAL E NUMÉRICA DOS CAMPOS DE TEMPERATURA E VELOCIDADES DO AR EM AERONAVES}

A medição do campo de temperaturas e de velocidades do ar em cabines tem sido largamente utilizado para analisar o ambiente térmico. Trata-se de uma fase anterior da avaliação do conforto térmico, porque a sensação térmica experimentada pelas pessoas é função direta das trocas térmicas e do balanço térmico do corpo humano. Em aeronaves, os passageiros trocam calor, basicamente, por convecção e por radiação e o seu efeito é avaliado com a determinação das temperaturas equivalentes.

Resultados de revisão bibliográfica mostram que é recente a preocupação com o levantamento das condições ambientais em cabines de aeronaves. Um dos primeiros trabalhos de avaliação numérico-experimental de escoamento isotérmico em duas cabines da Boeing é de Aboosaidi et al. (1992).

Estes autores apresentam alguns resultados e metodologia de medição de campos de velocidade e dados experimentais em duas cabines com arquiteturas de insuflamento diferentes. Medem a velocidade de ar com anemômetro de fio quente omnidirecional e 
direção com introdução de fumaça no escoamento. Na figura 4.1 são apresentados campos de velocidades medidas.
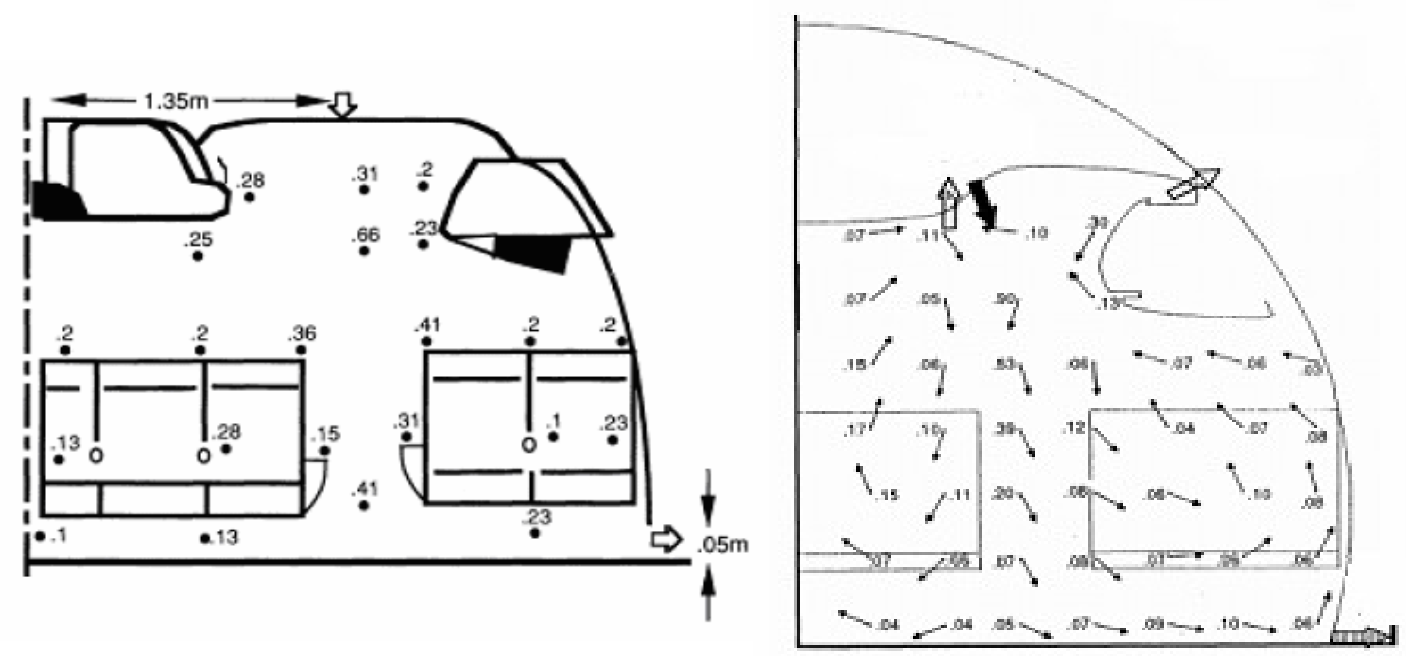

Figura 4.1 - Pontos de medição e valores das velocidades do ar para o primeiro caso (esquerda) e segundo caso (direita).

Um outro artigo, sobre qualidade do ar e conforto térmico em aeronaves, (Haghighat et al., 1999) traz um levantamento dos níveis de dióxido de carbono e da temperatura do ar, em 43 vôos com 1 hora de duração. Voltado à qualidade do ar, os autores não fazem um estudo detalhado do ambiente térmico, considerando somente a temperatura média da cabine, fornecida pelo sensor de temperatura do avião.

Em 2004, um estudo aborda a avaliação experimental do campo de escoamento em cabines de avião (Loomans et al., 2004): medição de velocidade (intensidade média e direção), índice de turbulência e temperatura do ar. Também são medidas as temperaturas de superfícies, ou seja, piso, janelas e acabamentos (liners) para uso posterior como condição de contorno nas simulações numéricas. As medições foram feitas em um avião tipo wide body com 7 assentos, sem passageiros, em duas seções seguidas de cadeiras (Figura 4.2). 


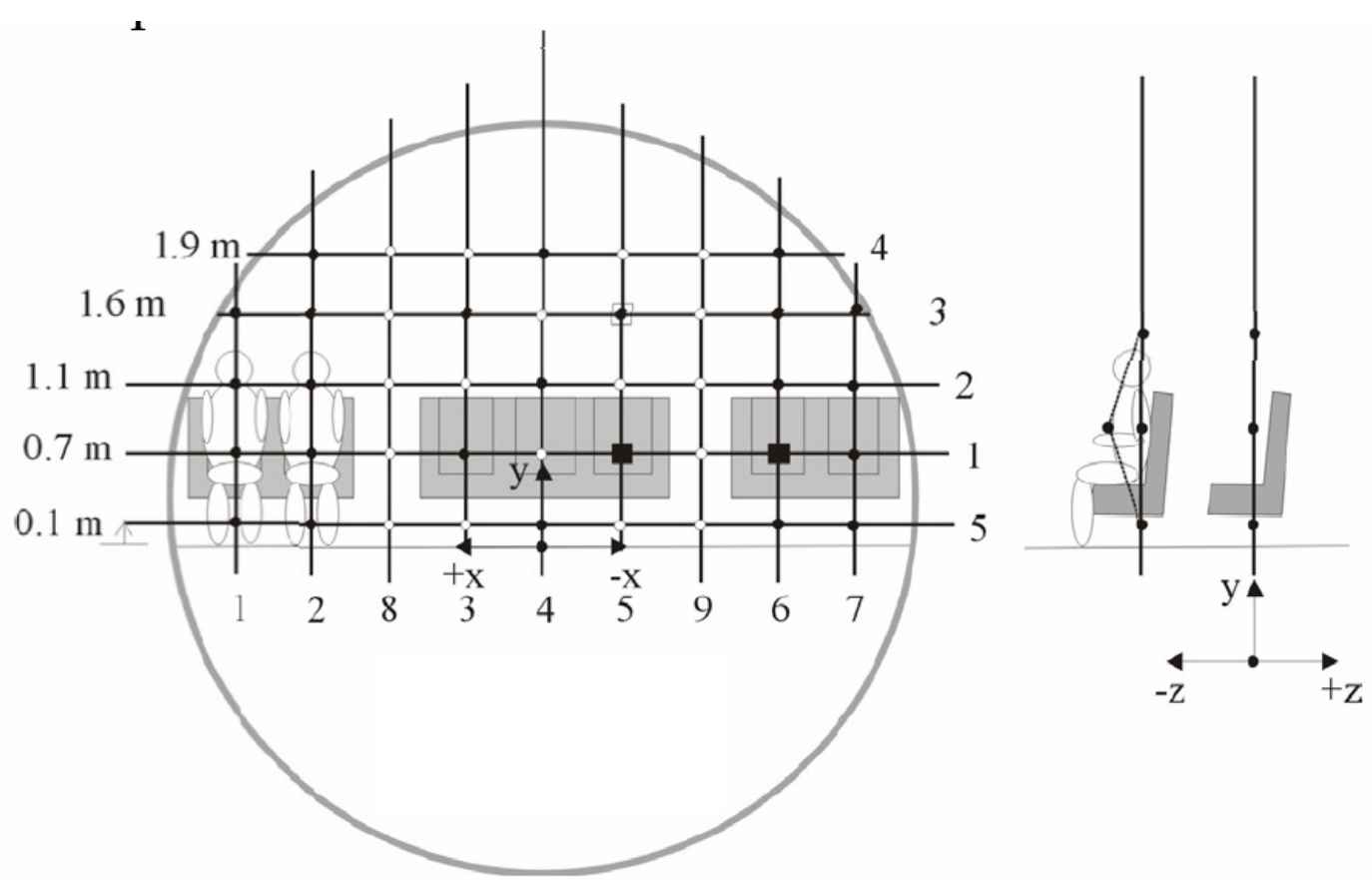

Figura 4.2 - Pontos de medição de velocidade (intensidade média e direção), índice de turbulência e temperatura do ar (Loomans et al., 2004).

Em outro artigo já comentado neste capítulo de Loomans et al. (2004), é realizada uma comparação numérica-experimental de uma cabine com 6 fileiras e 7 poltronas, com 3 modelos de turbulência para o ar e 3 programas diferentes. As diversas simulações ocorreram com as mesmas condições de contorno obtidas em um vôo experimental. As distribuições de temperatura e velocidade do escoamento foram muito próximas entre os resultados dos 3 modelos. Houve uma diferença em torno de $2{ }^{\circ} \mathrm{C}$ a mais na temperatura média da cabine no resultado das simulações.

Zhang e Chen (2007) fazem uma análise do ambiente térmico para uma seção de um Boeing 767 (Figura 4.3) para 3 tipos de insuflamentos com ventilação pessoal. Utiliza modelo de turbulência k- $\varepsilon$ re-normalizado (RNG) e obtém valores dentro da faixa de incertezas das medições de velocidade e temperatura. Fazem uma análise de efeito de correntes de ar avaliando as velocidades próximas da "cabeça" e do "peito". Concluíram que não existe desconforto por este efeito ao verificarem que as velocidades são menores que $0,25 \mathrm{~m} / \mathrm{s}$. Talvez fosse interessante uma análise, questionando se a condição é de aquecimento ou resfriamento, pois a norma ASHRAE 55 (2004) sugere que, para aquecimento (inverno), a velocidade do ar deve ser inferior a $0,15 \mathrm{~m} / \mathrm{s}$. 


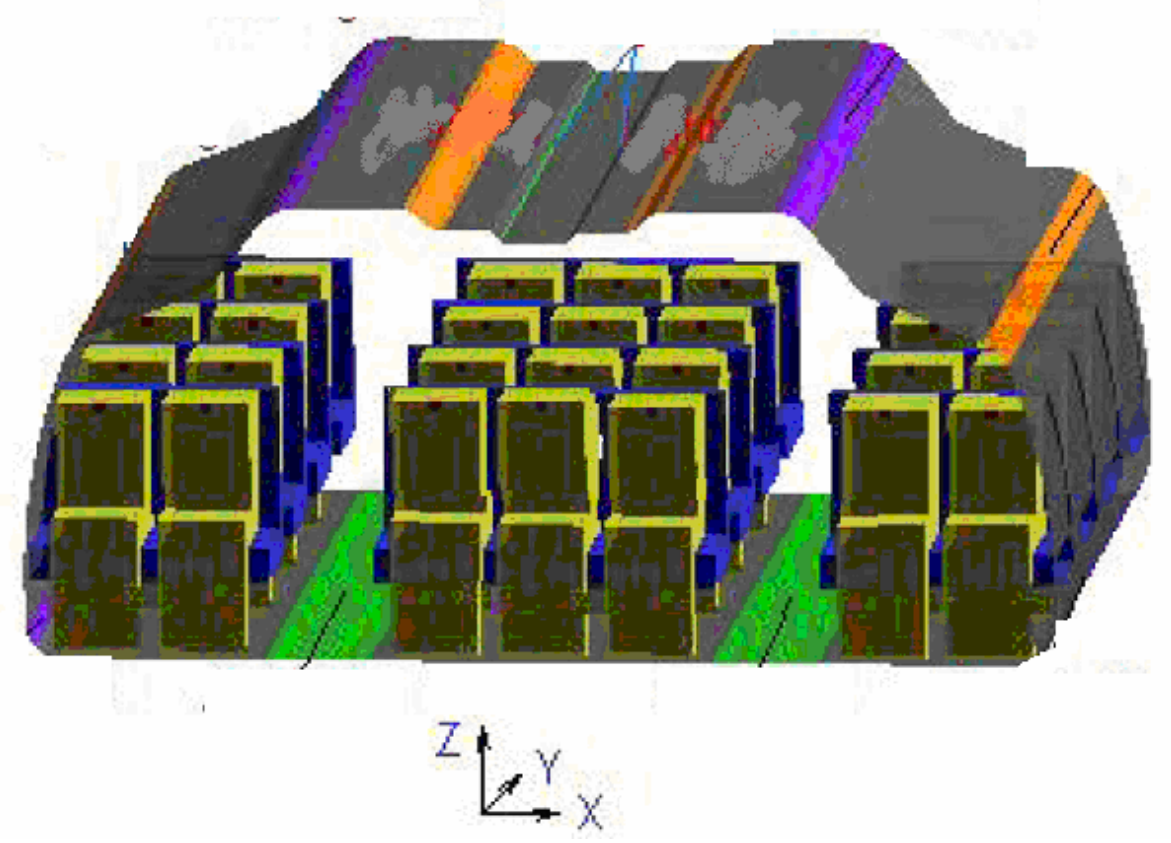

Figura 4.3 - Seção simulada (Zhang e Chen, 2007).

Também em 2007, outro artigo refere-se à simulação de escoamento em um Boeing 767-300 (Gao e Niu, 2007). Faz-se uma simulação com o programa Fluent de uma seção de cabine com 5 fileiras de 7 bancos. Coloca-se, em cada banco, um manequim com formas quadradas, e um manequim, mais detalhado, para estudo de emissão de contaminantes pela boca do manequim. As condições de contorno são quase iguais às do artigo anterior e também se baseiam no mesmo modelo de turbulência (k- $\varepsilon$ re-normalizado).

Em artigo no qual se procurou estudar a influência do movimento do passageiro, em um corredor de aeronave na dispersão de contaminantes, Mazumdar e Chen (2007) utilizaram modelo em CFD em uma seção de cabine com 4 fileiras de 7 assentos (Figura 4.4). Os passageiros foram simulados por manequins em forma de caixa. O passageiro que se movia no corredor foi modelado também como um paralelepípedo. Empregou-se o modelo de turbulência k- $\varepsilon$ re-normalizado e se utilizou o programa Fluent para os cálculos. 


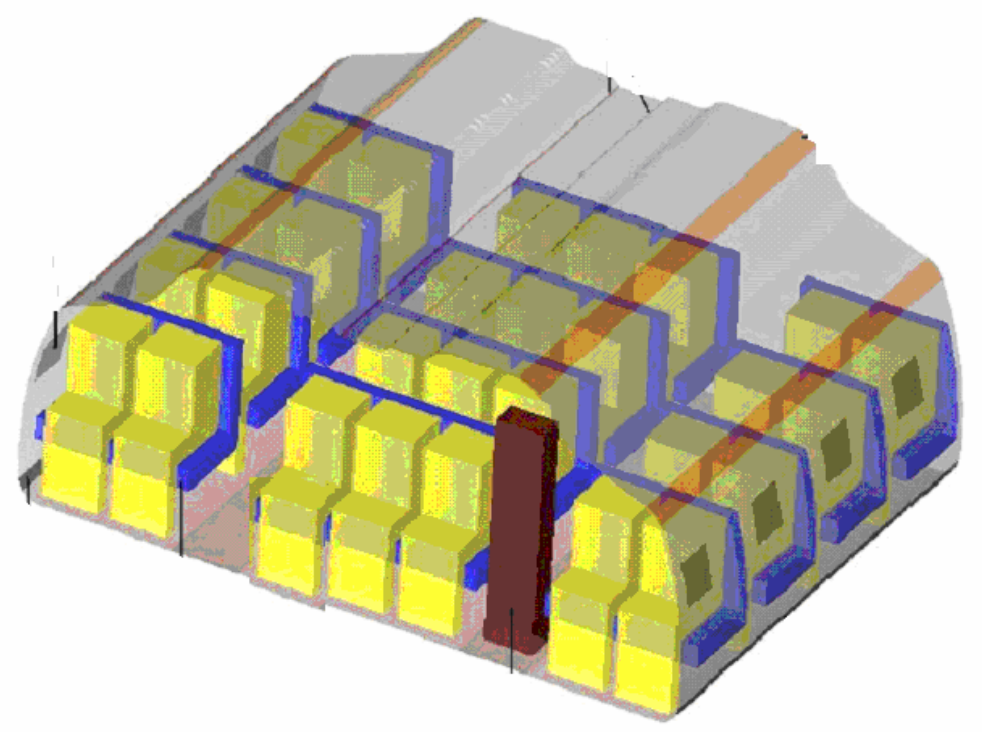

Figura 4.4 - Geometria utilizada por Manzumdar e Chen ( 2007).

Também com foco na área de saúde em aeronaves, em 2007 foi publicado um artigo a respeito de uma investigação, usando simulação numérica em CFD, sobre estratégias de descontaminação em cabines de aviões comerciais (Chen e Chen, 2007). Utilizando uma seção de cabine com 4 fileiras e 7 assentos, os autores fazem uma avaliação numéricaexperimental dos níveis de contaminantes por meio de um mock-up de um Boeing 767-300. Os autores conseguem uma razoável correlação entre o campo de velocidade numérico e experimental em uma seção vertical (Figura 4.5). Empregam o modelo de turbulência k- $\varepsilon$ renormalizado. Utilizam o programa Fluent para os cálculos.

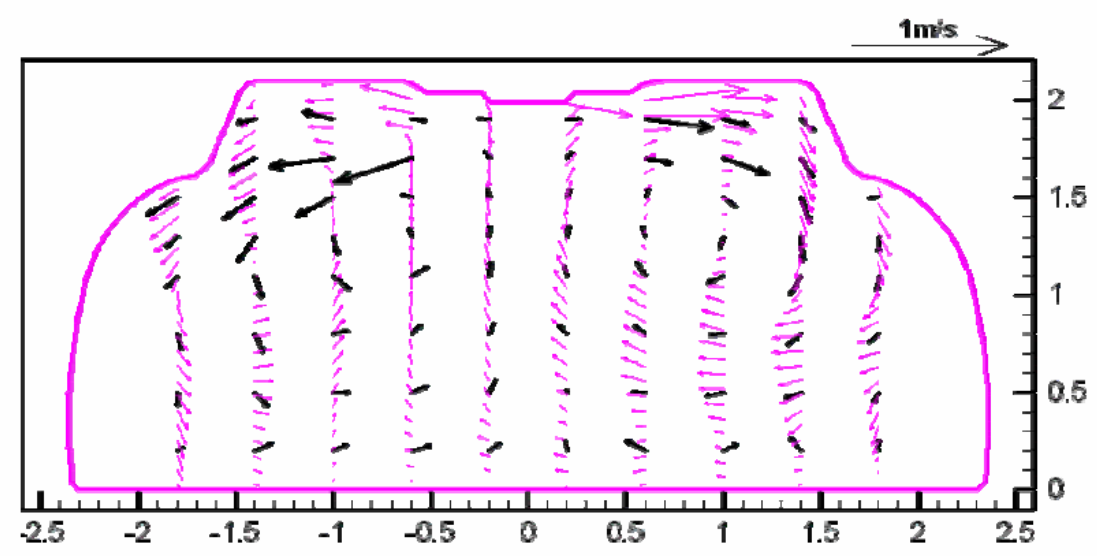

Figura 4.5 - Distribuição do escoamento numérico (rosa) e experimental (preto) em uma secção vertical da cabine (Chen e Chen, 2007). 
Outro artigo da mesma equipe do artigo anterior aborda contaminantes, mas visando agora o melhor posicionamento de um sensor na cabine (Zhang et al., 2007a). Utilizam como modelo de turbulência o modelo de turbulência k- $\varepsilon$ re-normalizado. Consideram manequins bastante simplificados aquecidos em cada banco (Figura 4.6).

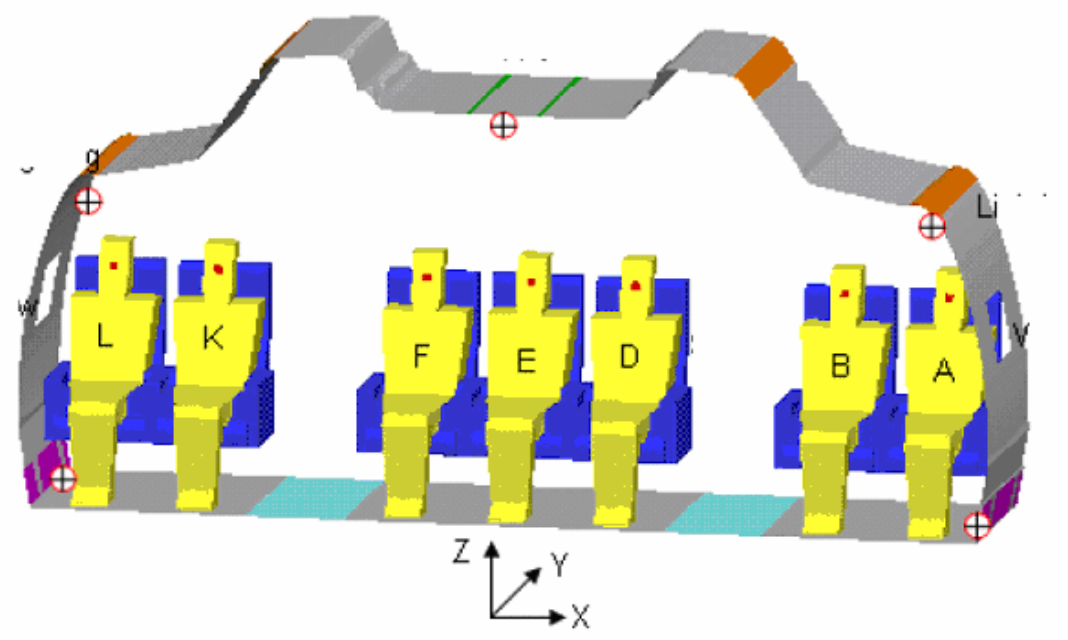

Figura 4.6 - Geometria da cabine utilizada por Zhang T. et al (2007a).

A mesma equipe apresenta, um artigo muito interessante (Zhang, et al., 2007b) sobre uma validação numérica-experimental do campo de velocidades, temperaturas e contaminantes na seção de cabine de um Boeing 767. Utilizam os dados experimentais como entrada para o modelo de CFD. A direção do insuflamento é determinada com introdução de fumaça no escoamento. Radiômetros manuais mediram as temperaturas das paredes e dos manequins. Os autores obtém razoável concordância do campo de velocidade, embora com alguns desvios próximos dos jatos; comentando que isto ocorreu devido à dificuldade de se medir, corretamente, as velocidades nos difusores, o que causou uma má correlação de distribuição de contaminantes. O campo de temperatura apresentou a melhor correlação, por causa do elevado efeito de mistura no insuflamento, na parte superior da cabine.

\subsection{AVALIAÇÃO EXPERIMENTAL DE TEMPERATURAS EQUIVALENTES EM AERONAVES}

Esta utilização é recente. Atualmente existem três centros de estudos dedicados à área de conforto térmico e qualidade do ar, que dispõem de mock-ups que simulam o interior de aeronaves com a possibilidade de resfriamento e aquecimentos de paredes e de reprodução das características de insuflamento na cabine. Os centros são o International Centre for Indoor 
Environment and Energy da Universidade Técnica da Dinamarca, Universidade de UrbanaChampain e Universidade de Purdue nos EUA.

O primeiro artigo sobre o uso de manequins térmicos é de Irgens e Melikov (2004), cujo objetivo foi avaliar o ambiente térmico de uma cabine de avião. O mock-up possui três fileiras de sete assentos. As avaliações das temperaturas equivalentes foram realizadas com dois manequins e simuladores térmicos. Foram medidas assimetrias térmicas em torno de $5{ }^{\circ} \mathrm{C}$ nas mãos e antebraços. Os dados foram apresentados em gráficos de barras (Figura 4.7)

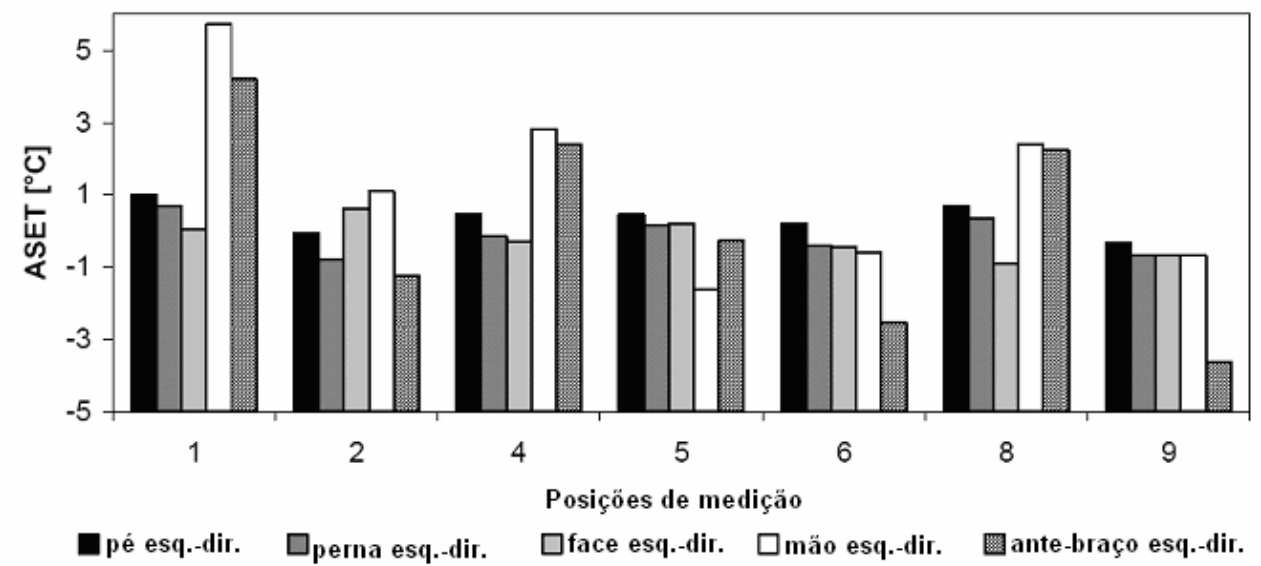

Figura 4.7 - Assimetrias nas temperaturas equivalentes em cada segmento (Irgens e Melikov, 2004).

Recentemente, outro estudo do grupo de pesquisadores da Universidade Técnica da Dinamarca (Strom-Tejsen et al., 2007) no mesmo mock-up, (Figura 4.8) apresentou um levantamento das temperaturas equivalentes (Figura 4.9) utilizando os mesmos manequins citados no artigo de e Irgens e Melikov (2004).

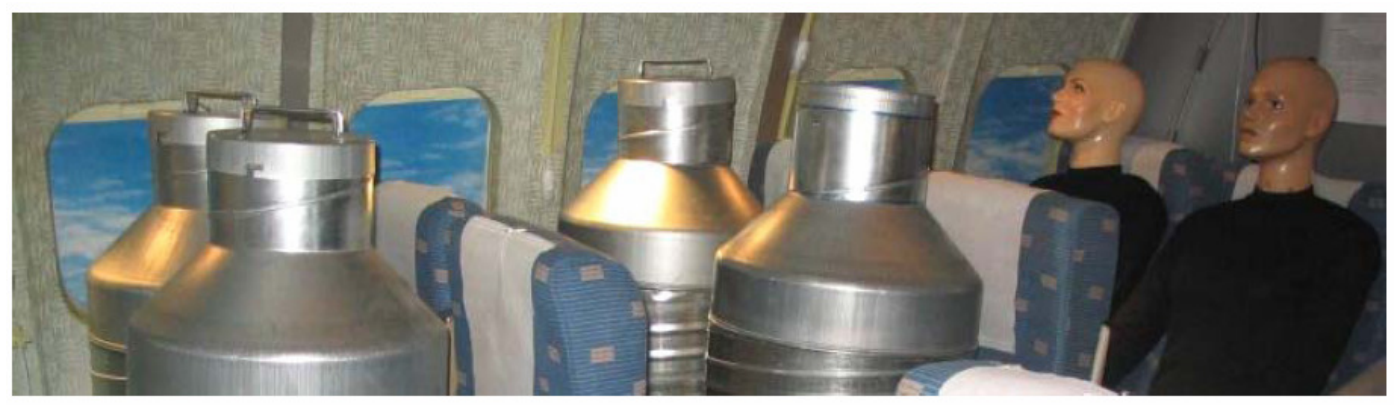

Figura 4.8 - Interior do mock-up com os manequins e os simuladores térmicos (Strom-Tejsen et al, 2007). 


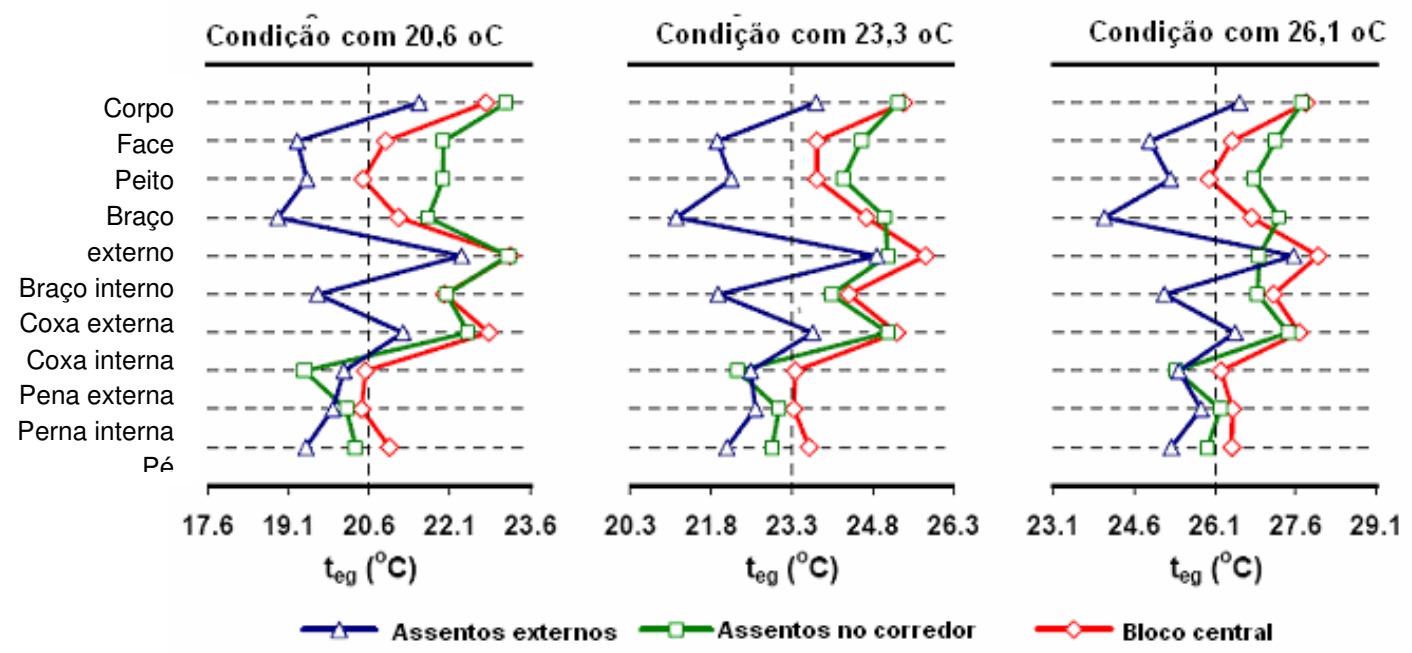

Figura 4.9 - Perfis de temperatura nos segmentos para os três grupos de assentos nas três temperaturas do teste (Strom-Tejsen et al., 2007).

É possível notar na figura 4.9 que as temperaturas equivalentes próximas da fuselagem são mais baixas, como era de se esperar pela proximidade das laterais frias da fuselagem. 
Capítulo 5

\section{Avaliação experimental do ambiente térmico em aeronave}

Neste capítulo são apresentados os procedimentos e equipamentos utilizados na avaliação experimental do ambiente térmico de cabine de aeronave. Os levantamentos experimentais foram realizados em mock-up de 12 lugares, utilizando 11 manequins aquecidos, simulando as pessoas, e um manequim térmico.

As atividades experimentais consistiram de:

- Avaliação dos campos de temperaturas e velocidades do ar;

○ Calibração do manequim;

- Avaliação das temperaturas equivalentes.

Resultados de temperaturas e velocidades do ar e de temperaturas equivalentes serão utilizados na comparação com resultados de simulação computacional do escoamento na cabine e de resultados obtidos com utilização de manequim térmico digital, respectivamente.

\subsection{EQUIPAMENTOS}

Neste item são apresentados os aparatos e acessórios utilizados nas avaliações experimentais.

\subsubsection{Mock-up}

Para a realização dos ensaios foi utilizado um mock-up, com dimensões de 3 x 3 x 2,5m de altura, que reproduz a seção de cabine de uma aeronave comercial (aviação regional), com três assentos duplos em ambos os lados (Figs 5.1 e 5.2). O insuflamento do ar é realizado pela parte superior e lateral dos bins (maleiros) e o retorno se dá pela parte inferior lateral (Figs. 5.3 e 5.4.), com possibilidade de insuflamento pelo piso (Moura, 2009). 


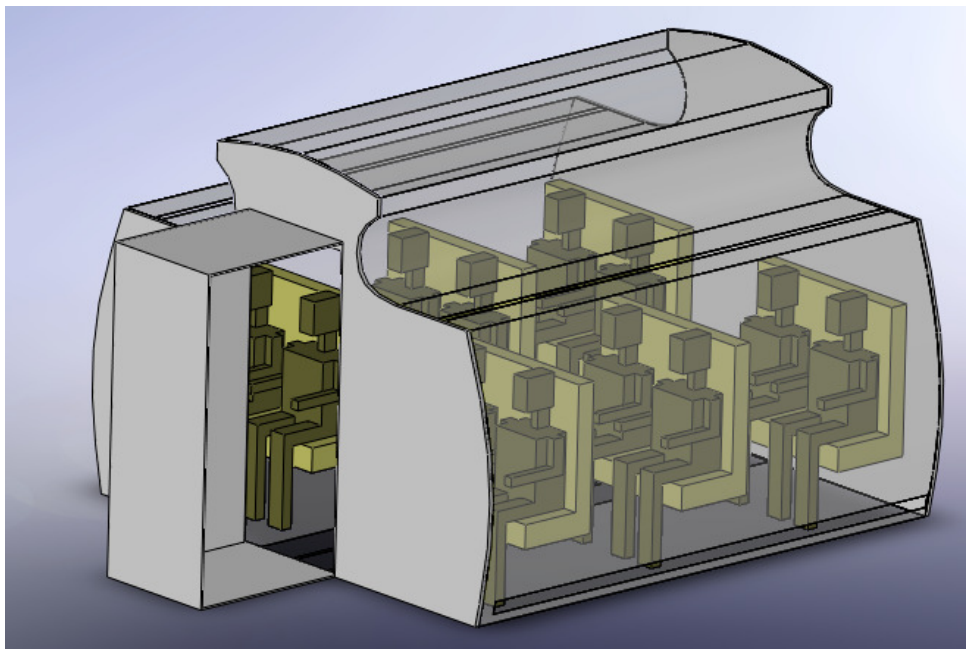

Figura 5.1 Vista esquemática do interior do mock-up (Moura, 2009)

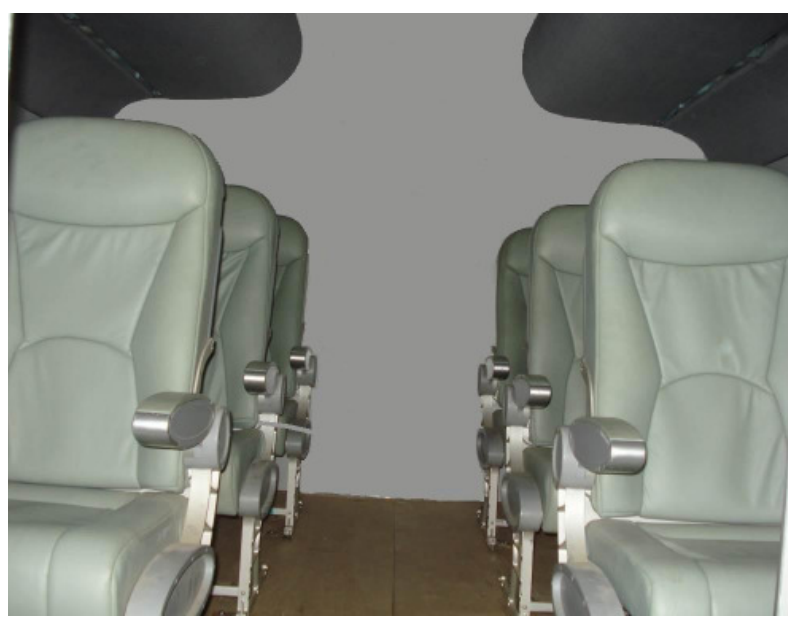

Figura 5.2 Vista interna do mock-up (Moura, 2009)

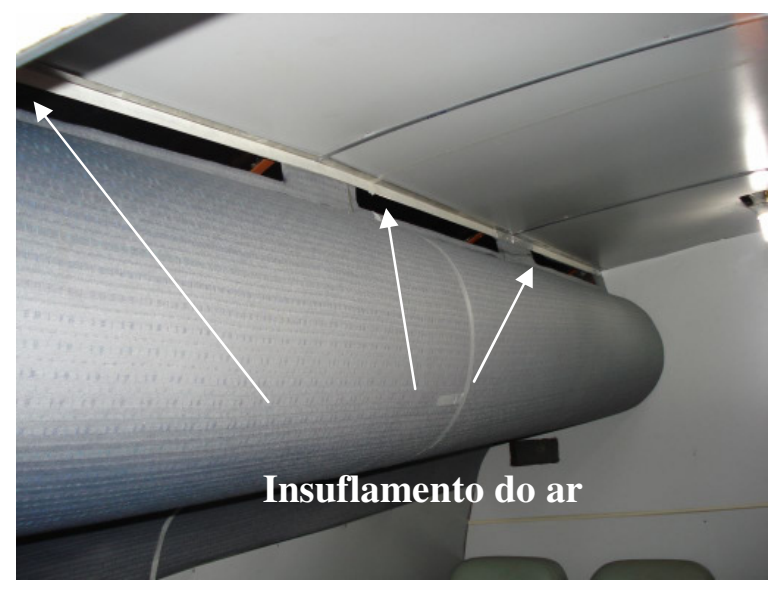

Figura 5.3 Detalhes do bin e de entradas de ar do mock-up - três em cada lado. (Moura ,2009) 


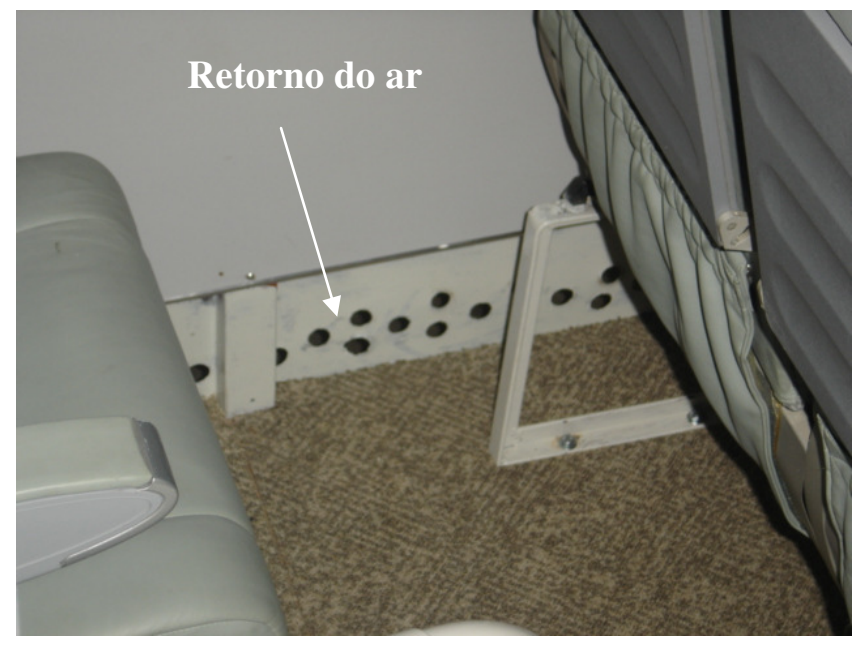

Figura 5.4 Detalhes do retorno do ar (Moura, 2009)

Conforme apresentado na figura 5.3, o mock-up possui seis entradas de ar sobre o bin, três de cada lado. As entradas têm dimensões iguais (740 mm por $40 \mathrm{~mm}$ ) e estão igualmente espaçadas na cabine com simetria do lado esquerdo e direito. Possui também aberturas laterais no bin, próximo à parede, para insuflamento para os passageiros junto à fuselagem; que permaneceram fechadas nas avaliações realizadas no presente trabalho. $\mathrm{O}$ ar chega ao mockup através de dutos pelo sistema de insuflamento pelo teto existente no laboratório (fig.5.5) e um sistema de controle automatizado controla a temperatura de insuflamento para se atingir temperaturas constantes no mock-up.

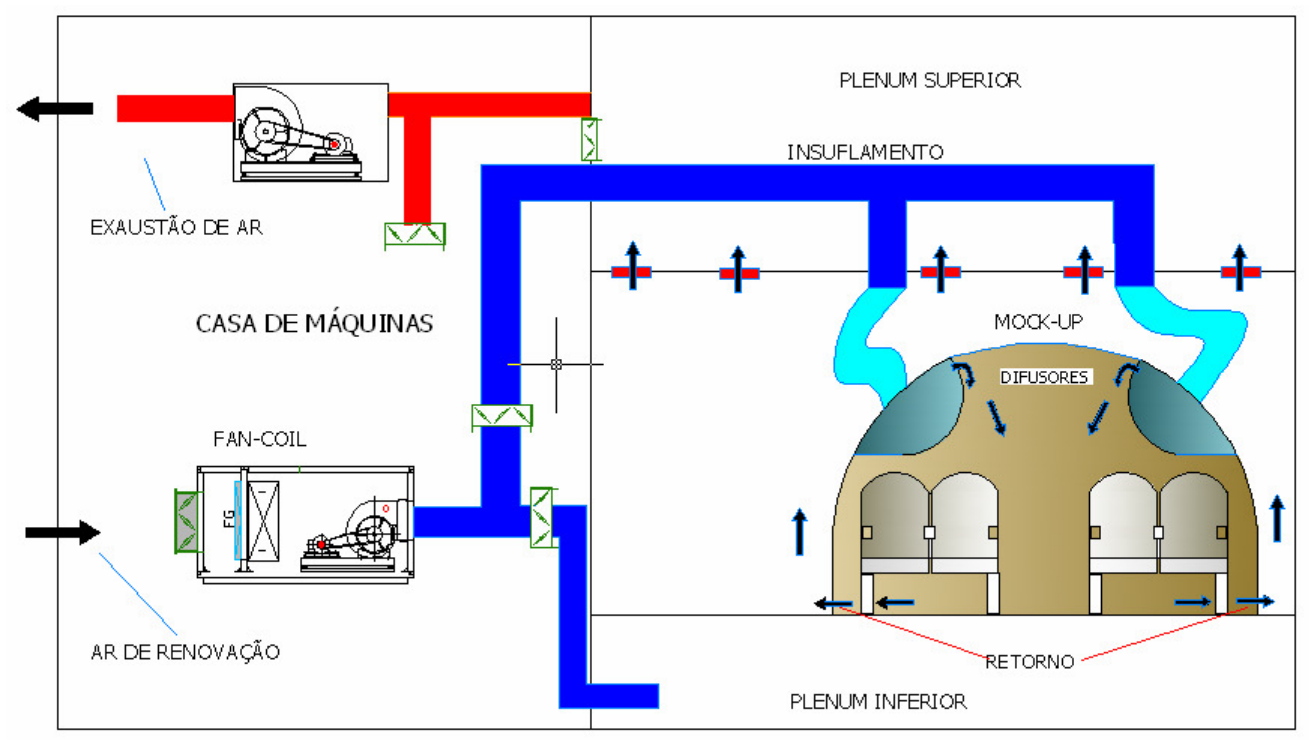

Figura 5.5 Fluxograma do ar da cabine do mock-up (Moura, 2009) 


\subsubsection{Simuladores térmicos}

A simulação da dissipação térmica das pessoas para as avaliações experimentais foi realizada por meio de simuladores térmicos (manequins aquecidos). Os simuladores apresentam melhorias com relação aos relatados na literatura (Strøm-Tejsen et al., 2007; Zhang et al., 2007) e apresentados no Capítulo 4.

Os simuladores utilizados no presente trabalho (Fig. 5.6) são constituídos por cabeça, tronco, pernas e pés. A cabeça é cilíndrica e o tronco elipsoidal. As pernas e pés são tubulares. Ventiladores fazem com que o ar aquecido por uma resistência elétrica circule pelas pernas/pés, tronco e cabeça, mantendo a superfície do manequim com temperaturas relativamente uniformes. A potência térmica da resistência elétrica dissipada é controlada por pulsos de tensão. Os manequins são ligados em série por um cabo elétrico que sai de uma caixa controladora. A potência térmica dissipada por cada simulador é determinada por um programa em um computador conectado à caixa controladora. Um led na cabeça do simulador informa se os ventiladores estão em funcionamento.

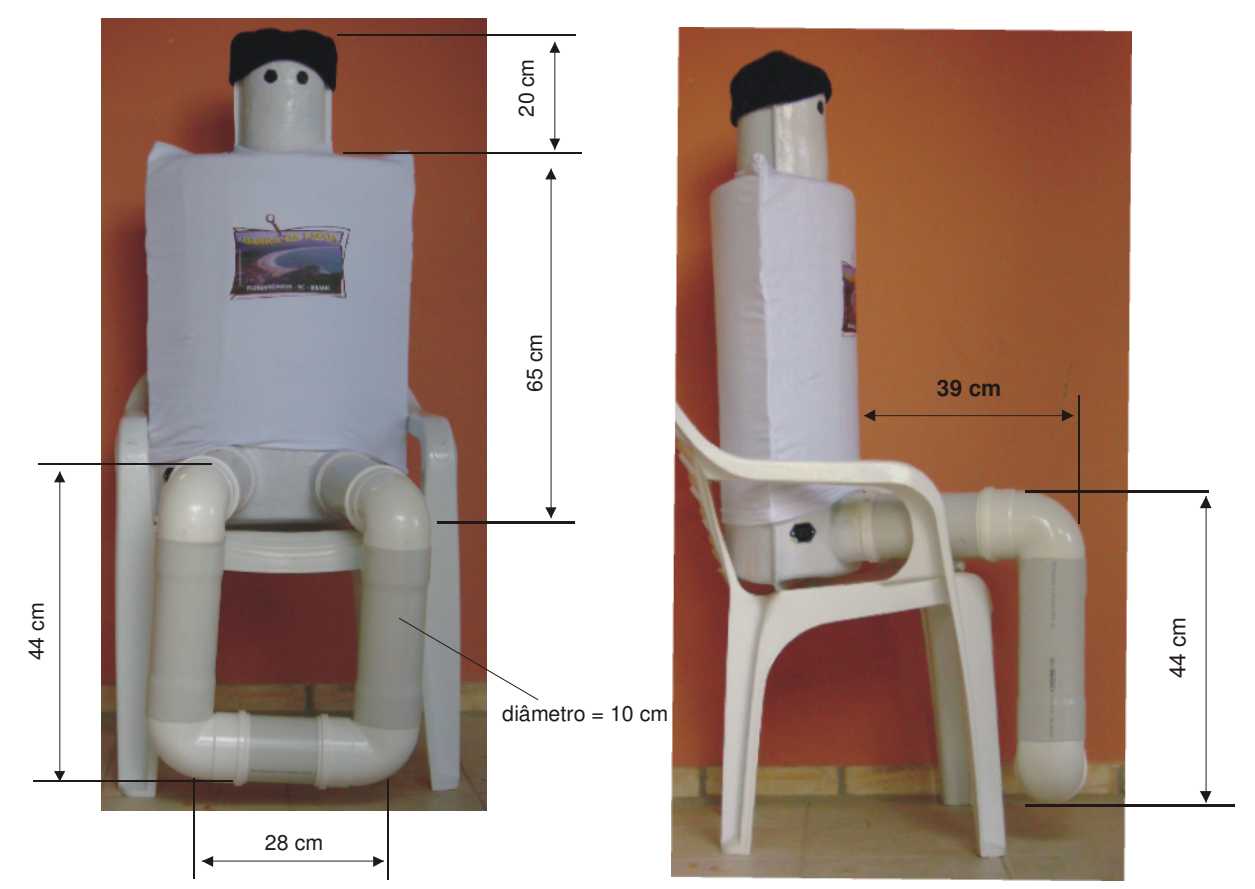

Figura 5.6 Vistas, com dimensões, dos manequins aquecidos. 


\subsubsection{Manequim térmico}

Foi utilizado um manequim térmico de fabricação nacional para a avaliação das temperaturas equivalentes. O manequim tem $1,77 \mathrm{~m}$ de altura e possui 21 zonas aquecidas por fios de resistências elétricas (fig. 5.7). Cada parte possui um fio trançado em direção ligeiramente diferente da resistência elétrica para obter uma leitura de temperatura mais representativa da superfície. Todos os membros são articulados e também o tronco na divisão entre costas superior e inferior e peito e abdômen.

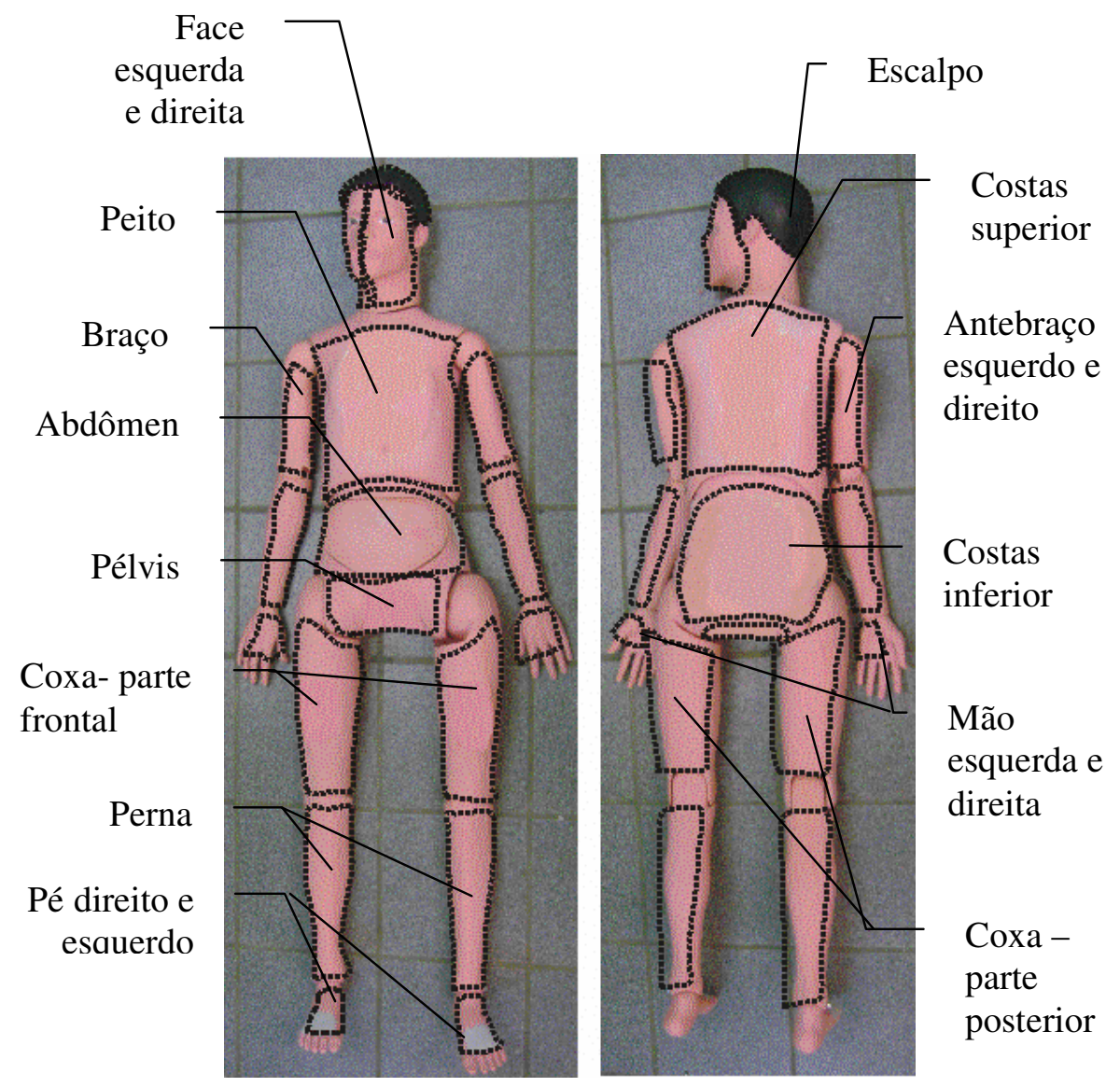

Figura 5.7 Segmentos do manequim térmico

O manequim térmico possui três modos de controle: temperatura constante, potência constante e equação de conforto de Fanger. As placas de leitura de temperatura ficam internas ao manequim. A informação das temperaturas chega por um cabo em uma caixa onde ficam as placas controladoras de cada zona. As ações para o controle são realizadas por um programa em um computador portátil que se comunica com a caixa intermediária através de 
comunicação serial. O programa possui uma tela de interface com o usuário, onde é possível se escolher o tipo de controle, ler ou definir as temperaturas ou potências por área de cada zona, e iniciar ou finalizar a gravação dos dados. O programa grava os dados de temperaturas e potências lidas, temperaturas ou potências, a cada segundo. É possível também visualizar graficamente a evolução das potências e temperaturas ao longo das medições. Isto é bastante útil para se verificar quando o manequim atingiu regime permanente analisando as potências dissipadas de cada segmento. O controle da potência é realizado através de pulsos de tensão nas resistências a cada dois segundos.

\subsubsection{Medição de velocidades e temperaturas do ar}

Para as medições de velocidade e temperatura de ar foi utilizado um anemômetro direcional de fio quente. Este anemômetro possui resolução de $0,01 \mathrm{~m} / \mathrm{s} \mathrm{e} 0,1{ }^{\circ} \mathrm{C}$. O instrumento foi calibrado pelo fabricante em 2005. Uma foto do equipamento está na Figura 5.8.

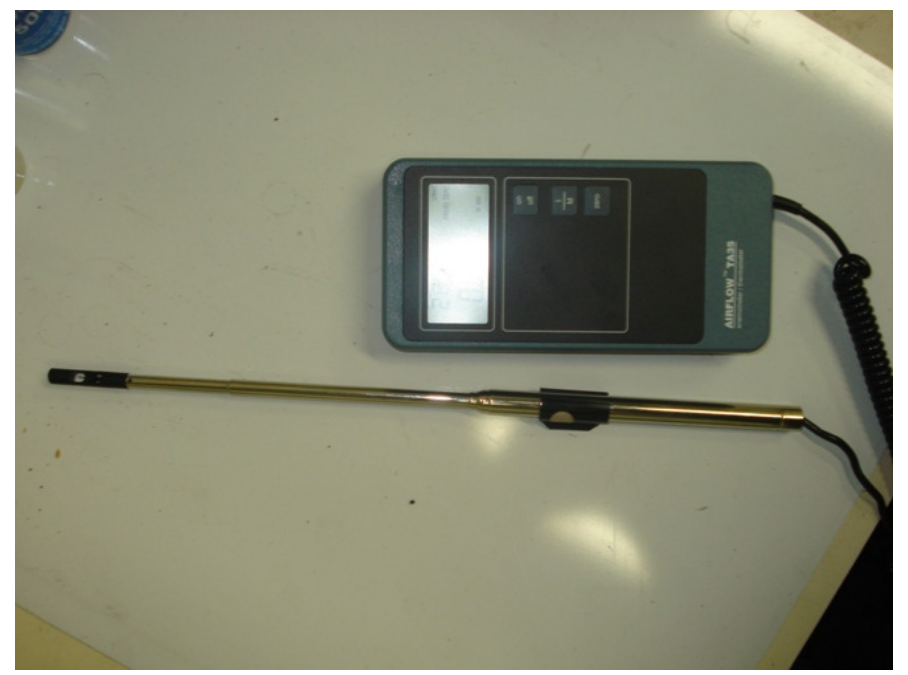

Figura 5.8 Anemômetro direcional 


\subsubsection{Medição de temperaturas superficiais}

Nas medições de temperaturas superficiais foi utilizado um termômetro de radiação infravermelho, que possui uma resolução de $0,2^{\circ} \mathrm{C}$ a $275^{\circ} \mathrm{C}$, com precisão de $+/-0,2^{\circ} \mathrm{C}$. A foto do equipamento está na fig. 5.9.

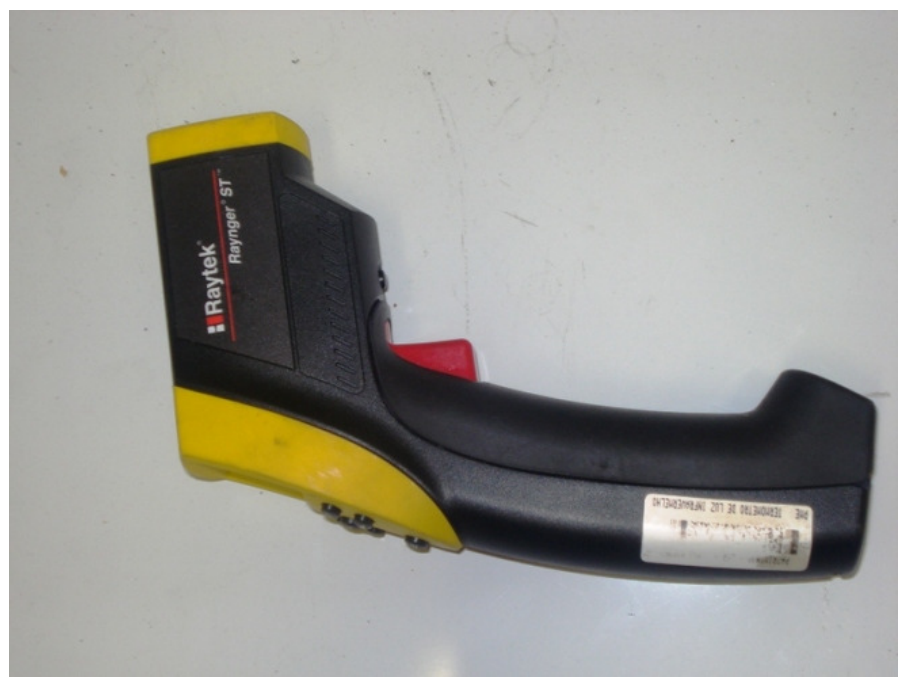

Figura 5.9 - Medidor de temperatura superficial

\subsubsection{Máquina de fumaça}

Foi utilizada uma máquina de fumaça para a verificação da movimentação do ar na cabine. Foi utilizado líquido de produção de fumaça média, pois as velocidades são baixas e o tempo de permanência é alto.

\subsection{MEDIÇÕES}

Inicialmente, foram medidos os campos de temperaturas e velocidades do ar em uma seção da cabine. Posteriormente, foram realizadas medições para determinação das temperaturas equivalentes. 


\subsubsection{Medições dos campos de temperatura e velocidade de ar}

O objetivo deste item é mostrar como foram feitas as medições das velocidades e temperaturas de uma seção do mock-up para posterior comparação com resultados de simulação computacional descritas no Capítulo 6. Foram definidas três situações a serem simuladas:

○ Cabine sem ocupação em situação de vôo;

○ Cabine com ocupação em situação de solo;

○ Cabine com ocupação em situação de vôo.

\section{Condições de ensaio}

Para simular estas três situações basicamente se mudou as condições externas do mock-up e a ocupação interna. A situação de vôo foi simulada climatizando o laboratório, onde está o mock-up, a $18{ }^{\circ} \mathrm{C}$. Isto foi conseguido através do uso de um aparelho do tipo split que existe na sala. A situação em solo foi criada através da simulação de radiação solar em uma lateral da sala, por meio de um painel de lâmpadas, (Fig. 5.10) com temperatura do ar a $28{ }^{\circ} \mathrm{C}$. A situação com ocupação foi conseguida colocando-se 12 simuladores ocupando os assentos. O sistema de climatização do mock-up foi regulado para uma temperatura de $20{ }^{\circ} \mathrm{C}$. Isto foi feito para se obter o máximo de estabilização das temperaturas de insuflamento (máxima capacidade de refrigeração do sistema) e temperaturas de insuflamento mínimas.

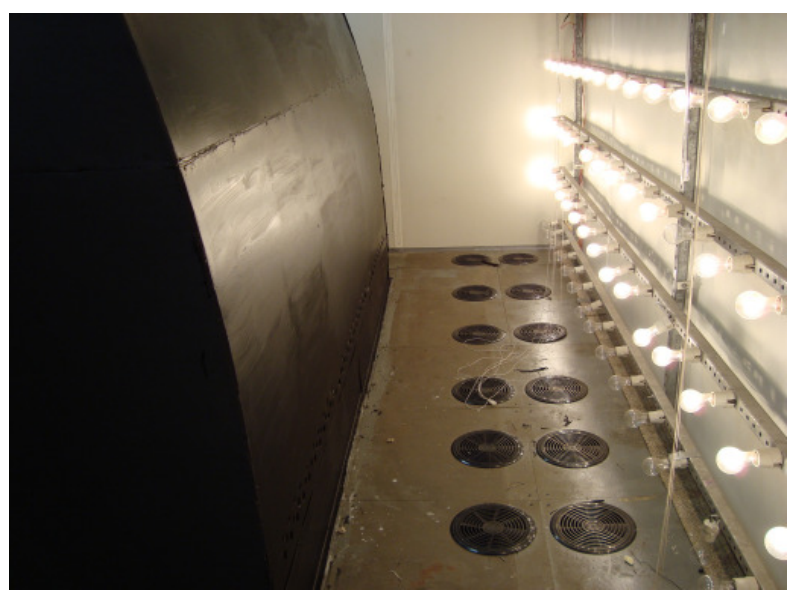

Figura 5.10 Painel de lâmpadas simulando radiação solar em uma das laterais do mock-up. 


\section{Variáveis medidas}

Temperaturas e velocidades de ar e temperaturas superficiais.

Temperaturas e velocidades horizontais e verticais do ar foram medidas em um plano vertical na segunda fileira dos bancos (Figs. 5.11 e 5.12). As medições de velocidades e temperaturas do ar foram feitas com um anemômetro de fio quente direcional. As velocidades foram lidas após estabilização do sistema, que ocorria depois de alguns poucos segundos. As leituras apresentaram uma variação para mais e para menos em torno $0,03 \mathrm{~m} / \mathrm{s}$. Foram anotados os valores médios.

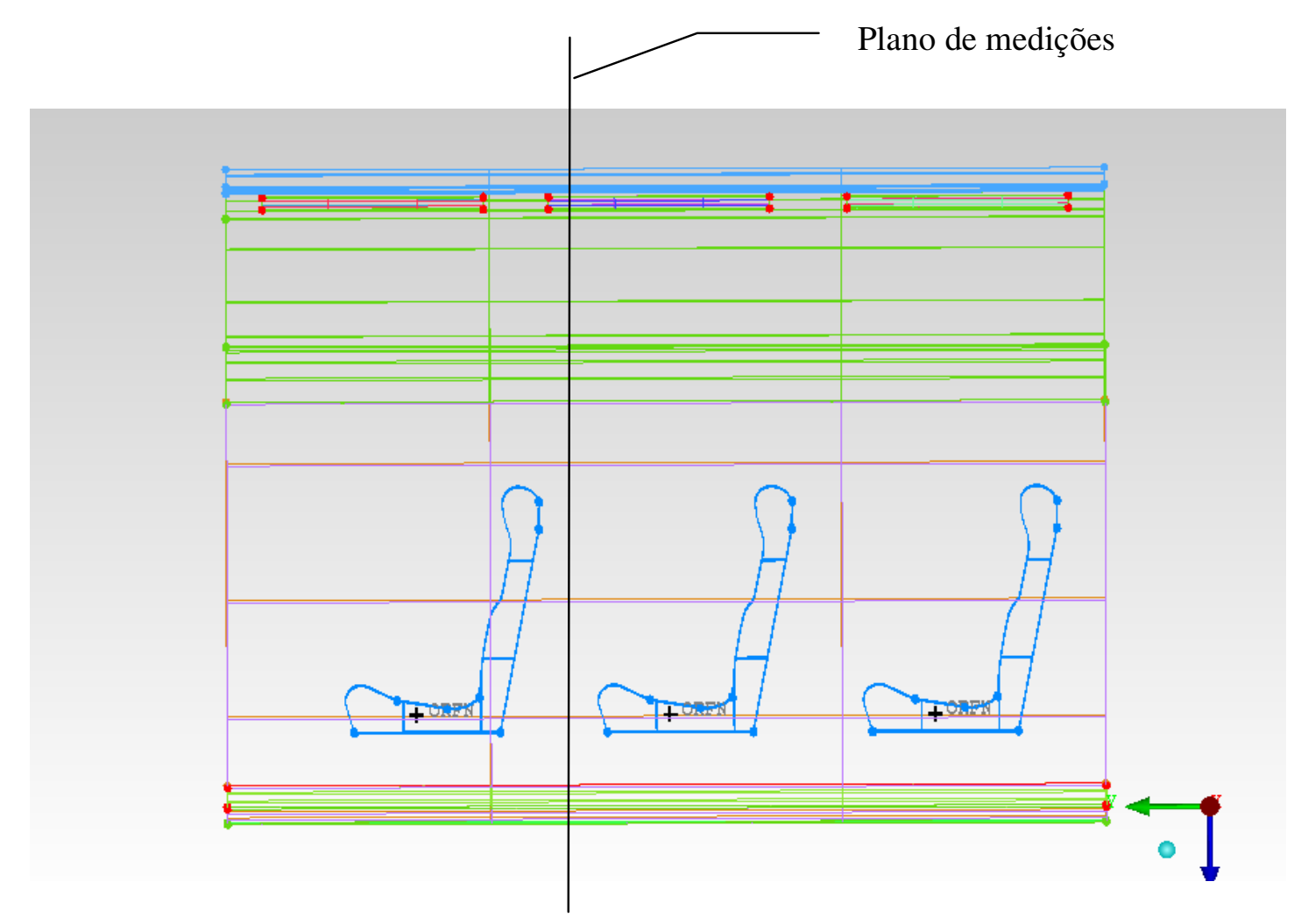

Figura 5.11 Plano de medições das velocidades e temperaturas do ar. 


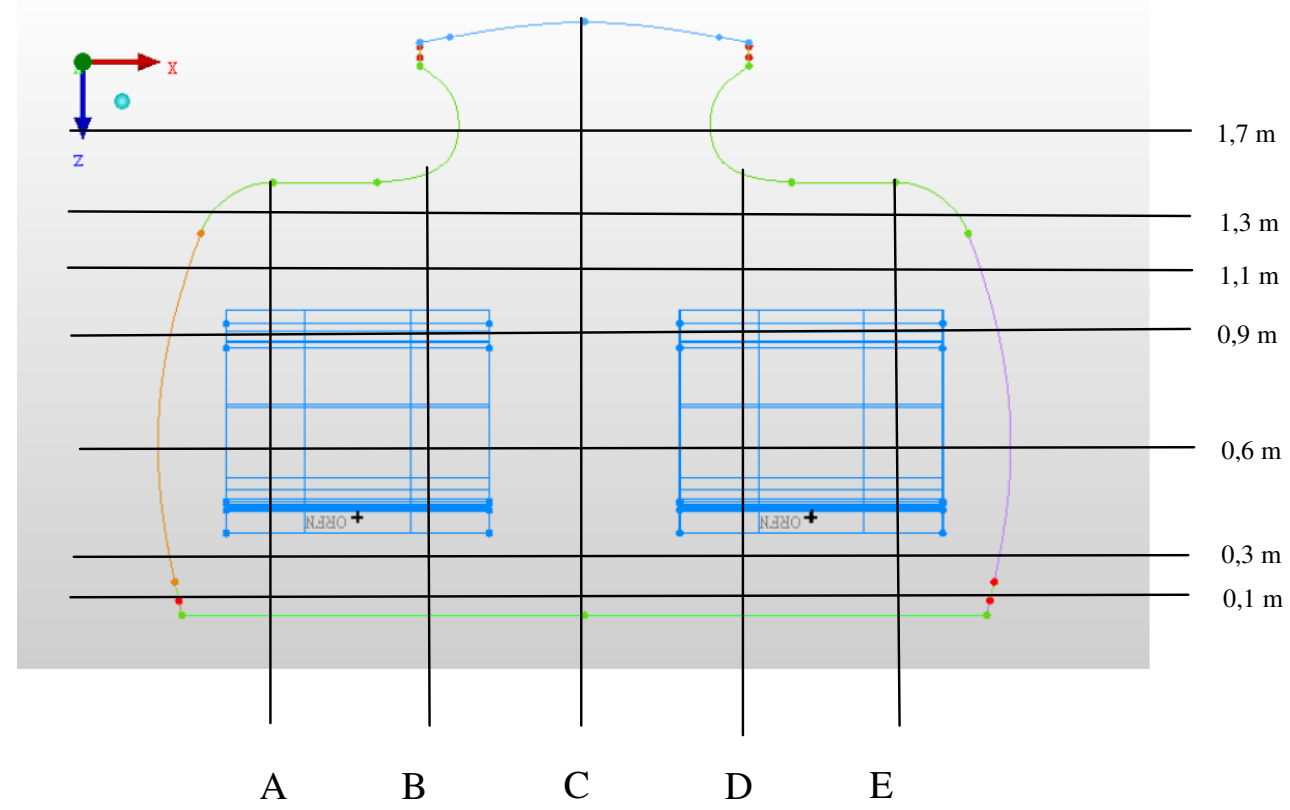

Lado esquerdo

Lado direito

Figura 5.12 Posições de medições no plano vertical.

Foram medidas as velocidades e temperaturas em 8 pontos de cada entrada de ar e calculadas as médias. Foram feitas 3 medidas de temperatura superficial, com o sensor de temperatura superficial, no teto, lateral esquerda e direita, piso e bins nas seções mediana dos bancos, e calculada a média de cada superfície. Foi também medida a temperatura superficial de cada manequim nas pernas, peito e cabeça e calculada uma temperatura média de todos os manequins.

\subsubsection{Calibração do manequim}

O objetivo deste item é apresentar as etapas na realização de calibrações do manequim. Para cobrir a faixa de temperaturas médias do ar interior do mock-up, ocorridas nos experimentos $\left(27^{\circ} \mathrm{C}\right.$ a $\left.18{ }^{\circ} \mathrm{C}\right)$, foram definidas três temperaturas de calibração.

$$
\begin{array}{ll}
\text { ○ } 24{ }^{\circ} \mathrm{C} ; \\
\text { ○ } 21,5{ }^{\circ} \mathrm{C} \text {; } \\
\text { ○ } 19,5{ }^{\circ} \mathrm{C} \text {. }
\end{array}
$$




\section{Condições de calibração}

A calibração do manequim foi realizada em uma cabine construída para este propósito no mesmo laboratório de conforto térmico onde está o mock-up (Fig.5.13). A sala é de forma cúbica de 1,80 m. Possui 4 difusores circulares no piso, que promovem velocidade baixa de insuflamento (velocidades abaixo de $0,01 \mathrm{~m} / \mathrm{s}$ ). $\mathrm{O}$ ar é retirado por duas grelhas de retorno no teto. Para se realizar a calibração, colocou-se o sensor de controle do sistema de climatização dentro da cabine. O manequim foi sentado na mesma posição que ocuparia na cabine. Nos ensaios realizados no presente trabalho não se utilizou roupa no manequim pelas seguintes razões:

- Roupas causam mudanças nos coeficientes de troca de calor quando da mudança de posição do manequim;

- Maior sensibilidade na medição dos fluxos de calor, com maiores variações nos fluxos de calor, no caso de manequins regulados com temperatura constante;

○ Facilidade na modelagem computacional, pois não é necessário se informar as resistências térmicas da roupa.

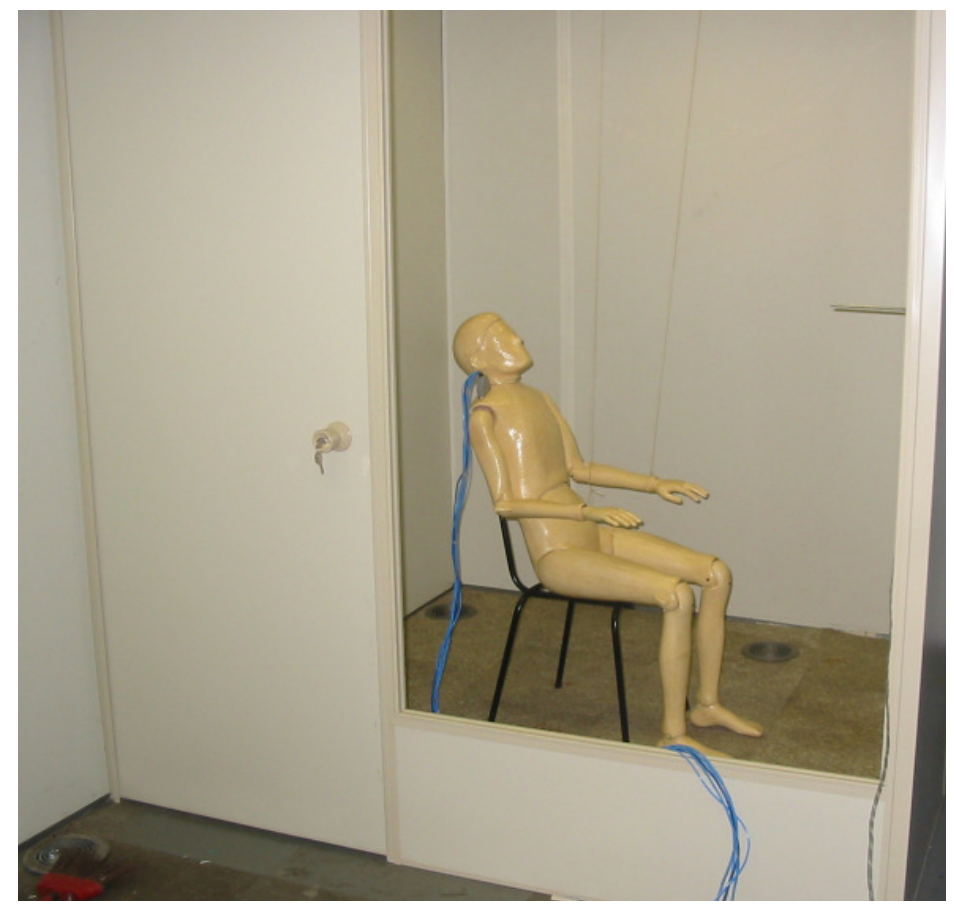

Figura 5.13 Manequim sentado para a calibração na cabine.

$\mathrm{Na}$ realização dos ensaios utilizou-se uma estrutura de cadeira sem os assentos para não se ter a influência da isolação das espumas. As mãos foram suspensas por fios para se 
deixar o braço, antebraço e mãos na mesma posição que terão no mock-up. As aquisições de dados foram feitos em 1 hora após a estabilização das temperaturas, com 13 horas de duração entre set-ups e medições.

\section{Variáveis medidas}

\section{Temperaturas e velocidades do ar e temperaturas superficiais}

A velocidade e temperatura do ar foi medida com anemômetro direcional. Foi feito uma leitura no início, meio e fim de cada medição. A medição foi feita durante uma hora após a estabilização dos fluxos do manequim térmico.

Foram feitas medidas de temperatura superficial, no teto, quatro paredes laterais e piso.

Fluxos de calor nos segmentos do manequim

Foram medidos os fluxos de calor por área nos 17 segmentos do manequim:

1. Escalpo

2. Face esquerda

3. Face direita

4. Braço esquerdo

5. Braço direito

6. Antebraço esquerdo

7. Antebraço direito

8. Mão esquerda

9. Mão direita

10. Coxa frontal esquerda

11. Coxa frontal direita

12. Coxa posterior esquerda

13. Coxa posterior direita

14. Perna esquerda

15. Perna direita

16. Pé esquerdo

17. Pé direito 
Não se mediu os fluxos no peito, costas superior, costas inferior, abdome e pélvis, pois estes tiveram o fluxo real afetado pelo aquecimento provocado pelas placas de controle colocadas no interior do manequim.

\subsubsection{Determinação das temperaturas equivalentes}

O objetivo deste item é mostrar como foram feitas as medições para determinação das temperaturas equivalentes, com o manequim sentado em uma das duas posições do mock-up: junto à fuselagem e no corredor, conforme mostrado nas figuras 5.14 e 5.15. Foram definidas três situações para serem analisadas:

- Cabine sem ocupação;

- Cabine com ocupação em baixo metabolismo;

○ Cabine com ocupação com médio metabolismo.

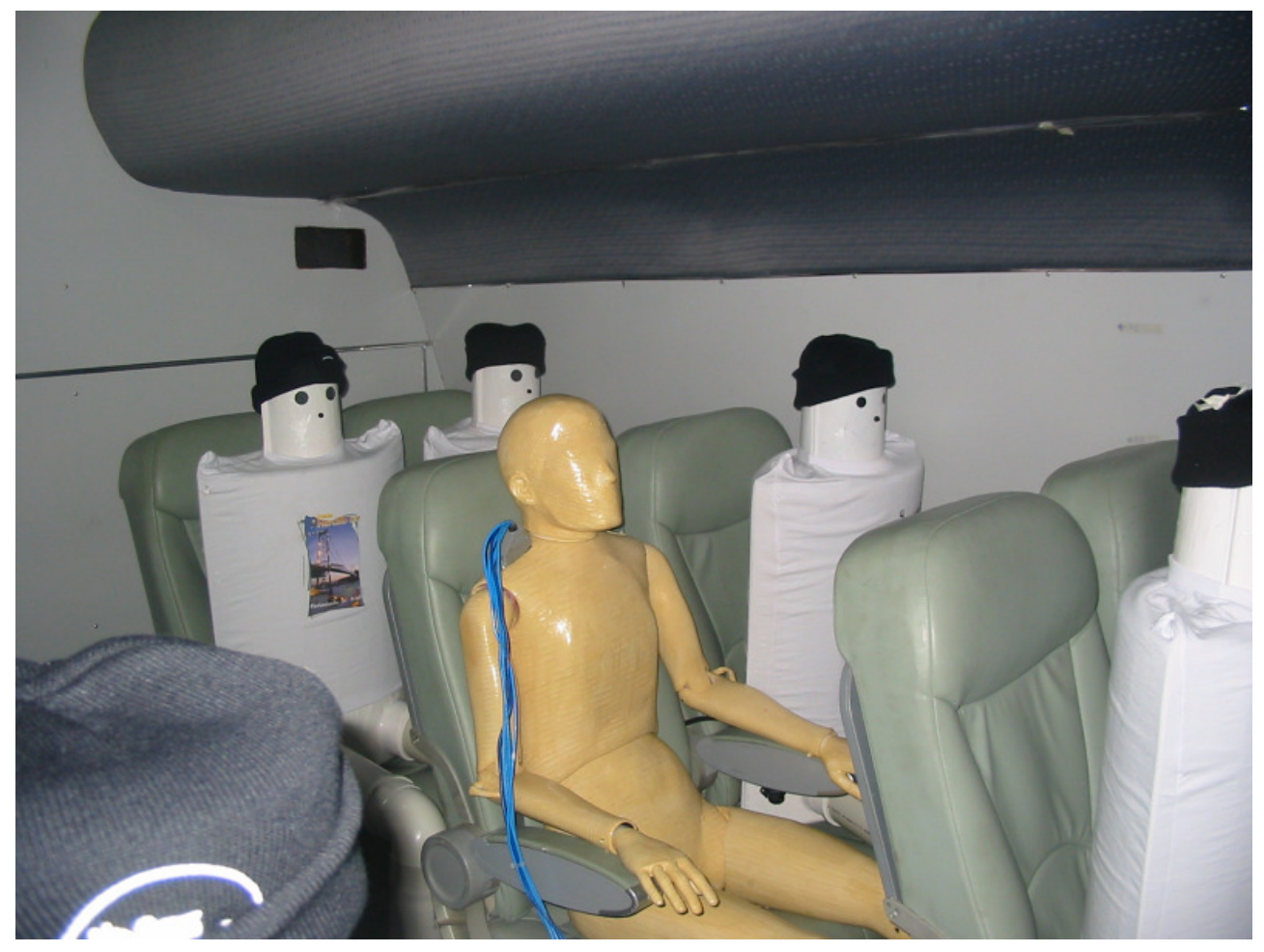

Figura 5.14 Manequim sentado em poltrona próxima ao corredor. 


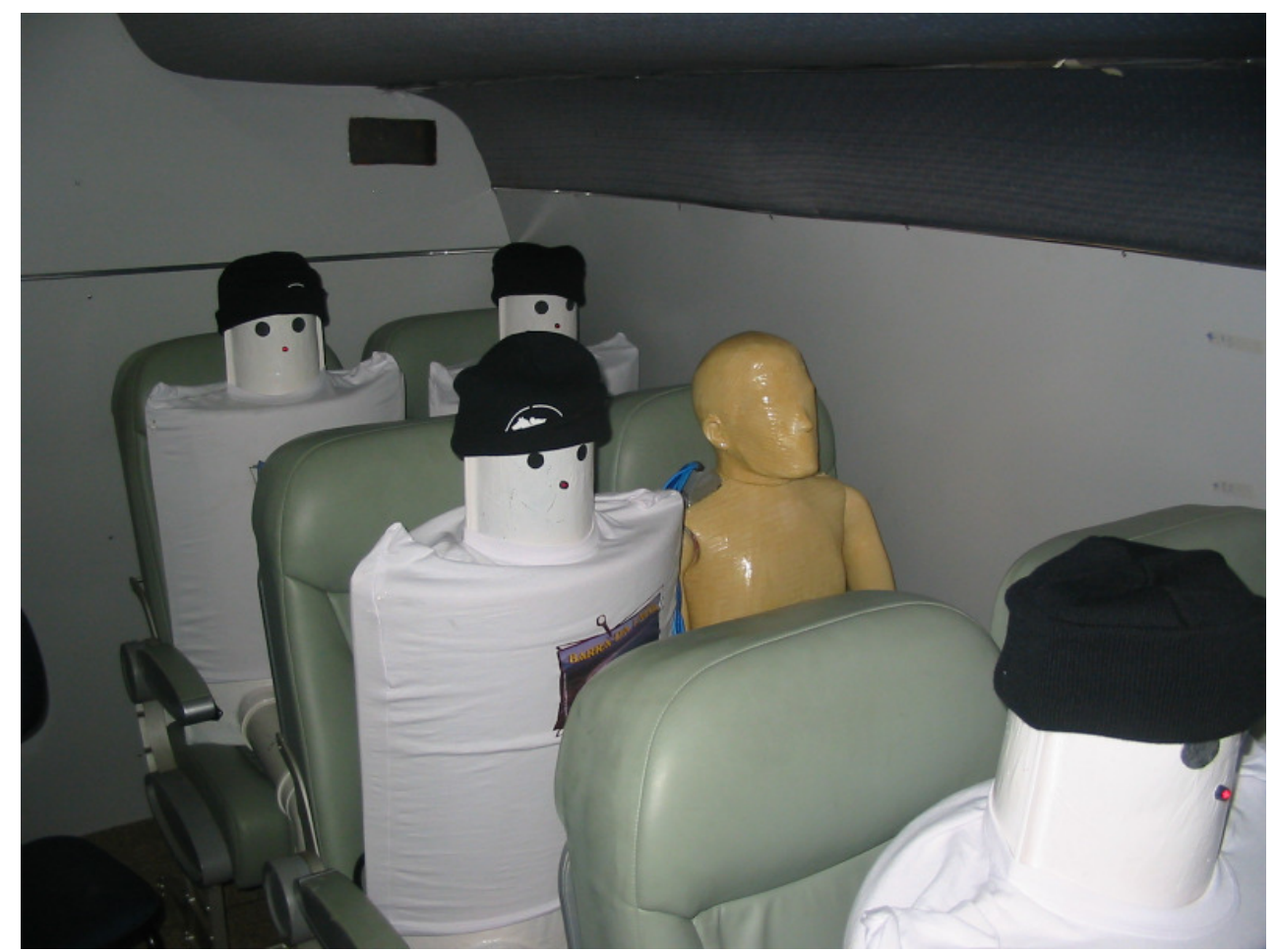

Figura 5.15 Manequim sentado em poltrona próxima à fuselagem.

\section{Condições de cabine}

Para simular estas três situações basicamente se mudou a dissipação térmica dos manequins. As situações com ocupação foram conseguidas colocando-se 12 simuladores sentados nos bancos, com dissipações térmicas de $50 \mathrm{~W} / \mathrm{m}^{2}$ e de $70 \mathrm{~W} / \mathrm{m}^{2}$ que correspondem, respectivamente, a um metabolismo baixo dos passageiros (sentado reclinado) e médio (em atividade similar a de escritório) em veículos. A situação de cabine sem ocupação foi simulada desligando-se os simuladores térmicos. Este ensaio visava principalmente se medir o campo de velocidades na seção dos testes anteriores para se verificar a influência da presença do volume das "pessoas" no campo de velocidades.

As três situações foram analisadas em condição de vôo, que foi simulada climatizando o laboratório onde está o mock-up a $18{ }^{\circ} \mathrm{C}$. O sistema de climatização do mock-up foi regulado para uma temperatura de $20{ }^{\circ} \mathrm{C}$. Isto foi feito para se obter o máximo de estabilização das temperaturas de insuflamento (máxima capacidade de refrigeração do sistema) e temperaturas de insuflamento mínimas. Em todas as avaliações se manteve constante a vazão de ar pelas bocas de insuflamento. 


\section{Variáveis medidas}

\section{Temperaturas e velocidades de ar e temperaturas superficiais}

A medição foi feita durante uma hora em cada posição após os fluxos do manequim térmico terem se estabilizado. Foi medida a temperatura de insuflamento de cada entrada de ar com anemômetro direcional. Foi feita uma leitura no início, meio e fim de cada medição. Também foi medida a temperatura do ar no meio geométrico da cabine - no meio do corredor e do mock-up.

Foram feitas 3 medidas de temperatura superficial no teto, lateral esquerda e direita, piso e bins nas seções mediana dos bancos e calculada a média de cada superfície. Foi também medida a temperatura superficial de cada manequim nas pernas, peito e cabeça e calculada uma temperatura média de todos os manequins.

\section{Fluxos de calor dos segmentos do manequim}

Foram medidos os fluxos de calor por área nos 17 segmentos do manequim:

1. Escalpo

2. Face esquerda

3. Face direita

4. Braço esquerdo

5. Braço direito

6. Antebraço esquerdo

7. Antebraço direito

8. Mão esquerda

9. Mão direita

10. Coxa frontal esquerda

11. Coxa frontal direita

12. Coxa posterior esquerda

13. Coxa posterior direita

14. Perna esquerda

15. Perna direita

16. Pé esquerdo

17. Pé direito 


\section{Capítulo 6}

\section{Avaliação numérica do ambiente térmico em aeronave}

O objetivo deste capítulo é apresentar e discutir os procedimentos nas simulações computacionais realizadas na cabine do mock-up, para avaliação numérica do ambiente térmico. Os resultados de simulação, juntamente com os resultados experimentais, são apresentados no Capítulo 7.

O presente capítulo está dividido em quatro partes:

a) A primeira parte se refere à modelagem matemática do escoamento do ar em ambientes interiores e de alguns detalhes da solução numérica das equações.

b) A segunda parte trata das simulações numéricas realizadas em uma seção da cabine do mock-up, considerando somente uma fileira de bancos e calibração de um manequim, para posterior comparação de resultados de simulação com resultados da literatura somente. Inicialmente, são discutidos detalhes do estudo de influência do refinamento de malha, modelos de turbulência e ordem de interpolação nos resultados do escoamento, com e sem transferência de calor por radiação, e considerando periodicidade. Em seguida são discutidos procedimentos nas simulações envolvendo a utilização de manequins digitais na determinação de temperaturas equivalentes e avaliação de condições de conforto térmico.

c) A terceira parte trata das simulações numéricas para avaliação dos campos de temperatura e velocidade do ar na cabine do mock-up, considerando as três fileiras de bancos, com assentos ocupados por simuladores térmicos conforme apresentado no Capítulo 5.

d) Na última parte são apresentados e discutidos detalhes do processo de simulação para determinação de temperaturas equivalentes considerando manequim térmico digital sentado junto ao corredor e junto à fuselagem, conforme apresentado no Capítulo 5. 


\subsection{MODELAGEM MATEMÁTICA}

A seguir são apresentadas as equações necessárias para resolver problemas de escoamento em ambientes ventilados. Tomando-se um elemento de fluido infinitesimal, a equação da conservação da massa é dada por:

$$
\frac{\partial \rho}{\partial t}+\operatorname{div}(\rho \cdot \vec{u})=0
$$

onde $\rho$ é a massa específica, t o tempo e $\vec{u}$ o vetor velocidade.

Aplicando-se a segunda lei de Newton num elemento infinitesimal, obtém-se:

$$
\frac{\partial}{\partial t}(\rho \vec{u})+\operatorname{div}(\rho \vec{u} \vec{u})=-\operatorname{grad} p+\operatorname{div}\left(\tau_{e f f}\right)+\rho \vec{g}+\vec{F}
$$

onde p é a pressão estática e $\tau_{\text {eff }}$ é o tensor das tensões devido à viscosidade efetiva (molecular e turbulenta), $\vec{g}$ é a aceleração gravitacional e $\vec{F}$ representa as forças externas e outros termos fontes, como meios porosos.

Em escoamentos onde há troca de calor, a primeira lei da termodinâmica é aplicada em um elemento infinitesimal e resulta na equação de conservação da energia:

$$
\frac{\partial \rho e}{\partial t}+\operatorname{div}(\rho e \vec{u})=-p \operatorname{div}(\vec{u})+\operatorname{div}\left(k_{e f f} \operatorname{grad} T\right)+\Phi+S_{e}
$$

onde $e$ é a energia, $\mathrm{k}_{\mathrm{eff}}$ a condutividade térmica efetiva, $\mathrm{T}$ a temperatura, $\Phi$ uma função de dissipação e $S_{\mathrm{e}}$ representa o termo fonte.

Sabe-se que a maioria dos escoamentos dos casos práticos é de característica turbulenta. Nesse regime de escoamento a viscosidade passa a ter uma característica randômica, e por essa razão são necessárias formas que possam prever esse comportamento para que os termos das equações que envolvem viscosidade ( $\tau_{\text {eff }}$ e $\left.\mathrm{k}_{\text {eff }}\right)$ sejam completos. Nesse contexto se enquadram os modelos de turbulência, que prevêem esse comportamento.

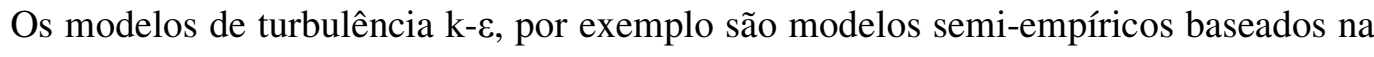
modelagem das equações de transporte da energia cinética turbulenta (k) e na sua taxa de dissipação $(\varepsilon)$. O modelo para a equação de energia cinética $\mathrm{k}$ é derivado da equação exata, enquanto a taxa de dissipação $\varepsilon$ é obtida por raciocínio físico e tem pouca semelhança com a outra equação. 


$$
\begin{gathered}
\frac{\partial}{\partial t}(\rho \mathrm{k})+\frac{\partial}{\partial \mathrm{x}_{\mathrm{i}}}\left(\rho \mathrm{ku}_{\mathrm{i}}\right)=\frac{\partial}{\partial \mathrm{x}_{\mathrm{j}}}\left[\left(\mu+\frac{\mu_{\mathrm{t}}}{\sigma_{\mathrm{k}}}\right) \frac{\partial \mathrm{k}}{\partial \mathrm{x}_{\mathrm{j}}}\right]+\mathrm{G}_{\mathrm{k}}+\mathrm{G}_{\mathrm{b}}-\rho \varepsilon-\mathrm{Y}_{\mathrm{M}}+\mathrm{S}_{\mathrm{k}} \\
\frac{\partial}{\partial \mathrm{t}}(\rho \varepsilon)+\frac{\partial}{\partial \mathrm{x}_{\mathrm{i}}}\left(\rho \varepsilon \mathrm{u}_{\mathrm{i}}\right)=\frac{\partial}{\partial \mathrm{x}_{\mathrm{j}}}\left[\left(\mu+\frac{\mu_{\mathrm{t}}}{\sigma_{\mathrm{k}}}\right) \frac{\partial \varepsilon}{\partial \mathrm{x}_{\mathrm{j}}}\right]+\mathrm{C}_{1 \varepsilon} \frac{\varepsilon}{\mathrm{k}}\left(\mathrm{G}_{\mathrm{k}}+\mathrm{C}_{3 \varepsilon} \mathrm{G}_{\mathrm{b}}\right)-\mathrm{C}_{2 \varepsilon} \rho \frac{\varepsilon}{\mathrm{k}}+\mathrm{S}_{\varepsilon}
\end{gathered}
$$

Nas equações (6.4) e (6.5), $\mathrm{G}_{\mathrm{k}}$ representa a geração de energia cinética turbulenta devido ao gradiente das velocidades médias; $G_{b}$ é a geração de energia cinética devido à flutuação; $\mathrm{Y}_{\mathrm{M}}$ representa o termo da dissipação da dilatação em escoamentos compressíveis; $\mathrm{C}_{1 \varepsilon}$ e $\mathrm{C}_{2 \varepsilon}$ são constantes; $\sigma_{\varepsilon}$ e $\sigma_{\mathrm{k}}$ são os números de Prandtl para as taxas de turbulência k- $\varepsilon$ e $\mathrm{S}_{\varepsilon}$ e $\mathrm{S}_{\mathrm{k}}$ são as fontes definidas pelo usuário.

A viscosidade turbulenta $\left(\mu_{\mathrm{t}}\right)$ é calculada da seguinte forma:

$$
\mu_{\mathrm{t}}=\rho \mathrm{C}_{\mu} \frac{\mathrm{k}^{2}}{\varepsilon}
$$

As constantes do modelo foram obtidas experimentalmente para escoamentos turbulentos fundamentais e funcionam bem em escoamentos turbulentos forçados e livres (Fluent, 2006).

$$
\mathrm{C} 1 \varepsilon=1,44 ; \mathrm{C} 2 \varepsilon=1,92 ; \mathrm{C} \mu=0,09 ; \quad \sigma_{\varepsilon}=1,3 ; \quad \sigma_{\mathrm{k}}=1,0
$$

\section{- Tratamento junto à parede}

Para as regiões de baixa turbulência, por exemplo, nas proximidades de superfícies

sólidas, onde não é satisfeita a condição $\mu_{t} / \mu>1$, as equações empregadas nos modelos de turbulência não são resolvidas. Nestas regiões são utilizadas equações algébricas para a determinação de $\mu_{\mathrm{t}}$ ou k e $\varepsilon$. Essas relações são obtidas supondo que a turbulência está em equilíbrio nestas regiões e representam uma generalização da lei de parede (por exemplo, a lei logarítmica) que ocorre no escoamento turbulento paralelo à uma superfície plana. Como estas equações têm validade para uma região restrita do escoamento, isso impõe uma restrição 
severa sobre a qualidade da malha utilizada, que deve ter pontos mais próximos à parede localizados a uma faixa de distância $\left(y^{+}\right)$adimensional para que os resultados obtidos sejam válidos:

$$
y^{+}=\frac{y \sqrt{\tau_{0} / \rho}}{v}
$$

com $y$ sendo uma distância a partir da parede, $\rho$ representa a densidade, $v$ a viscosidade cinemática e $\tau_{0}$ a tensão de cisalhamento na parede.

Em todas as simulações computacionais realizadas no presente trabalho foi utilizado o programa comercial de CFD Fluent (2006) e a lei de parede otimizada.

\section{Modelo de radiação}

$\mathrm{Na}$ simulação das trocas de calor por radiação foi utilizado modelo de ordenadas discretas do Fluent (2006), onde a radiação emitida por um elemento superficial se divide em ângulos sólidos, que somados resultam em um ângulo sólido semi hemisférico. Este procedimento implica em baixo custo computacional.

Adotou-se uma divisão do ângulo sólido hemisférico em 4 partes e as equações de troca de calor por radiação foram resolvidas desacopladas das demais. A cada 10 interações do programa Fluent se recalculavam as trocas por radiação.

\section{Geração de malha}

Foi utilizado o programa ICEM CFD 11.0 para geração de malhas.

\subsection{SIMULAÇÃO DA CABINE CONSIDERANDO UMA FILEIRA DE BANCOS}

Inicialmente, foram realizados estudos com o objetivo de verificar a influência do refinamento de malha na obtenção do campo de velocidades e temperaturas do ar na cabine e nos coeficientes de troca de calor dos manequins. A geometria utilizada neste estudo foi uma seção do mock-up experimental considerando uma fileira de bancos somente. Nesta seção foi admitido insuflamento pelas grelhas de entrada de ar sobre e sob o bin, com entrada de ar próxima à cabeça do passageiro perto da janela, como se pode observar na Figura 6.1. 


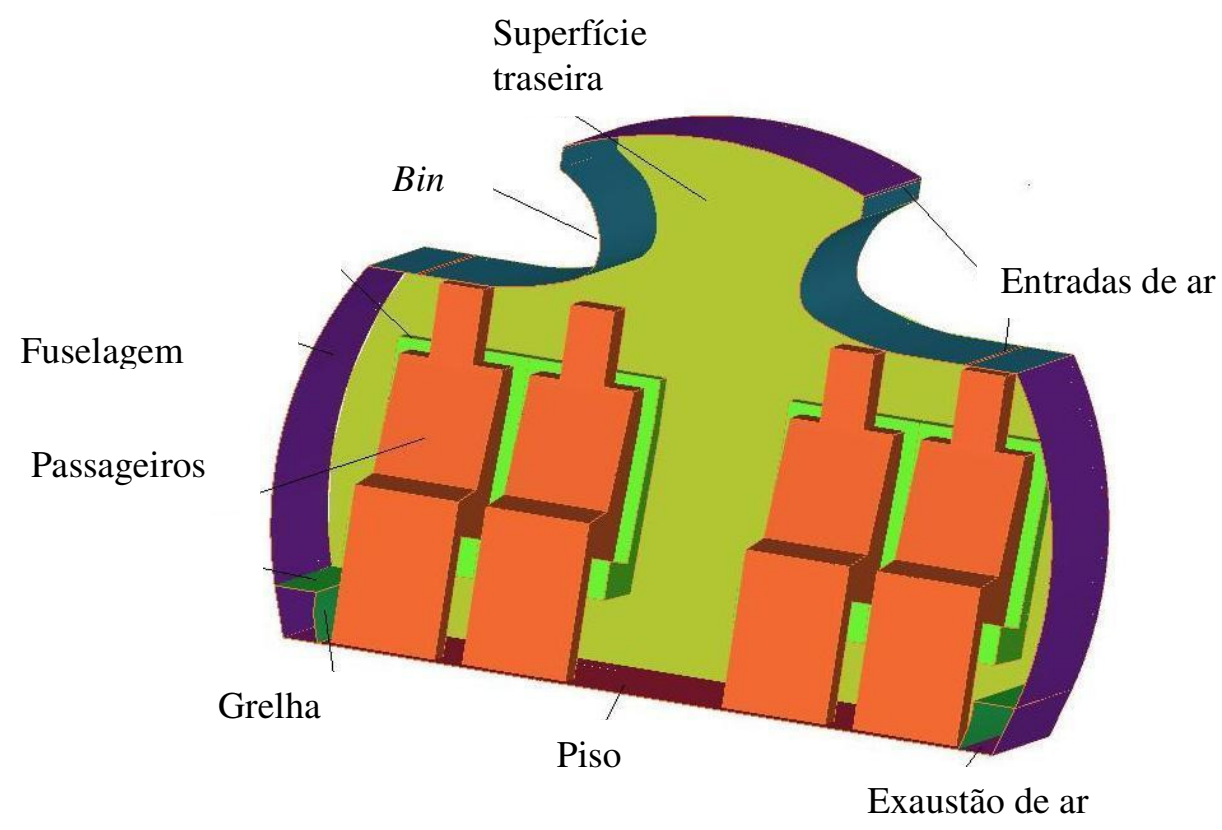

Figura 6.1 Detalhes da seção de uma fileira de bancos com manequins simples

\subsubsection{Estudo da influência da malha no escoamento}

Nos estudos de independência de malha foram considerados manequins simples (sem detalhamento dos segmentos), apresentados na figura 6.1. Foram geradas onze malhas tetraédricas, não estruturadas e sem elementos internos aos passageiros (manequins) e bancos, conforme apresentado na Tabela 6.1. Nesses estudos iniciais não foi considerada troca de calor por radiação.

Tabela 6.1 Quantidade de elementos das malhas.

\begin{tabular}{c}
\hline $\begin{array}{c}\text { Quantidade de Elementos } \\
\text { (em milhares) }\end{array}$ \\
\hline 404 \\
505 \\
544 \\
650 \\
711 \\
799 \\
1501 \\
1763 \\
2000 \\
2496 \\
\hline
\end{tabular}


Para se avaliar a influência da quantidade de elementos das malhas e do nível de refinamento em zonas de maior velocidade do ar foram definidas condições de contorno apresentadas na Tabela 6.2. Os parâmetros estudados foram o fluxo de calor médio nos manequins e os campos de temperatura e velocidade do ar.

Tabela 6.2 Condições de Contorno

\begin{tabular}{ll}
\hline Superfícies & Condição de Contorno \\
\hline Fuselagem & Parede Adiabática \\
Bin & Parede Adiabática \\
Piso & Parede Adiabática \\
Assentos & Parede Adiabática \\
Parede frontal e fundo & Parede Adiabática \\
Superfície trazeira & Exaustão com pressão prescrita ( 0 Pa) \\
Superfície frontal & Entrada com pressão prescrita $(0 \mathrm{~Pa})$ \\
Entradas de ar & Entrada com velocidade prescrita \\
Exaustão de ar & Exaustão com pressão prescrita $(-48 \mathrm{~Pa})$ \\
Passageiros & Superfície com temperatura prescrita $\left(34^{\circ} \mathrm{C}\right)$ \\
\hline
\end{tabular}

As condições do insuflamento nas entradas de ar foram: direção perpendicular, velocidade de $0,8032 \mathrm{~m} / \mathrm{s}$, temperatura de $15^{\circ} \mathrm{C}$, diâmetro hidráulico de $0,0025 \mathrm{~m}$, e $5 \%$ de intensidade turbulenta.

Os passageiros foram definidos como superfícies de temperatura constante de $34^{\circ} \mathrm{C}$ e revestidos de um material chamado de "algodão", com espessura de 0,00576 m, e as seguintes propriedades físicas:

\footnotetext{
Densidade $=80 \mathrm{~kg} / \mathrm{m}^{3}$

Calor específico $=1300 \mathrm{~J} / \mathrm{kg} .{ }^{\circ} \mathrm{C}$

Condutividade térmica $=0,06 \mathrm{~W} / \mathrm{m} .{ }^{\circ} \mathrm{C}$
}

O volume definido pelas grelha, fuselagem e exaustão de ar, foi modelado como um meio poroso, simulando dessa forma a perda de carga da grelha real. A perda de carga foi modelada como equivalente a um cotovelo com um ângulo de $90^{\circ}$. Tomando como referência HVAC - System Duct Desing (SMACNA, 1990) levantou-se a curva de perda de carga em função da velocidade do ar para a geometria em questão (Fig. 6.2). 


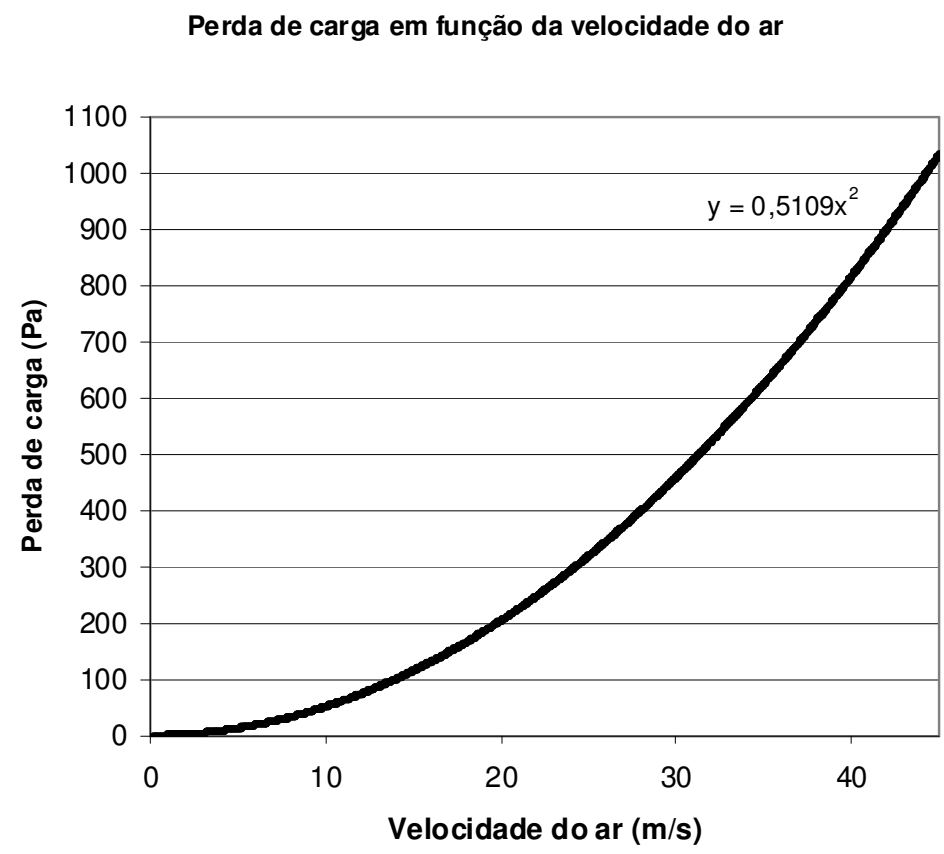

Figura 6.2 Perda de carga em um cotovelo de $90^{\circ}$

Com a equação da curva apresentada na figura 6.2 pode-se determinar os coeficientes C0 e C1 necessários para definir o meio poroso, já que o programa Fluent define esses coeficientes na equação de perda de carga $\operatorname{com} \mathrm{Y}=\mathrm{C} 0 \cdot \mathrm{X}^{\mathrm{C} 1}$, onde $\mathrm{Y}$ é a perda de carga e $\mathrm{X}$ a velocidade do fluido. Assim $\mathrm{C} 0=0,5109$ e $\mathrm{C} 1=2$.

A pressão na exaustão de ar deve ser tal que seja suficiente para que o fluido supere a perda de carga definida na grelha e material poroso. Assim a pressão na exaustão foi definida como $-0,48 \mathrm{~Pa}$.

$\mathrm{O}$ ar foi modelado como gás perfeito, com as seguintes propriedades:

○ Calor específico $=1006,43 \mathrm{~J} / \mathrm{kg} \mathrm{K}$;

○ Condutividade térmica $=0,0242 \mathrm{~W} / \mathrm{m} \mathrm{K}$;

○ $\mu=1,7894 \cdot 10^{-5} \mathrm{~kg} / \mathrm{m} . \mathrm{s}$;

○ Massa molecular média $=28,966 \mathrm{~kg} / \mathrm{kmol}$.

O modelo de turbulência adotado foi o k- $\varepsilon$ padrão, com as seguintes constantes do modelo: 
○ $\mathrm{Cmu}=0,09$;

○ $\mathrm{C} 1-\varepsilon=1,44$

$\circ \quad \mathrm{C} 2-\varepsilon=1,92$;

○ Número de Prandtl TKE = 1;

○ Número de Prandtl TDR = 1,3;

○ Número de energia de Prandtl =0,85;

○ Número de parede de Prandtl = 0,85.

Foi utilizada a lei de parede otimizada com efeitos térmicos e de convecção natural em todas as simulações deste capítulo (Fluent, 2006).

\subsubsection{Simulações considerando periodicidade}

Nos estudos anteriores da seção de cabine foram geradas malhas com nível de refinamento independente, sem fator de escala e as simulações foram realizadas sem a condição periódica; o que não reflete bem o que ocorre em uma cabine real. Dessa forma, foi realizado um segundo estudo comparativo onde se buscou aperfeiçoar as simulações utilizando-se fatores não utilizados anteriormente como: geração de malhas pelo fator de escala (refinamento eqüitativo e gradual, dependente) e conformes (superfície frontal e traseira conformes) para simulações com periodicidade.

Para resolver o problema foram geradas malhas de 339, 586, 821 e 1870 mil elementos (Fig. 6.3). Nas respectivas malhas acrescentou-se elementos prismáticos sobre os manequins e obteve-se malhas de 385, 650, 890 e 1880 mil elementos (Figs. 6.4 e 6.5) para avaliar a diferença na captação do fenômeno em relação às malhas tetraédricas sem prismas. A camada de prismas foi de $60 \mathrm{~mm}$ de espessura com seis camadas com espessura uniforme, estipulado de acordo com estudos anteriores. 


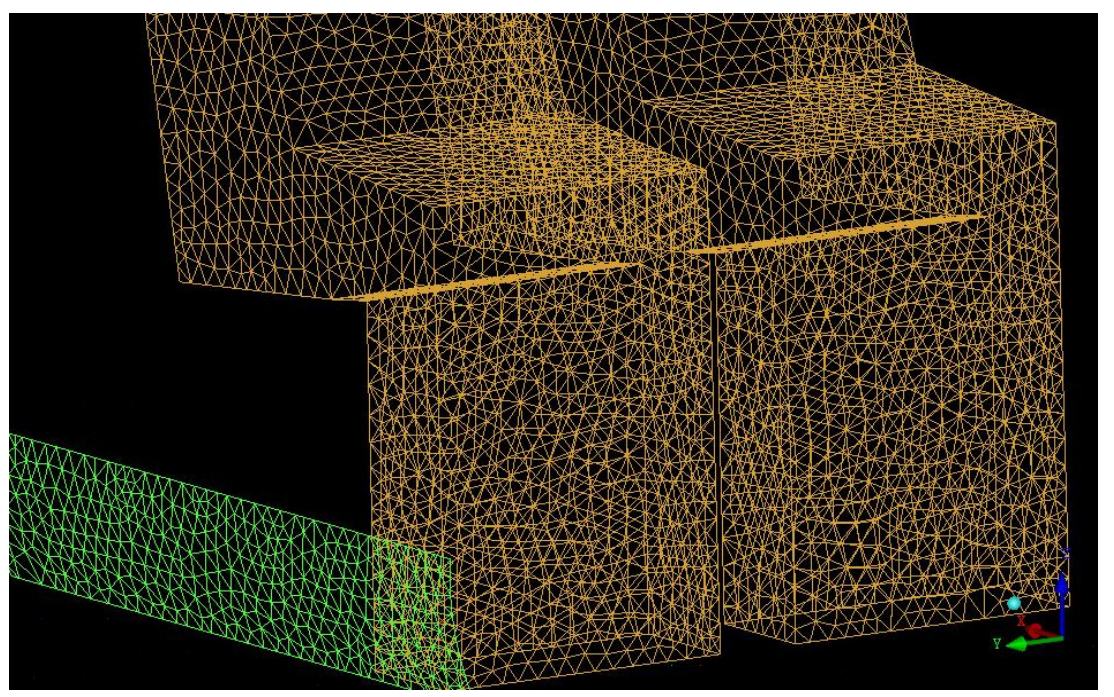

Figura 6.3 Malha superficial tetraédrica no retorno do ar e sobre os passageiros (821 mil elementos).

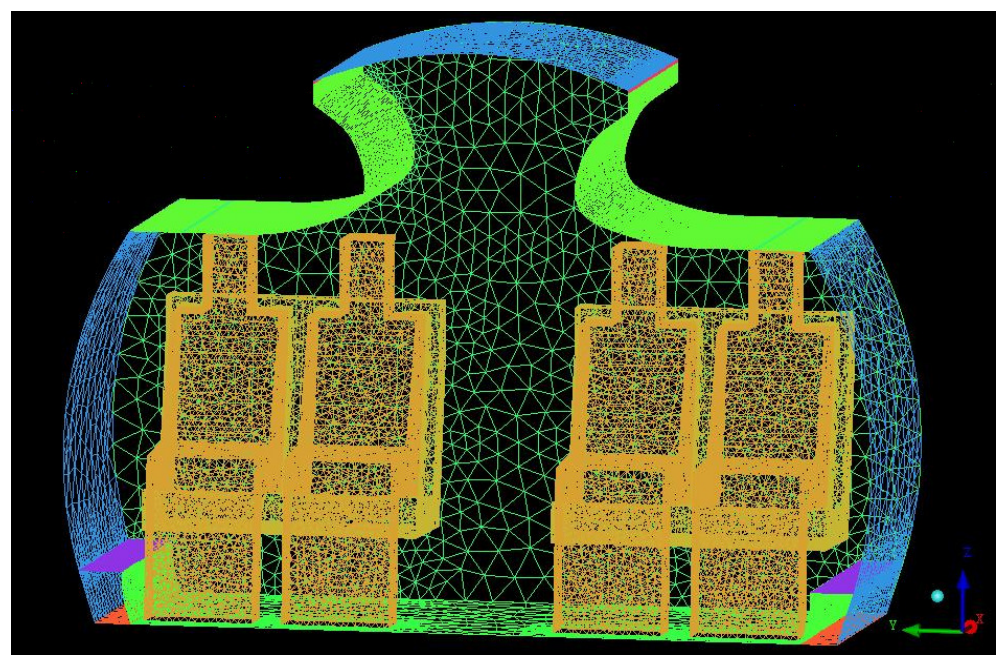

Figura 6.4 Malha superficial tetraédrica com prismas sobre os passageiros (890 mil elementos). 


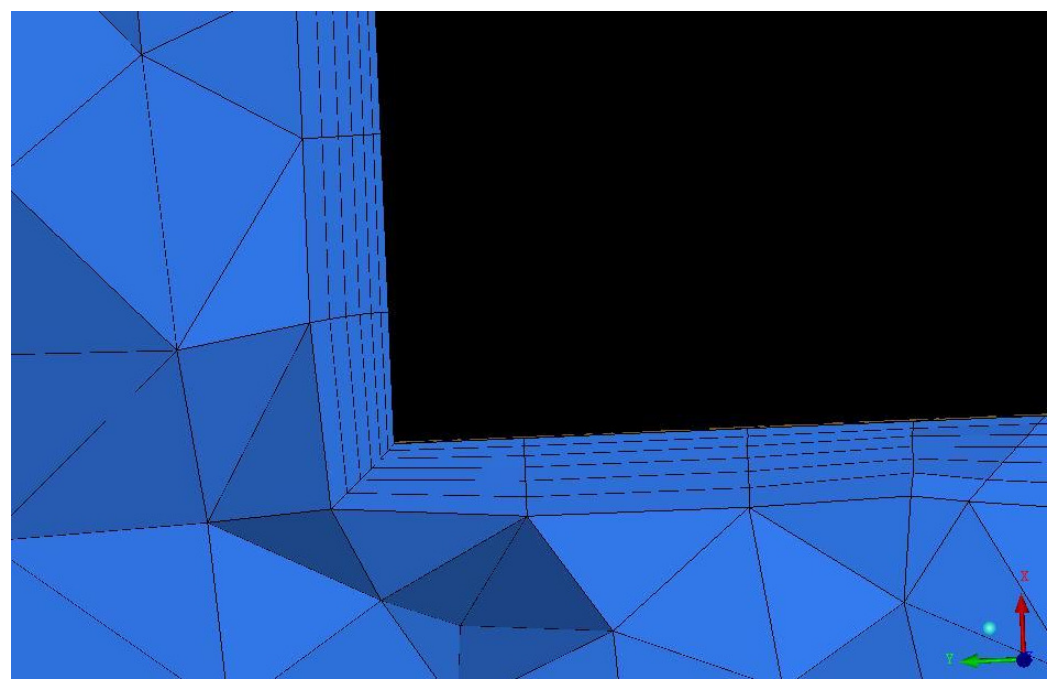

Figura 6.5 Corte na malha sobre os passageiros mostrando a camada de seis prismas (890 mil elementos).

Posteriormente, foram realizadas simulações objetivando análise dos fluxos de calor. Nessas simulações também foi avaliada a influência da quantidade de elementos e do nível de refinamento das malhas. Usou-se as condições de contorno apresentadas na Tabela 6.3.

Tabela 6.3 Condições de contorno.

\begin{tabular}{ll}
\hline Superfícies & Condição de Contorno \\
\hline Fuselagem & Parede Adiabática \\
Bin & Parede Adiabática \\
Piso & Parede Adiabática \\
Assentos & Parede Adiabática \\
Parede frontal e fundo & Parede Adiabática \\
Superfície traseira & Periodicidade \\
Superfície frontal & Periodicidade \\
Entradas de ar & Entrada com velocidade prescrita \\
Exaustão de ar & Exaustão com pressão prescrita $(-48 \mathrm{~Pa})$ \\
Passageiros & Superfície com temperatura prescrita $\left(34^{\circ} \mathrm{C}\right)$ \\
\hline
\end{tabular}

Verifica-se da Tabela 6.3, que foram utilizadas as mesmas condições de contorno do estudo anterior, a menos das superfícies periódicas. 


\subsubsection{Simulações considerando manequim digital 1 para determinação de temperaturas equivalentes}

Após a realização destes estudos preliminares enfocando o escoamento, foram realizadas simulações considerando trocas térmicas por convecção e radiação com manequins digitais para determinação de temperaturas equivalentes.

Inicialmente, realizaram-se simulações para estudar a influência do refinamento de malha e de modelos de turbulência sobre os coeficientes de troca de calor de calibração de manequins, $h_{\text {cal }}$, para posterior comparação com aqueles obtidos por Nilsson (2004).

Para a realização dos estudos utilizou-se condições de contorno (Tabela 6.4) e geometrias do manequim digital e sala de calibração (Figs. 6.6 e 6.7) utilizados por Nilsson (2004). As áreas de cada segmento do manequim são apresentadas na Tabela 6.5. Este manequim será denominado de manequim digital 1.

Tabela 6.4 Condições de contorno utilizadas nas simulações de calibração do manequim digital.

\begin{tabular}{ll}
\hline Superfícies & Condição de Contorno \\
\hline Paredes laterais & $\begin{array}{l}\text { Superfície com temperatura prescrita }\left(21{ }^{\circ} \mathrm{C}\right. \\
\left.\text { para situação de inverno e } 25^{\circ} \mathrm{C} \text { para verão }\right)\end{array}$ \\
Tapete & Superfície com temperatura prescrita $\left(21{ }^{\circ} \mathrm{C}\right.$ \\
& para situação de inverno e $25^{\circ} \mathrm{C}$ para verão $)$ \\
Piso & Entrada com velocidade prescrita $(0,03 \mathrm{~m} / \mathrm{s}$ e \\
& $21{ }^{\circ} \mathrm{C}$ para situação de inverno e $25{ }^{\circ} \mathrm{C}$ para \\
& verão $)$ \\
Teto & Exaustão com pressão prescrita $(0 \mathrm{~Pa})$ \\
Manequim & Superfície com temperatura prescrita $\left(34^{\circ} \mathrm{C}\right)$ \\
\hline
\end{tabular}



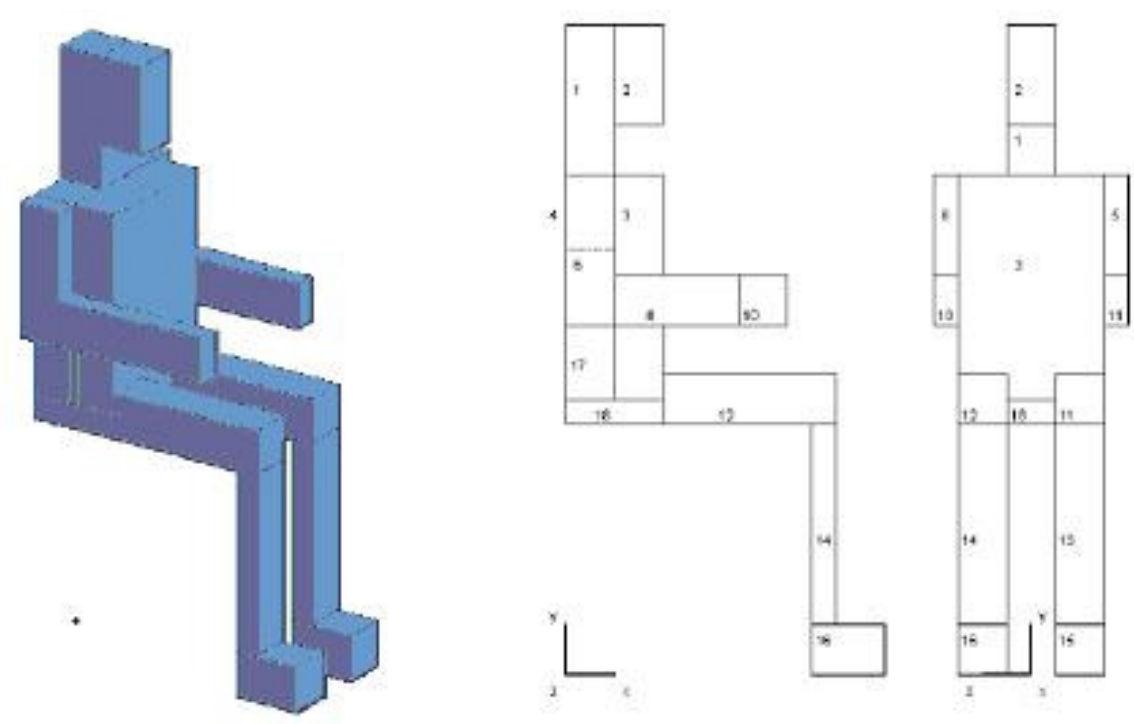

Figura 6.6 Manequim digital com 18 segmentos (Nilsson, 2004).

Tabela 6.5 Áreas de troca de calor dos segmentos do manequim digital (Nilsson, 2004)

\begin{tabular}{lc}
\hline Segmentos & Area $\left(\boldsymbol{m}^{2}\right)$ \\
\hline $\mathbf{1}$ Escalpo & 0,110 \\
$\mathbf{2}$ Face & 0,080 \\
$\mathbf{3}$ Peito & 0,225 \\
$\mathbf{4}$ Costas superior & 0,065 \\
$\mathbf{5}$ Antebraço esquerdo & 0,060 \\
$\mathbf{6}$ Antebraço direito & 0,065 \\
$\mathbf{7}$ Braço esquerdo & 0,070 \\
$\mathbf{8}$ Braço direito & 0,065 \\
$\mathbf{9}$ Mão esquerda & 0,035 \\
$\mathbf{1 0}$ Mão direita & 0,035 \\
$\mathbf{1 1}$ Coxa esquerda & 0,145 \\
$\mathbf{1 2}$ Coxa direita & 0,145 \\
$\mathbf{1 3}$ Canela esquerda & 0,120 \\
$\mathbf{1 4}$ Canela direita & 0,120 \\
$\mathbf{1 5}$ Pé esquerdo & 0,075 \\
$\mathbf{1 6}$ Pé direito & 0,075 \\
$\mathbf{1 7}$ Costas inferior & 0,120 \\
$\mathbf{1 8}$ Nádegas & 0,100 \\
\hline
\end{tabular}




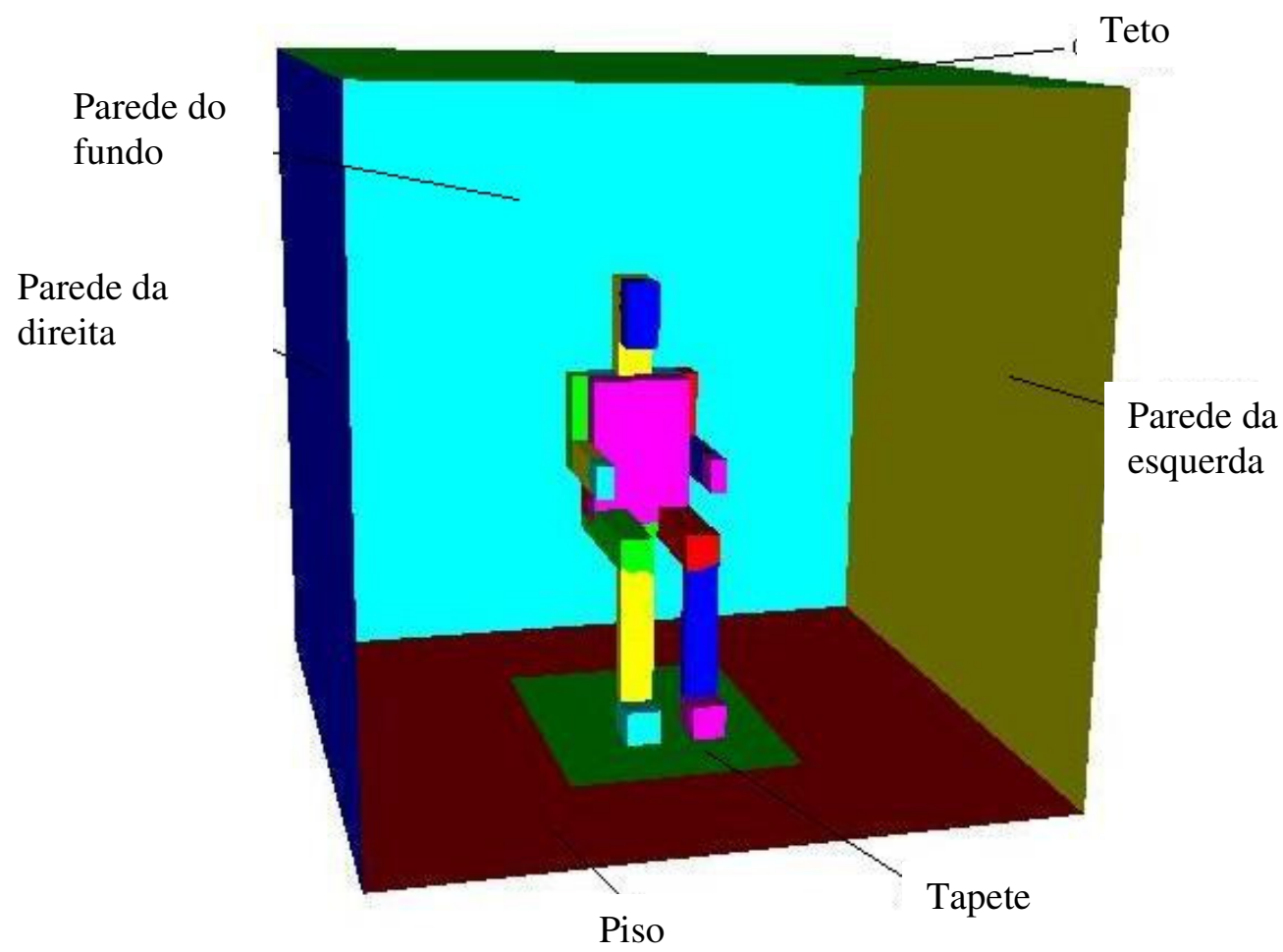

Figura 6.7 Geometria da sala simulada (Nilsson, 2004)

As avaliações experimentais realizadas por Nilsson (2004) foram feitas com o manequim vestido com roupas de verão e inverno. Por isso, para simular as resistências térmicas das roupas, foram colocadas sobre os diversos segmentos do manequim espessuras do material "algodão", criado anteriormente no item 6.2.1. As espessuras estão descritas na Tabela 6.6. 
Tabela 6.6 Espessura da roupa para cada segmento do manequim

\begin{tabular}{|c|c|c|c|c|}
\hline \multirow[b]{2}{*}{ Segmentos } & \multicolumn{2}{|c|}{ Valores experimentais } & \multicolumn{2}{|c|}{$\begin{array}{c}\text { Valores calculados das } \\
\text { espessuras }\end{array}$} \\
\hline & $\underset{\left(\mathbf{m}^{2} \mathbf{K} / \mathbf{W}\right)}{\text { Rcl_s }}$ & $\begin{array}{c}\text { Rcl_w } \\
\left(\mathbf{m}^{2} \mathbf{K} / \mathbf{W}\right)\end{array}$ & Esp._s (m) & Esp._w (m) \\
\hline 1 Escalpo & 0,178 & 0,160 & 0,01068 & 0,00960 \\
\hline 2 Face & 0,009 & 0,013 & 0,00054 & 0,00078 \\
\hline 3 Peito & 0,130 & 0,380 & 0,00780 & 0,02280 \\
\hline 4 Costas superior & 0,077 & 0,205 & 0,00462 & 0,01230 \\
\hline 5 Braço esquerdo & 0,142 & 0,353 & 0,00852 & 0,02118 \\
\hline 6 Braço direito & 0,127 & 0,333 & 0,00762 & 0,01998 \\
\hline 7 Antebraço esquerdo & 0,096 & 0,207 & 0,00576 & 0,01242 \\
\hline 8 Antebraço direito & 0,094 & 0,206 & 0,00564 & 0,01236 \\
\hline 9 Mão esquerda & 0,000 & 0,032 & 0,00000 & 0,00192 \\
\hline 10 Mão direita & 0,000 & 0,042 & 0,00000 & 0,00252 \\
\hline 11 Coxa esquerda & 0,088 & 0,101 & 0,00528 & 0,00606 \\
\hline 12 Coxa direita & 0,093 & 0,100 & 0,00558 & 0,00600 \\
\hline 13 Canela esquerda & 0,089 & 0,094 & 0,00534 & 0,00564 \\
\hline 14 Canela direita & 0,089 & 0,093 & 0,00534 & 0,00558 \\
\hline 15 Pé esquerdo & 0,170 & 0,135 & 0,01020 & 0,00810 \\
\hline 16 Pé direito & 0,154 & 0,133 & 0,00924 & 0,00798 \\
\hline 17 Costas inferior & 0,185 & 0,310 & 0,01110 & 0,01860 \\
\hline 18 Nádegas & 0,107 & 0,088 & 0,00642 & 0,00528 \\
\hline
\end{tabular}

Estudo do efeito do refinamento de malha sobre $o s \mathbf{h}_{\text {cal }}$

Foram geradas malhas com elementos tetraédricos em toda a superfície variando entre 230 mil e 1,2 milhão de elementos. Também gerou-se malhas com elementos prismáticos ao redor do manequim, com três níveis de refinamento: 500 mil, 800 mil e 1 milhão e 400 mil elementos, cujo exemplo com 230 mil elementos é apresentada na figura 6.8 . 


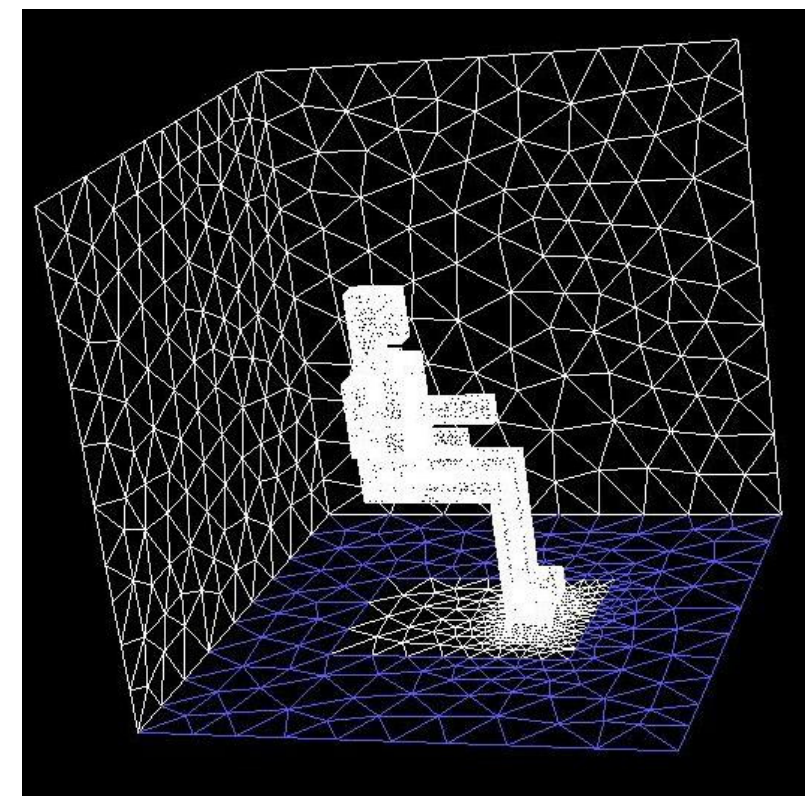

Figura 6.8 Malha tetraédrica com 230 mil elementos.

Foi utilizado modelo de gás ideal para o ar com modelo de turbulência k- $\varepsilon$ padrão e cálculo de troca térmica por radiação utilizando ordenadas discretas. Os $\mathrm{h}_{\text {cal }}$ foram calculados utilizando-se a equação 3.11 .

\section{Estudo do efeito do modelo de turbulência sobre os $\mathbf{h}_{\text {cal }}$}

O objetivo desta avaliação é verificar se existe grande influência dos modelos de turbulência no cálculo dos coeficiêntes de troca de calor de calibração e qual modelo apresenta melhor resultado. Para isto, resolveu-se utilizar malha de 230 mil elementos (Fig. 6.9), tetraédrica, sem camada de prismas, pois a mesma apresentou no estudo anterior as menores diferenças com os valores de $\mathrm{h}_{\mathrm{cal}}$ experimentais e apresentou convergência numérica mais rápida em função de ser a malha com menor número de elementos. Assim, utilizou-se as mesmas condições do estudo anterior para situação de verão. Os $\mathrm{h}_{\text {cal }}$ foram calculados utilizando-se a equação 3.11 . 


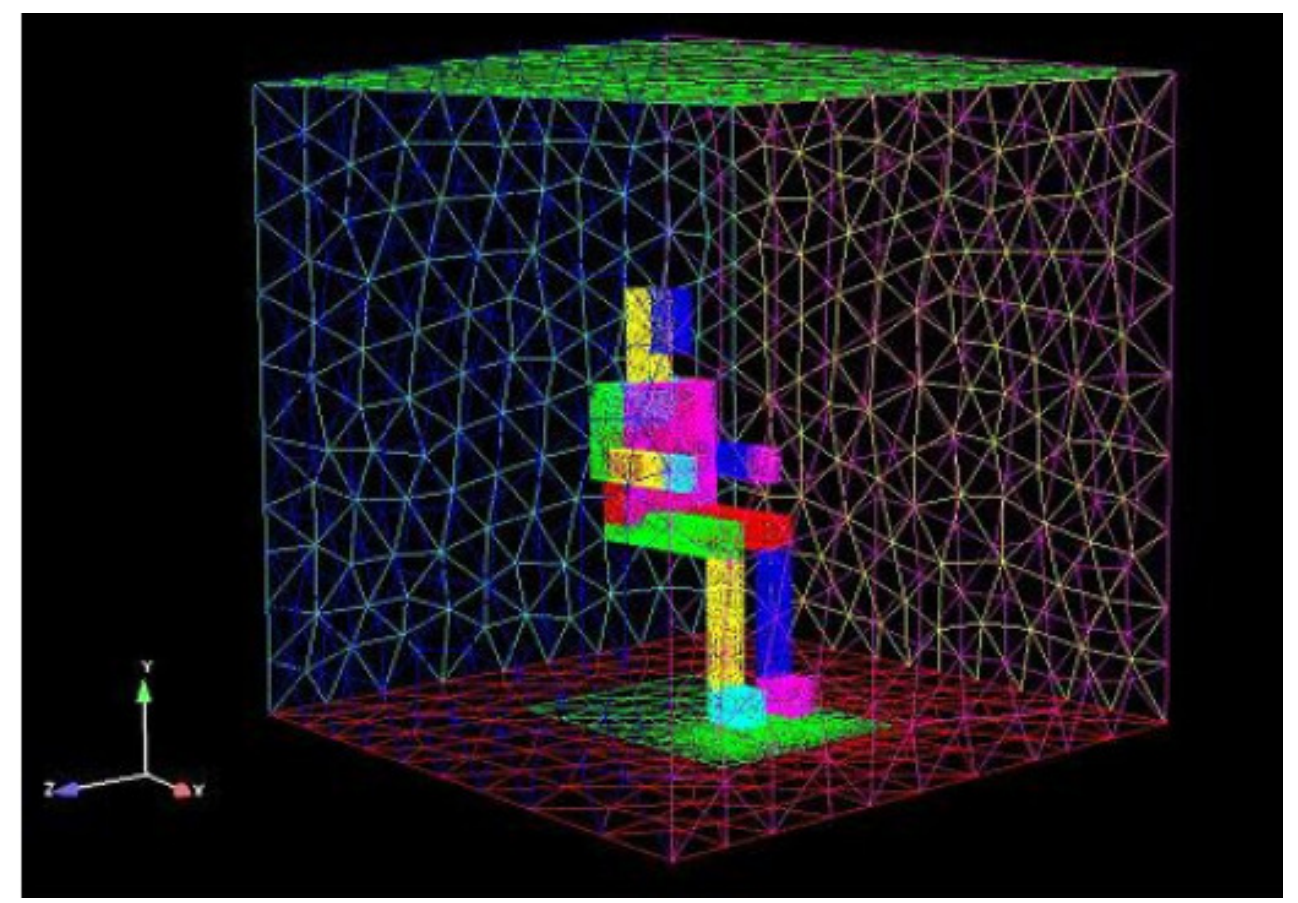

Figura 6.9 Malha de 230 mil elementos utilizada no estudo dos modelos de turbulência.

Estudou-se os cinco modelos de turbulência disponíveis no programa Fluent (2006) para simulação do escoamento em ambientes interiores:

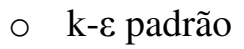
○ $\mathrm{k}-\varepsilon$ realizável
○ $\mathrm{k}-\varepsilon$ RNG
○ k- $\omega$ SST
○ k- $\omega$ padrão

\subsubsection{Avaliação de conforto térmico em aeronave com manequim digital 1}

As avaliações anteriores culminaram no desenvolvimento de um manequim térmico digital que apresentou bons resultados em código de CFD para avaliações das trocas térmicas por radiação e convecção. Estudos detalhados foram realizados para se determinar as melhores práticas com relação à refinamento de malha, modelos de turbulência e grau das interpolações. Decidiu-se avaliar numericamente o conforto na cabine anteriormente simulada em três situações: em solo, em vôo e em situação de pouca vazão de insuflamento (situação de emergência). 


\section{O manequim}

O manequim digital usado foi o descrito no item 6.2.3. Usou-se sobre cada parte uma resistência térmica diferente, iguais às utilizadas na calibração de verão descrita no item 6.2.3. A condição de contorno na superfície do manequim foi temperatura de superfície constante de $34{ }^{\circ} \mathrm{C}$, como nos casos anteriores.

\section{A cabine}

A geometria da cabine utilizada nas simulações é apresentada na figura 6.10.

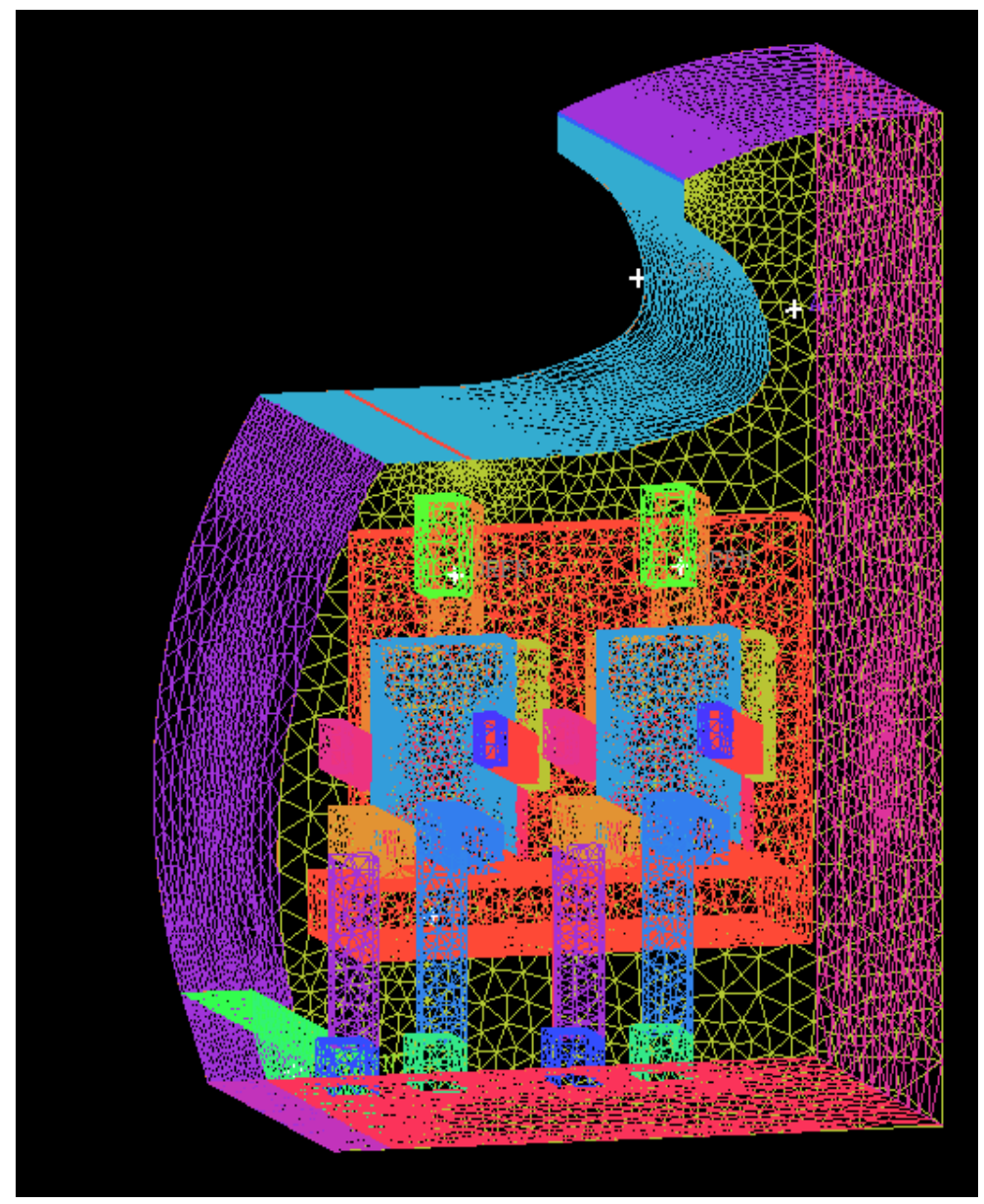

Figura 6.10 Cabine simétrica 
Foi utilizada a mesma geometria da cabine descrita nos itens anteriores, a menos do banco, e com a introdução de dois manequins digitais (Fig. 6.10). Como a cabine e as respectivas condições de contorno são simétricas, foi utilizado este fato para se criar uma seção lateral esquerda com um banco que se adaptasse aos novos dois manequins. Foi mantida a mesma largura e as espessuras medias do banco anterior com os manequins nos mesmos planos médios dos anteriores.

Dados dos bancos:

- Espessura do encosto vertical: $100 \mathrm{~mm}$

- Espessura do assento: $130 \mathrm{~mm}$

- Comprimento de encosto vertical: $890 \mathrm{~mm}$

- Comprimento do assento: $436 \mathrm{~mm}$

- Condutividade térmica do assento: $0,43 \mathrm{~W} / \mathrm{m}$. K

- Calor especifico da espuma: $1880 \mathrm{~J} / \mathrm{kg} \mathrm{K}$

- Densidade: $45 \mathrm{~kg} / \mathrm{m}^{3}$

Foi utilizada condição periódica na frente e traz com diferença de pressão nula. Foi utilizado o modelo de radiação de ordenadas discretas, como nos casos anteriores. O modelo de turbulência adotado foi o $\mathrm{k}-\varepsilon$ realizável.

\section{Simulações}

Foram considerados três casos para avaliação de conforto: situação em vôo de cruzeiro, em solo e em caso de falha do sistema de ar condicionado (emergência).

Para o caso de vôo foi considerado uma temperatura exterior da fuselagem igual à -40 ${ }^{\circ} \mathrm{C}$ e no caso em solo $42{ }^{\circ} \mathrm{C}$. Foi considerado uma espessura de parede de fuselagem igual à $0,15 \mathrm{~m}$ com isolamento em fibra de vidro (condutividade térmica de 0,038 W/m. K).

As condições de contorno das bocas de insuflamento e retorno foram iguais a dos casos anteriores, conforme item 6.2. Para a situação de emergência foi admitido uma vazão de 0,7 litros/s mínimo por pessoa (ASHRAE, 2004) fornecendo uma velocidade de $0,58 \mathrm{~m} / \mathrm{s}$ nas bocas de insuflamento com uma temperatura de $15^{\circ} \mathrm{C}$.

Para as simulações foi utilizada uma malha de 750 mil elementos que equivale às malhas rodadas anteriormente de 1,5 milhão. 


\subsection{SIMULAÇÃO DA CABINE CONSIDERANDO MOCK-UP INTEIRO}

Neste item irá se apresentar a geometria e malha, os modelos e condições de contorno utilizados para se calcular o campo de velocidades e temperaturas do ar nos experimentos realizados no mock-up experimental em três situações:
- Cabine sem ocupação em situação de vôo;
○ Cabine com ocupação em situação de solo;
○ Cabine com ocupação em situação de vôo.

\subsubsection{Geometrias, malhas e condições de contorno para cabine}

\section{Geometrias e malhas}

É apresentada a geometria da cabine com e sem ocupação respectivamente nas figuras 6.11 e 6.12. Os detalhes das malhas são apresentadas nas figuras 6.13 a 6.19 .

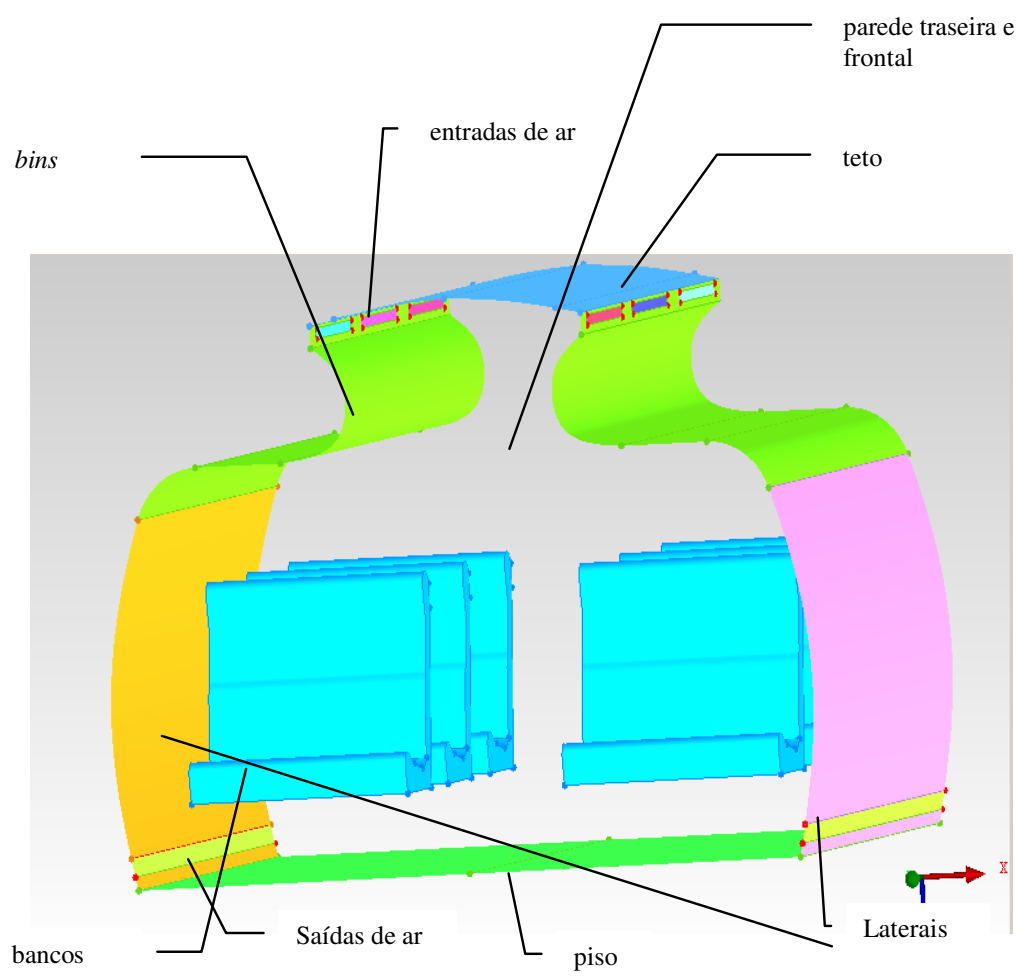

Figura 6.11 Superfícies da cabine virtual sem simuladores térmicos. 


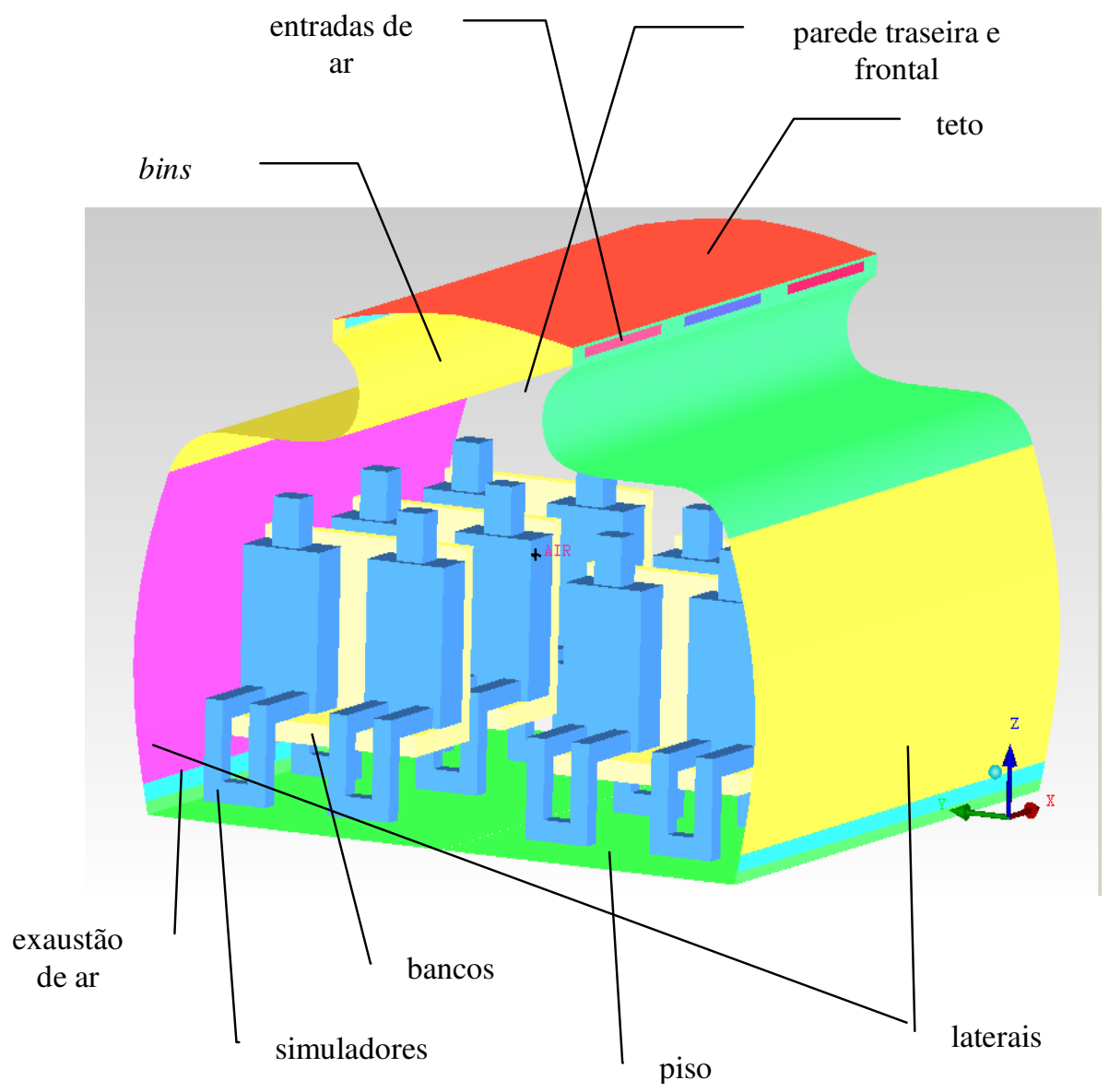

Figura 6.12 Geometria e superfícies da cabine virtual com simuladores térmicos

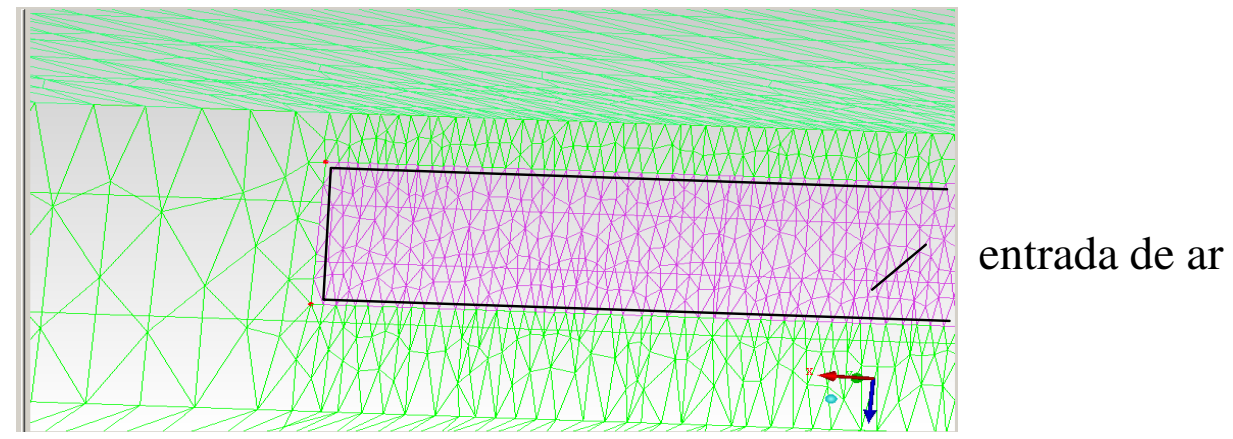

Figura 6.13 Detalhe da malha superficial nas entradas de ar sobre os bins. 


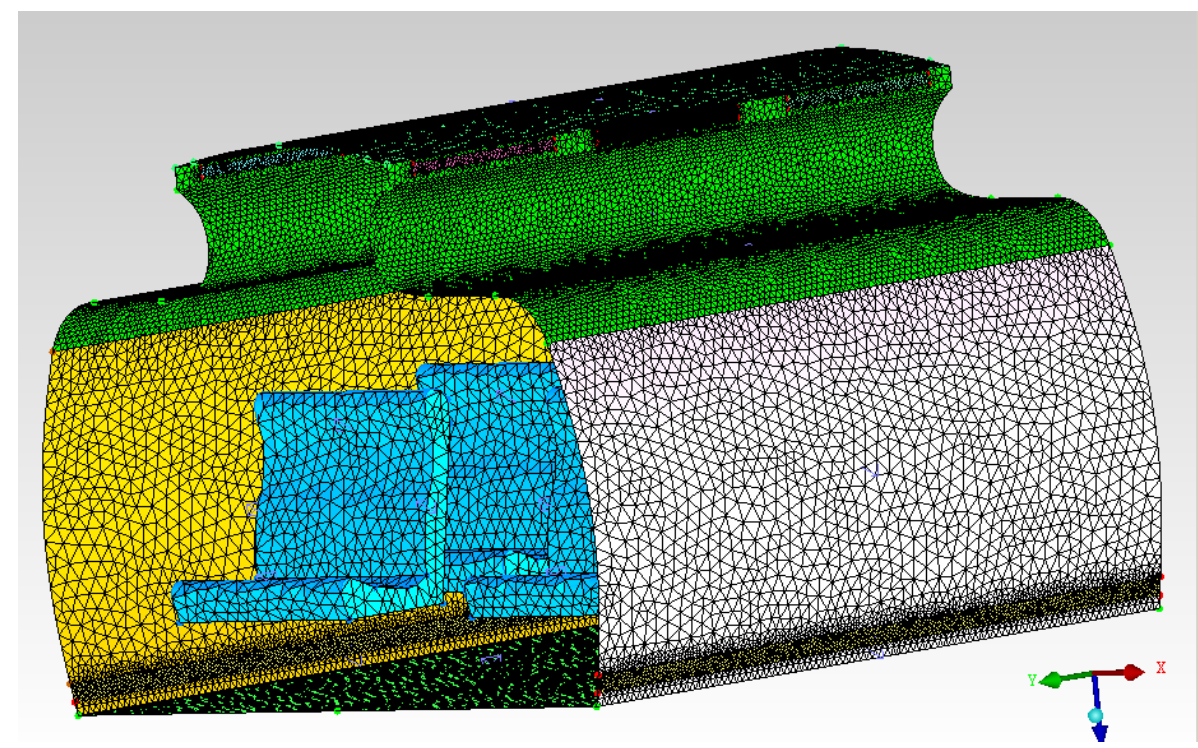

Figura 6.14 Malha gerada para a análise numérica de cabine sem ocupação.

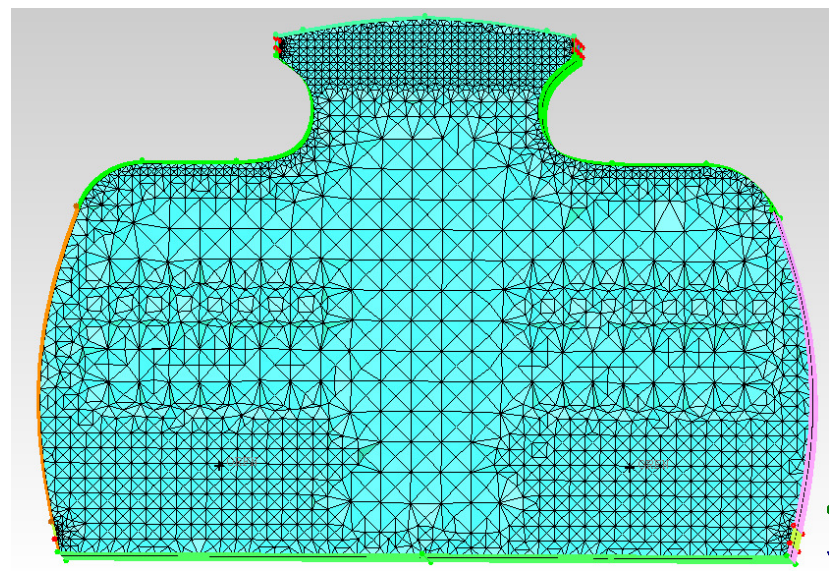

Figura 6.15 Seção da malha da cabine sem ocupação na posição da seção das avaliações numérica e experimental.

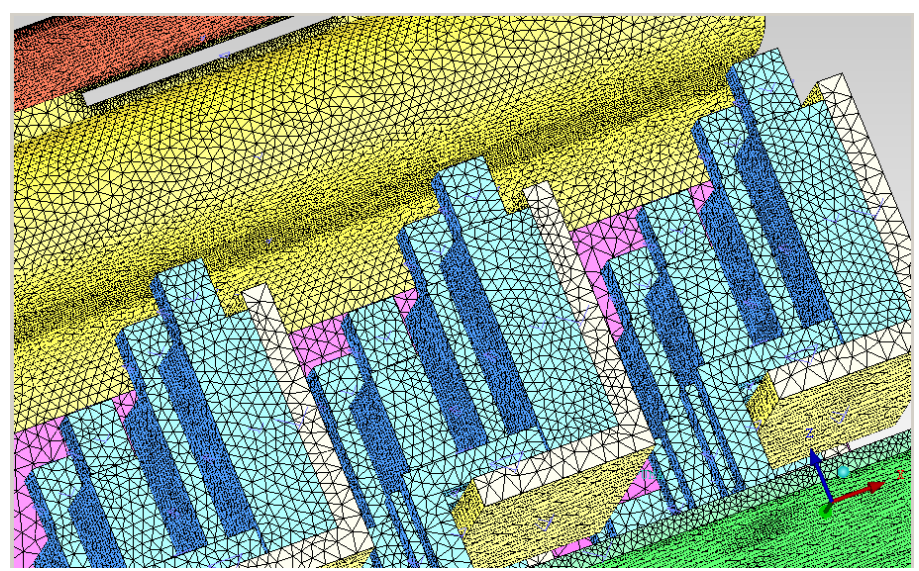

Figura 6.16 Malha superficial na cabine com os simuladores térmicos. 


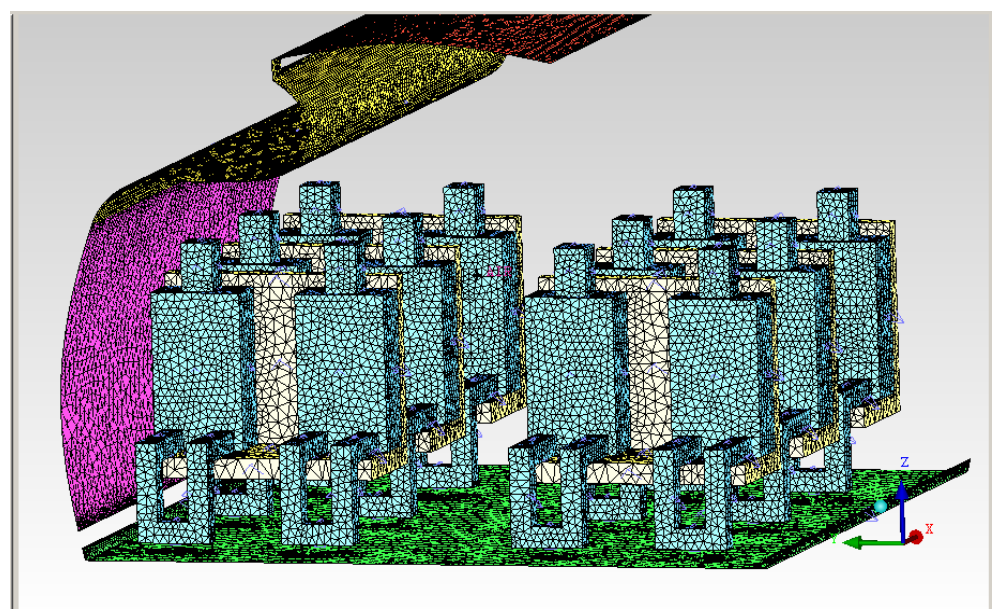

Figura 6.17 Geometria e malha utilizada nas simulações da cabine com os simuladores térmicos.

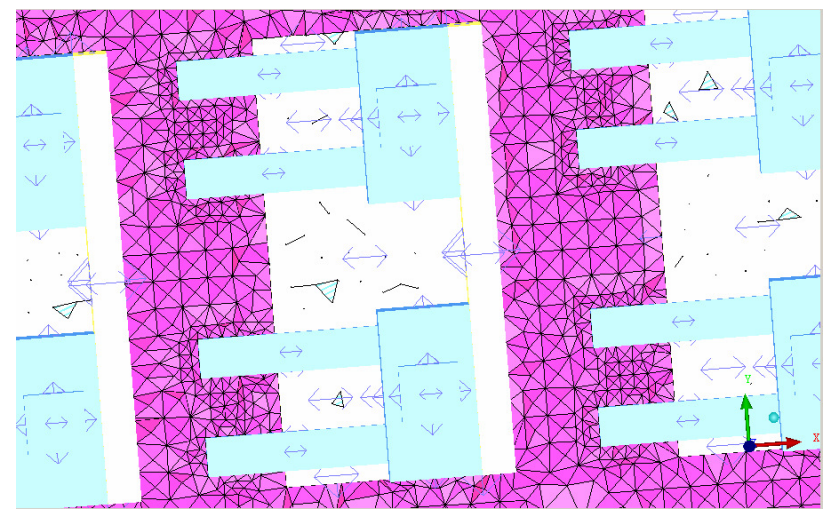

Figura 6.18 Corte horizontal na malha volumétrica de cabine com ocupação na altura dos joelhos.

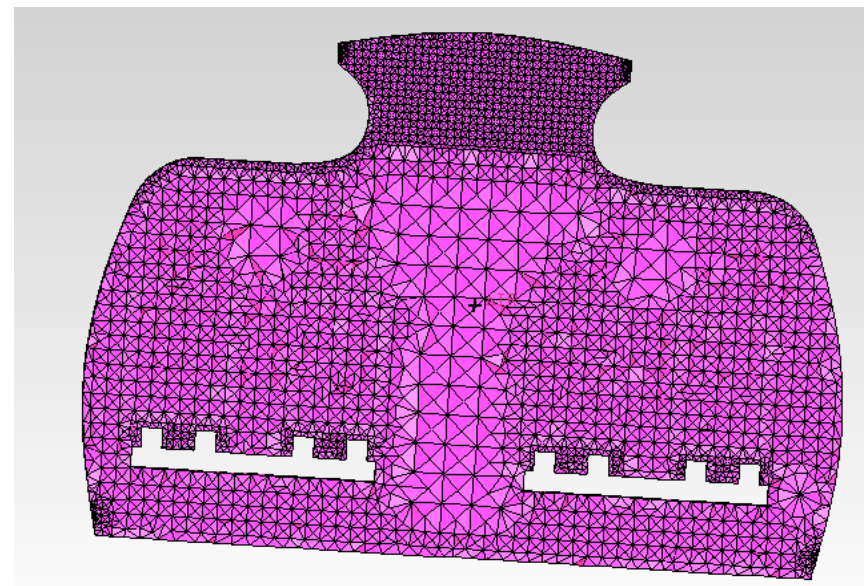

Figura 6.19 Corte vertical na altura dos joelhos em malha de cabine com ocupação. 
Procurou-se gerar uma geometria (Fig. 6.11) a mais fiel possível ao mock-up experimental, com as simplificações devidas. Não se modelou os pés dos bancos por simplificação da geometria e pelo possível baixo impacto no escoamento na parte debaixo dos bancos. As entradas de ar (Fig. 6.12) foram simuladas somente como uma entrada retangular, o que é muito próximo à realidade.

Foi construída uma malha de 1 milhão de elementos tetraédricos (Fig. 6.13) para a cabine sem ocupação. Todos os elementos tiveram uma qualidade maior que 0,4 . As entradas de ar foram discretizadas com elementos triangulares com arestas médias de $8 \mathrm{~mm}$ possuindo assim pelo menos 5 elementos na dimensão vertical das exaustões de ar (Fig. 6.12). As exaustões de ar foram modeladas com elementos triangulares com tamanho médio de $24 \mathrm{~mm}$, resultando com pelo menos 5 elementos na altura da exaustão.

A malha gerada para simulação do escoamento com ocupação possuiu 1,5 milhões de elementos. Nesta malha foram gerados elementos volumétricos nos bancos para se simular a condução de calor pela espuma. Todos os elementos tiveram uma qualidade maior que 0,3.

Foi aplicado um refinamento de malha na região do encontro dos dois jatos de ar para se captar esta interação como se pode notar na figura 6.14 e 6.19. A região entre o teto e o início do bin foi discretizada com elementos com tamanho médio de $32 \mathrm{~mm}$.

\section{Modelos e condições de contorno}

Nas simulações com programa Fluent (2006) foi utilizada solução implícita, regime permanente. Usou-se modelo de gás ideal para o ar com modelo de turbulência k- $\varepsilon$ realizável. Não se utilizou modelos de solução de radiação. As condições de contorno são apresentadas na Tabela 6.7. 
Tabela 6.7 Condições de contorno medidas e adotadas numericamente.

\begin{tabular}{|c|c|c|c|c|}
\hline Superfície & Condição de contorno & $\begin{array}{c}\text { Sem } \\
\text { ocupação }\end{array}$ & $\begin{array}{c}\text { Com } \\
\text { ocupação. } \\
\text { Solo }\end{array}$ & $\begin{array}{c}\text { Com } \\
\text { ocupação. } \\
\text { Vôo }\end{array}$ \\
\hline Piso & Temperatura prescrita & $21,5^{\circ} \mathrm{C}$ & $24,0^{\circ} \mathrm{C}$ & $20,0^{\circ} \mathrm{C}$ \\
\hline Bancos & & Adiabática & Mista & Mista \\
\hline Lateral esquerda & Temperatura prescrita & $21,7^{\circ} \mathrm{C}$ & $28,2^{\circ} \mathrm{C}$ & $21,8^{\circ} \mathrm{C}$ \\
\hline Lateral direita & Temperatura prescrita & 21,2 & 26,4 & 22,1 \\
\hline Teto & Temperatura prescrita & $22,3{ }^{\circ} \mathrm{C}$ & $22,5^{\circ} \mathrm{C}$ & $18,0{ }^{\circ} \mathrm{C}$ \\
\hline Parede dianteira & Temperatura prescrita & $22,4{ }^{\circ} \mathrm{C}$ & 26,4 & 22,4 \\
\hline Parede traseira & Temperatura prescrita & $23,4{ }^{\circ} \mathrm{C}$ & $25{ }^{\circ} \mathrm{C}$ & $20,0{ }^{\circ} \mathrm{C}$ \\
\hline Bins & Temperatura prescrita & $21,7^{\circ} \mathrm{C}$ & $22,1{ }^{\circ} \mathrm{C}$ & $19,0{ }^{\circ} \mathrm{C}$ \\
\hline Simuladores térmicos & Temperatura prescrita & inexistente & $34,0{ }^{\circ} \mathrm{C}$ & $29,0{ }^{\circ} \mathrm{C}$ \\
\hline Entrada de ar esquerda & $\begin{array}{l}\text { Velocidade perpendicular } \\
\text { prescrita }\end{array}$ & $\begin{array}{l}0,85 \mathrm{~m} / \mathrm{s} \mathrm{e} \\
21,6{ }^{\circ} \mathrm{C}\end{array}$ & $\begin{array}{l}0,85 \mathrm{~m} / \mathrm{s} \\
16,8^{\circ} \mathrm{C}\end{array}$ & $\begin{array}{l}0,85 \mathrm{~m} / \mathrm{s} \\
14,3{ }^{\circ} \mathrm{C}\end{array}$ \\
\hline Entrada d & $\begin{array}{l}\text { Velocidade perpendicular } \\
\text { prescrita }\end{array}$ & $\begin{array}{l}0,83 \mathrm{~m} / \mathrm{s} \mathrm{e} \\
21,3{ }^{\circ} \mathrm{C}\end{array}$ & $\begin{array}{l}0,83 \mathrm{~m} / \mathrm{s} \\
16,8^{\circ} \mathrm{C}\end{array}$ & $\begin{array}{l}0,83 \mathrm{~m} / \mathrm{s} \\
14,3{ }^{\circ} \mathrm{C}\end{array}$ \\
\hline Entrada d & $\begin{array}{l}\text { Velocidade perpendicular } \\
\text { prescrita }\end{array}$ & $\begin{array}{l}0,83 \mathrm{~m} / \mathrm{s} \\
21,5^{\circ} \mathrm{C}\end{array}$ & $\begin{array}{l}0,83 \mathrm{~m} / \mathrm{s} \\
16,8^{\circ} \mathrm{C}\end{array}$ & $\begin{array}{l}0,83 \mathrm{~m} / \mathrm{s} \\
13,8^{\circ} \mathrm{C}\end{array}$ \\
\hline Entrada de a & $\begin{array}{l}\text { Velocidade perpendicular } \\
\text { prescrita }\end{array}$ & $\begin{array}{l}1,00 \mathrm{~m} / \mathrm{s} \mathrm{e} \\
21,2{ }^{\circ} \mathrm{C}\end{array}$ & $\begin{array}{l}1,00 \mathrm{~m} / \mathrm{s} \\
16,0{ }^{\circ} \mathrm{C}\end{array}$ & $\begin{array}{l}1,10 \mathrm{~m} / \mathrm{s} \\
14,3^{\circ} \mathrm{C}\end{array}$ \\
\hline Entrada de ar direita 2 & $\begin{array}{l}\text { Velocidade perpendicular } \\
\text { prescrita }\end{array}$ & $\begin{array}{l}1,11 \mathrm{~m} / \mathrm{s} \mathrm{e} \\
20,8^{\circ} \mathrm{C}\end{array}$ & $\begin{array}{l}1,11 \mathrm{~m} / \mathrm{s} \\
16,0{ }^{\circ} \mathrm{C}\end{array}$ & $\begin{array}{l}1,11 \mathrm{~m} / \mathrm{s} \\
14,0{ }^{\circ} \mathrm{C}\end{array}$ \\
\hline Entrada de ar direita 3 & $\begin{array}{l}\text { Velocidade perpendicular } \\
\text { prescrita }\end{array}$ & $\begin{array}{l}1,10 \mathrm{~m} / \mathrm{s} \mathrm{e} \\
20,7^{\circ} \mathrm{C}\end{array}$ & $\begin{array}{l}1,10 \mathrm{~m} / \mathrm{s} \\
16,0^{\circ} \mathrm{C}\end{array}$ & $\begin{array}{l}1,00 \mathrm{~m} / \mathrm{s} \\
13,4^{\circ} \mathrm{C}\end{array}$ \\
\hline Exaustão de ar & $\begin{array}{l}\text { Exaustão com pressão } \\
\text { prescrita }\end{array}$ & $0 \mathrm{~Pa}$ & $0 \mathrm{~Pa}$ & $0 \mathrm{~Pa}$ \\
\hline
\end{tabular}

O banco da malha da cabine com ocupação foi modelado com condição de contorno mista ,ou seja, condução pela malha interna do banco e convecção com o ar. Foi adotado uma condutividade de $0,04 \mathrm{~W} / \mathrm{m} \mathrm{K}$ para o material do banco.

\subsubsection{Calibração de manequim digital 2}

A fim de se fazer os cálculos numéricos de temperatura equivalente em cabine decidiu-se construir um novo manequim com uma geometria mais próxima do corpo humano, mantendo-se somente algumas simplificações geométricas como ausência de detalhes na face, dedos individuais nos pés e mãos, tronco facetado.

\section{Geometria, malha e condições de contorno.}

Procurou-se gerar um manequim com maior representatividade do corpo humano como se pode observar na fig. 6.20: 


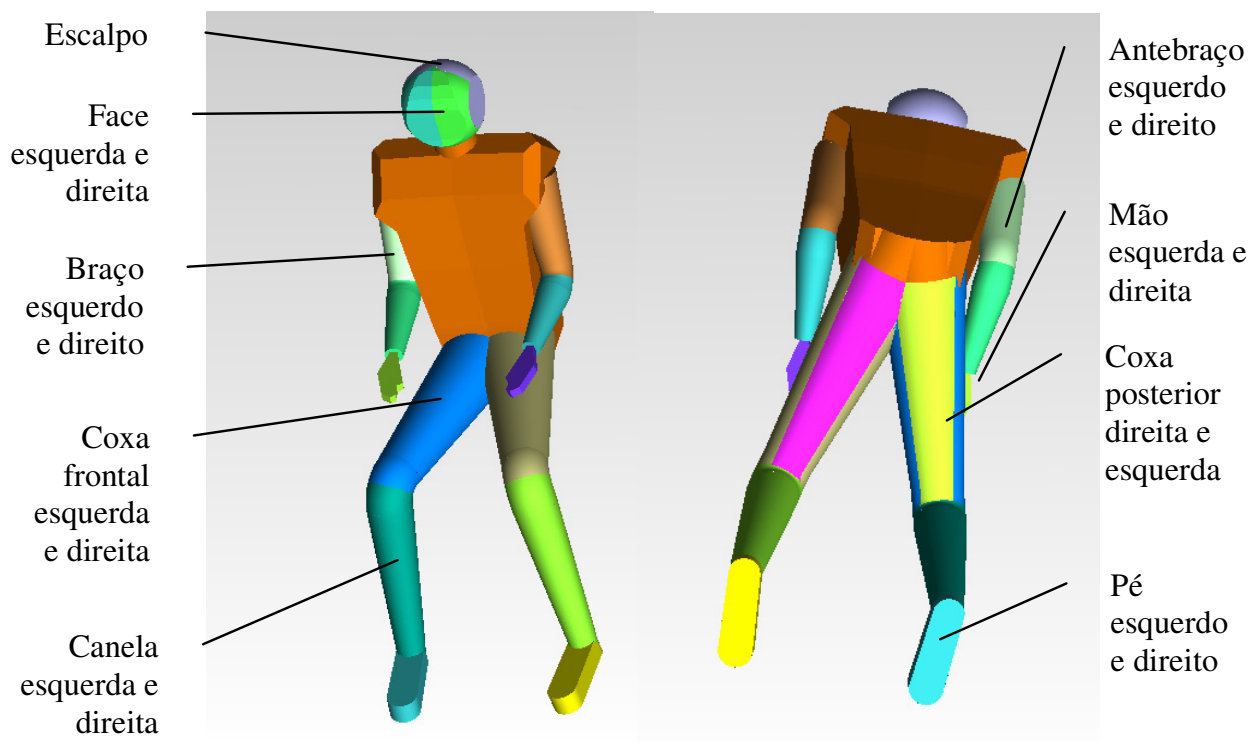

Figura 6.20 Partes do manequim digital 2.

As áreas de cada parte do manequim está na Tabela 6.8

Tabela 6.8 Áreas do manequim virtual 2.

\begin{tabular}{cc}
\hline Partes & Área $\left(\mathrm{m}^{2}\right)$ \\
\hline anteb.dir. & 0,042 \\
anteb.esq. & 0,042 \\
braço dir. & 0,045 \\
braço esq. & 0,045 \\
escalpo & 0,063 \\
canela dir. & 0,112 \\
canela esq. & 0,112 \\
coxa fron. dir. & 0,129 \\
coxa fron.esq. & 0,129 \\
coxa pos.dir. & 0,044 \\
coxa pos.esq. & 0,044 \\
face dir. & 0,019 \\
face esq. & 0,019 \\
mão dir. & 0,016 \\
mão esq. & 0,016 \\
pé dir. & 0,046 \\
pé esq. & 0,046 \\
\hline
\end{tabular}

Colocou-se este manequim centrado em uma sala cúbica com 3 metros de aresta. Sob o manequim foi colocado um tapete de $1 \mathrm{~m}$ por $1,5 \mathrm{~m}$. Os pés ficaram $0,1 \mathrm{~m}$ acima do tapete.A figura da malha gerada e as superfícies são apresentadas na fig. 6.21. 


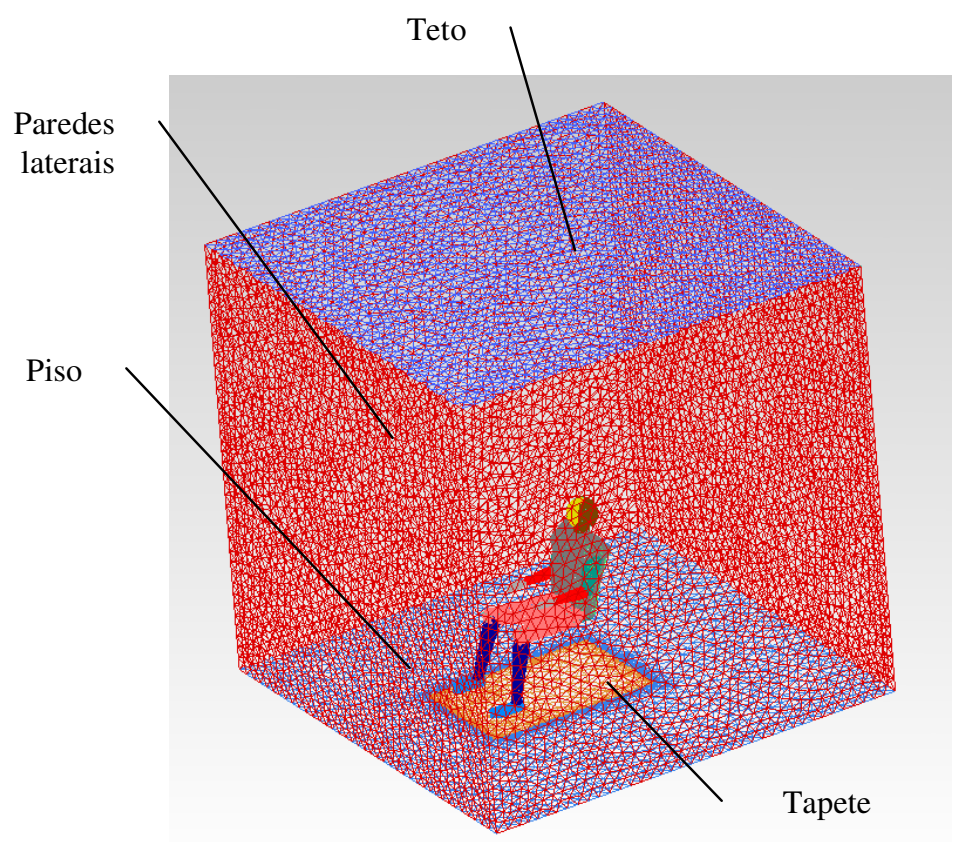

Figura 6.21 Superfícies no volume de calibração.

Foi gerada uma malha com 900 mil elementos e utilizou-se o mesmo refinamento superficial, condições de contorno e modelos do estudo de modelos de turbulência na calibração do item 6.2.3 a menos da resistência da roupa sobre o manequim, que não houve pois assim é possível se comparar os $\mathrm{h}_{\text {cal }}$ da simulação com os medidos na calibração descrita no item 5.2.2. Foi utilizado modelo de turbulência k-E realizável.

\subsection{SIMULAÇÃO DAS TEMPERATURAS EQUIVALENTES COM MANEQUIM DIGITAL 2}

Neste item se descreve as simulações numéricas com o objetivo de se determinar as temperaturas equivalentes nos mesmos segmentos do manequim experimental. Os cálculos foram realizados com o manequim digital nas mesmas posições adotadas na avaliação experimental. Assim, foram feitas duas geometrias, uma com o manequim sentado junto à fuselagem e outra junto ao corredor. 


\subsubsection{Geometria e malhas}

Usou-se geometria idêntica do mock-up virtual descrito no item 6.3.1. A geometrias são apresentadas nas figuras 6.22 e 6.23 :

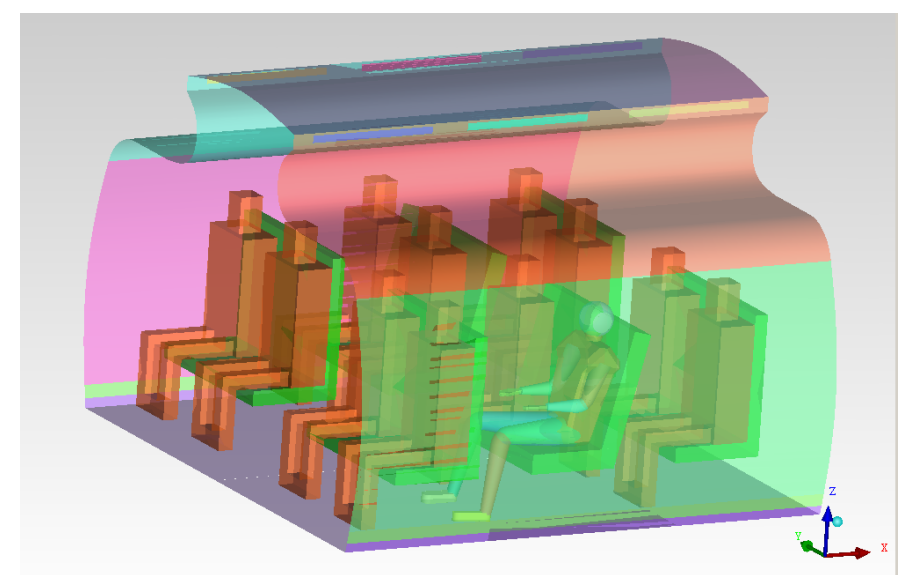

Figura 6.22. Manequim térmico sentado junto à fuselagem.

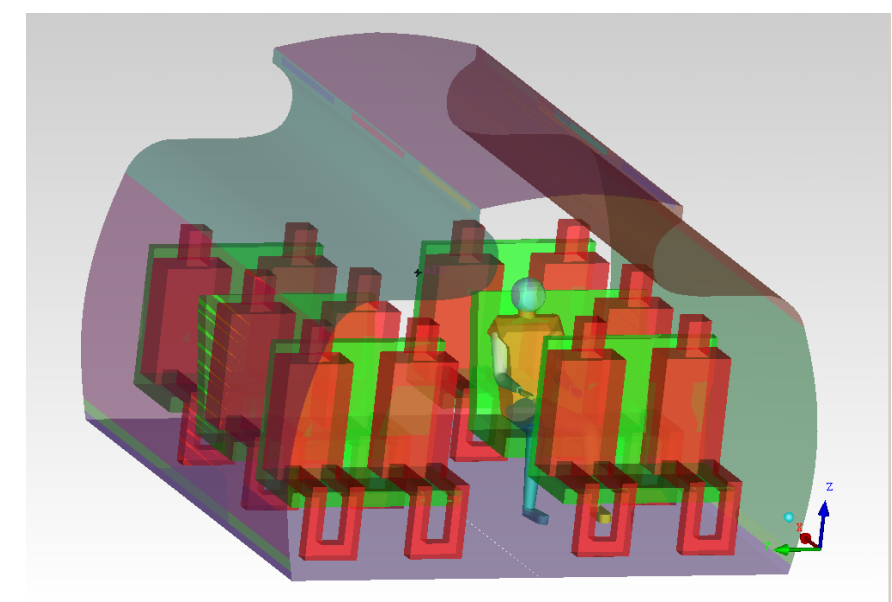

Figura 6.23. Manequim térmico sentado ao lado do corredor.

Os assentos na fileira do meio foram colocados com encosto vertical inclinado para melhor representatividade com os bancos do mock-up experimental. O manequim teve parte da coxa posterior e costas em contato com o assento para simular áreas em contato com o banco como se pode observar na figura 6.24. 


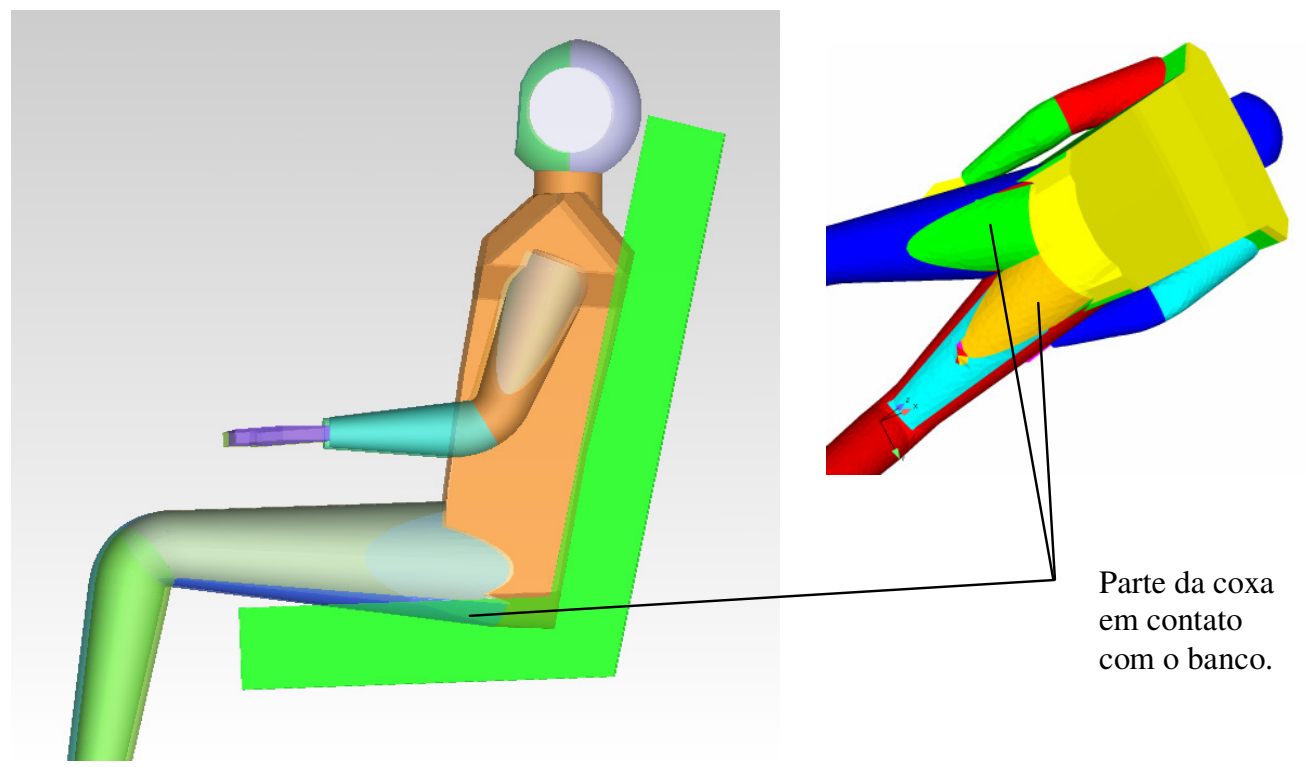

Figura 6.24 Superfície da coxa em contato com o banco.

As malhas para as duas geometrias tiveram os mesmos níveis de refinamento das malhas utilizadas para simulação e avaliação do escoamento da cabine, descrita no item 6.3.1. No manequim foi aplicado o mesmo nível de refinamento achado bom no item 6.2.3 referente ao estudo de modelos de turbulência na calibração, ou seja tamanhos médios de $20 \mathrm{~mm}$. A malha superficial sobre o manequim é apresentada na fig. 6.25 .

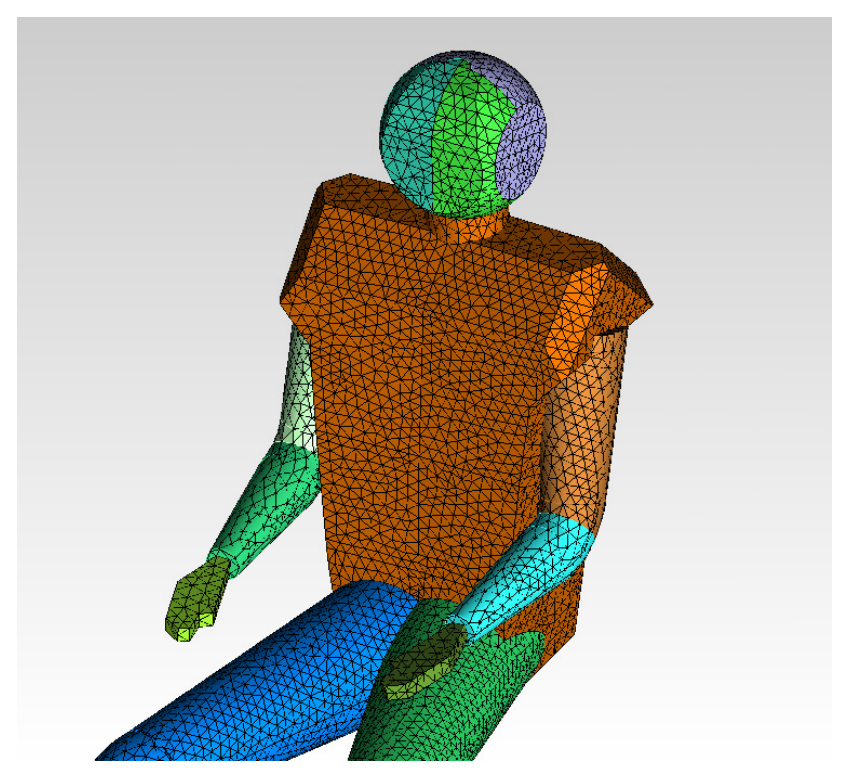

Figura 6.25 Malha superficial sobre o manequim. 
Foi aplicado um refinamento volumétrico na região dos jatos na parte central da cabine com elementos tetraédricos com tamanho médio de $16 \mathrm{~mm}$. As entradas de ar centrais foram refinadas com elementos com tamanho médio de $8 \mathrm{~mm}$ e os as entradas laterais com 16 mm. Malha superficial nas superfícies do mock-up é apresentada na fig. 6.26.

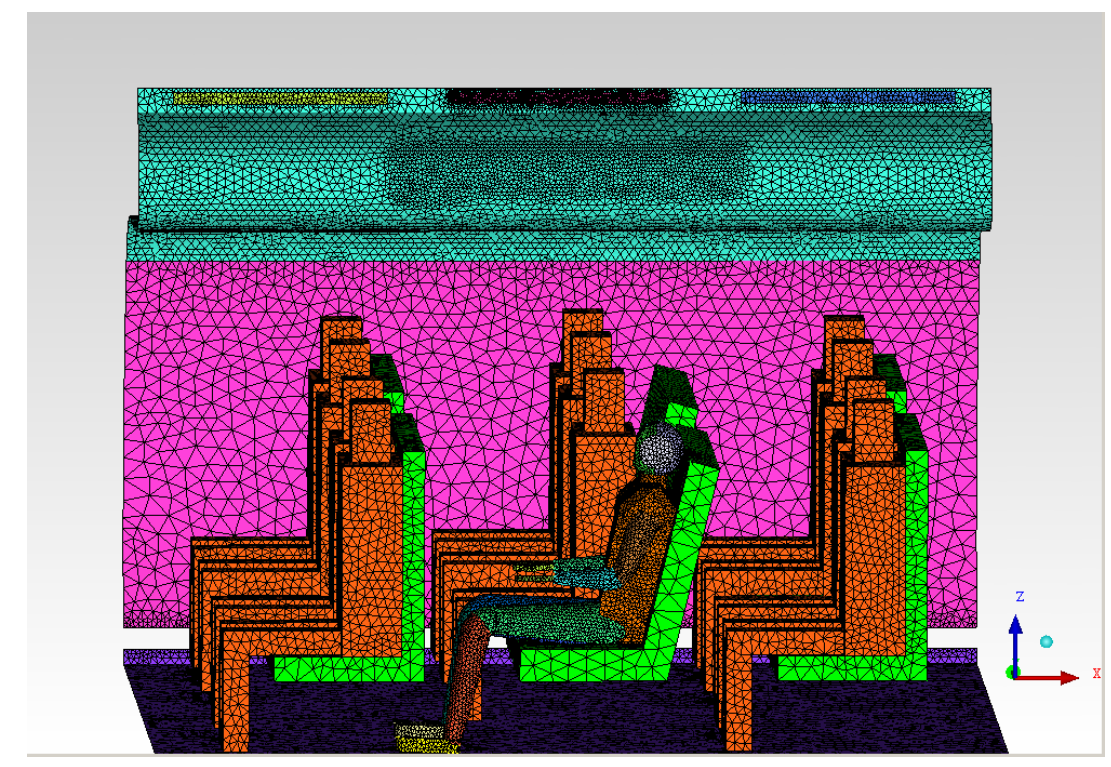

Figura 6.26 Malha superficial nas superfícies do mock-up.

\subsubsection{Modelos e condições de contorno}

Utilizou-se solução implícita, regime permanente solucionando-se as equações de quantidade de movimento, energia, turbulência e radiação. Foi utilizado o modelo de gás ideal para o ar com modelo de turbulência k- $\varepsilon$ realizável e adotado modelo de radiação de ordenadas discretas. Todas as superfícies tiveram suas emissividades adotadas como 0,95. Foi adotado um índice de turbulência de $10 \%$ e diâmetro hidráulico de $0,04 \mathrm{~m}$ para todas as entradas. Foi adotada condição de contorno mista para o banco com condutividade interna de $0,04 \mathrm{~W} / \mathrm{m} . \mathrm{K}$.

O valor de cada condição de contorno adotado corresponde a valores médios medidos no ensaio. 
As condições de contorno específicas são apresentadas na tabela 6.9.

Tabela 6.9 Condições de contorno medidas e adotadas numericamente.

\begin{tabular}{|c|c|c|c|c|}
\hline Superfície & $\begin{array}{l}\text { Condição de } \\
\text { contorno }\end{array}$ & $70 \mathrm{~W} / \mathrm{m}^{2}$ & $50 \mathrm{~W} / \mathrm{m}^{2}$ & $0 \mathrm{~W} / \mathrm{m}^{2}$ \\
\hline Piso & Temperatura prescrita & $25,0{ }^{\circ} \mathrm{C}$ & $20,6^{\circ} \mathrm{C}$ & $17,8^{\circ} \mathrm{C}$ \\
\hline Bancos & Mista & & & \\
\hline Lateral esquerda & Temperatura prescrita & $29,1{ }^{\circ} \mathrm{C}$ & $23,8^{\circ} \mathrm{C}$ & $20,3{ }^{\circ} \mathrm{C}$ \\
\hline Lateral direita & Temperatura prescrita & $28,1{ }^{\circ} \mathrm{C}$ & $22,6^{\circ} \mathrm{C}$ & $17,0^{\circ} \mathrm{C}$ \\
\hline Teto & Temperatura prescrita & $23,0^{\circ} \mathrm{C}$ & $19,5^{\circ} \mathrm{C}$ & $16,2^{\circ} \mathrm{C}$ \\
\hline Parede dianteira & Temperatura prescrita & $25,0{ }^{\circ} \mathrm{C}$ & $22,0{ }^{\circ} \mathrm{C}$ & $17,5^{\circ} \mathrm{C}$ \\
\hline Parede traseira & Temperatura prescrita & $25,0^{\circ} \mathrm{C}$ & $22,0^{\circ} \mathrm{C}$ & $17,5^{\circ} \mathrm{C}$ \\
\hline Bins & Temperatura prescrita & $24,0^{\circ} \mathrm{C}$ & $20,6^{\circ} \mathrm{C}$ & $17,0^{\circ} \mathrm{C}$ \\
\hline Manequim térmico 2 & Temperatura prescrita & $34,0^{\circ} \mathrm{C}$ & $34,0{ }^{\circ} \mathrm{C}$ & $34,0{ }^{\circ} \mathrm{C}$ \\
\hline $\begin{array}{l}\text { Simuladores } \\
\text { térmicos }\end{array}$ & $\begin{array}{l}\text { Temperatura prescrita } \\
\text { / adiabático }\end{array}$ & $47,0^{\circ} \mathrm{C}$ & $34,0{ }^{\circ} \mathrm{C}$ & Adiabático \\
\hline $\begin{array}{l}\text { Entrada de ar } \\
\text { esquerda } 1\end{array}$ & $\begin{array}{l}\text { Velocidade } \\
\text { perpendicular } \\
\text { prescrita }\end{array}$ & $\begin{array}{l}0,85 \mathrm{~m} / \mathrm{s} \mathrm{e} \\
15,6{ }^{\circ} \mathrm{C}\end{array}$ & $\begin{array}{l}0,85 \\
\mathrm{~m} / \mathrm{s}, 14,2 \\
{ }^{\circ} \mathrm{C}\end{array}$ & $\begin{array}{l}0,85 \mathrm{~m} / \mathrm{s} \\
13,7^{\circ} \mathrm{C}\end{array}$ \\
\hline $\begin{array}{l}\text { Entrada de ar } \\
\text { esquerda } 2\end{array}$ & $\begin{array}{l}\text { Velocidade } \\
\text { perpendicular } \\
\text { prescrita }\end{array}$ & $\begin{array}{l}0,83 \mathrm{~m} / \mathrm{s} \mathrm{e} \\
15,6^{\circ} \mathrm{C}\end{array}$ & $\begin{array}{l}0,83 \mathrm{~m} / \mathrm{s} \\
14,2{ }^{\circ} \mathrm{C}\end{array}$ & $\begin{array}{l}0,83 \mathrm{~m} / \mathrm{s} \\
13,4{ }^{\circ} \mathrm{C}\end{array}$ \\
\hline $\begin{array}{l}\text { Entrada de ar } \\
\text { esquerda } 3\end{array}$ & $\begin{array}{l}\text { Velocidade } \\
\text { perpendicular } \\
\text { prescrita }\end{array}$ & $\begin{array}{l}0,83 \mathrm{~m} / \mathrm{s} \\
15,7^{\circ} \mathrm{C}\end{array}$ & $\begin{array}{l}0,83 \mathrm{~m} / \mathrm{s} \\
14,2{ }^{\circ} \mathrm{C}\end{array}$ & $\begin{array}{l}0,83 \mathrm{~m} / \mathrm{s} \\
13,9{ }^{\circ} \mathrm{C}\end{array}$ \\
\hline $\begin{array}{l}\text { Entrada de ar direita } \\
1\end{array}$ & $\begin{array}{l}\text { Velocidade } \\
\text { perpendicular } \\
\text { prescrita }\end{array}$ & $\begin{array}{l}1,00 \mathrm{~m} / \mathrm{s} \mathrm{e} \\
15,8^{\circ} \mathrm{C}\end{array}$ & $\begin{array}{l}1,10 \mathrm{~m} / \mathrm{s} \\
14,1^{\circ} \mathrm{C}\end{array}$ & $\begin{array}{l}1,10 \mathrm{~m} / \mathrm{s} \\
13,9^{\circ} \mathrm{C}\end{array}$ \\
\hline $\begin{array}{l}\text { Entrada de ar direita } \\
2\end{array}$ & $\begin{array}{l}\text { Velocidade } \\
\text { perpendicular } \\
\text { prescrita }\end{array}$ & $\begin{array}{l}1,11 \mathrm{~m} / \mathrm{s} \mathrm{e} \\
15,8^{\circ} \mathrm{C}\end{array}$ & $\begin{array}{l}1,11 \\
\mathrm{~m} / \mathrm{s}, 14,2 \\
{ }^{\circ} \mathrm{C}\end{array}$ & $\begin{array}{l}1,11 \mathrm{~m} / \mathrm{s} \\
13,7^{\circ} \mathrm{C}\end{array}$ \\
\hline $\begin{array}{l}\text { Entrada de ar direita } \\
3\end{array}$ & $\begin{array}{l}\text { Velocidade } \\
\text { perpendicular } \\
\text { prescrita }\end{array}$ & $\begin{array}{l}1,10 \mathrm{~m} / \mathrm{s} \mathrm{e} \\
15,5{ }^{\circ} \mathrm{C}\end{array}$ & $\begin{array}{l}1,00 \mathrm{~m} / \mathrm{s} \\
14,2{ }^{\circ} \mathrm{C}\end{array}$ & $\begin{array}{l}1,00 \mathrm{~m} / \mathrm{s} \\
13,6^{\circ} \mathrm{C}\end{array}$ \\
\hline Exaustão de ar & $\begin{array}{l}\text { Exaustão com pressão } \\
\text { prescrita }\end{array}$ & $0 \mathrm{~Pa}$ & $0 \mathrm{~Pa}$ & $0 \mathrm{~Pa}$ \\
\hline
\end{tabular}




\section{Capítulo 7}

\section{$7 \quad$ Resultados}

O objetivo deste capítulo é apresentar os resultados das avaliações descritas no capítulo 5 e 6 . Inicialmente, são apresentados os resultados das simulações em cabine considerando uma fileira de bancos. Em seguida, são apresentados os resultados considerando cabine completa. Os resultados estão agrupados por experimentos para facilitar a comparação dos resultados numéricos e experimentais, quando houver. $\mathrm{O}$ conjunto de resultados numéricos e experimentais aqui apresentados constituem-se em um embrião de uma metodologia numérica para avaliação de ambiente térmico em cabines de aeronaves.

\subsection{RESULTADOS DAS AVALIAÇÕES CONSIDERANDO UMA FILEIRA DE BANCOS.}

O objetivo deste item é apresentar os resultados das simulações da cabine considerando uma fileira de bancos, conforme descrito no capítulo 6. Os resultados estão na mesma seqüência do capítulo 6 e seguem ordem de estudos com complexidade crescente, culminando em uma avaliação de conforto térmico numérico. O conjunto de resultados pode ser considerado como um embrião de uma metodologia de avaliação numérica de conforto em aeronaves.

\subsubsection{Resultados do estudo de influência de malha no escoamento}

Os resultados a seguir se referem ao estudo descrito no Capítulo 6, item 6.2.1.

Nas Figuras 7.1 a 7.6 são apresentados campos de temperaturas e de velocidades do ar em uma seção da cabine. Para evidenciar as variações de temperaturas e velocidades do ar na cabine, os manequins e bancos são apresentados nas cores azul e vermelho, respectivamente 


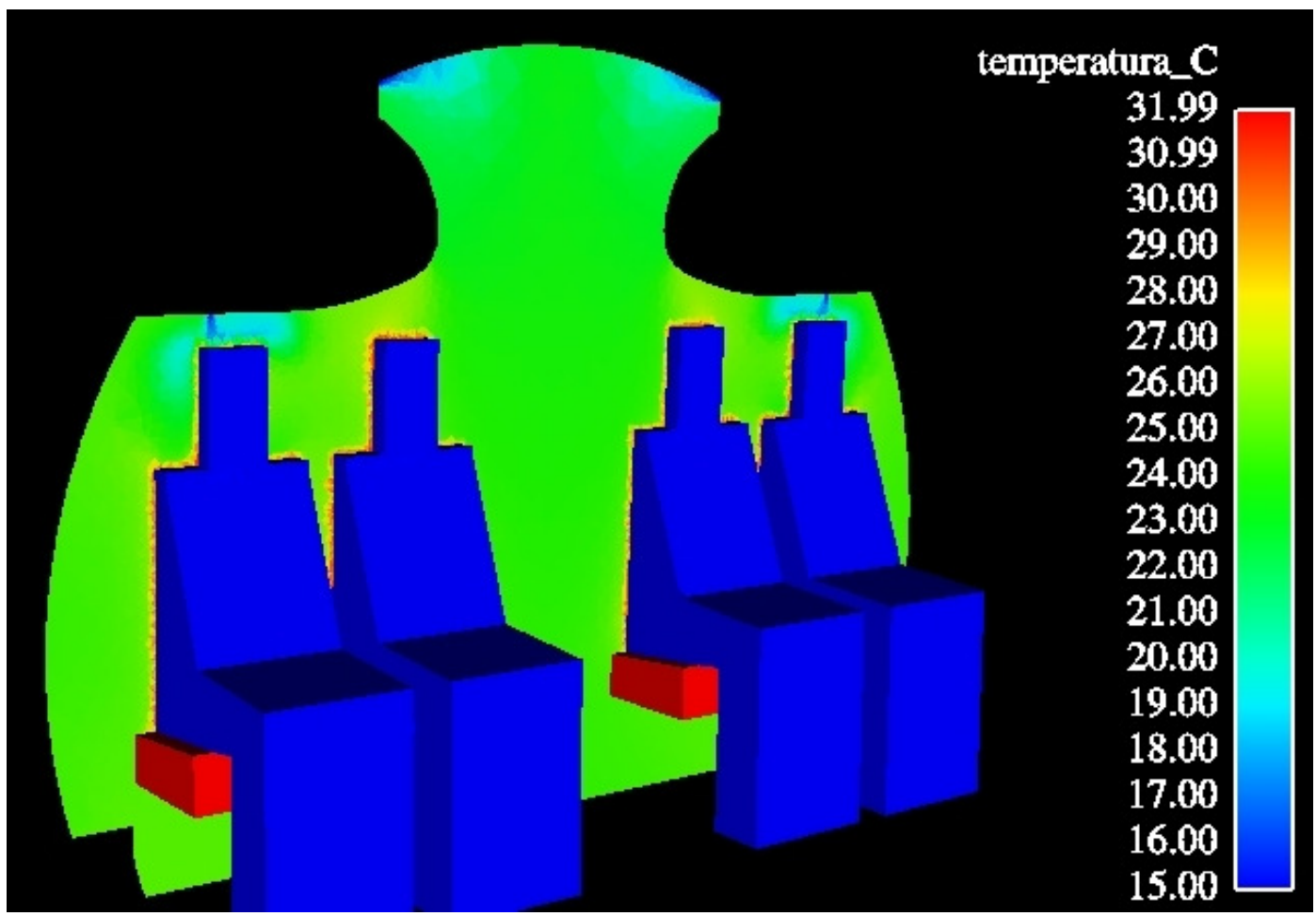

Figura 7.1 Distribuição de temperaturas do ar em corte transversal da cabine

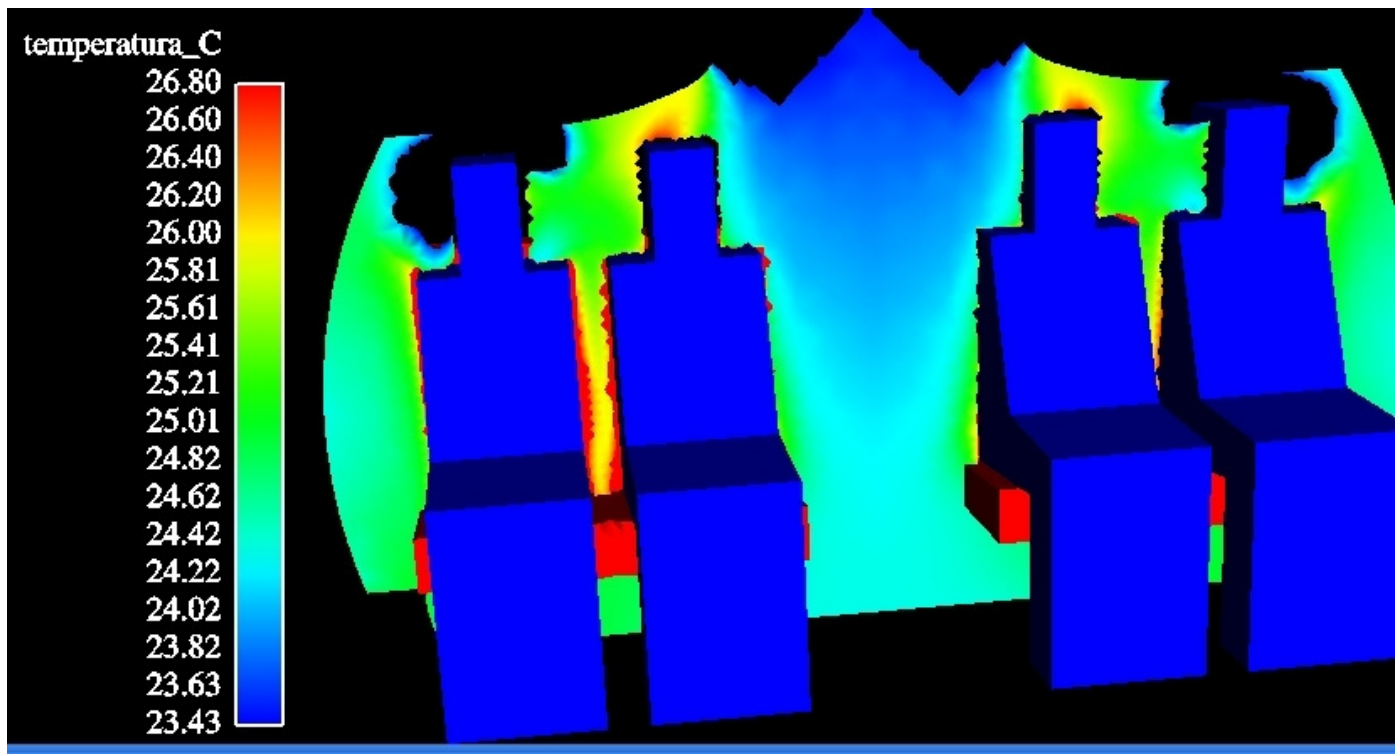

Figura 7.2 Camadas térmicas junto aos manequins. 


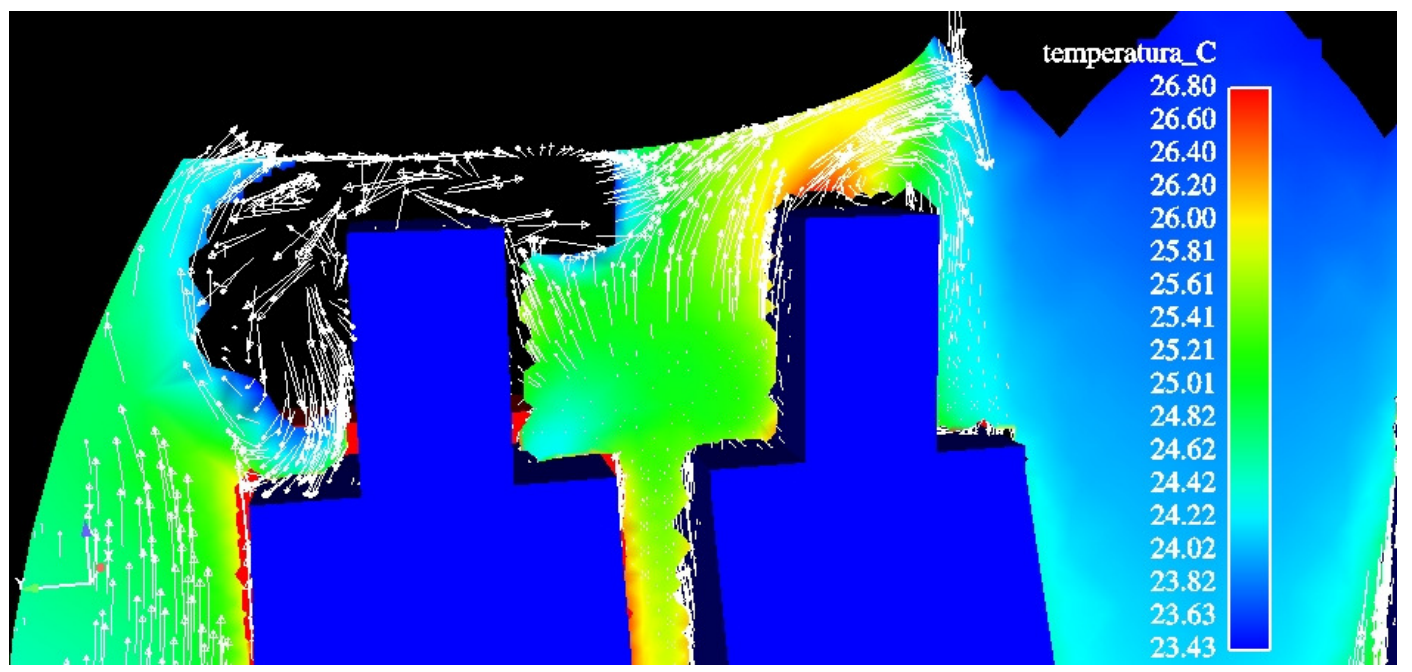

Figura 7.3 Zonas de recirculação do ar junto às cabeças dos manequins.

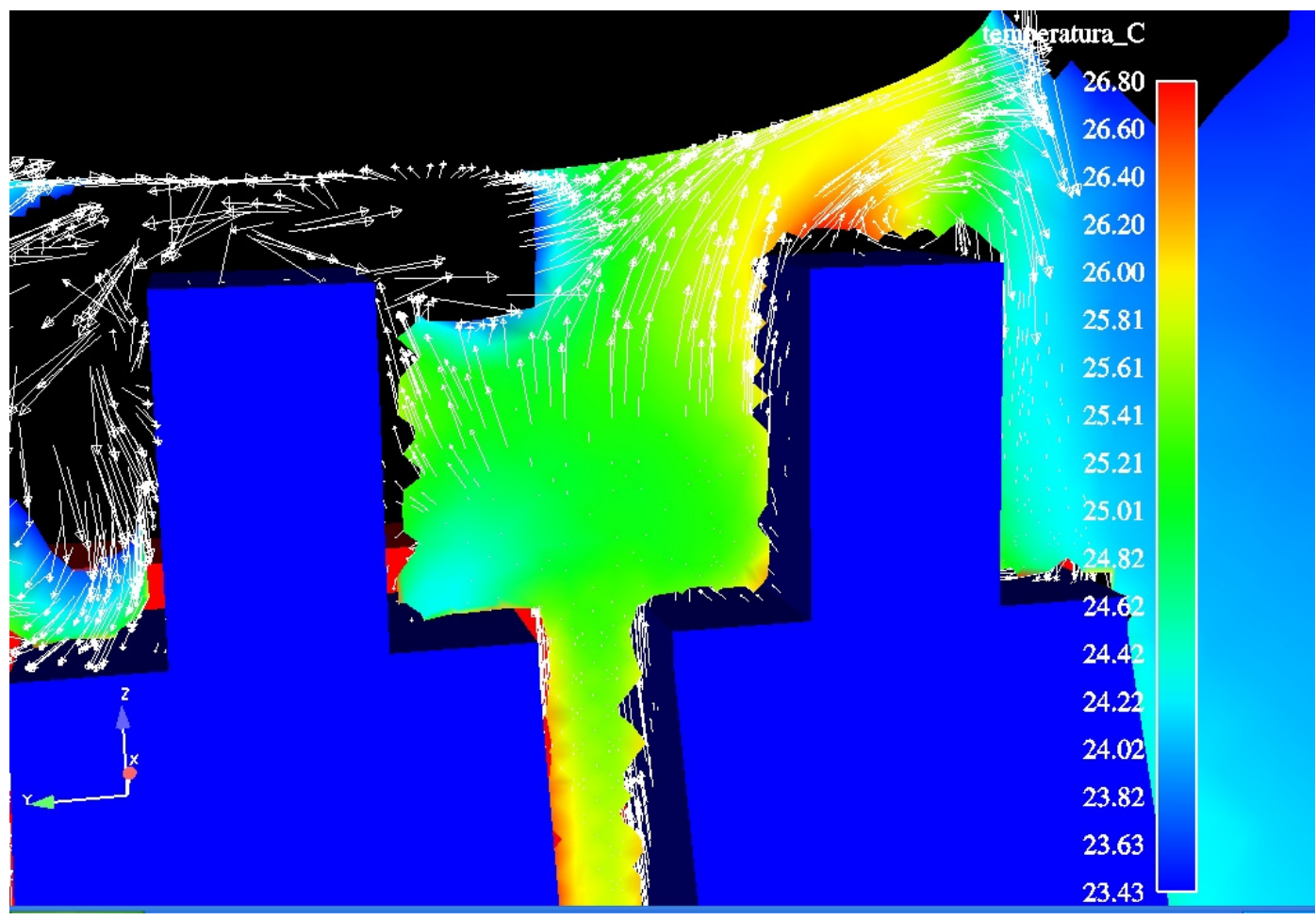

Figura 7.4 Detalhe da recirculação do ar sobre a cabeça do manequim. 


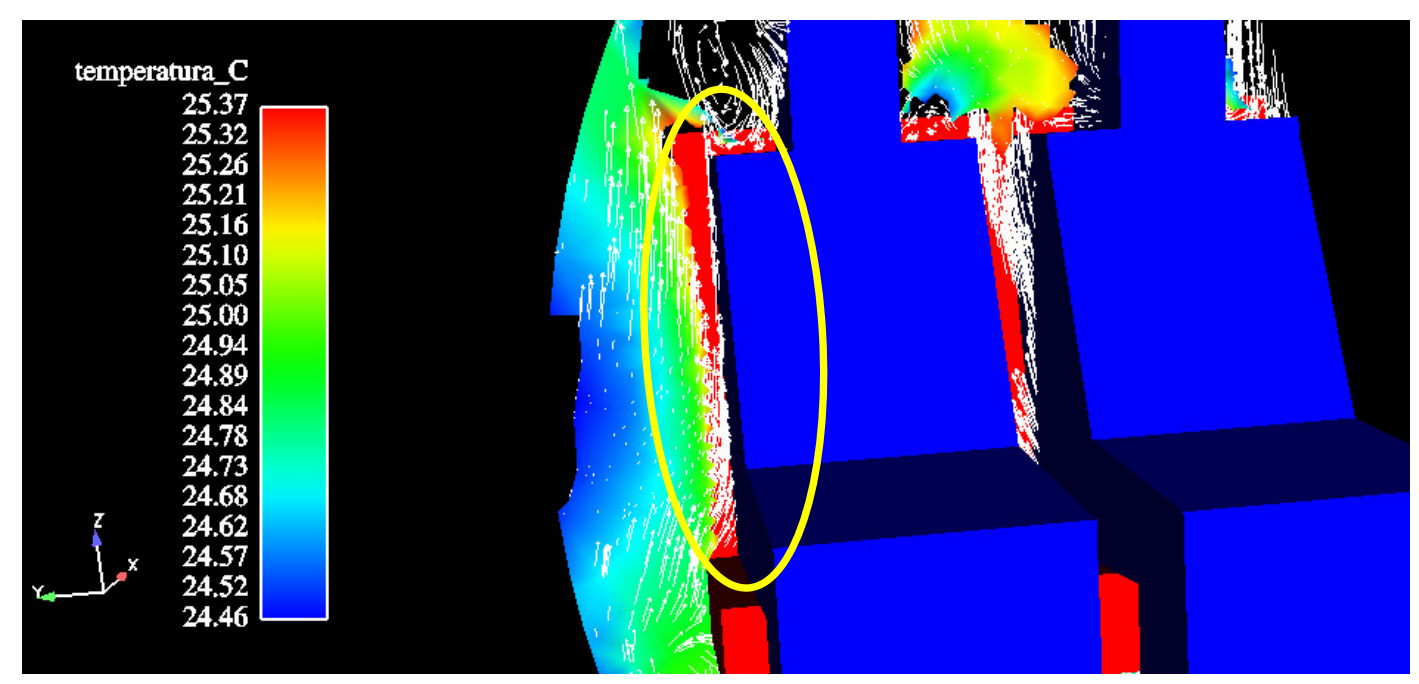

Figura 7.5 Crescimento da camada térmica na lateral do manequim junto à parede.

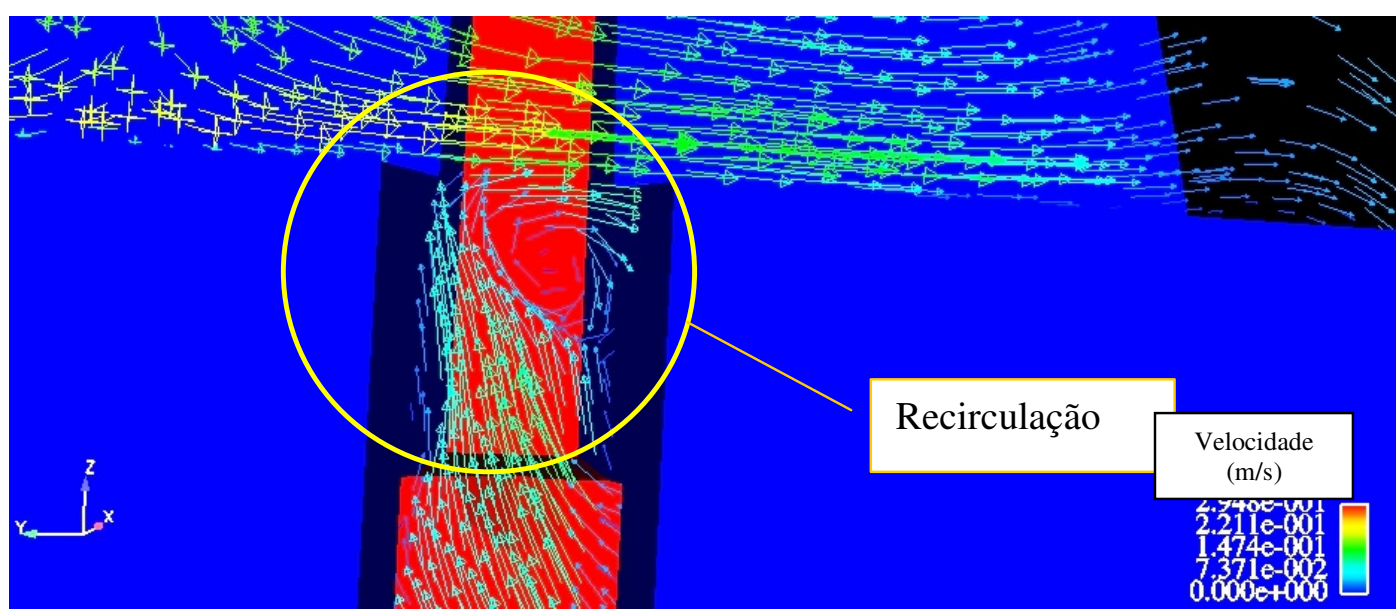

Figura 7.6 Recirculação do ar entre as coxas dos manequins contíguos. A visualização é feita considerando a frente dos manequins.

Pode-se notar nas figuras 7.3 a 7.5 que a camada térmica, que sobe à lateral do manequim do lado da parede, interage com o jato frio que incide na cabeça deste manequim, gerando uma recirculação do ar junto ao ombro e cabeça daquele lado. Também é possível notar nas figuras 7.3 e 7.4 que existe uma outra área de recirculação sobre a cabeça do manequim, do lado do corredor, criado pelo ar quente que sobe entre as cabeças e ar frio que desce no corredor.

Outras recirculações de ar são possíveis de se verificar, como aquela que ocorre entre as coxas do manequim causado pela convecção natural entre as pernas e o ar frio que desce do jato de ar do bin, como mostrado na figura 7.6. Este é um tubo de vórtice que entra no canal formado pelas coxas dos manequins para alimentar a corrente de ar quente que sobe por entre as laterais dos manequins. 
Na tabela 7.1 são apresentados os fluxos médios de troca de calor por convecção dos manequins para as diversas malhas simuladas.

Tabela 7.1 Fluxos de calor por convecção dos manequins para as diversas malhas e ordens de interpolação.

\begin{tabular}{ccccc}
\hline $\begin{array}{c}\text { Malha } \\
\text { (em milhares de } \\
\text { elementos) }\end{array}$ & $\begin{array}{c}\text { Ordem de } \\
\text { interpolação }\end{array}$ & $\begin{array}{c}\text { Fluxo de calor médio nos } \\
\text { manequins }\left(\mathbf{W} / \mathbf{m}^{2}\right)\end{array}$ & $\begin{array}{c}\mathbf{y}^{+} \\
(\text {médio })\end{array}$ & $\begin{array}{c}\text { Distância do 10 } \\
\text { centróide até a } \\
\text { parede }(\mathbf{m m})\end{array}$ \\
\hline $\mathbf{4 0 4}$ & 1 & 28,10 & 11,94 & 21,1 \\
$\mathbf{4 0 4}$ & 1 e 2 (na energia) & 29,62 & 11,71 & 21,1 \\
$\mathbf{5 0 5}$ & 1 & 30,34 & 6,24 & 9,6 \\
$\mathbf{5 0 5}$ & 1 e 2 (na energia) & 28,62 & 6,25 & 9,6 \\
$\mathbf{5 4 4}$ & 1 & 32,13 & 5,33 & 8,1 \\
$\mathbf{5 4 4}$ & 1 e 2 (na energia) & 30,18 & 5,37 & 8,1 \\
$\mathbf{6 5 0}$ & 1 & 24,18 & 5,83 & 12,7 \\
$\mathbf{7 1 1}$ & 1 e 2 (na energia) & 33,04 & 4,49 & 6,2 \\
$\mathbf{7 9 9}$ & 1 & 36,36 & 3,89 & 5,1 \\
$\mathbf{1 5 0 1}$ & 1 & 29,66 & 7,41 & 8,8 \\
$\mathbf{1 7 6 3}$ & 1 & 33,18 & 1,57 & 3,1 \\
$\mathbf{2 0 0 0}$ & 1 & 24,82 & 3,85 & 7,7 \\
$\mathbf{2 4 9 6}$ & 1 & 34,15 & 1,34 & 2,7 \\
\hline Média & & 30,33 & & \\
\hline Desvio padrão & & 3,3 & & \\
\hline
\end{tabular}

Também não se notou influências significativas nos fluxos de calor dos manequins, quanto ao refinamento de malha junto à parede e à ordem de interpolação. Talvez, em função de não se observarem grandes gradientes de velocidade, as malhas foram suficientemente refinadas para não se notar diferenças quanto à discretização espacial e de interpolação.

É importante ressaltar que o desvio padrão dos fluxos de calor, da ordem de $10 \%$ do valor médio, está dentro da faixa de erro experimental normalmente esperado para trocas de calor em ambientes interiores. 


\subsubsection{Resultados da simulação considerando periodicidade.}

\section{Estudo de independência de malhas}

Os resultados a seguir se referem ao estudo descrito no Capítulo 6, item 6.2.2. Os fluxos de calor médios para as malhas tetraédricas e tetraédricas com prismas são apresentados respectivamente nas tabelas 7.2 e 7.3.

Tabela 7.2 Fluxos de calor dos passageiros para malhas tetraédricas.

\begin{tabular}{ccc}
\hline Quantidade de elementos & Fluxo de calor $\left(\mathrm{W} / \mathrm{m}^{2}\right)$ & \multicolumn{1}{l}{$y+$} \\
\hline 339.000 & 42,97 & 12,3 \\
586.000 & 43,69 & 5,2 \\
821.000 & 44,06 & 4,5 \\
1.870 .000 & 44,14 & 3,2
\end{tabular}

Tabela 7.3 Fluxos de calor dos passageiros para malhas tetraédricas com prismas.

\begin{tabular}{ccc}
\hline Quantidade de elementos & Fluxo de calor $\left(\mathrm{W} / \mathrm{m}^{2}\right)$ & $y+$ \\
\hline 385.000 & 43,56 & 2,3 \\
650.000 & 44,30 & 1,5 \\
890.000 & 43,11 & 1,2 \\
1.880 .000 & 41,70 & 1,1
\end{tabular}

Os fluxos de calor por quantidade de elementos das malhas tetraédricas e das malhas tetraédricas com camadas de prismas são apresentados na figura 7.7: 


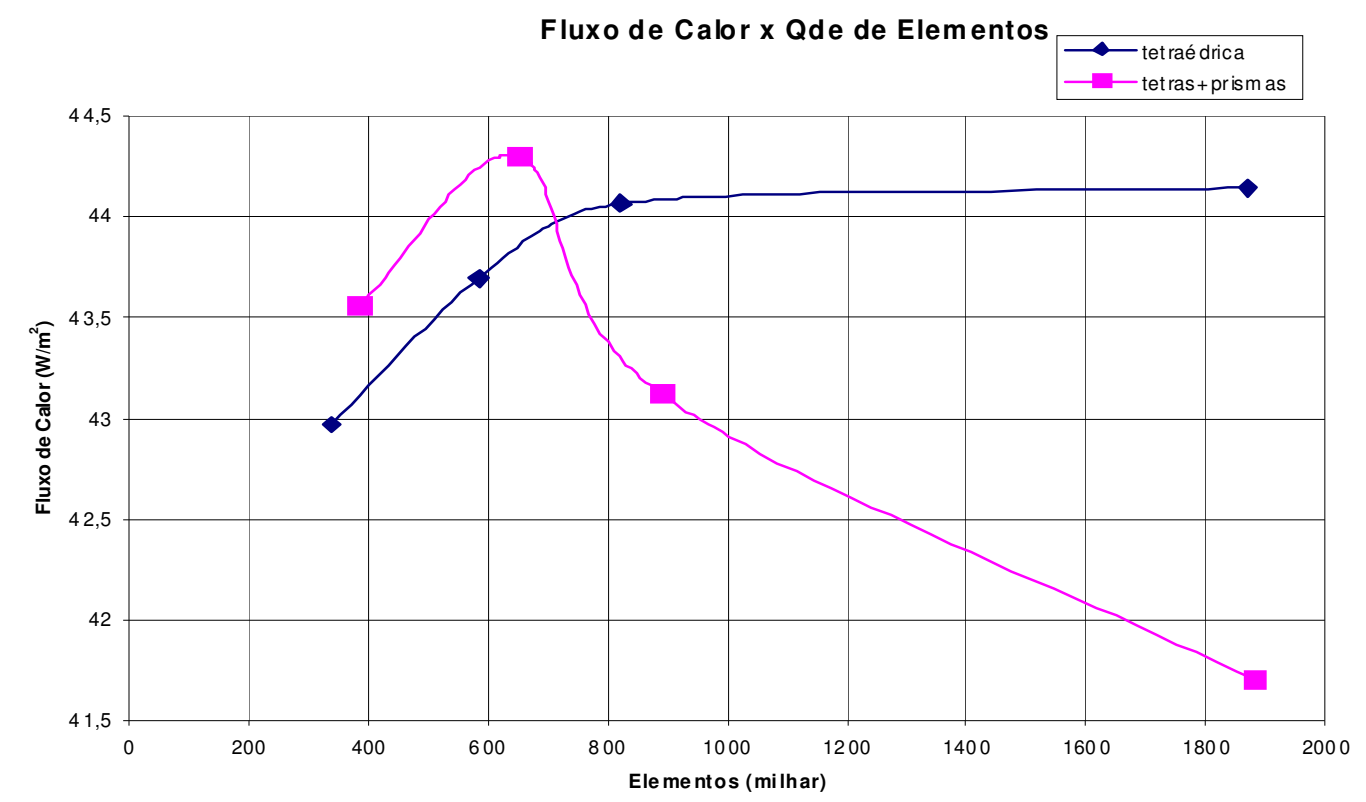

Figura 7.7 Fluxos de calor dos passageiros para malhas tetraédricas e tetraédricas com prismas.

Verificando os valores de $y+$ nas tabelas 7.2 e 7.3, percebe-se que as malhas com prismas tiveram o valor do $y+$ na superfície dos manequins em torno do valor 1 , enquanto as malhas tetraédricas tiveram seus valores todos acima de 3. Pode-se notar na figura 7.7 que os fluxos de calor estão em tendência de estabilização para as malhas tetraédricas. O mesmo não acontece para as malhas tetraédricas com camadas de prismas. Isto pode ter sido causado por uma melhor adaptação de lei de parede utilizada para y+ entre 3 e 100, o que é comentado no manual do programa Fluent. Analisando o número de elementos das malhas tetraédricas na tabela 7.2 nota-se que quase se dobrou o números de elementos da malha 3 para a 4 e o aumento no fluxo de calor foi só de $0,13 \%$. Assim se verifica que um refinamento de malha que forneça um $y+$ próximo de 4 será suficiente para se obter um resultado com erro numérico menor que $1 \%$.

As simulações das malhas de 1,8 milhões de elementos levaram 24 horas para realizarem em torno de 5 mil interações em um computador com quatro processadores Pentium de $1 \mathrm{GHz}$ de velocidade de processamento.

Nas figuras 7.8 e 7.9 são apresentados os campos de temperatura do ar e fluxos de calor dos manequins, respectivamente. 


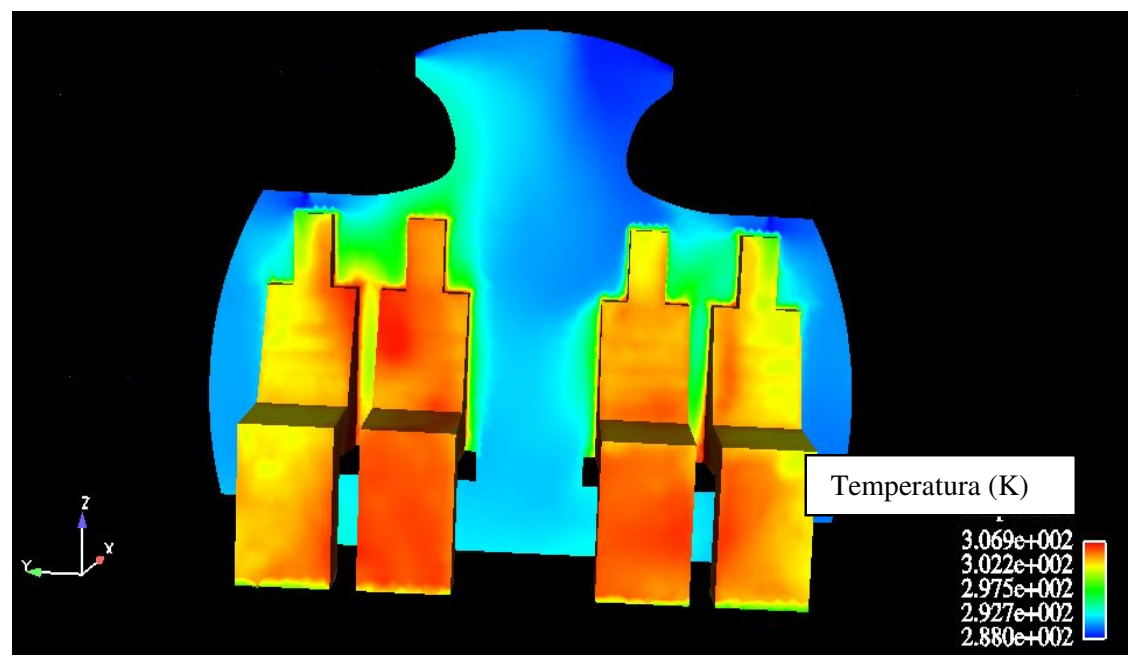

Figura 7.8 Distribuição de temperaturas do ar e dos manequins (corte transversal).

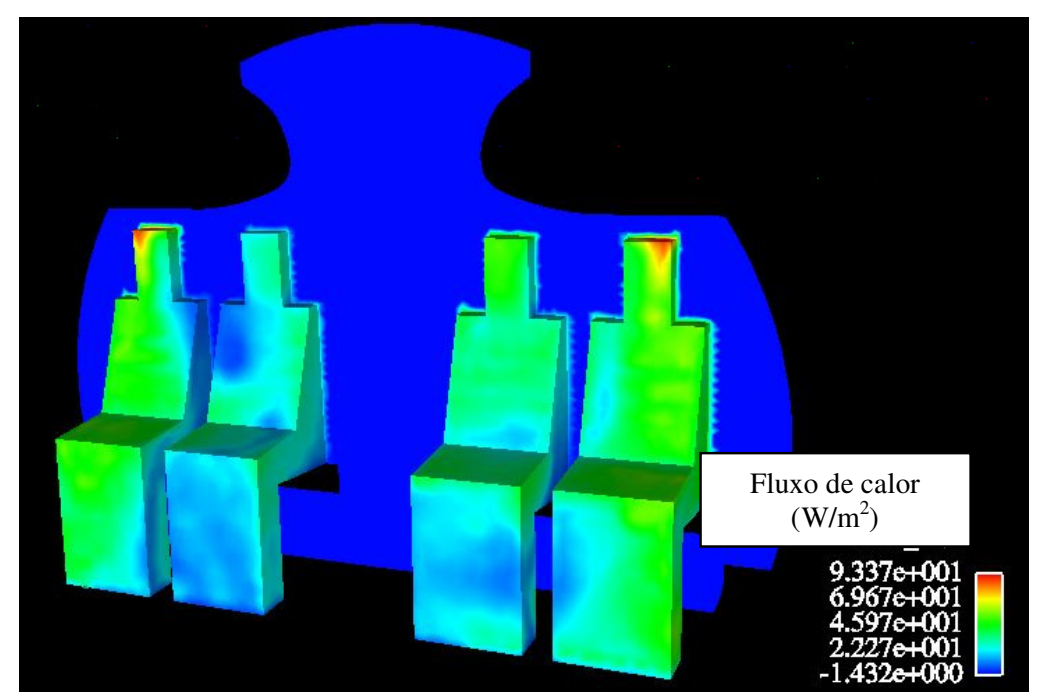

Figura 7.9 Fluxos de calor nos manequins.

Também se notou em todas as simulações com a condição periódica uma pequena assimetria no campo de temperaturas e velocidades como pode ser observado nas figuras $7.8 \mathrm{e}$ 7.9. Isto pode ter sido causado por uma não simetria da malha periódica, já que a mesma foi gerada simulando uma seção circular com raio infinito.

\section{Conclusão:}

Nesta etapa do trabalho, gerou-se malhas escaladas periódicas tetraédricas e tetraédricas com prismas nas superfícies dos passageiros. Verifica que um refinamento de 
malha que forneça um $y+$ próximo de 4 será suficiente para se obter um resultado com erro numérico menor que $1 \%$.

\subsubsection{Resultados da avaliação do manequim digital 1 - efeito de malha.}

Os resultados a seguir se referem ao estudo descrito no Capítulo 6, item 6.2.3. A partir dos fluxos de calor de cada segmento (Q") obtidos nas simulações computacionais, calculouse os coeficientes de troca de calor de calibração $\left(\mathrm{h}_{\text {cal }}\right)$ de cada segmento, utilizando a equação (3.11). Nas tabelas 7.4 a 7.7 são apresentados os $h_{\text {cal }}$ para as condições de verão e inverno:

São utilizados nos cabeçalhos das tabelas 7.4 a 7.7 os seguintes símbolos para indicar o grau dos interpolantes e se houve elementos prismáticos nas superfícies do manequim.

*- simulação com interpolação de primeira ordem;

\#- simulação com interpolação de segunda ordem;

§- malhas com elementos prismáticos na superfície.

O número ao lado de $\mathrm{h}_{\text {cal }}$ nos cabeçalhos das tabelas 7.4 a 7.7 indica o tamanho da malha em milhares de elementos. 
Tabela 7.4 Resultados de $\mathrm{h}_{\text {cal }}$ para a condição de verão.

\begin{tabular}{|c|c|c|c|c|c|c|}
\hline & $\begin{array}{c}\mathbf{h}_{\text {cal_s }}\left(\mathrm{W} / \mathrm{m}^{2} \mathrm{~K}\right) \\
\text { Experimental } \\
(\text { Nilsson, 2004) }\end{array}$ & $\begin{array}{c}\mathbf{h}_{\mathrm{cal}} 230 \\
\left(\mathrm{~W} / \mathbf{m}^{2} \mathbf{K}\right)^{*}\end{array}$ & $\begin{array}{c}\mathbf{h}_{\mathrm{cal}} \mathbf{2 3 0} \\
\left(\mathbf{W} / \mathbf{m}^{2} \mathbf{K}\right)^{\#}\end{array}$ & $\begin{array}{c}\mathbf{h}_{\mathrm{cal}} \mathbf{2 8 0} \\
\left(\mathrm{W} / \mathbf{m}^{2} \mathbf{K}\right)^{*}\end{array}$ & $\begin{array}{c}\mathbf{h}_{\mathrm{cal}} 280 \\
\left(\mathbf{W} / \mathbf{m}^{2} \mathbf{K}\right)\end{array}$ & $\begin{array}{c}h_{\mathrm{cal}} \mathbf{4 2 0} \\
\left(\mathrm{W} / \mathbf{m}^{2} \mathbf{K}\right)^{*}\end{array}$ \\
\hline 1 Escalpo & 3,49 & 3,14 & 3,47 & 3,14 & 3,42 & 3,13 \\
\hline 2 Face & 8,25 & 9,27 & $\mathbf{9 , 5 0}$ & 9,28 & 10,65 & 9,44 \\
\hline 3 Peito & 3,89 & 3,59 & 3,47 & $\mathbf{3 , 5 8}$ & 3,47 & 3,59 \\
\hline 4 Costas superior & 5,79 & 5,32 & 5,43 & 5,28 & 5,12 & 5,30 \\
\hline 5 Braço esquerdo & 4,26 & 3,78 & 3,94 & 3,78 & 3,78 & 3,79 \\
\hline 6 Braço direito & 4,69 & 4,01 & 3,92 & 4,03 & 3,96 & 4,02 \\
\hline 7 Antebraço esquerdo & 5,22 & 4,32 & 4,22 & 4,31 & 4,14 & 4,35 \\
\hline 8 Antebraço direito & 5,13 & 4,38 & 4,26 & 4,37 & 4,23 & 4,38 \\
\hline 9 Mão esquerda & 8,6 & 9,69 & 9,01 & 9,78 & 9,14 & 9,74 \\
\hline 10 Mão direita & 8,49 & 9,74 & 9,12 & $\mathbf{9 , 8 3}$ & 9,31 & 9,80 \\
\hline 11 Coxa esquerda & 4,96 & 4,58 & 4,41 & 4,57 & 4,23 & 4,59 \\
\hline 12 Coxa direita & 4,82 & 4,45 & 4,33 & 4,46 & 4,15 & 4,46 \\
\hline 13 Perna esquerda & 5,11 & 4,88 & 4,72 & 4,87 & 4,61 & 4,86 \\
\hline 14 Perna direita & 4,83 & 4,88 & 4,74 & 4,87 & 4,59 & 4,84 \\
\hline 15 Pé esquerdo & 3,63 & $3, \mathbf{3 3}$ & 3,23 & 3,32 & 3,23 & 3,32 \\
\hline 16 Pé direito & 3,82 & 3,54 & 3,44 & $3, \mathbf{5 3}$ & 3,42 & $\mathbf{3 , 5 3}$ \\
\hline 17 Costas inferior & 3,11 & 3,30 & 3,28 & 3,30 & 3,19 & 3,30 \\
\hline \multirow[t]{2}{*}{18 Nádegas } & 4,59 & 4,36 & $\mathbf{4 , 4 0}$ & 4,35 & 4,21 & 4,34 \\
\hline & $\begin{array}{c}\mathbf{h}_{\mathrm{cal} \_} \mathbf{S} \\
\left(\mathbf{W} / \mathbf{m}^{2} \mathbf{K}\right) \\
\text { Experimental } \\
(\text { Nilsson, } \\
\text { 2004) } \\
\end{array}$ & $\begin{array}{c}\mathbf{h}_{\mathrm{cal}} \mathbf{5 0 0} \\
\left(\mathbf{W} / \mathbf{m}^{2} \mathbf{K}\right)^{*}\end{array}$ & $\begin{array}{c}\mathbf{h}_{\mathrm{cal}} \mathbf{5 0 0} \\
\left(\mathbf{W} / \mathbf{m}^{2} \mathbf{K}\right)^{*} \\
\S\end{array}$ & $\begin{array}{c}\mathbf{h}_{\mathrm{cal}} \mathbf{8 0 0} \\
\left(\mathbf{W} / \mathbf{m}^{2} \mathbf{K}\right) \\
* \S\end{array}$ & $\begin{array}{c}\mathbf{h}_{\mathrm{cal}} 1191 \\
\left(\mathrm{~W} / \mathbf{m}^{2} \mathrm{~K}\right) \\
*\end{array}$ & $\begin{array}{c}h_{\text {cal }} 1400 \\
\left(W / \mathbf{m}^{2}\right)^{*} \S\end{array}$ \\
\hline 1 Escalpo & 3,49 & 3,15 & 3,00 & 2,98 & 3,09 & 2,99 \\
\hline 2 Face & 8,25 & 9,44 & 8,51 & 8,38 & 9,75 & 8,49 \\
\hline 3 Peito & 3,89 & 3,59 & 3,31 & 3,29 & 3,49 & 3,30 \\
\hline 4 Costas superior & 5,79 & 5,33 & 4,94 & 4,88 & 5,27 & 4,91 \\
\hline 5 Braço esquerdo & 4,26 & 3,78 & 3,60 & 3,58 & 3,76 & 3,59 \\
\hline 6 Braço direito & 4,69 & 4,01 & 3,84 & 3,81 & 3,99 & 3,82 \\
\hline 7 Antebraço esquerdo & 5,22 & 4,33 & 4,16 & 4,15 & 4,35 & 4,14 \\
\hline 8 Antebraço direito & 5,13 & 4,39 & 4,19 & 4,19 & 4,41 & 4,18 \\
\hline 9 Mão esquerda & 8,6 & $\mathbf{9 , 8 8}$ & 9,48 & 9,40 & 10,60 & 9,39 \\
\hline 10 Mão direita & 8,49 & 9,79 & 9,48 & 9,40 & 10,63 & 9,39 \\
\hline 11 Coxa esquerda & 4,96 & 4,59 & 4,33 & 4,30 & 4,58 & 4,32 \\
\hline 12 Coxa direita & 4,82 & 4,47 & 4,21 & 4,19 & 4,45 & 4,20 \\
\hline 13 Perna esquerda & 5,11 & 4,87 & 4,53 & 4,51 & 4,83 & 4,54 \\
\hline 14 Perna direita & 4,83 & 4,85 & 4,53 & 4,50 & 4,81 & 4,52 \\
\hline 15 Pé esquerdo & 3,63 & 3,33 & 3,24 & 3,23 & 3,33 & 3,24 \\
\hline 16 Pé direito & 3,82 & $\mathbf{3 , 5 3}$ & 3,44 & 3,43 & 3,54 & 3,43 \\
\hline 17 Costas inferior & 3,11 & 3,29 & 3,14 & 3,11 & 3,25 & 3,13 \\
\hline 18 Nádegas & 4,59 & 4,36 & 4,27 & 4,26 & 4,37 & 4,26 \\
\hline
\end{tabular}

Analisando o módulo da diferença entre o resultado obtido numericamente e os dados experimentais tem-se os resultados apresentados na tabela 7.5: 
Tabela 7.5 Módulo da diferença entre os resultados experimentais e os obtidos numericamente para condição de verão

\begin{tabular}{|c|c|c|c|c|c|}
\hline & $\begin{array}{c}\left|\mathbf{h}_{\text {cal }} 230\right| \\
\left(\mathbf{W} / \mathbf{m}^{2} \mathbf{K}\right)^{*}\end{array}$ & $\begin{array}{c}\mid \mathbf{h}_{\mathrm{cal}} \mathbf{2 3 0 |} \\
\left(\mathbf{W} / \mathbf{m}^{2} \mathbf{K}\right)^{\#}\end{array}$ & 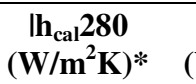 & $\begin{array}{c}\left|\mathbf{h}_{\text {ca }} 280\right| \\
\left(\mathbf{W} / \mathbf{m}^{2} \mathbf{K}\right)^{\#}\end{array}$ & $\begin{array}{c}\left|\mathbf{h}_{\mathrm{cal}} 420\right| \\
\left(\mathrm{W} / \mathbf{m}^{2} \mathrm{~K}\right)^{*}\end{array}$ \\
\hline 1 Escalpo & $\mathbf{0 , 3 5}$ & 0,02 & $\mathbf{0 , 3 5}$ & $\mathbf{0 , 0 7}$ & $\mathbf{0 , 3 6}$ \\
\hline 2 Face & 1,02 & 1,25 & 1,03 & 2,40 & 1,19 \\
\hline 3 Peito & $\mathbf{0 , 3 0}$ & 0,42 & 0,31 & 0,42 & $\mathbf{0 , 3 0}$ \\
\hline 4 Costas superior & 0,47 & $\mathbf{0 , 3 6}$ & $\mathbf{0 , 5 1}$ & 0,67 & 0,49 \\
\hline 5 Braço esquerdo & 0,48 & 0,32 & 0,48 & 0,48 & 0,47 \\
\hline 6 Braço direito & 0,68 & 0,77 & 0,66 & 0,73 & 0,67 \\
\hline 7 Antebraço esquerdo & $\mathbf{0 , 9 0}$ & 1,00 & 0,91 & 1,08 & 0,87 \\
\hline 8 Antebraço direito & 0,75 & $\mathbf{0 , 8 7}$ & 0,76 & 0,90 & 0,75 \\
\hline 9 Mão esquerda & 1,09 & 0,41 & 1,18 & 0,54 & 1,14 \\
\hline 10 Mão direita & 1,25 & 0,63 & 1,34 & $\mathbf{0 , 8 2}$ & 1,31 \\
\hline 11 Coxa esquerda & 0,38 & 0,55 & 0,39 & $\mathbf{0 , 7 3}$ & 0,37 \\
\hline 12 Coxa direita & $\mathbf{0 , 3 7}$ & 0,49 & $\mathbf{0 , 3 6}$ & 0,67 & $\mathbf{0 , 3 6}$ \\
\hline 13 Perna esquerda & $\mathbf{0 , 2 3}$ & 0,39 & 0,24 & $\mathbf{0 , 5 0}$ & 0,25 \\
\hline 14 Perna direita & 0,05 & 0,09 & 0,04 & 0,24 & 0,01 \\
\hline 15 Pé esquerdo & $\mathbf{0 , 3 0}$ & 0,40 & 0,31 & 0,40 & $\mathbf{0 , 3 1}$ \\
\hline 16 Pé direito & 0,28 & 0,38 & 0,29 & 0,40 & 0,29 \\
\hline 17 Costas inferior & 0,19 & 0,17 & 0,19 & 0,08 & 0,19 \\
\hline 18 Nádegas & $\mathbf{0 , 2 3}$ & 0,19 & 0,24 & $\mathbf{0 , 3 8}$ & 0,25 \\
\hline Média: & 0,52 & 0,48 & 0,53 & 0,64 & $\mathbf{0 , 5 3}$ \\
\hline$y+$ médio & 4,22 & 3,64 & 4,12 & 4,00 & 4,25 \\
\hline & $\begin{array}{c}\mid \mathbf{h}_{\mathrm{cal}} \mathbf{5 0 0 |} \\
\left(\mathbf{W} / \mathbf{m}^{2} \mathbf{K}\right)^{*}\end{array}$ & $\begin{array}{c}\mid \mathbf{h}_{\mathrm{cal}} \mathbf{5 0 0 |} \\
\left(\mathbf{W} / \mathbf{m}^{2} \mathbf{K}\right)^{*} \S\end{array}$ & $\begin{array}{c}\mid \mathbf{h}_{\mathrm{cal}} \mathbf{8 0 0 |} \\
\left(\mathbf{W} / \mathbf{m}^{2} \mathbf{K}\right) * \S\end{array}$ & $\begin{array}{cc} & \left|\mathbf{h}_{\text {cal }} 1191\right| \\
\S & \left(\mathbf{W} / \mathbf{m}^{2} \mathbf{K}\right)^{*}\end{array}$ & $\begin{array}{l}\left|\mathbf{h}_{\mathrm{cal}} 1400\right| \\
\left(\mathrm{W} / \mathbf{m}^{2}\right)^{*} \S\end{array}$ \\
\hline 1 Escalpo & 0,34 & 0,49 & 0,51 & 0,40 & 0,50 \\
\hline 2 Face & 1,19 & 0,26 & $\mathbf{0 , 1 3}$ & 1,50 & 0,24 \\
\hline 3 Peito & $\mathbf{0 , 3 0}$ & 0,58 & 0,60 & 0,40 & 0,59 \\
\hline 4 Costas superior & 0,46 & 0,85 & 0,91 & 0,52 & $\mathbf{0 , 8 8}$ \\
\hline 5 Braço esquerdo & 0,48 & 0,66 & 0,68 & 0,50 & 0,67 \\
\hline 6 Braço direito & 0,68 & 0,85 & 0,88 & 0,70 & 0,87 \\
\hline 7 Antebraço esquerdo & $\mathbf{0 , 8 9}$ & 1,06 & 1,07 & $\mathbf{0 , 8 7}$ & 1,08 \\
\hline 8 Antebraço direito & 0,74 & 0,94 & 0,94 & 0,72 & 0,95 \\
\hline 9 Mão esquerda & 1,28 & $\mathbf{0 , 8 8}$ & $\mathbf{0 , 8 0}$ & 2,00 & 0,79 \\
\hline 10 Mão direita & 1,30 & 0,99 & 0,91 & 2,14 & 0,90 \\
\hline 11 Coxa esquerda & 0,37 & 0,63 & 0,66 & $\mathbf{0 , 3 8}$ & 0,64 \\
\hline 12 Coxa direita & 0,35 & 0,61 & 0,63 & 0,37 & 0,62 \\
\hline 13 Perna esquerda & 0,24 & 0,58 & 0,60 & 0,28 & 0,57 \\
\hline 14 Perna direita & 0,02 & $\mathbf{0 , 3 0}$ & $\mathbf{0 , 3 3}$ & 0,02 & $\mathbf{0 , 3 1}$ \\
\hline 15 Pé esquerdo & $\mathbf{0 , 3 0}$ & 0,39 & 0,40 & $\mathbf{0 , 3 0}$ & $\mathbf{0 , 3 9}$ \\
\hline 16 Pé direito & 0,29 & 0,38 & 0,39 & 0,28 & $\mathbf{0 , 3 9}$ \\
\hline 17 Costas inferior & 0,18 & $\mathbf{0 , 0 3}$ & 0,00 & 0,14 & $\mathbf{0 , 0 2}$ \\
\hline 18 Nádegas & 0,23 & 0,32 & $\mathbf{0 , 3 3}$ & 0,22 & $\mathbf{0 , 3 3}$ \\
\hline Média: & $\mathbf{0 , 5 4}$ & 0,60 & 0,60 & 0,65 & 0,60 \\
\hline$y$ + médio & 4,22 & 0,58 & 0,51 & 1,77 & 0,57 \\
\hline
\end{tabular}


Para a condição de inverno os resultados são apresentados na tabela 7.6:

Tabela 7.6 Resultados de $\mathrm{h}_{\text {cal }}$ para a condição de inverno

\begin{tabular}{|c|c|c|c|c|c|}
\hline & $\begin{array}{c}\mathbf{h}_{\text {cal_LW }} \\
(\mathbf{W} / \mathbf{m} 2 \mathbf{K}) \\
\text { Nilsson } \\
(2004) \\
\end{array}$ & $\begin{array}{c}\mathbf{h}_{\text {cal }} 230 \\
\left(\mathbf{W} / \mathbf{m}^{2} \mathbf{K}\right)^{*}\end{array}$ & $\begin{array}{c}\mathbf{h}_{\text {cal }} \mathbf{2 3 0} \\
\left(\mathbf{W} / \mathbf{m}^{2} \mathbf{K}\right)^{\#}\end{array}$ & $\begin{array}{c}\mathbf{h}_{\mathrm{ca}} \mathbf{2 8 0} \\
\left(\mathbf{W} / \mathbf{m}^{2} \mathbf{K}\right)^{\#}\end{array}$ & $\begin{array}{c}\mathbf{h}_{\text {cal }} \mathbf{4 2 0} \\
\left(\mathbf{W} / \mathbf{m}^{2} \mathbf{K}\right)^{*}\end{array}$ \\
\hline 1 Escalpo & 3,78 & 3,58 & 3,86 & 3,74 & 3,52 \\
\hline 2 Face & 8,19 & 1,91 & 2,03 & 2,84 & 1,81 \\
\hline 3 Peito & 2,08 & 1,80 & 1,78 & 1,72 & 1,78 \\
\hline 4 Costas superior & 3,40 & 3,10 & 3,16 & 2,97 & 3,08 \\
\hline 5 Braço esquerdo & 2,37 & 2,07 & 2,16 & 2,05 & 2,07 \\
\hline 6 Braço direito & 2,44 & 2,16 & 2,11 & 2,11 & 2,15 \\
\hline 7 Antebraço esquerdo & 3,47 & 2,89 & 2,90 & 2,75 & 2,89 \\
\hline 8 Antebraço direito & 3,40 & 2,91 & 2,85 & 2,78 & 2,89 \\
\hline 9 Mão esquerda & 6,98 & 7,33 & 7,16 & 6,95 & 7,34 \\
\hline 10 Mão direita & 6,70 & 6,78 & 6,53 & 6,53 & 6,80 \\
\hline 11 Coxa esquerda & 4,71 & 4,43 & 4,29 & 4,07 & 4,44 \\
\hline 12 Coxa direita & 4,76 & 4,45 & 4,31 & 4,11 & 4,45 \\
\hline 13 Perna esquerda & 4,98 & 4,82 & 4,71 & 4,46 & 4,80 \\
\hline 14 Perna direita & 4,90 & 4,85 & 4,73 & 4,47 & 4,80 \\
\hline 15 Pé esquerdo & 4,32 & 3,85 & 3,72 & 3,62 & 3,85 \\
\hline 16 Pé direito & 4,35 & 3,89 & 3,78 & 3,66 & 3,89 \\
\hline 17 Costas inferior & 2,44 & 2,31 & 2,32 & 2,21 & 2,31 \\
\hline \multirow[t]{2}{*}{18 Nádegas } & 5,05 & 4,89 & 4,90 & 4,59 & 4,84 \\
\hline & $\begin{array}{c}\mathbf{h}_{\text {cal_w }} \\
(\mathbf{W} / \mathbf{m} 2 \mathbf{K}) \\
(\text { Nilsson, } \\
\mathbf{2 0 0 4})\end{array}$ & $\begin{array}{c}\mathbf{h}_{\mathrm{cal}} \mathbf{5 0 0} \\
\left(\mathbf{W} / \mathbf{m}^{2} \mathbf{K}\right)^{*}\end{array}$ & $\begin{array}{c}\mathbf{h}_{\mathrm{cal}} \mathbf{5 0 0} \\
\left(\mathbf{W} / \mathbf{m}^{2} \mathbf{K}\right)^{*} \S\end{array}$ & $\begin{array}{c}\mathbf{h}_{\text {cal }} \mathbf{8 0 0} \\
\left(\mathbf{W} / \mathbf{m}^{2} \mathbf{K}\right) * \S\end{array}$ & $\begin{array}{c}\mathbf{h}_{\text {cal }} 1191 \\
\left(\mathrm{~W} / \mathbf{m}^{2} K\right)^{*}\end{array}$ \\
\hline 1 Escalpo & 3,78 & 3,57 & 3,36 & 3,14 & 3,51 \\
\hline 2 Face & 8,19 & 9,71 & 8,58 & 8,01 & 9,95 \\
\hline 3 Peito & 2,08 & 1,78 & 1,67 & 1,59 & 1,73 \\
\hline 4 Costas superior & 3,40 & 3,11 & 2,94 & 2,75 & 3,06 \\
\hline 5 Braço esquerdo & 2,37 & 2,06 & 2,00 & 1,90 & 2,05 \\
\hline 6 Braço direito & 2,44 & 2,15 & 2,09 & 1,99 & 2,13 \\
\hline 7 Antebraço esquerdo & 3,47 & 2,88 & 2,80 & 2,69 & 2,89 \\
\hline 8 Antebraço direito & 3,40 & 2,89 & 2,81 & 2,70 & 2,91 \\
\hline 9 Mão esquerda & 6,98 & 7,55 & 7,16 & 6,85 & 7,86 \\
\hline 10 Mão direita & 6,70 & 6,90 & 6,61 & 6,33 & 7,20 \\
\hline 11 Coxa esquerda & 4,71 & 4,48 & 4,18 & 4,01 & 4,44 \\
\hline 12 Coxa direita & 4,76 & 4,51 & 4,20 & 4,04 & 4,46 \\
\hline 13 Perna esquerda & 4,98 & 4,86 & 4,45 & 4,28 & 4,79 \\
\hline 14 Perna direita & 4,90 & 4,88 & 4,47 & 4,30 & 4,80 \\
\hline 15 Pé esquerdo & 4,32 & 3,90 & 3,75 & 3,66 & 3,90 \\
\hline 16 Pé direito & 4,35 & 3,93 & 3,78 & 3,68 & 3,93 \\
\hline 17 Costas inferior & 2,44 & 2,32 & 2,20 & 2,11 & 2,26 \\
\hline 18 Nádegas & 5,05 & 4,94 & 4,73 & 4,62 & 4,89 \\
\hline
\end{tabular}


Os módulos das diferenças entre os valores experimentais e os obtidos na simulação, para a condição de inverno são apresentados na tabela 7.7:

Tabela 7.7 Módulo da diferença entre os resultados experimentais e os obtidos numericamente para condição de inverno

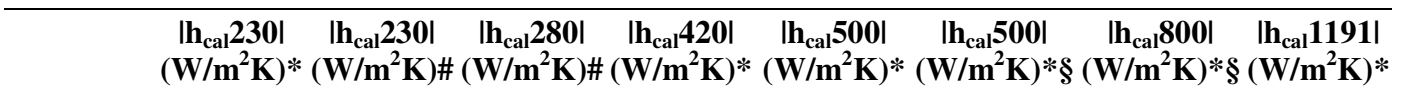

\begin{tabular}{|c|c|c|c|c|c|c|c|c|}
\hline Escalpo & $\mathbf{0 , 2 0}$ & 0,08 & 0,04 & 0,26 & 0,21 & 0,42 & 0,64 & 0,27 \\
\hline Face & 6,28 & 6,16 & 5,35 & 6,38 & 1,52 & 0,39 & 0,18 & 1,76 \\
\hline Peito & 0,28 & $\mathbf{0 , 3 0}$ & 0,36 & $\mathbf{0 , 3 0}$ & $\mathbf{0 , 3 0}$ & 0,41 & 0,49 & $\mathbf{0 , 3 5}$ \\
\hline $\begin{array}{l}\text { Costas } \\
\text { superior }\end{array}$ & $\mathbf{0 , 3 0}$ & 0,24 & 0,43 & $\mathbf{0 , 3 2}$ & 0,29 & 0,46 & 0,65 & $\mathbf{0 , 3 4}$ \\
\hline $\begin{array}{l}\text { Braço } \\
\text { esquerdo }\end{array}$ & $\mathbf{0 , 3 0}$ & 0,21 & $\mathbf{0 , 3 2}$ & $\mathbf{0 , 3 0}$ & $\mathbf{0 , 3 1}$ & $\mathbf{0 , 3 7}$ & 0,47 & 0,32 \\
\hline $\begin{array}{l}\text { Braço } \\
\text { direito }\end{array}$ & 0,28 & $\mathbf{0 , 3 3}$ & $\mathbf{0 , 3 3}$ & 0,29 & 0,29 & $\mathbf{0 , 3 5}$ & 0,45 & $\mathbf{0 , 3 1}$ \\
\hline $\begin{array}{l}\text { Antebraço } \\
\text { esquerdo }\end{array}$ & $\mathbf{0 , 5 8}$ & $\mathbf{0 , 5 7}$ & 0,72 & $\mathbf{0 , 5 8}$ & $\mathbf{0 , 5 9}$ & 0,67 & $\mathbf{0 , 7 8}$ & 0,58 \\
\hline $\begin{array}{l}\text { Antebraço } \\
\text { direito } \\
\text { Mão }\end{array}$ & 0,49 & 0,55 & 0,62 & $\mathbf{0 , 5 1}$ & $\mathbf{0 , 5 1}$ & $\mathbf{0 , 5 9}$ & $\mathbf{0 , 7 0}$ & 0,49 \\
\hline esquerda & 0,35 & 0,18 & $\mathbf{0 , 0 3}$ & 0,36 & 0,57 & 0,18 & 0,13 & $\mathbf{0 , 8 8}$ \\
\hline $\begin{array}{l}\text { Mão } \\
\text { direita }\end{array}$ & $\mathbf{0 , 0 8}$ & $\mathbf{0 , 1 7}$ & $\mathbf{0 , 1 7}$ & $\mathbf{0 , 1 0}$ & $\mathbf{0 , 2 0}$ & 0,09 & $\mathbf{0 , 3 7}$ & $\mathbf{0 , 5 0}$ \\
\hline $\begin{array}{l}\text { Coxa } \\
\text { esquerda }\end{array}$ & 0,28 & 0,42 & 0,64 & $\mathbf{0 , 2 7}$ & 0,23 & $\mathbf{0 , 5 3}$ & $\mathbf{0 , 7 0}$ & 0,27 \\
\hline $\begin{array}{l}\text { Coxa } \\
\text { direita }\end{array}$ & $\mathbf{0 , 3 1}$ & 0,45 & 0,65 & $\mathbf{0 , 3 1}$ & 0,25 & 0,56 & 0,72 & $\mathbf{0 , 3 0}$ \\
\hline $\begin{array}{l}\text { Perna } \\
\text { esquerda }\end{array}$ & 0,16 & 0,27 & 0,52 & $\mathbf{0 , 1 8}$ & 0,12 & $\mathbf{0 , 5 3}$ & $\mathbf{0 , 7 0}$ & 0,19 \\
\hline $\begin{array}{l}\text { Perna } \\
\text { direita } \\
\text { Pé }\end{array}$ & 0,05 & $\mathbf{0 , 1 7}$ & 0,43 & 0,10 & $\mathbf{0 , 0 2}$ & 0,43 & 0,60 & 0,10 \\
\hline esquerdo & 0,47 & 0,60 & $\mathbf{0 , 7 0}$ & 0,47 & 0,42 & $\mathbf{0 , 5 7}$ & 0,66 & 0,42 \\
\hline Pé direito & 0,46 & $\mathbf{0 , 5 7}$ & 0,69 & 0,46 & 0,42 & $\mathbf{0 , 5 7}$ & 0,67 & 0,42 \\
\hline $\begin{array}{l}\text { Costas } \\
\text { inferior }\end{array}$ & 0,13 & 0,12 & $\mathbf{0 , 2 3}$ & 0,13 & 0,12 & 0,24 & $\mathbf{0 , 3 3}$ & 0,18 \\
\hline Nádegas & 0,16 & 0,15 & 0,46 & 0,21 & 0,11 & 0,32 & 0,43 & 0,16 \\
\hline Média & 0,62 & 0,64 & $\mathbf{0 , 7 0}$ & 0,64 & 0,36 & 0,43 & 0,54 & 0,44 \\
\hline$y+$ médio & 4,63 & 3,97 & 4,32 & $\mathbf{4 , 5 5}$ & 4,52 & $\mathbf{0 , 6 3}$ & 0,56 & 1,92 \\
\hline
\end{tabular}

Em geral pode-se notar que as diferenças médias dos coeficientes de troca de calor de calibração ficaram próximas a $10 \%$ dos valores experimentais, que está dentro dos erros experimentais de trocas de calor por convecção e radiação. Observou-se uma grande discrepância entre os valores experimentais e os simulados dos $h_{\text {cal }}$ nas malhas de 230 a 420 mil elementos referente ao segmento "face" nas simulações de condição de inverno. 
Verificou-se que um erro ao se digitar a condição de contorno (temperatura superficial de $54{ }^{\circ} \mathrm{C}$ ) foi o causador desta discrepância

Comparando-se as malhas que foram simuladas com interpolantes de primeira e segunda ordem, notou-se que não houve diferenças significativas. Isto pode indicar que a resolução da malha está próxima o suficiente para a ordem de interpolação apresentar diferenças significativas. Isto se comprova também por não ter havido diferenças significativas com relação às malhas com prismas e sem. Assim, pode-se concluir que avaliações de trocas térmicas com resolução de malha que forneçam valores de $y+$ iguais ou menores que 4 devem apresentar bons resultados com a lei de parede usada.

\section{Conclusão}

Consegui-se modelar numericamente as trocas térmicas por convecção e radiação de um manequim térmico com precisão de $10 \%$ frente a dados experimentais (Nilsson, 2004) para 17 segmentos do corpo humano para situações de verão e inverno.

Os melhores resultados foram atingidos com $y+$ em torno de 4 e distância média do centróide da primeira célula à superfície do manequim de $7 \mathrm{~mm}$. Isto indica que este é o nível de refinamento para se obter bons resultados para a situação estudada. O modelo de radiação de ordenadas discretas e o modelo de turbulência k- $\varepsilon$ padrão se mostraram satisfatórios para a situação estudada.

Embora o manequim digital 1 tenha uma geometria relativamente simples, mostrou-se adequado para futuras avaliações em cabines nas quais se queira estudar o conforto dos passageiros.

\subsubsection{Resultado da avaliação de manequim digital 1 - efeito dos modelos de turbulência}

Os resultados a seguir se referem ao estudo descrito no Capítulo 6, item 6.2.3.

Os resultados dos coeficientes de troca de calor de calibração estão na tabela 7.8: 
Tabela 7.8 Valores de coeficientes de troca de calor de calibração dos segmentos do manequim.

\begin{tabular}{|c|c|c|c|c|c|c|}
\hline \multirow[b]{3}{*}{$\underline{\text { Segmentos do manequim }}$} & \multicolumn{6}{|c|}{$\begin{array}{l}\text { Coeficientes de troca de calor de calibração, } \mathrm{h}_{\text {cal }} \\
\text { Modelos de turbulência }\end{array}$} \\
\hline & \multicolumn{2}{|c|}{$\mathrm{k}-\omega$} & \multicolumn{3}{|c|}{$\mathbf{k}-\varepsilon$} & \multirow{2}{*}{$\begin{array}{l}\text { Experimental } \\
\text { (Nilsson, } \\
2004)\end{array}$} \\
\hline & $S S T$ & Padrãod & Padrão & Realizável & $R N G$ & \\
\hline 01- Braço esquerdo & 4,13 & 4,08 & 4,87 & 4,41 & 4,55 & 5,22 \\
\hline 02- Antebraço esquerdo & 3,63 & 3,60 & 4,23 & 3,81 & $3, \mathbf{8 8}$ & 4,26 \\
\hline 03-Braço direito & 4,19 & 4,16 & 4,63 & 4,47 & 5,01 & 5,13 \\
\hline 04- Antebraço direito & 3,85 & 3,83 & 4,22 & 4,05 & 4,54 & 4,69 \\
\hline 05- Costas inferior & 3,20 & 3,18 & 3,51 & 3,31 & 3,45 & 3,11 \\
\hline 06- Costas superior & 5,04 & 4,97 & 5,82 & 5,32 & 5,66 & 5,79 \\
\hline 07- Perna esquerda & 4,61 & 4,61 & 5,11 & 4,84 & 5,13 & 5,11 \\
\hline 08- Perna direita & 4,62 & 4,61 & 5,02 & 4,85 & 5,23 & 4,83 \\
\hline 09- Peito & 3,41 & 3,40 & 3,81 & 3,62 & 3,85 & 3,89 \\
\hline 10-Face & 8,41 & 8,22 & 10,67 & 8,84 & 11,14 & 8,25 \\
\hline 11- Pé esquerdo & 3,22 & 3,24 & 3,46 & 3,37 & 3,58 & 3,63 \\
\hline 12- Pé direito & 3,42 & 3,42 & 3,64 & 3,58 & 3,87 & 3,82 \\
\hline 13- Mão esquerda & 9,10 & 8,83 & 11,01 & $\mathbf{9 , 7 2}$ & 10,37 & 8,6 \\
\hline 14- Mão direita & 9,03 & 8,75 & 10,16 & $\mathbf{9 , 7 4}$ & 11,57 & 8,49 \\
\hline 15- Escalpo & 3,04 & 3,02 & 3,58 & 3,17 & 3,52 & 3,49 \\
\hline 16- Nádegas & 4,23 & 4,21 & 4,85 & 4,37 & 4,83 & 4,59 \\
\hline 17- Coxa esquerda & 4,34 & 4,26 & 4,91 & 4,60 & 4,79 & 4,96 \\
\hline 18- Coxa direita & 4,23 & 4,13 & 4,65 & 4,46 & 4,81 & 4,82 \\
\hline$\Delta h_{\text {médio }}$ Eq (7.1) & $\mathbf{0 , 5 3 1 5}$ & 0,5166 & 0,526 & 0,4729 & 0,5869 & \\
\hline
\end{tabular}

Em geral obteve-se boas convergências dos resíduos e dos fluxos de calor. Todos os modelos foram simulados em primeira ordem e posteriormente segunda ordem.

Analisando os valores de $h_{\text {cal }}$ da tabela 7.8 , percebe-se que todos os modelos apresentaram bons resultados dos coeficientes de troca de calor com uma diferença média com os valores experimentais na faixa dos $10 \%$, o que está dentro dos erros experimentais para trocas térmicas por convecção e radiação. Pode-se notar nos resultados apresentados na 
tabela 7.8 que não houve diferenças significativas entre os modelos, sendo o que apresentou melhor resultado foi o modelo $\mathrm{k}-\varepsilon$ realizável.

\section{Conclusão}

Não houve variações significativas entre os modelos de turbulência estudados, sendo que se obteve diferenças médias de $10 \%$. O modelo $\mathrm{k}-\varepsilon$ realizável apresentou melhor resultado.

\subsubsection{Resultado da avaliação de conforto térmico em aeronave com manequim digital 1.}

Os resultados a seguir se referem ao estudo descrito no Capítulo 6, item 6.2.4.

\section{Perfis de temperaturas equivalentes}

Foram calculadas as temperaturas equivalentes dos 17 segmentos dos dois manequins para os o caso de avião em solo, vôo e situação de emergência, conforme descrito no item 6.2.4 do Capítulo 6. As temperaturas equivalentes, $\mathrm{t}_{\mathrm{eq}}$, foram calculadas usando a Equação 3.12. Foram utilizados para o cálculo das $t_{\text {eqs }}$ os $h_{\text {cal }}$ obtidos na calibração utilizando o modelo de turbulência $\mathrm{k}-\varepsilon$ realizável, conforme apresentado na Tabela 7.8.

\section{Temperaturas equivalentes nos manequins}

Com a utilização do programa Ensight foi feita a visualização das distribuições das t $t_{\text {eqs }}$ para cada segmento dos manequins.

\section{Em solo}

Foram calculadas as temperaturas equivalentes de cada um dos 17 segmentos dos manequins e plotadas em diagrama de sensação térmica (Fig. 7.10) apresentado em Nilsson (2004), com as zonas de conforto referente a verão, conforme apresentado no item 3.6 e figura 3.4 . 


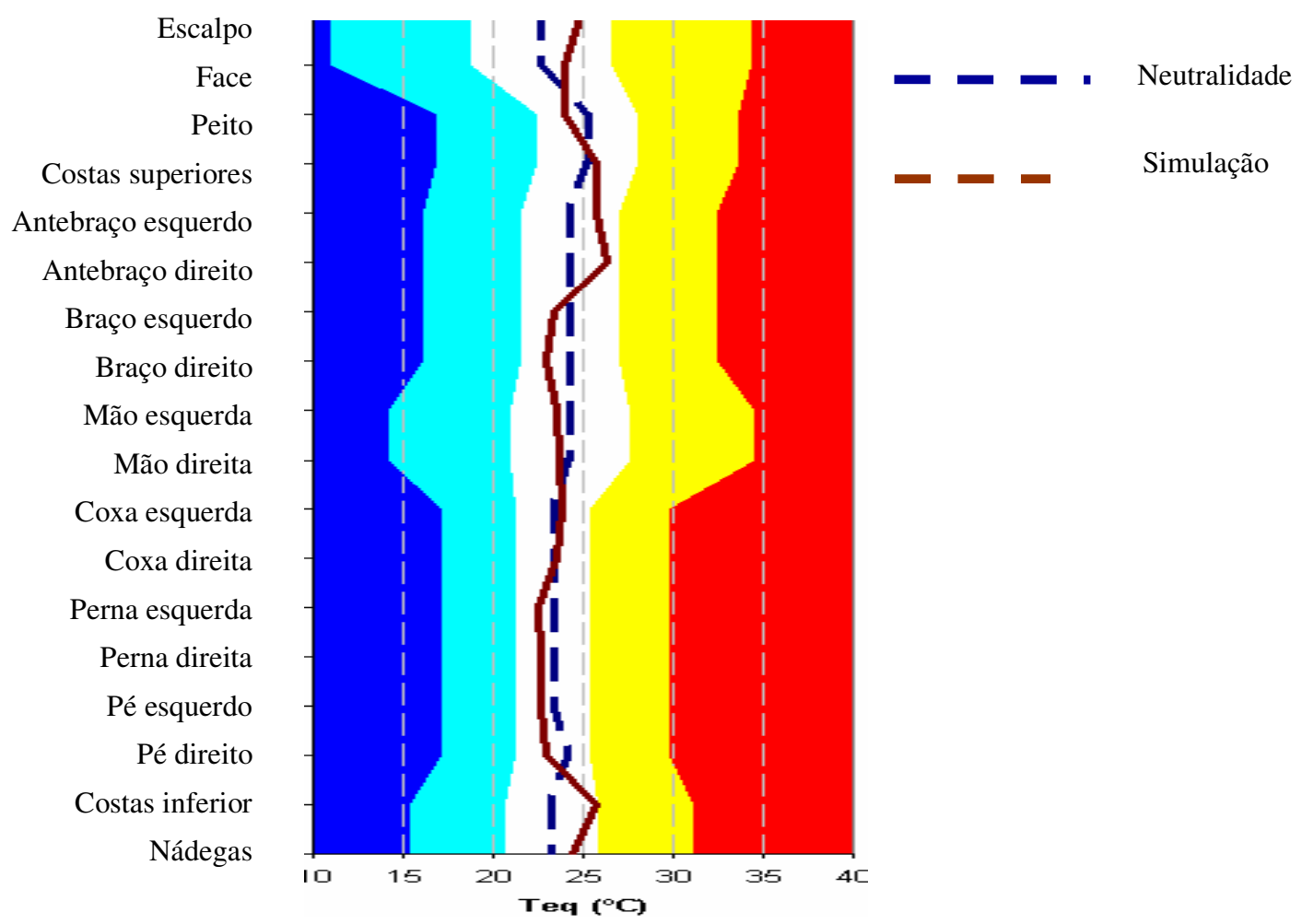

Figura 7.10 Diagrama de sensação térmica com temperaturas equivalentes na situação de avião em solo.

Como se pode notar na Figura 7.10 todos os segmentos estão dentro da zona de conforto. Somente o segmento inferior das costas está saindo da área de neutralidade térmica para a área com aquecimento confortável. Isto é de se esperar em função do isolamento promovido pelo banco. Nota-se que o segmento das costas superior está em condição de neutralidade.

A distribuição das temperaturas equivalentes para cada segmento do corpo no caso do avião em solo é apresentada nas figuras 7.11 e 7.12. A faixa azul no piso indica o lado da fuselagem. 


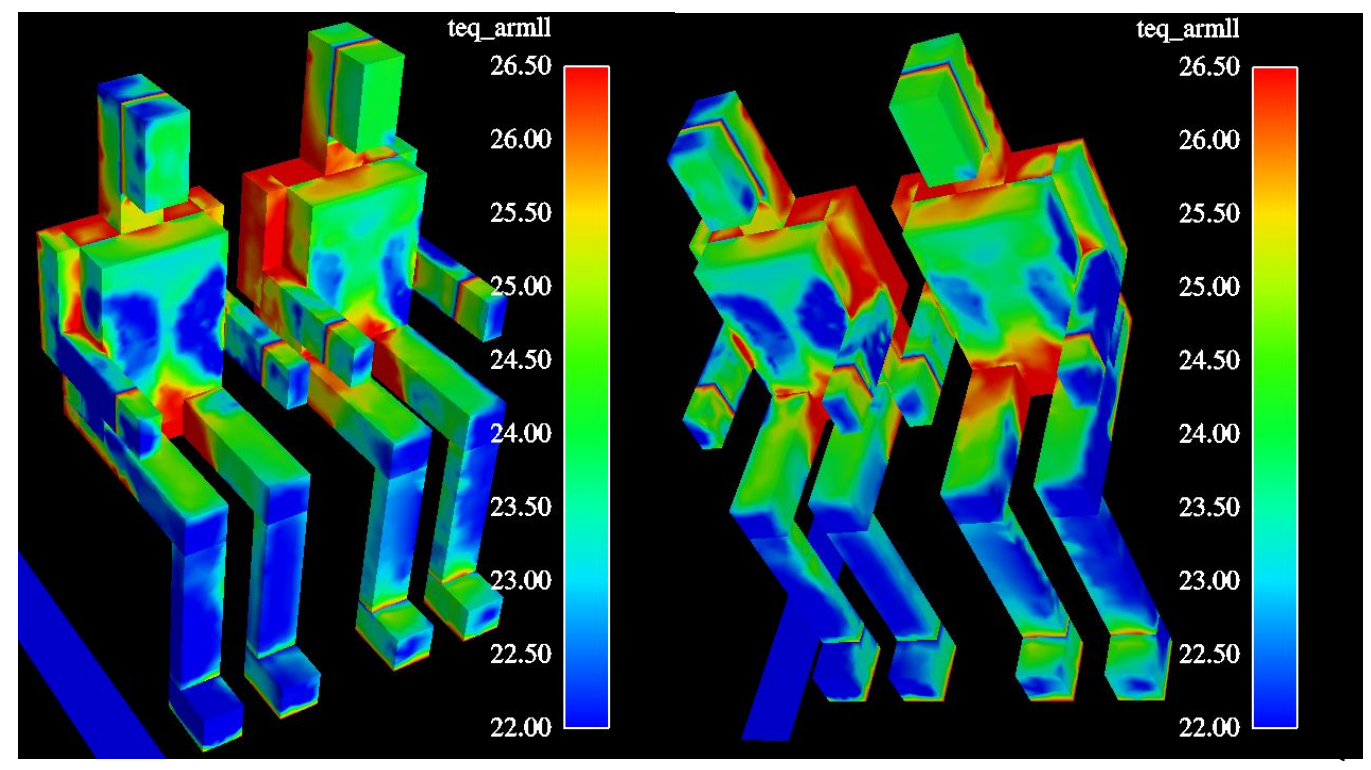

Figura 7.11 Distribuições das temperaturas equivalentes no caso do avião em solo.

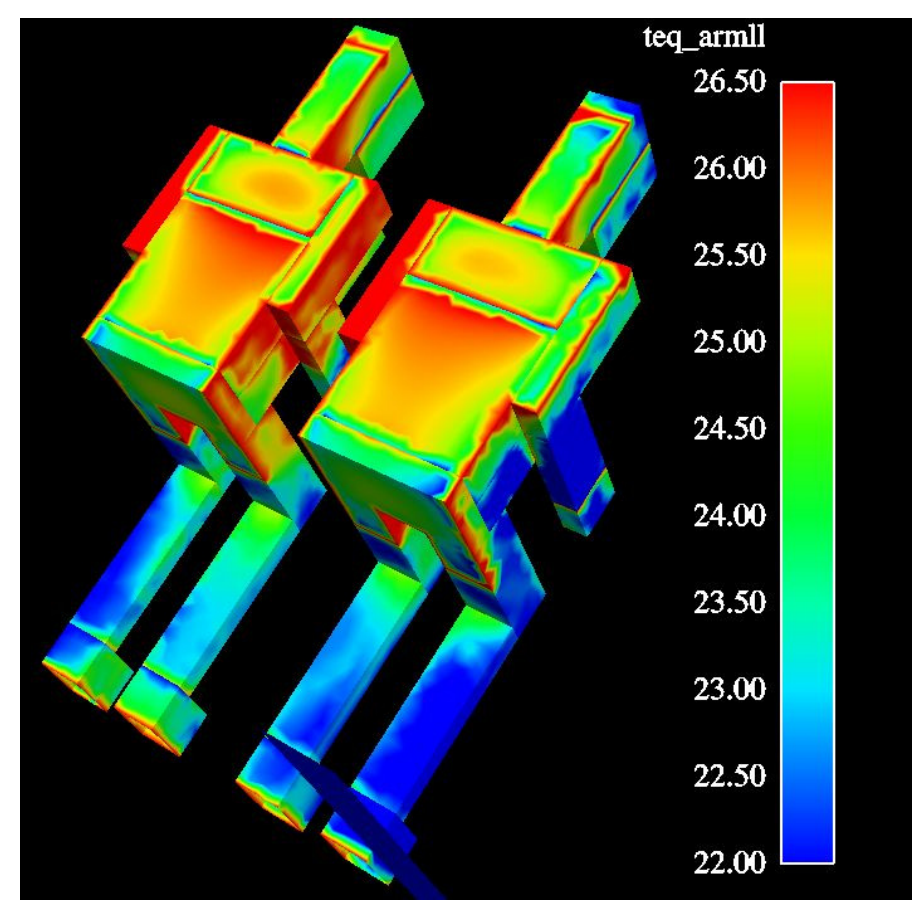

Figura 7.12 Distribuição das temperaturas equivalentes nas regiões de contato com o banco.

Pode-se reparar nas figuras 7.11 e 7.12 que o modelo conseguiu captar as variações das temperaturas equivalentes nos diversos segmentos. No braço de ambos os manequins se pode notar variações de $4,5{ }^{\circ} \mathrm{C}$. Regiões de pouca circulação de ar e próximas de outras 
superfícies apresentam temperaturas equivalentes altas como no encontro do braço, antebraço e peito e também na região da virilha. Existem assimetrias entre os lados internos dos manequins, mas os campos de temperatura são relativamente simétricos ao plano entre os manequins com exceção dos pés. Podem ser observadas descontinuidades das temperaturas equivalentes nos diversos segmentos por se ter resistências térmicas superficiais diferentes em cada segmento e não se ter simulado condução lateral pelas resistências térmicas superficiais.

$\mathrm{Na}$ figura 7.12 nota-se que as regiões de contato com o banco apresentaram temperaturas equivalentes mais altas, mas ainda dentro da faixa de conforto.

\section{Em vôo}

As temperaturas equivalentes com avião em vôo de cruzeiro são apresentadas na figura 7.13

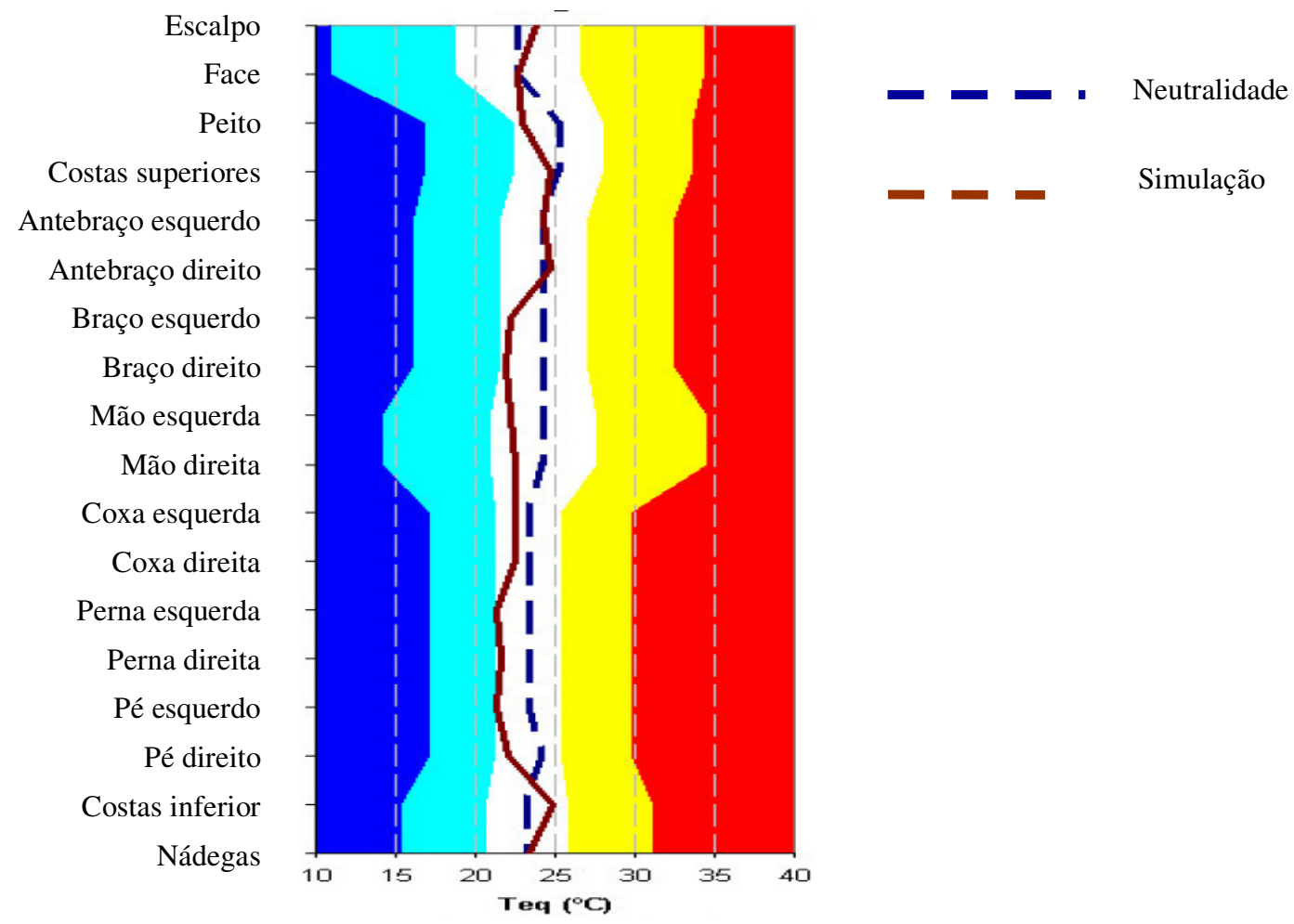

Figura 7.13 Temperaturas equivalentes com avião em vôo de cruzeiro.

Pode-se notar na figura 7.13 que as temperaturas equivalentes em vôo tiveram mesmas distribuição do caso do avião em solo com um deslocamento para o lado mais frio em média de $1,2{ }^{\circ} \mathrm{C}$. Isto se deve a uma temperatura média do ar mais baixa de $0,75^{\circ} \mathrm{C}$ e temperaturas mais baixas das paredes de $1,81{ }^{\circ} \mathrm{C}$. Assim, pode-se dizer que embora esteja na zona de 
conforto, tem os pés entrando na zona de desconforto e as costas e braços em conforto. Isto corrobora algumas medidas em vôo que indicam temperaturas equivalentes mais baixas nos pés.

A distribuição das temperaturas equivalentes no caso do avião em vôo é apresentada nas figuras 7.14 e 7.15. A caixa azul e vermelha no piso indica o lado da fuselagem.

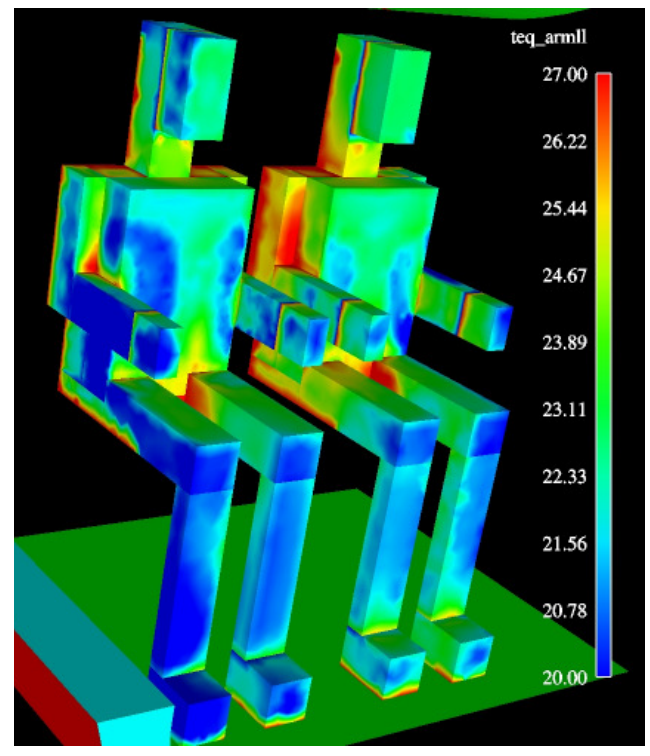

Figura 7.14 Temperaturas equivalentes com vista pela fuselagem.

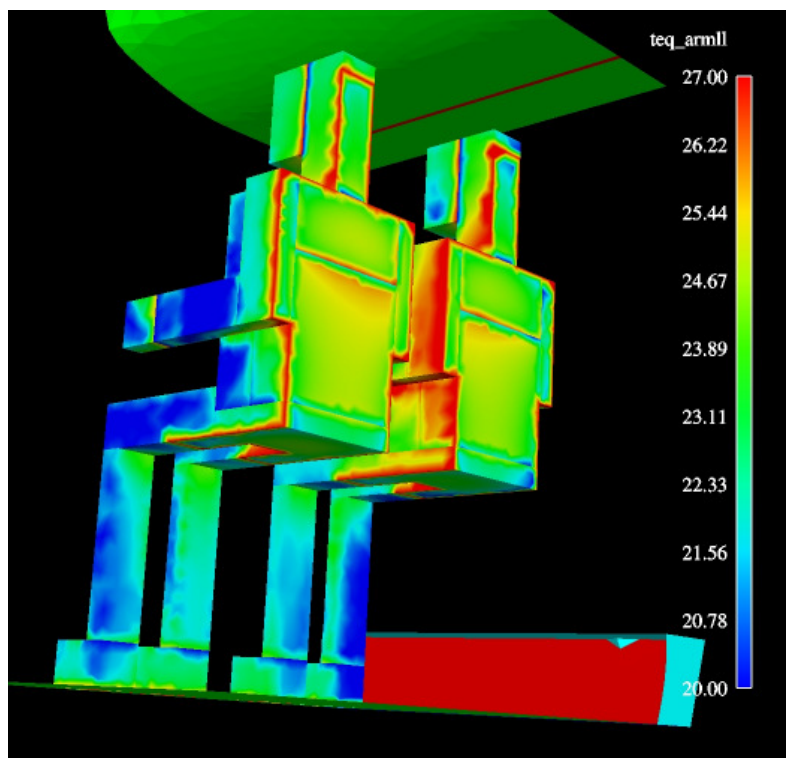

Figura 7.15 Temperaturas equivalentes vistas pelo lado do corredor. 
As visualizações das distribuições das temperaturas equivalentes nos manequins nas figuras 7.14 e 7.15 permitem visualizar assimetrias térmicas individuais que em uma análise em conjunto não é possível se observar. Pode-se verificar que existe uma assimetria térmica nos antebraços no manequim em torno de $6{ }^{\circ} \mathrm{C}$ no manequim próximo à janela. Pode-se notar que nesta região as assimetrias para o manequim próximo ao corredor também ocorrem, mas em um valor menor, próximo de $4{ }^{\circ} \mathrm{C}$. Em função das perdas por radiação para a parede da fuselagem, pode-se notar nas regiões das pernas uma evolução das $t_{\text {eqs }}$ para valores mais baixos com a proximidade da parede.

\section{Em emergência}

As temperaturas equivalentes com avião em condição de emergência são apresentadas na figura 7.16.

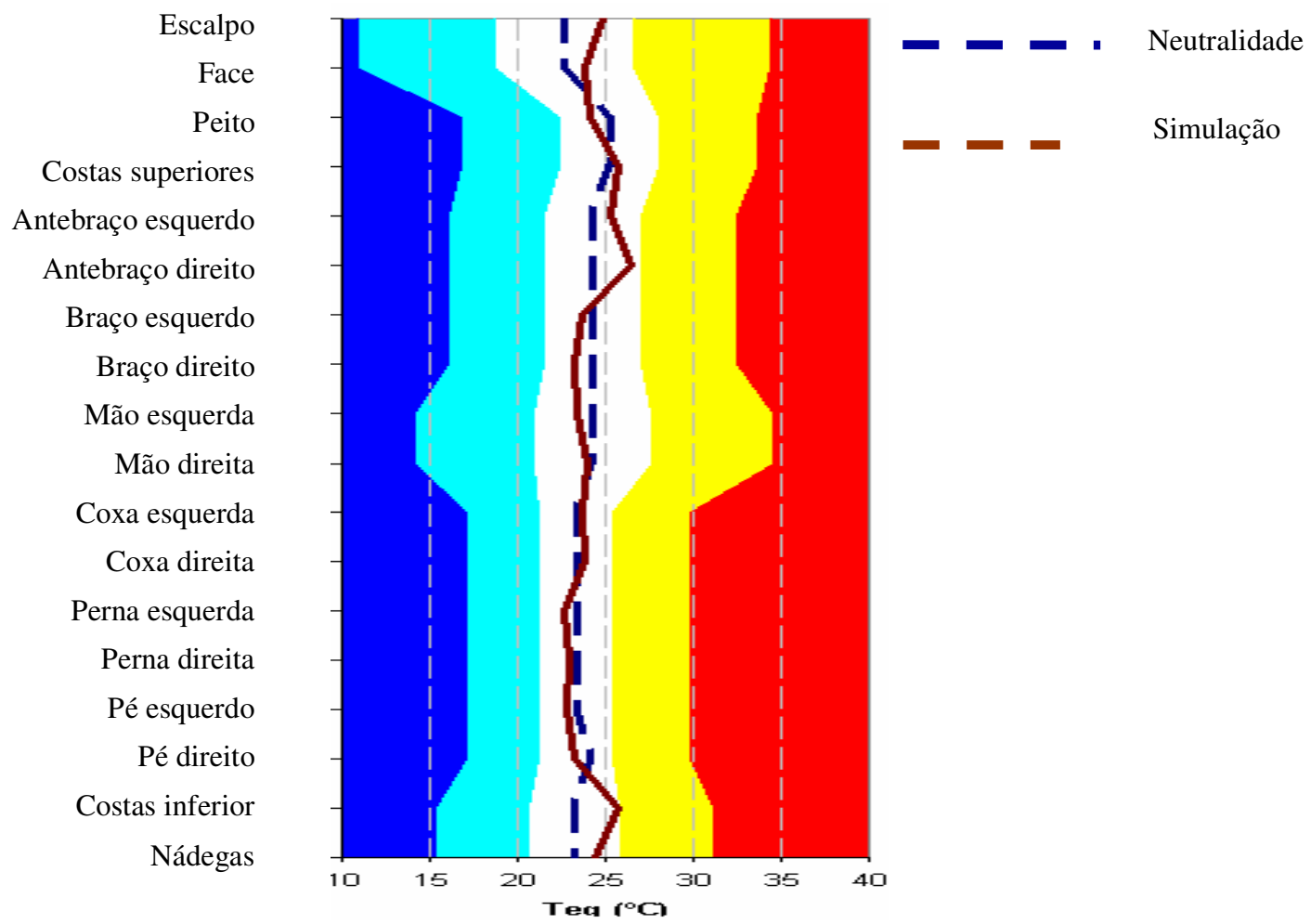

Figura 7.16 Temperaturas Equivalentes para situação de emergência.

Comparativamente pode-se verificar que na condição de falha, que possui uma vazão de ar $68 \%$ da vazão dos casos anteriores, apresenta um ganho nas temperaturas equivalentes de $1,2{ }^{\circ} \mathrm{C}$ causado por uma aumento médio de $1,1{ }^{\circ} \mathrm{C}$ na temperatura do ar referente ao vôo e 
0,8 ${ }^{\circ} \mathrm{C}$ nas paredes. Pode-se notar na figura 7.16 que o perfil da curva das $t_{\text {eqs }}$ também não houve modificação. Assim, as condições de conforto do caso de falha se aproximam bastante das condições em solo. Notar que ambas as situações propiciam melhores condições de conforto que em vôo, com as teqs mais próximas da linha de conforto. Portanto se nota a necessidade de em vôo se aumentar a temperatura do ar de insuflamento. Não se recomenda a outra possibilidade de diminuir a vazão de ar, pois chegaria à um nível mínimo recomendável como mostrou a situação de falha. As temperaturas equivalentes plotadas no manequim estão figura 7.17.

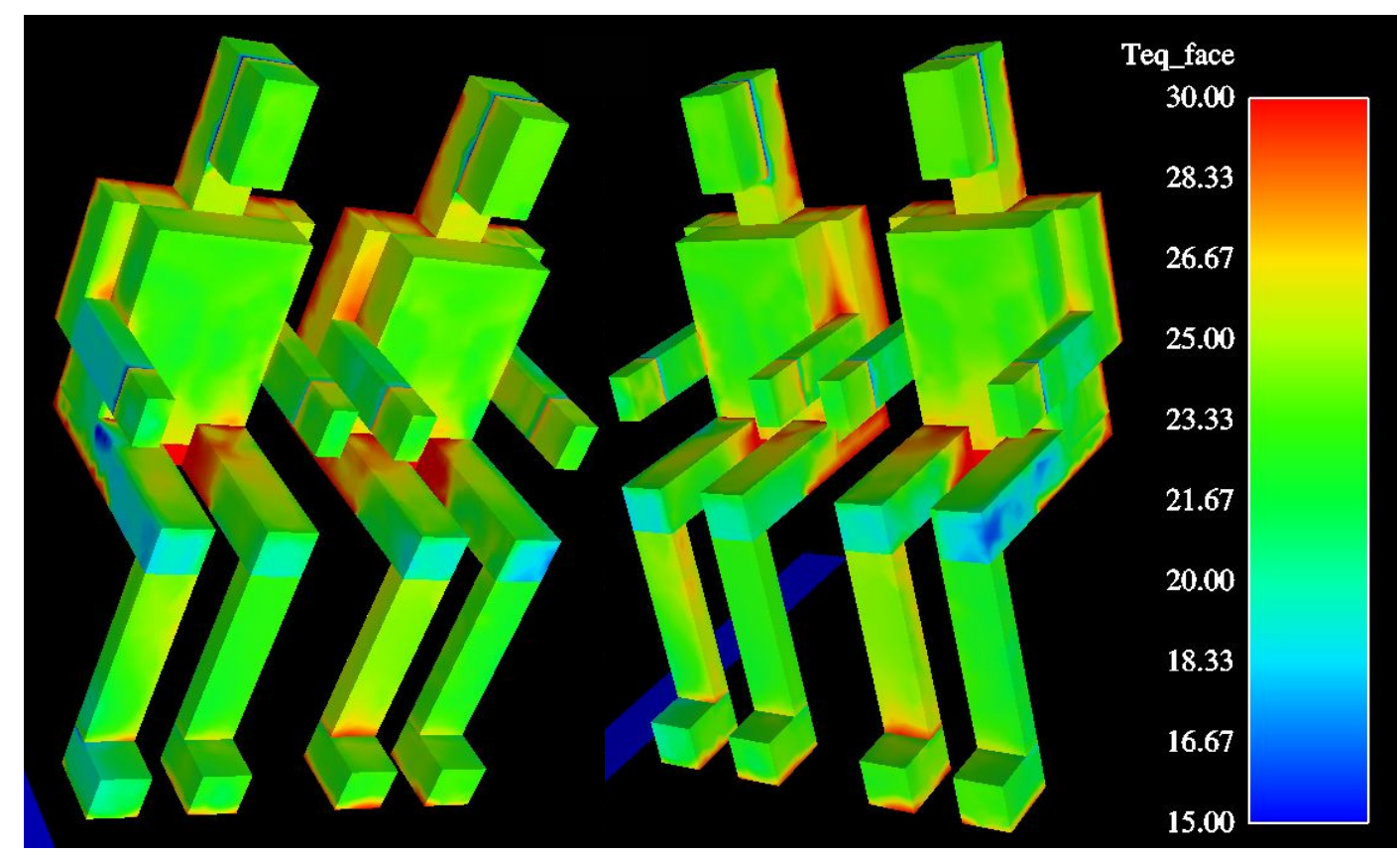

Figura 7.17 Distribuição das temperaturas equivalentes nos manequins no caso de situação de emergência.

\section{Conclusão}

A metodologia apresentada permite obter uma previsão dos níveis de conforto nos diversos segmentos do corpo humano para um passageiro a bordo de uma aeronave. Vê-se a necessidade de maiores investigações experimentais para validar os modelos numéricos, cujos resultados são apresentados a seguir. 


\subsection{RESULTADOS DE AVALIAÇÕES CONSIDERANDO CABINE COMPLETA}

O objetivo deste item é apresentar os resultados experimentais e numéricos das avaliações de cabine completa descritas nos Capítulos 5 e 6 . Como comentado no item anterior, a realização das avaliações experimentais surgiu da necessidade de se avaliar experimentalmente os modelos e técnicas numéricas desenvolvidas nas simulações na cabine considerando uma fileira de assentos. Para facilitar esta análise, os resultados numéricos e experimentais em cada experimento foram agrupados. Serão analisados e comparados os campos de temperatura e velocidade do ar em uma seção do mock-up inteiro. Posteriormente, serão analisadas as temperaturas equivalentes determinadas experimentalmente e as simuladas em duas posições na cabine.

\subsubsection{Resultados da avaliação do campo de velocidades e temperaturas do ar.}

Neste item são apresentados os resultados das avaliações numéricas e experimentais do campo de velocidades e temperaturas realizadas no mock-up experimental descritas nos Capítulos 5 e 6, item 5.2.1 e 6.3 respectivamente:

○ Cabine sem ocupação em situação de vôo;

○ Cabine com ocupação em situação de solo;

○ Cabine com ocupação em situação de vôo.

\section{Cabine sem ocupação em situação de vôo}

Na Figura 7.9 são apresentados os valores médios para as variáveis medidas experimentalmente na cabine do mock-up: 
Tabela 7.9 Valores médios medidos experimentalmente na cabine do mock-up

\begin{tabular}{cc}
\hline Medida & Valor \\
\hline Temperatura do piso & $21,5{ }^{\circ} \mathrm{C}$ \\
Temperatura superfície lateral esquerda & $21,7{ }^{\circ} \mathrm{C}$ \\
Temperatura superfície lateral direita & $21,2{ }^{\circ} \mathrm{C}$ \\
Temperatura do teto & $22,3{ }^{\circ} \mathrm{C}$ \\
Temperatura das paredes traseira e frontal & $22,4{ }^{\circ} \mathrm{C}$ \\
Temperatura dos bins & $23,4{ }^{\circ} \mathrm{C}$ \\
Entrada de ar difusor 1 da esquerda & $0,85 \mathrm{~m} / \mathrm{s} \mathrm{e} 21,6{ }^{\circ} \mathrm{C}$ \\
Entrada de ar difusor 2 da esquerda & $0,83 \mathrm{~m} / \mathrm{s} \mathrm{e} 21,3{ }^{\circ} \mathrm{C}$ \\
Entrada de ar difusor 3 da esquerda & $0,83 \mathrm{~m} / \mathrm{s} 21,5{ }^{\circ} \mathrm{C}$ \\
Entrada de ar difusor 1 da direita & $1,00 \mathrm{~m} / \mathrm{s} \mathrm{e} 21,2{ }^{\circ} \mathrm{C}$ \\
Entrada de ar difusor 2 da direita & $1,11 \mathrm{~m} / \mathrm{s} \mathrm{e} 20,8{ }^{\circ} \mathrm{C}$ \\
Entrada de ar difusor 3 da direita & $1,10 \mathrm{~m} / \mathrm{s} \mathrm{e} 20,7{ }^{\circ} \mathrm{C}$ \\
\hline
\end{tabular}

Como se pode perceber na tabela 7.9 houve uma maior velocidade nas entradas de ar do lado direito. Também as temperaturas do lado direito foram ligeiramente menores em função dos dutos de insuflamento estarem mais próximos de um aparelho split de ar condicionado que mantinha o laboratório a uma temperatura mais baixa.

Na tabela 7.10 são apresentados os valores experimentais e numéricos das velocidades verticais (Vv) e horizontais (Vh).

Tabela 7.10 Velocidades do ar: horizontais e verticais a diferentes alturas.

\begin{tabular}{|c|c|c|c|c|c|c|c|c|c|c|c|}
\hline \multicolumn{11}{|c|}{$\begin{array}{l}\text { Velocidades do ar horizontais e verticais a diferentes alturas } \\
\mathrm{m} / \mathrm{s}\end{array}$} & \multirow[b]{3}{*}{ Alturas } \\
\hline \multicolumn{5}{|c|}{ Medidas } & \multicolumn{5}{|c|}{ Calculadas pelo modelo numérico } & & \\
\hline A & B & $\mathrm{C}$ & D & $\mathbf{E}$ & $\mathbf{A}$ & B & $\mathbf{C}$ & D & $\mathbf{E}$ & & \\
\hline & & $\mathbf{0 , 3}$ & & & & & 0,02 & & & $\mathbf{V v}$ & \\
\hline & & $\mathbf{0 , 2}$ & & & & & 0,01 & & & $\mathbf{V h}$ & 1,7 \\
\hline 0 & 0 & 0,22 & 0 & 0 & 0 & 0,04 & 0,04 & 0,05 & 0,05 & $\mathbf{V v}$ & \\
\hline $\mathbf{0}$ & $\mathbf{0}$ & $\mathbf{0}$ & $\mathbf{0}$ & $\mathbf{0}$ & $\mathbf{0 , 0 2}$ & $\mathbf{0}$ & $\mathbf{0 , 0 2}$ & 0,12 & 0,05 & Vh & 1,3 \\
\hline $\mathbf{0}$ & $\mathbf{0}$ & $\mathbf{0}$ & $\mathbf{0}$ & $\mathbf{0}$ & $\mathbf{0}$ & 0,2 & 0,06 & 0,06 & 0,05 & $\mathbf{V v}$ & \\
\hline $\mathbf{0}$ & $\mathbf{0}$ & $\mathbf{0}$ & $\mathbf{0}$ & $\mathbf{0}$ & $\mathbf{0 , 0 3}$ & $\mathbf{0 , 0 7}$ & $\mathbf{0}$ & $\mathbf{0 , 0 2}$ & 0,01 & $\mathbf{V h}$ & 1,1 \\
\hline 0 & 0 & 0 & $\mathbf{0}$ & 0 & 0 & 0,28 & 0,07 & $\mathbf{0 , 0 7}$ & 0,05 & $\mathbf{V v}$ & \\
\hline 0 & 0 & 0 & 0 & 0 & $\mathbf{0 , 0 3}$ & 0,07 & 0,09 & 0,02 & 0,01 & Vh & 0,9 \\
\hline 0 & 0 & & $\mathbf{0}$ & 0 & 0,05 & 0,22 & & 0,05 & $\mathbf{0 , 0 3}$ & $\mathbf{V v}$ & \\
\hline 0 & 0 & & 0 & 0 & $\mathbf{0 , 0 3}$ & 0,04 & & 0,06 & $\mathbf{0 , 0 4}$ & Vh & 0,6 \\
\hline 0 & 0 & 0 & 0 & 0 & 0,15 & 0,21 & $\mathbf{0 , 0 7}$ & 0,02 & 0,02 & $\mathbf{V v}$ & \\
\hline 0 & 0 & 0 & 0 & 0 & 0,01 & 0,01 & 0,09 & 0,11 & $\mathbf{0 , 0 8}$ & $\mathbf{V h}$ & 0,3 \\
\hline 0 & 0 & 0 & 0 & 0 & 0,1 & 0,13 & 0,06 & 0 & 0 & $\mathbf{V v}$ & \\
\hline 0 & 0 & 0 & 0 & 0 & 0,07 & $\mathbf{0 , 0 2}$ & 0,08 & 0,15 & 0,14 & Vh & 0,1 \\
\hline
\end{tabular}

Pode-se notar na tabela 7.10 que o campo de velocidades numérico foi em média superior $0,03 \mathrm{~m} / \mathrm{s}$ que os valores experimentais. Nota-se também que somente em dois pontos na região superior do corredor as velocidades experimentais foram acima da resolução do 
anemômetro. Notou-se experimentalmente que, como não existem cargas térmicas, o ar é insuflado à mesma temperatura do ar da cabine, e as velocidades são muito baixas com um movimento pistonado para baixo. Posteriormente, os campos de velocidade foram medidos com a presença de simuladores térmicos sem geração de calor e notou-se o mesmo fenômeno. Assim, pode-se concluir que a pluma térmica dos passageiros causa uma movimentação no ar em cabines com vazões típicas.

As temperaturas do ar medidas e calculadas no modelo numérico são apresentadas na tabela 7.11.

Tabela 7.11 Temperaturas do ar medidas e calculadas nas diversas alturas e posições da cabine.

\begin{tabular}{ccccc|cccccc}
\hline \multicolumn{4}{c|}{ Temperaturas do ar medidas } & \multicolumn{7}{c}{ Temperaturas do ar calculadas } \\
\hline A & B & C & D & E & A & B & C & D & E & alturas \\
\hline & & 21,6 & & & & & 21,8 & & & 1,7 \\
21,3 & 21,3 & 21,3 & 21,1 & 21,3 & 22 & 22 & 21,7 & 21,8 & 21,8 & 1,3 \\
21,3 & 21,3 & 21,3 & 21,2 & 21,1 & 21,9 & 21,6 & 21,8 & 21,8 & 21,7 & 1,1 \\
21,3 & 21,3 & 21,3 & 21,1 & 21,2 & 21,9 & 21,6 & 21,8 & 21,7 & 21,7 & 0,9 \\
21,3 & 21,3 & 21,3 & 21,1 & 21,2 & 21,8 & 21,6 & 21,7 & 21,7 & 21,7 & 0,6 \\
21,3 & 21,3 & 21,3 & 21,1 & 21,2 & 21,7 & 21,7 & 21,7 & 21,7 & 21,7 & 0,3 \\
21,3 & 21,3 & 21,3 & 21,1 & 21,2 & 21,7 & 21,7 & 21,7 & 21,7 & 21,7 & 0,1 \\
\hline
\end{tabular}

Nota-se na tabela 7.11 que as temperaturas do ar calculadas foram bastantes homogêneas em função de se ter temperaturas superficiais muito próximas das insufladas e ausência de carga térmica interna. Houve uma boa concordância entre os valores numéricos e experimentais.

As velocidades do ar na seção da cabine descrita no item 5.1.2 do Capítulo 5 são apresentas nas figuras 7.18 e 7.19 . 


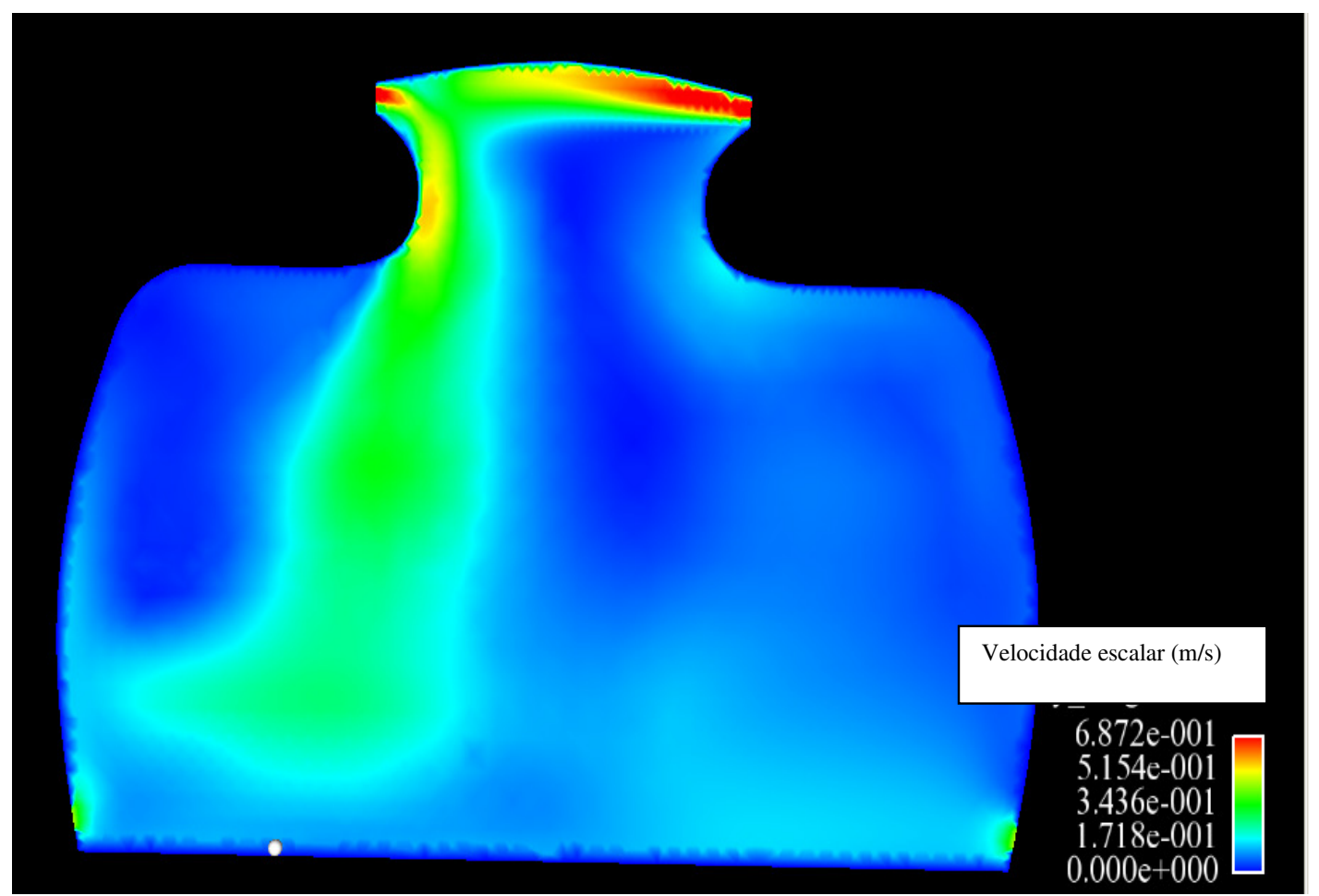

Figura 7.18 Campo de velocidades escalares.

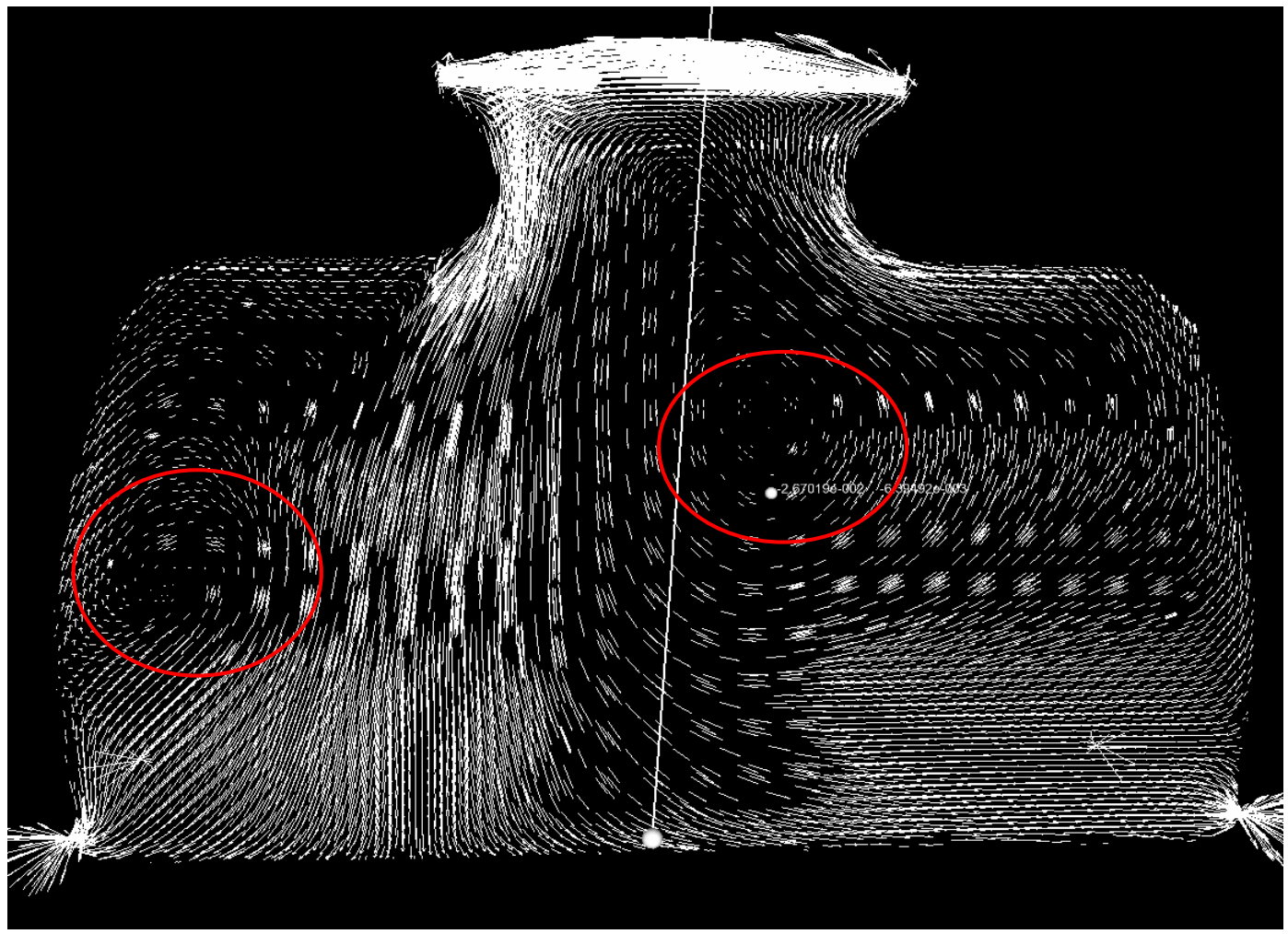

Figura 7.19 Campo vetorial das velocidades mostrando duas áreas de recirculação. 
É possível se observar nas figuras 7.19 e 7.20 que o jato mais forte à direita causa uma assimetria no escoamento com campo de velocidades maiores à esquerda. Dois vórtices de recirculação são observados na figura 7.19.

\section{Cabine com ocupação em situação de solo}

Os valores médios para as variáveis medidas experimentalmente são apresentadas na tabela 7.12:

Tabela 7.12 Condições de contorno medidas e adotadas numericamente.

\begin{tabular}{cl}
\hline Superfície & \multicolumn{1}{c}{ Valores } \\
\hline Piso & $24,0{ }^{\circ} \mathrm{C}$ \\
Lateral esquerda & $28,2{ }^{\circ} \mathrm{C}$ \\
Lateral direita & 26,4 \\
Teto & $22,5{ }^{\circ} \mathrm{C}$ \\
Parede dianteira & 26,4 \\
Parede traseira & $25{ }^{\circ} \mathrm{C}$ \\
Bins & $22,1{ }^{\circ} \mathrm{C}$ \\
Simuladores térmicos & $34,0{ }^{\circ} \mathrm{C}$ \\
Entrada de ar esquerda 1 & $0,85 \mathrm{~m} / \mathrm{s} \mathrm{e} 16,8{ }^{\circ} \mathrm{C}$ \\
Entrada de ar esquerda 2 & $0,83 \mathrm{~m} / \mathrm{s} \mathrm{e} 16,8{ }^{\circ} \mathrm{C}$ \\
Entrada de ar esquerda 3 & $0,83 \mathrm{~m} / \mathrm{s} 16,8{ }^{\circ} \mathrm{C}$ \\
Entrada de ar direita 1 & $1,00 \mathrm{~m} / \mathrm{s} \mathrm{e} 16,0{ }^{\circ} \mathrm{C}$ \\
Entrada de ar direita 2 & $1,11 \mathrm{~m} / \mathrm{s} \mathrm{e} 16,0{ }^{\circ} \mathrm{C}$ \\
Entrada de ar direita 3 & $1,10 \mathrm{~m} / \mathrm{s} \mathrm{e} 16,0{ }^{\circ} \mathrm{C}$ \\
\hline
\end{tabular}

Pode-se notar na tabela 7.12 que a lateral esquerda ficou mais quente $1,8{ }^{\circ} \mathrm{C}$ que a direita, pelo efeito de simulação de radiação solar pelo lado esquerdo. O teto e bins apresentam baixa temperatura pelo efeito convectivo do ar frio que sai por cima dos bagageiros.

As velocidades experimentais e numéricas do ar a diferentes alturas são apresentadas na tabela 7.13 . 
Tabela 7.13 Velocidades do ar horizontais e verticais a diferentes alturas e posições.

\begin{tabular}{|c|c|c|c|c|c|c|c|c|c|c|c|}
\hline \multicolumn{11}{|c|}{$\begin{array}{c}\text { Velocidades do ar horizontais e verticais a diferentes alturas } \\
\mathrm{m} / \mathrm{s}\end{array}$} & \multirow[b]{3}{*}{ Alturas } \\
\hline & \multicolumn{3}{|c|}{ Medidas } & \multirow[b]{2}{*}{$\mathbf{E}$} & \multicolumn{5}{|c|}{ Calculadas } & & \\
\hline $\mathbf{A}$ & B & $\mathrm{C}$ & D & & $\mathbf{A}$ & B & $\mathrm{C}$ & D & $\mathbf{E}$ & & \\
\hline & & 0,20 & & & & & 0,06 & & & $\mathbf{V v}$ & 17 \\
\hline & & 0,13 & & & & & 0,04 & & & Vh & 1,7 \\
\hline 0,06 & 0,05 & 0,12 & 0,10 & 0,09 & 0,07 & 0,22 & 0,05 & 0,00 & 0,01 & $\mathbf{V v}$ & 13 \\
\hline 0,03 & 0,06 & 0,09 & 0,07 & 0,04 & 0,15 & 0,20 & 0,10 & $\mathbf{0 , 1 5}$ & 0,07 & Vh & \\
\hline 0,08 & 0,06 & 0,20 & 0,06 & 0,12 & 0,14 & 0,10 & 0,05 & 0,03 & 0,03 & $\mathbf{V v}$ & 1 \\
\hline 0,05 & 0,07 & 0,09 & 0,06 & 0,06 & 0,10 & 0,12 & 0,08 & 0,13 & 0,07 & Vh & 1,1 \\
\hline 0,13 & $\mathbf{0 , 0 8}$ & 0,10 & 0,06 & $\mathbf{0 , 0 3}$ & 0,21 & 0,08 & 0,02 & 0,05 & 0,05 & $\mathbf{V v}$ & 00 \\
\hline 0,04 & 0,08 & 0,08 & 0,05 & 0,11 & 0,08 & 0,07 & 0,05 & 0,00 & 0,05 & Vh & \\
\hline 0,10 & 0,08 & & 0,05 & 0,04 & 0,20 & 0,07 & & 0,06 & 0,09 & $\mathbf{V v}$ & \\
\hline 0,03 & 0,06 & & 0,05 & 0,03 & 0,03 & $\mathbf{0 , 0 3}$ & & 0,02 & 0,03 & Vh & 0,6 \\
\hline $\mathbf{0 , 0 7}$ & $\mathbf{0 , 0 8}$ & 0,24 & 0,05 & 0,06 & 0,16 & $\mathbf{0 , 0 0}$ & $\mathbf{0 , 0 3}$ & 0,09 & 0,15 & $\mathbf{V v}$ & 03 \\
\hline 0,10 & 0,17 & 0,07 & $\mathbf{0 , 0 7}$ & 0,04 & 0,02 & 0,00 & 0,08 & 0,02 & 0,02 & Vh & 0,3 \\
\hline 0,04 & 0,07 & 0,08 & 0,03 & 0,06 & 0,05 & 0,02 & 0,01 & 0,01 & $\mathbf{0 , 0 0}$ & $\mathbf{V v}$ & 01 \\
\hline 0,10 & 0,23 & 0,11 & 0,04 & 0,07 & 0,02 & $\mathbf{0 , 0 3}$ & 0,18 & 0,03 & 0,02 & Vh & \\
\hline
\end{tabular}

Nota-se que o campo de velocidades experimentais, com e sem carga térmica (carga térmica de ocupação) são bastante diferentes, com uma maior movimentação com o efeito das plumas térmicas dos simuladores.

As temperaturas do ar a diversas alturas são apresentadas na tabela 7.14.

Tabela 7.14 Temperaturas do ar a diversas alturas e posições da cabine.

\begin{tabular}{|c|c|c|c|c|c|c|c|c|c|c|}
\hline \multicolumn{5}{|c|}{$\begin{array}{l}\text { Temperaturas do ar medidas } \\
{ }^{\circ} \mathrm{C}\end{array}$} & \multicolumn{5}{|c|}{$\begin{array}{l}\text { Temperaturas do ar calculadas } \\
{ }^{\circ} \mathrm{C}\end{array}$} & \multirow[b]{2}{*}{ alturas } \\
\hline A & B & $\mathrm{C}$ & $\mathrm{D}$ & $\bar{E}$ & $\mathrm{~A}$ & B & $\mathrm{C}$ & $\mathrm{D}$ & $\bar{E}$ & \\
\hline & & 22,5 & & & & & 24,7 & & & 1,7 \\
\hline 24,0 & 23,9 & 23,2 & 23,8 & 24,8 & 22,3 & 23,0 & 24,6 & 24,4 & 24,0 & 1,3 \\
\hline 23,9 & 23,6 & 23,3 & 24,0 & 25,5 & 22,4 & 24 & 24,6 & 24,4 & 24,0 & 1,1 \\
\hline 23,8 & 23,6 & 23,3 & 24,0 & 25,1 & 22,3 & 24,1 & 24,4 & 24,7 & 24,1 & 0,9 \\
\hline 23,7 & 23,6 & & 24,0 & 25,4 & 22,3 & 24 & & 24,7 & 24,7 & 0,6 \\
\hline 23,6 & 23,5 & 23,5 & 24,0 & 25,4 & 22,5 & 25,2 & 24,2 & 25,0 & 24,6 & 0,3 \\
\hline 23,6 & 23,4 & 23,6 & 24,4 & 26,0 & 23,3 & 25,3 & 23,7 & 25,6 & 25,5 & 0,1 \\
\hline
\end{tabular}

Pode-se notar na tabela 7.14 que houve uma boa correspondência quanto aos valores numérico e experimental da temperatura do ar. Experimentalmente verifica-se que as temperaturas do ar medidas no corredor estão menores que nas laterais. Isto indica que o ar insuflado desce preferencialmente pelo corredor, pois os bagageiros estrangulam o escoamento, forçando-o a se encaminhar pelo centro da cabine. Numericamente isto também ocorre, mas o jato mais forte do lado direito causa um desvio desta coluna de ar frio para a esquerda, como se pode observar na tabela 7.14. 
Os campos de velocidades e de temperaturas do ar da simulação são apresentados nas figuras 7.20 a 7.22 .

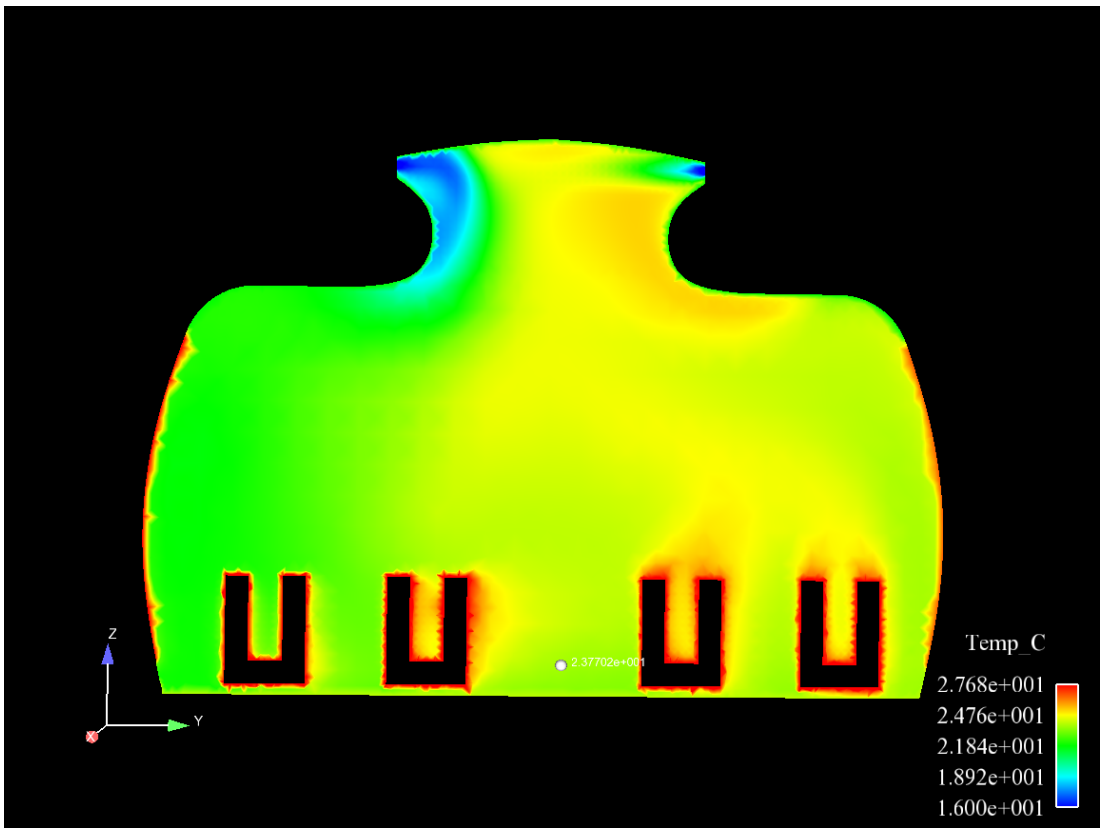

Figura 7.20 Campo de temperaturas do ar.

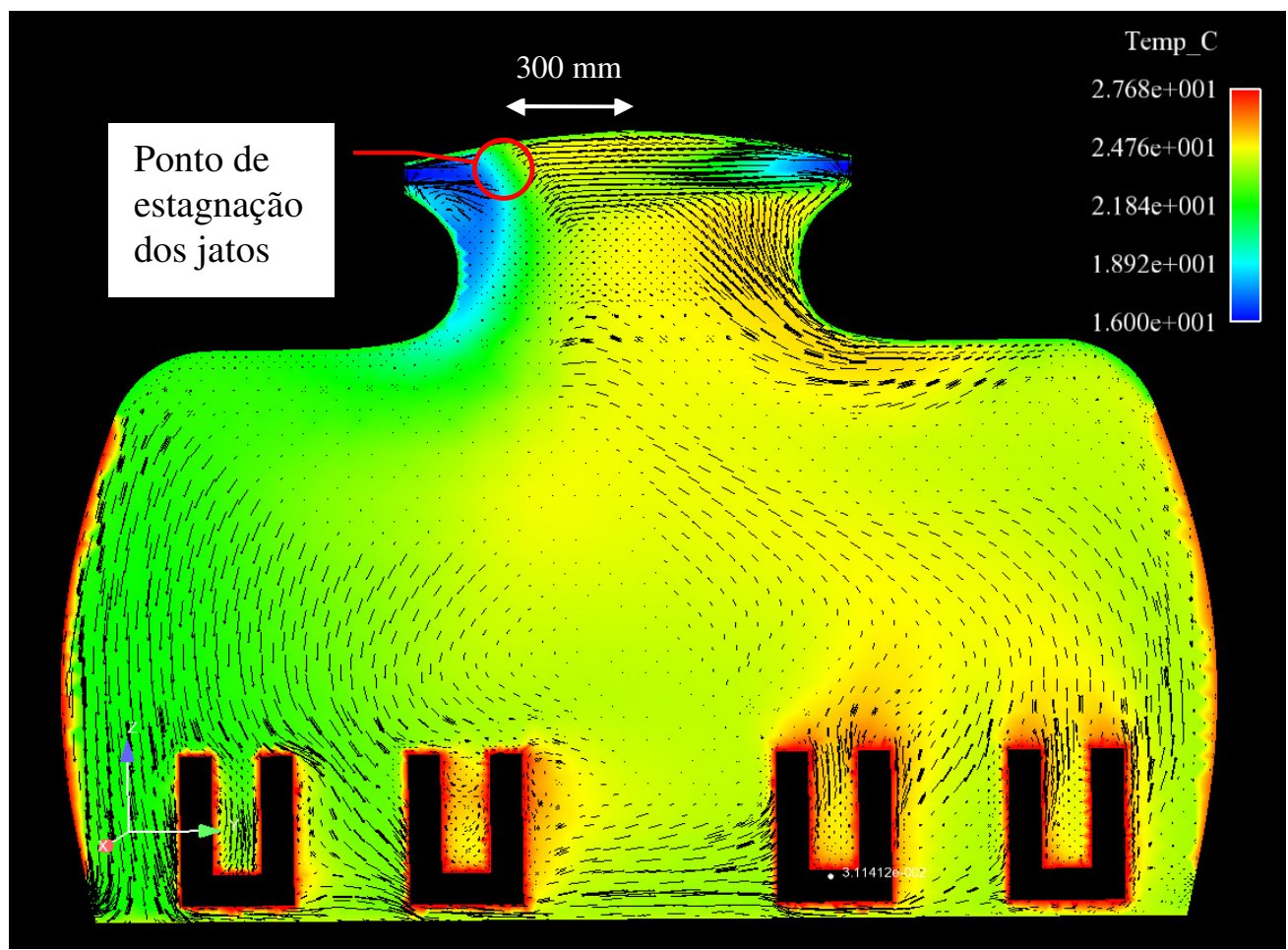

Figura 7.21 Campos de velocidades vetoriais e de temperaturas do ar na seção de medição com posição do ponto de estagnação dos jatos. 


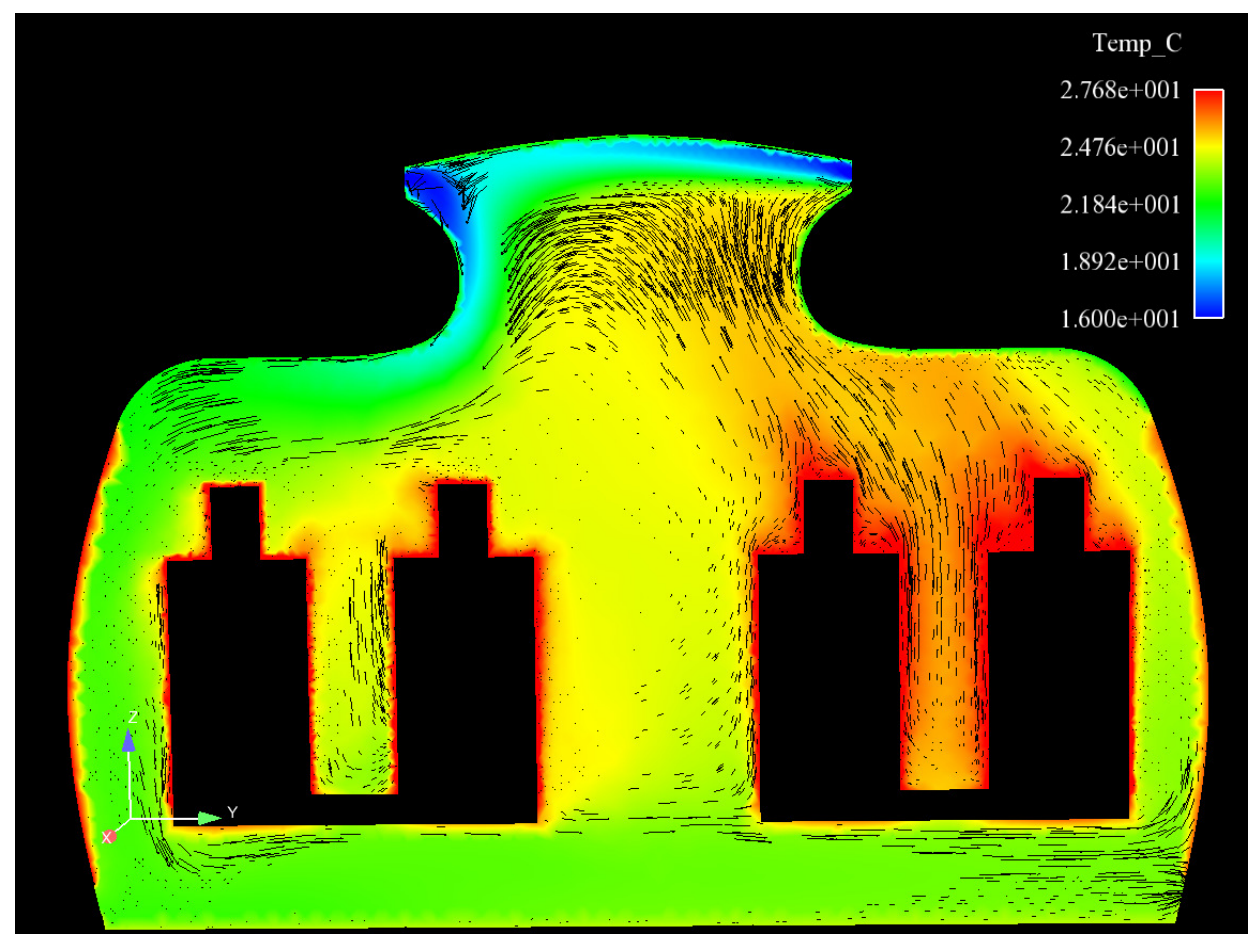

Figura 7.22 Campos de velocidades vetoriais e de temperaturas do ar na seção mediana dos simuladores térmicos.

Ocorre uma grande circulação no sentido anti-horário, causado pela diferença nas vazões das entradas de ar esquerda e direita. Experimentalmente, o ponto de estagnação mostrado na figura 7.21 ocorre a $60 \mathrm{~mm}$ da linha do centro e não a $300 \mathrm{~mm}$ como aparece na simulação. Na figura 7.22 pode-se notar as plumas térmicas ascendente dos simuladores à direita. Já os simuladores à esquerda têm sua pluma térmica ascendente diminuída pelo campo de velocidade descendente.

\section{Cabine com ocupação em condição de vôo}

Os valores médios das variáveis medidas experimentais são apresentados na tabela 7.15: 
Tabela 7.15 Condições de contorno medidas

\begin{tabular}{cc}
\hline Superfície & Valores \\
\hline Piso & $20,0{ }^{\circ} \mathrm{C}$ \\
Lateral esquerda & $21,8{ }^{\circ} \mathrm{C}$ \\
Lateral direita & $22,1{ }^{\circ} \mathrm{C}$ \\
Teto & $18,0{ }^{\circ} \mathrm{C}$ \\
Parede dianteira & $22,4{ }^{\circ} \mathrm{C}$ \\
Parede traseira & $20,0{ }^{\circ} \mathrm{C}$ \\
Bins & $19,0{ }^{\circ} \mathrm{C}$ \\
Simuladores térmicos & $29,0{ }^{\circ} \mathrm{C}$ \\
Entrada de ar esquerda 1 & $0,85 \mathrm{~m} / \mathrm{s} \mathrm{e} 14,3{ }^{\circ} \mathrm{C}$ \\
Entrada de ar esquerda 2 & $0,83 \mathrm{~m} / \mathrm{s} \mathrm{e} 14,3{ }^{\circ} \mathrm{C}$ \\
Entrada de ar esquerda 3 & $0,83 \mathrm{~m} / \mathrm{s} \mathrm{e} 13,8{ }^{\circ} \mathrm{C}$ \\
Entrada de ar direita 1 & $1,10 \mathrm{~m} / \mathrm{s} \mathrm{e} 14,3{ }^{\circ} \mathrm{C}$ \\
Entrada de ar direita 2 & $1,11 \mathrm{~m} / \mathrm{s} \mathrm{e} 14,0{ }^{\circ} \mathrm{C}$ \\
Entrada de ar direita 3 & $1,00 \mathrm{~m} / \mathrm{s} \mathrm{e} 13,4{ }^{\circ} \mathrm{C}$ \\
\hline
\end{tabular}

As velocidades e temperaturas do ar são apresentadas na tabelas 7.16 e 7.17 respectivamente.

Tabela 7.16 Velocidades do ar horizontais e verticais a diferentes alturas e posições.

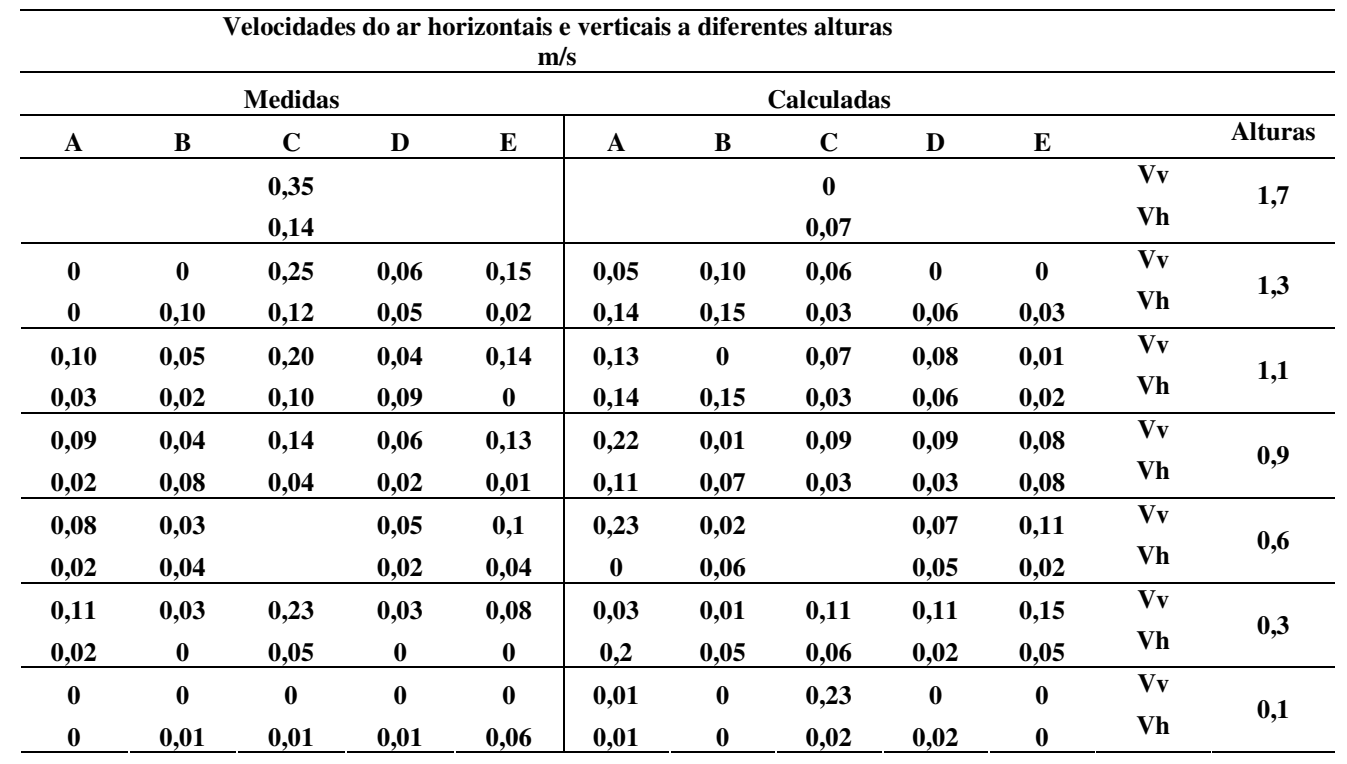


Tabela 7.17 Temperaturas do ar a diversas alturas e posições da cabine.

\begin{tabular}{ccccc|cccccc}
\hline \multicolumn{4}{c|}{ Temperaturas do ar medidas } & \multicolumn{6}{c}{ Temperaturas do ar calculadas } \\
\hline A & B & C & D & E & A & B & C & D & E & alturas \\
\hline & & 18 & & & & & 20,7 & & & 1,7 \\
18,9 & 19,0 & 18,5 & 18,5 & 18,3 & 19,0 & 20,0 & 20,7 & 20,7 & 20,7 & 1,3 \\
19,6 & 19,4 & 19,3 & 19,2 & 19,0 & 19,1 & 20,3 & 20,7 & 20,6 & 20,4 & 1,1 \\
19,5 & 19,6 & 19,6 & 19,4 & 19,4 & 19,0 & 20,2 & 20,3 & 20,5 & 20,5 & 0,9 \\
19,6 & 19,4 & & 19,3 & 19,3 & 19,1 & 20,0 & & 20,7 & 20,9 & 0,6 \\
19,8 & 19,1 & 19,2 & 19,2 & 19,2 & 20,2 & 21,3 & 20,2 & 20,8 & 20,9 & 0,3 \\
18,8 & 19,0 & 18,7 & 19,1 & 19,1 & 21,3 & 20,8 & 19,5 & 21,2 & 21,4 & 0,1 \\
\hline
\end{tabular}

Pode-se notar na tabela 7.16 que as velocidades medidas maiores (verticais) estão na região do corredor. Numericamente esta região foi deslocada para a esquerda. Nota-se que tanto experimentalmente como numericamente o escoamento próximo dos pés apresenta escoamento horizontal. Nota-se na tabela 7.17 que o campo de temperaturas medidas foi menor em média $1{ }^{\circ} \mathrm{C}$ que as calculadas (simulação). Também o campo de temperaturas medidas indica que o jato principal está na região do corredor, pois as temperaturas mais baixas estão nos pontos mais altos deste.

Os campos de velocidades e temperaturas do ar da simulação e experimentais são apresentadas nas figuras 7.23 e 7.24 .

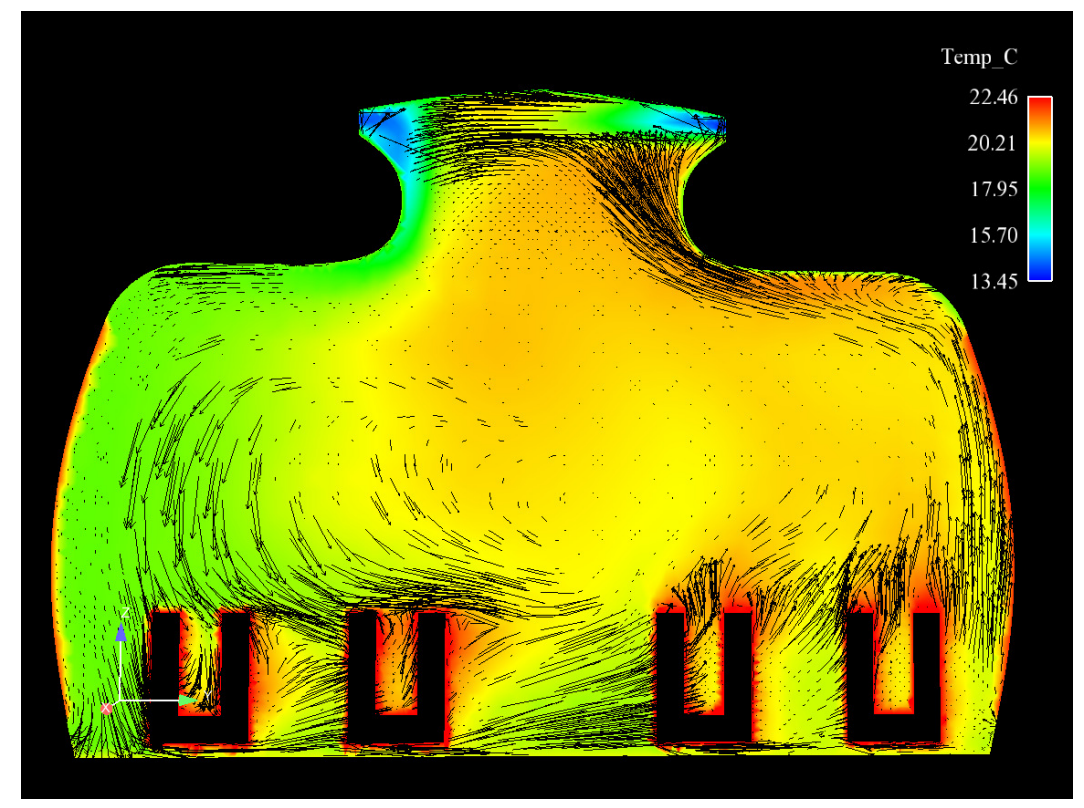

Figura 7.23 Campos calculados de velocidades vetoriais e de temperaturas do ar na seção de medição. 


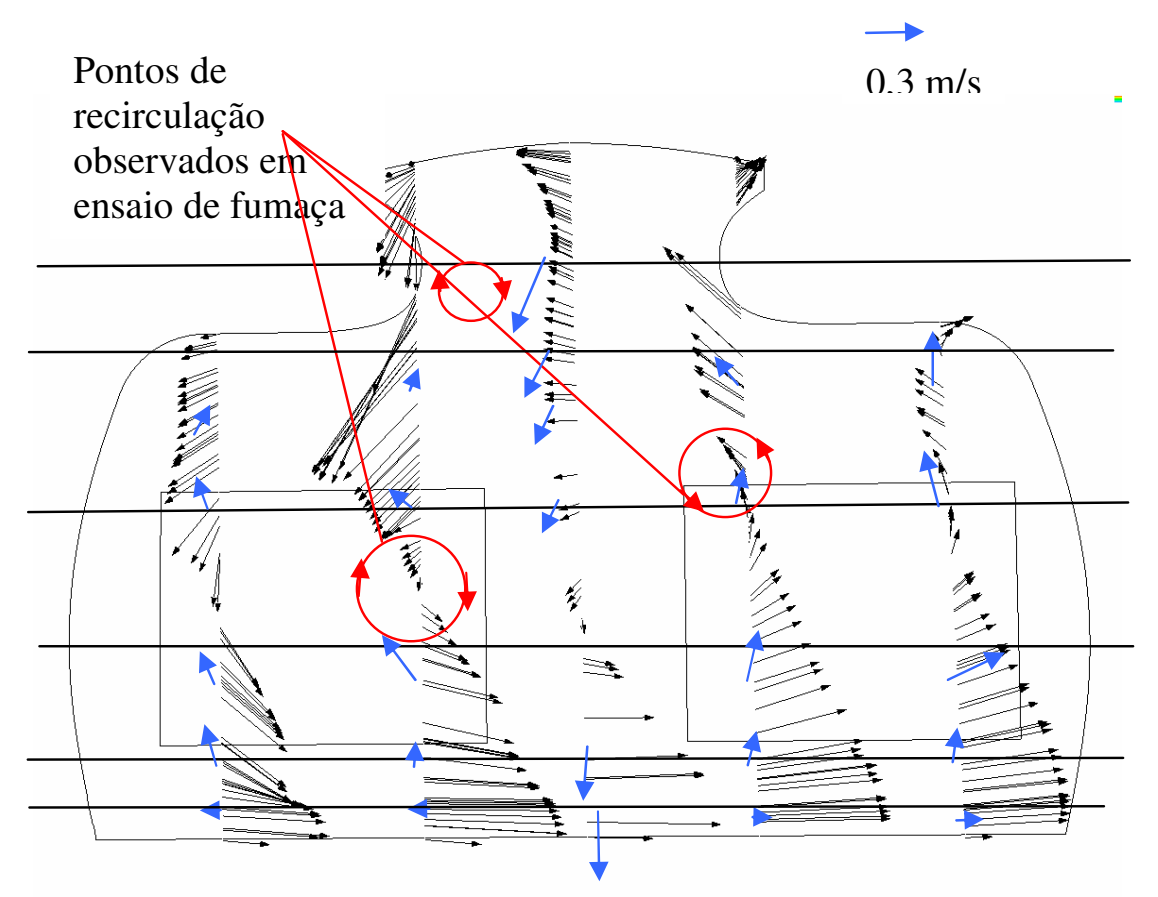

Figura 7.24 Campo de vetores de velocidades calculadas (preto) e medidas (azul).

As direções dos vetores mostrados na fig. 7.24 foram determinadas com introdução de fumaça no escoamento. A visualização com fumaça se mostrou um bom modo de se observar o escoamento. Notaram-se três pontos de recirculação que são mostrados na fig. 7.24. Pode-se notar na fig. 7.24 que o escoamento numérico na região do lado direito foi ascendente com baixa velocidade. Experimentalmente, notou-se também que do lado direito esta coluna de ar quente era sugada pelo jato acima dos bins. Experimentalmente notou-se que no lado esquerdo, esta coluna de ar quente subia até a cabeça dos manequins, não conseguindo subir além deste ponto, e o escoamento no corredor era descendente. Como é possível se observar na figura 7.24, o campo de velocidades do lado esquerdo da simulação é descendente.

\section{Conclusão}

Houve uma boa concordância dos resultados para campos de temperatura do ar numérico com o experimental. Velocidades muito baixas do ar dificultaram uma melhor medição do campo de velocidade para validação com os resultados numéricos. As oscilações das velocidades nas entradas de ar dificultam uma medição precisa das condições de contorno para as simulações numéricas. A simulação numérica serviu como um indicativo do formato do campo de velocidades. Experimentalmente se verificou que as plumas térmicas dos 
passageiros aumentam as velocidades em uma cabine com vazões típicas. Sugere-se para um trabalho posterior um levantamento do campo de velocidades com técnica de anemometria a laser (LDA) ou de imagens de partículas (PIV).

\subsubsection{Resultados da calibração do manequim}

Neste item são apresentados e comentados os resultados da calibração do manequim experimental e do manequim digital 2, descritos respectivamente no Capítulo 5 e 6, itens 5.2.2 e 6.3.5. Estes resultados serão utilizados no cálculo das temperaturas equivalentes descritas no final do presente capítulo.

\section{Resultados da calibração experimental do manequim térmico}

Os resultados a seguir se referem à calibração descrita no Capítulo 5, item 5.2.2. Os coeficientes de troca de calor de calibração experimental do manequim térmico são apresentados na tabela 7.18 .

Tabela 7.18 Coeficientes de troca de calor de calibração nos diversos segmentos do manequim térmico experimental.

\begin{tabular}{|c|c|c|c|}
\hline Segmentos & $\mathrm{h}_{\mathrm{cal}} @ 19,5^{\circ} \mathrm{C}$ & $\mathrm{h}_{\mathrm{cal}} @ 22,5^{\circ} \mathrm{C}$ & $h_{\text {cal }} @ 24,2^{\circ} \mathrm{C}$ \\
\hline Antebraço dir. & 7,99 & 7,54 & 6,78 \\
\hline Antebraço esq. & 6,95 & 6,57 & 5,82 \\
\hline Braço dir. & $\mathbf{9 , 9 0}$ & $\mathbf{9 , 4 2}$ & 8,59 \\
\hline Braço esq. & 7,17 & 6,49 & 5,32 \\
\hline Escalpo & 10,88 & 10,54 & $\mathbf{9 , 7 5}$ \\
\hline Perna dir. & 10,95 & 11,32 & 10,26 \\
\hline Perna esq. & 11,98 & 11,56 & 11,05 \\
\hline Coxa frontal dir. & 12,95 & 12,46 & 11,40 \\
\hline Coxa frontal esq. & 19,94 & 17,71 & 15,97 \\
\hline Coxa posterior dir. & 13,42 & 13,55 & 12,56 \\
\hline Coxa posterior esq. & 13,72 & 14,16 & 13,64 \\
\hline Face dir. & 11,65 & 11,30 & 10,12 \\
\hline Face esq. & 11,83 & 11,65 & 10,35 \\
\hline Mão dir. & 16,36 & 16,03 & 14,65 \\
\hline Mão esq. & 20,22 & 19,44 & 17,57 \\
\hline Pé dir. & 13,96 & 13,70 & 12,02 \\
\hline Pé esq. & 12,51 & 11,82 & 10,50 \\
\hline
\end{tabular}

Pode-se notar na tabela 7.18 que em todos os segmentos os coeficientes de troca de calor de calibração aumentam com a diminuição de temperatura de calibração, conforme comentado na literatura (Nilsson, 2004; CABCLI 1999). As diferenças entre os segmentos 
simétricos se devem à instrumentação e não a possíveis assimetrias, pois em outras calibrações em outras posições as mesmas diferenças foram observadas. Excluindo as quatro primeiras zonas da tabela, os valores dos coeficientes estão mais altos que os observados na literatura (de Dear et al., 1997) em torno de 50\%. Em posterior análise no software do manequim, verificou-se que as áreas foram aproximadas por áreas retangulares planas, o que deve ser melhor avaliado em trabalhos próximos. Nota-se que estas diferenças entre os valores determinados e os da literatura não impactam na precisão das temperaturas equivalentes, pois estas são dependentes da repetibilidade das medições dos $h_{\text {cal }}$.

Para se estimar a repitibilidade das medições dos fluxos os $\mathrm{h}_{\text {cal }}$ medidos à $24{ }^{\circ} \mathrm{C}$ em dois dias diferentes, por pessoas diferentes, os valores são apresentados na tabela 7.19:

Tabela 7.19 Coeficientes de troca de calor de calibração médios em dois experimentos

\begin{tabular}{lccc}
\hline \multicolumn{1}{c}{ Segmento } & $\mathbf{h}_{\text {cal }} \mathbf{1}$ & $\mathbf{h}_{\text {cal }} \mathbf{2}$ & Diferença $(\%)$ \\
\hline Antebraço dir. & $\mathbf{6 , 7 8}$ & $\mathbf{6 , 6 9}$ & $\mathbf{1 , 3 8}$ \\
Antebraço esq. & $\mathbf{5 , 8 2}$ & $\mathbf{5 , 9 9}$ & $\mathbf{2 , 8 4}$ \\
Braço esq. & $\mathbf{5 , 3 2}$ & $\mathbf{5 , 8 4}$ & $\mathbf{9 , 7 3}$ \\
Escalpo & $\mathbf{9 , 7 5}$ & $\mathbf{9 , 5 0}$ & $\mathbf{2 , 5 7}$ \\
Perna dir. & $\mathbf{1 0 , 2 6}$ & $\mathbf{1 0 , 4 6}$ & $\mathbf{1 , 9 8}$ \\
Perna esq. & 11,05 & 11,13 & $\mathbf{0 , 7 4}$ \\
Coxa frontal dir. & $\mathbf{1 1 , 4 0}$ & 11,75 & $\mathbf{3 , 0 8}$ \\
Coxa posterior dir. & $\mathbf{1 2 , 5 6}$ & $\mathbf{1 2 , 8 9}$ & $\mathbf{2 , 6 0}$ \\
Coxa frontal esq. & $\mathbf{1 5 , 9 7}$ & $\mathbf{1 7 , 6 3}$ & $\mathbf{1 0 , 4 0}$ \\
Coxa Posterior esq. & $\mathbf{1 3 , 6 4}$ & $\mathbf{1 0 , 4 6}$ & $\mathbf{2 3 , 2 9}$ \\
Face dir.. & $\mathbf{1 0 , 1 2}$ & $\mathbf{1 1 , 1 2}$ & $\mathbf{9 , 8 0}$ \\
Face esq. & $\mathbf{1 0 , 3 5}$ & $\mathbf{1 1 , 5 1}$ & $\mathbf{1 1 , 1 9}$ \\
Mão dir. & $\mathbf{1 4 , 6 5}$ & $\mathbf{1 5 , 1 8}$ & $\mathbf{3 , 6 1}$ \\
Mão esq. & $\mathbf{1 7 , 5 7}$ & $\mathbf{1 9 , 1 0}$ & $\mathbf{8 , 7 1}$ \\
Pé dir.. & $\mathbf{1 2 , 0 2}$ & $\mathbf{1 2 , 5 0}$ & $\mathbf{3 , 9 2}$ \\
Pé esq. & $\mathbf{1 0 , 5 0}$ & $\mathbf{1 2 , 4 0}$ & $\mathbf{1 8 , 0 9}$ \\
\hline Média & & & $\mathbf{1 2 , 5 8}$ \\
\hline
\end{tabular}

Analisando os resultados na tabela 7.19 , nota-se que existe uma variação média de $12 \%$ nos coeficientes de troca de calor. Supondo-se um erro de $12 \%$ nas medições dos $\mathrm{h}_{\text {cal }} \mathrm{e}$ de $3 \%$ nos fluxos de calor, isto leva a incertezas nos valores das temperaturas em média de $\pm 1,5^{\circ} \mathrm{C}$.

\section{Conclusão}

Foi realizada a calibração experimental do manequim experimental em três temperaturas. Houve um aumento nos coeficientes de troca de calor de calibração para 
temperaturas mais baixas; o que está de acordo com o apresentado na literatura. Os braços e antebraços apresentaram $\mathrm{h}_{\text {cals }}$ próximos aos da literatura. Notou-se que as áreas dos segmentos do manequim necessitam ser mais bem avaliadas. Uma estimativa da repetibilidade foi feita com duas calibrações na mesma temperatura e concluiu-se que se espera uma incerteza de $\pm 1,5{ }^{\circ} \mathrm{C}$ nos resultados das temperaturas equivalentes.

\section{Resultados da calibração do manequim digital 2}

Os resultados a seguir se referem à calibração descrita no Capítulo 6, item 6.3.5. Os coeficientes de troca de calor de calibração do manequim digital 2 são apresentados na tabela 7.20:

Tabela 7.20 Coeficientes de troca de calor de calibração do manequim digital 2.

\begin{tabular}{lccc}
\hline \multicolumn{1}{c}{ Segmentos } & $\mathrm{h}_{\text {cal }} @ 19,5^{\circ} \mathrm{C}$ & $\mathrm{h}_{\text {cal }} @ 22,5^{\circ} \mathrm{C}$ & $\mathrm{h}_{\text {cal }} @ 24,2^{\circ} \mathrm{C}$ \\
\hline Antebraço dir. & 10,32 & 10,49 & 10,72 \\
Antebraço esq. & 10,32 & 10,49 & 10,72 \\
Braço dir. & 10,47 & 10,72 & 11,05 \\
Braço esq. & 10,47 & 10,72 & 11,05 \\
Escalpo & 11,18 & 10,49 & 11,37 \\
Perna dir. & 11,41 & 11,60 & 11,96 \\
Perna esq. & 11,41 & 11,60 & 11,96 \\
Coxa frontal dir. & 10,80 & 11,10 & 11,53 \\
Coxa frontal esq. & 10,80 & 11,10 & 11,53 \\
Coxa posterior dir. & 11,38 & 11,60 & 12,00 \\
Coxa posterior esq. & 11,38 & 11,60 & 12,00 \\
Face dir. & 11,38 & 12,85 & 13,00 \\
Face esq. & 11,38 & 12,85 & 13,00 \\
Mão dir. & 9,44 & 9,56 & 9,75 \\
Mão esq. & 9,44 & 9,56 & 9,75 \\
Pé dir. & 10,21 & 10,26 & 10,40 \\
Pé esq. & 10,21 & 10,26 & 10,40 \\
\hline
\end{tabular}

Nota-se nos resultados apresentados na tabela 7.20 que os valores obtidos são muito próximos e não apresentam grandes variações com a temperatura de calibração. Nota-se na tabela 7.20 que os coeficientes aumentaram em média $5 \%$ de 19,5 para $24{ }^{\circ} \mathrm{C}$. Isto deve ter ocorrido em função de erros numéricos no cálculo dos fluxos de calor por radiação e convecção que, como foi verificado nos resultados anteriores (item 7.1.3 e 7.1.4), tem variação em torno de $10 \%$. Supondo erros numéricos de $10 \%$ nos cálculos dos fluxos de calor obtém-se erros numéricos nas temperaturas equivalentes de $\pm 1,3{ }^{\circ} \mathrm{C}$. 


\section{Conclusão}

Observou-se um aumento em média de $5 \%$ nos $\mathrm{h}_{\text {cal }}$ para um aumento de temperatura de calibração de $4,5^{\circ} \mathrm{C}$. A tendência de aumento não era esperada. Isto deve ter ocorrido em função dos erros em torno de $10 \%$ nos erros das avaliações de trocas térmicas simuladas.

\subsubsection{Resultados das temperaturas equivalentes}

Neste item serão comentados os resultados numéricos e experimentais das avaliações das temperaturas equivalentes nas duas posições: próximo à fuselagem e ao corredor, conforme descrito no capítulo 5 e 6 , itens 5.2 .3 e 6.4 respectivamente. Os resultados são agrupados em cada posição.

Os dados das três situações estudadas são apresentados na tabela 7.21:

Tabela 7.21 Temperaturas médias medidas nas avaliações de temperaturas equivalentes

\begin{tabular}{lccc}
\hline & & Temperaturas médias $\left({ }^{\circ} \mathrm{C}\right)$ & \\
& $70 \mathrm{~W} / \mathrm{m}^{2}$ & $50 \mathrm{~W} / \mathrm{m}^{2}$ & $0 \mathrm{~W} / \mathrm{m}^{2}(*)$ \\
\hline Simuladores & 45,5 & 34,0 & 16,7 \\
Ar da cabine & 27,8 & 21,6 & 16,4 \\
Teto & 23,0 & 19,5 & 16,2 \\
Piso & 25,1 & 20,6 & 17,8 \\
Lateral esq. & 29,1 & 23,8 & 20,3 \\
Lateral dir. & 28,1 & 22,6 & 17,0 \\
Frente & 25,9 & 22,9 & 22,2 \\
Trás & 25,7 & 20,9 & 21,6 \\
Entrada de ar esq. 1 & 15,6 & 14,2 & 13,7 \\
Entrada de ar esq. 2 & 15,1 & 14,1 & 13,4 \\
Entrada de ar esq. 3 & 15,6 & 14,3 & 13,9 \\
Entrada de ar dir. 1 & 15,7 & 14,1 & 13,9 \\
Entrada de ar dir. 2 & 15,8 & 14,2 & 13,7 \\
Entrada de ar dir. 3 & 15,5 & 14,2 & 13,6 \\
\hline
\end{tabular}

(*) sem liberação de calor nos simuladores (simuladores desligados)

Como se pode observar na tabela 7.21, conseguiu-se ambientes térmicos bastante diversos, mudando-se somente a carga térmica interna. Conseguiu-se assim ambientes com temperaturas de ar decrescentes em torno de $5{ }^{\circ} \mathrm{C}\left(27,8 ; 21,6\right.$ e $\left.16,4{ }^{\circ} \mathrm{C}\right)$. 


\section{Análise de incerteza das temperaturas equivalentes}

Conforme a teoria de erros, a incerteza de uma grandeza que é função de outras grandezas é a média geométrica ponderada pela derivada parcial da função em relação às variáveis com erros associados (Coleman e Steele, 1989; INMETRO, 1998; Vuolo, 1996), ou seja:

$$
\frac{\Delta \bar{f}}{f(\bar{x}, \bar{y})}=\sqrt{\left(\frac{\partial f}{\partial x}\right)^{2} \cdot\left(\frac{(\Delta \bar{x})}{\bar{x}}\right)^{2}+\left(\frac{\partial f}{\partial y}\right)^{2} \cdot\left(\frac{(\Delta \bar{y})}{\bar{y}}\right)^{2}}
$$

onde

$\Delta \overline{\mathrm{f}}=$ erro absoluto da grandeza $\mathrm{f}$

$\mathrm{f}(\overline{\mathrm{x}}, \overline{\mathrm{y}})=$ grandeza função de variáveis $\mathrm{x}$ e $\mathrm{y}$.

Aplicando a equação 7.2 na equação de definição de temperatura equivalente 3.12 temos

$$
\frac{\Delta \overline{\mathrm{t}}_{\mathrm{eq}}}{\overline{\mathrm{t}}_{\mathrm{eq}}}=\sqrt{\left(\frac{\left(\Delta \overline{\mathrm{Q}}^{\prime \prime}\right)}{\overline{\mathrm{Q}}^{\prime \prime}}\right)^{2}+\left(\frac{\left(\Delta \overline{\mathrm{h}}_{\mathrm{cal}}\right)}{\overline{\mathrm{h}}_{\mathrm{cal}}}\right)^{2}}
$$

onde

$\Delta \mathrm{t}_{\mathrm{eq}}=$ erro absoluto da temperatura equivalente, ${ }^{\circ} \mathrm{C}$

$\frac{\left(\Delta \overline{\mathrm{Q}}^{\prime \prime}\right)}{\overline{\mathrm{Q}}^{\prime \prime}}=$ erro relativo dos fluxos de calor nos segmentos

$\frac{\left(\Delta \overline{\mathrm{h}}_{\text {cal }}\right)}{\overline{\mathrm{h}}_{\text {cal }}}=$ erro relativo dos coeficientes de troca de calor calibrados

\section{Cálculo das incertezas das temperaturas equivalentes numéricas.}

Foi considerado um erro relativo de $10 \%$ dos fluxos de calor numérico e dos $\mathrm{h}_{\text {cal }}$ conforme item 7.14. Usando os valores das temperaturas equivalentes numéricas da tabela 7.22 obtém-se um $t_{\text {eq }}$ numérico médio de $19,2{ }^{\circ} \mathrm{C}$. Colocando estes valores na equação 7.3 obtém-se um valor de incerteza de $\mathrm{t}_{\mathrm{eq}}$ numérico de $\pm 2,7^{\circ} \mathrm{C}$. 
Cálculo das incertezas das temperaturas equivalente experimentais.

Foi considerado um erro relativo de $3 \%$ dos fluxos de calor experimentais e $12 \%$ dos $\mathrm{h}_{\text {cal }}$ conforme análise realizada no item 7.2.2. Usando os valores das temperaturas equivalentes experimentais da tabela 7.22 obtém-se um $\mathrm{t}_{\mathrm{eq}}$ experimental médio de $21,7{ }^{\circ} \mathrm{C}$. Colocando estes valores na equação 7.3 obtém-se um valor de incerteza de $t_{\text {eq }}$ numérico de $\pm 2,8^{\circ} \mathrm{C}$.

Temperaturas equivalentes experimentais e numéricas na posição próxima à fuselagem.

Neste item serão comentados os resultados numéricos e experimentais das temperaturas equivalentes do manequim junto à fuselagem. As temperaturas equivalentes são apresentadas na tabela 7.22 e figuras $7.25,7.26$ e 7.27 .

Tabela 7.22 Temperaturas equivalentes experimentais e numéricas do manequim junto à fuselagem.

\begin{tabular}{|c|c|c|c|c|c|c|}
\hline & $\begin{array}{l}\mathrm{t}_{\mathrm{eq}} 70 \mathrm{~W} / \mathrm{m}^{2} \\
\text { Num. }\left({ }^{\circ} \mathrm{C}\right)\end{array}$ & $\begin{array}{c}\mathbf{t}_{\mathrm{eq}} \mathbf{7 0 \mathrm { W }} / \mathrm{m}^{2} \\
\operatorname{Exp} .\left({ }^{\circ} \mathrm{C}\right)\end{array}$ & $\begin{array}{l}\mathbf{t}_{\mathrm{eq}} 50 \mathrm{~W} / \mathrm{m}^{2} \\
\text { Num. } .\left({ }^{\circ} \mathrm{C}\right)\end{array}$ & $\begin{array}{c}\mathbf{t}_{\mathrm{eq}} 50 \mathrm{~W} / \mathrm{m}^{2} \\
\operatorname{Exp} .\left({ }^{\circ} \mathrm{C}\right)\end{array}$ & 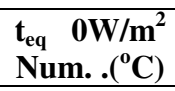 & $\begin{array}{l}\mathbf{t}_{\mathrm{eq}} \quad 0 \mathrm{~W} / \mathrm{m}^{2} \\
\operatorname{Exp} .\left({ }^{\circ} \mathrm{C}\right)\end{array}$ \\
\hline anteb.dir. & 27,7 & 29,0 & 21,2 & 26,5 & 14,9 & 16,8 \\
\hline anteb.esq. & 23,3 & 26,9 & 19,5 & 24,7 & 10,9 & 18,4 \\
\hline braço dir. & 31,5 & 28,0 & 24,6 & 25,3 & 16,5 & 16,6 \\
\hline braço esq. & 27,4 & 27,0 & 22,4 & 25,4 & 16,9 & 17,3 \\
\hline escalpo & 27,7 & 27,1 & 20,4 & 26,0 & 14,7 & 19,1 \\
\hline perna dir. & 25,2 & 25,5 & 19,0 & 22,4 & 15,3 & 16,1 \\
\hline perna esq. & 23,7 & 24,8 & 17,4 & 20,4 & 14,0 & 18,0 \\
\hline coxa fron dir. & 26,3 & 30,1 & 21,1 & 26,6 & 14,9 & 20,3 \\
\hline coxa fron.esq. & 24,5 & 27,0 & 20,4 & 24,7 & 12,4 & 20,4 \\
\hline coxa pos.dir. & 30,0 & 32,8 & 27,3 & 32,1 & 25,0 & 32,6 \\
\hline coxa pos.esq. & 29,4 & 32,5 & 27,1 & 31,8 & 25,2 & 31,6 \\
\hline face dir. & 26,2 & 28,5 & 23,7 & 24,4 & 10,8 & 16,5 \\
\hline face esq. & 27,6 & 25,6 & 22,3 & 22,6 & 14,1 & 13,7 \\
\hline mao dir. & 26,0 & 27,7 & 19,5 & 24,3 & 9,3 & 15,9 \\
\hline mão esq. & 22,9 & 26,3 & 18,0 & 24,0 & 6,9 & 16,6 \\
\hline pé dir. & 20,6 & 26,3 & 14,5 & 23,0 & 12,3 & 19,7 \\
\hline pé esq. & 20,0 & 26,5 & 14,4 & 22,5 & 12,1 & 19,5 \\
\hline Média & 25,1 & 27,0 & 19,7 & 24,1 & 12,7 & 17,6 \\
\hline
\end{tabular}




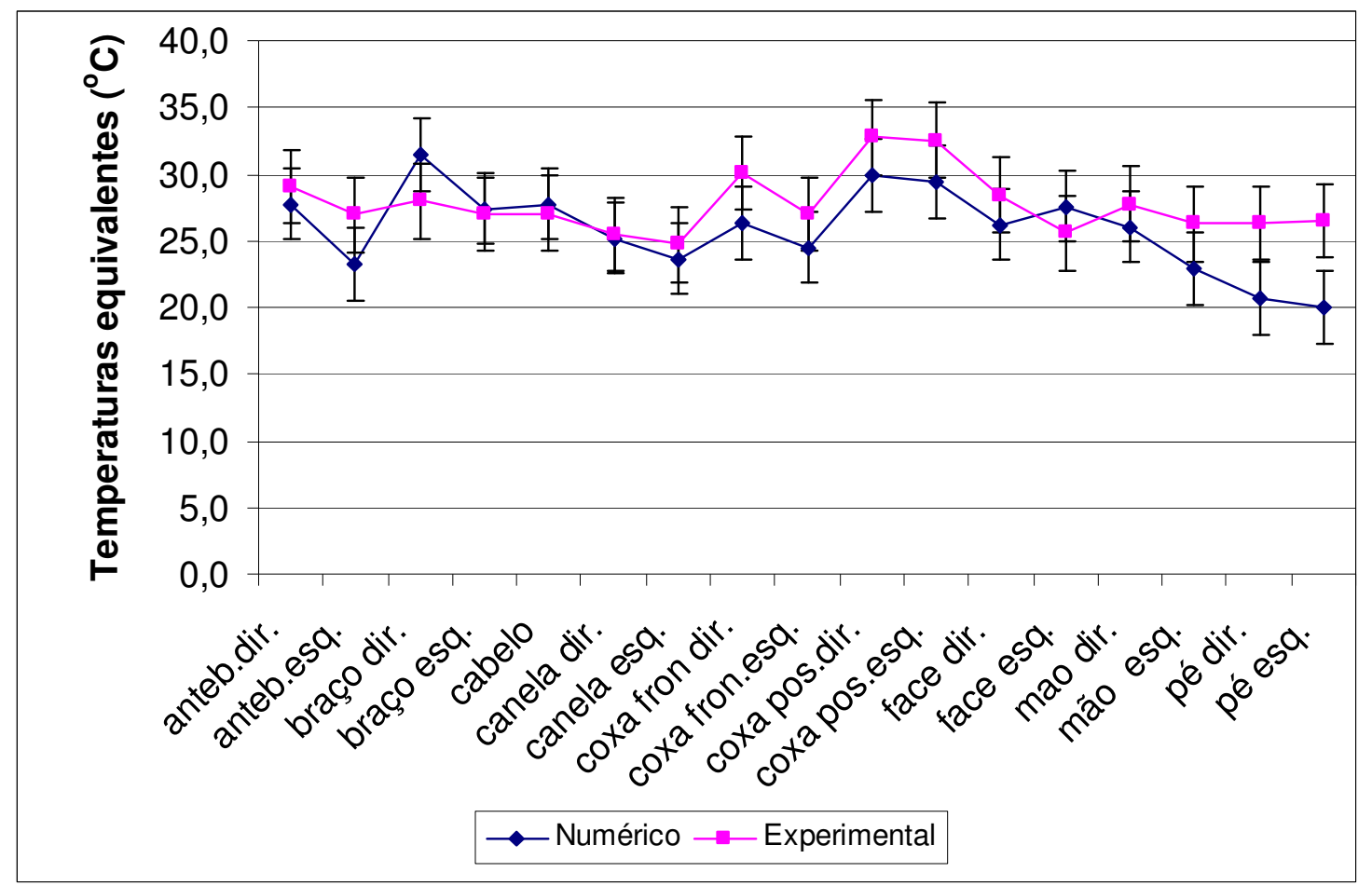

Figura 7.25 Temperaturas equivalentes experimentais e numéricas com manequim posicionado na janela com simuladores com dissipação de $70 \mathrm{~W} / \mathrm{m}^{2}$.

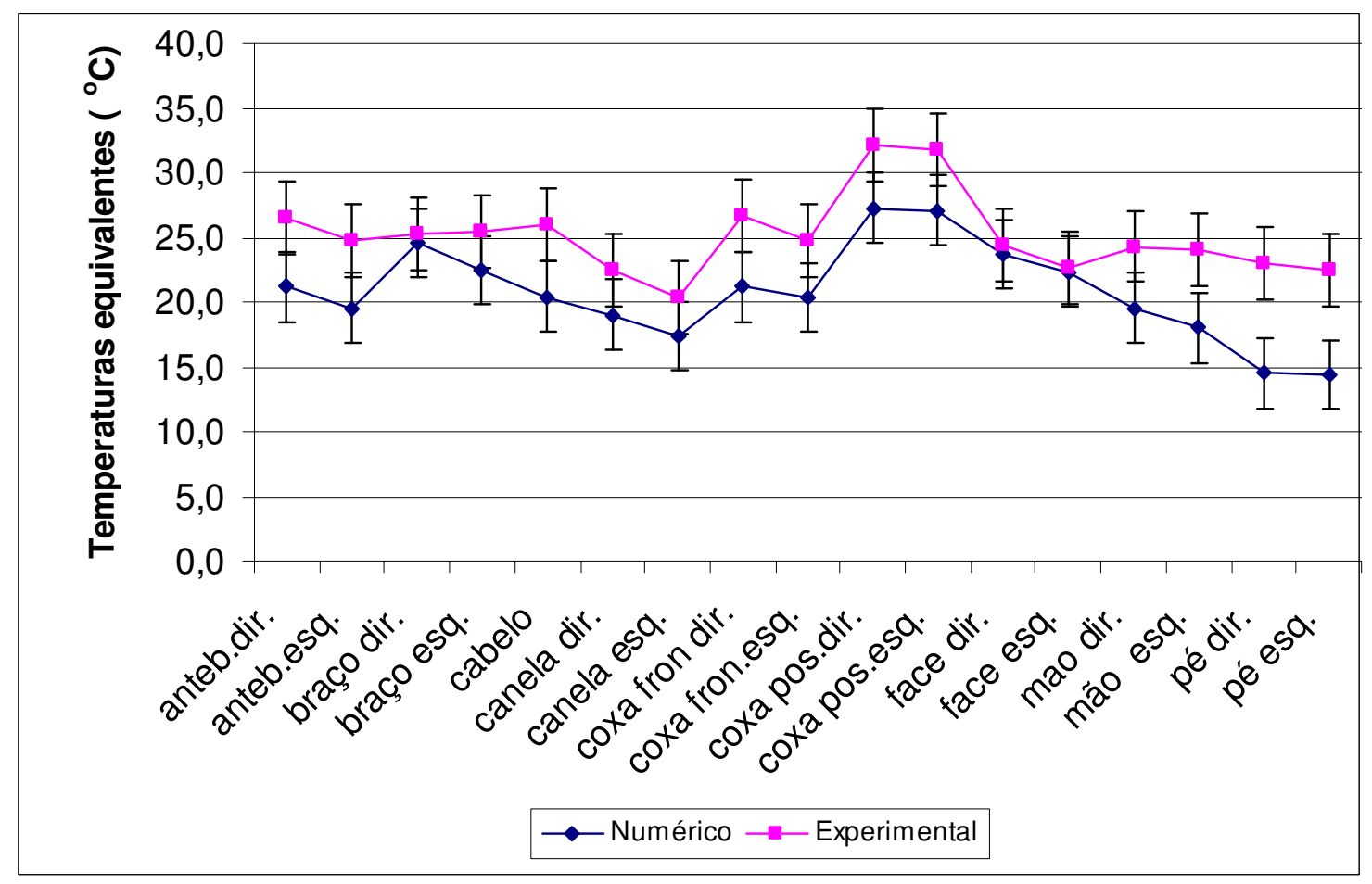

Figura 7.26 Temperaturas equivalentes experimentais e numéricas com manequim posicionado na janela com simuladores com dissipação de $50 \mathrm{~W} / \mathrm{m}^{2}$. 


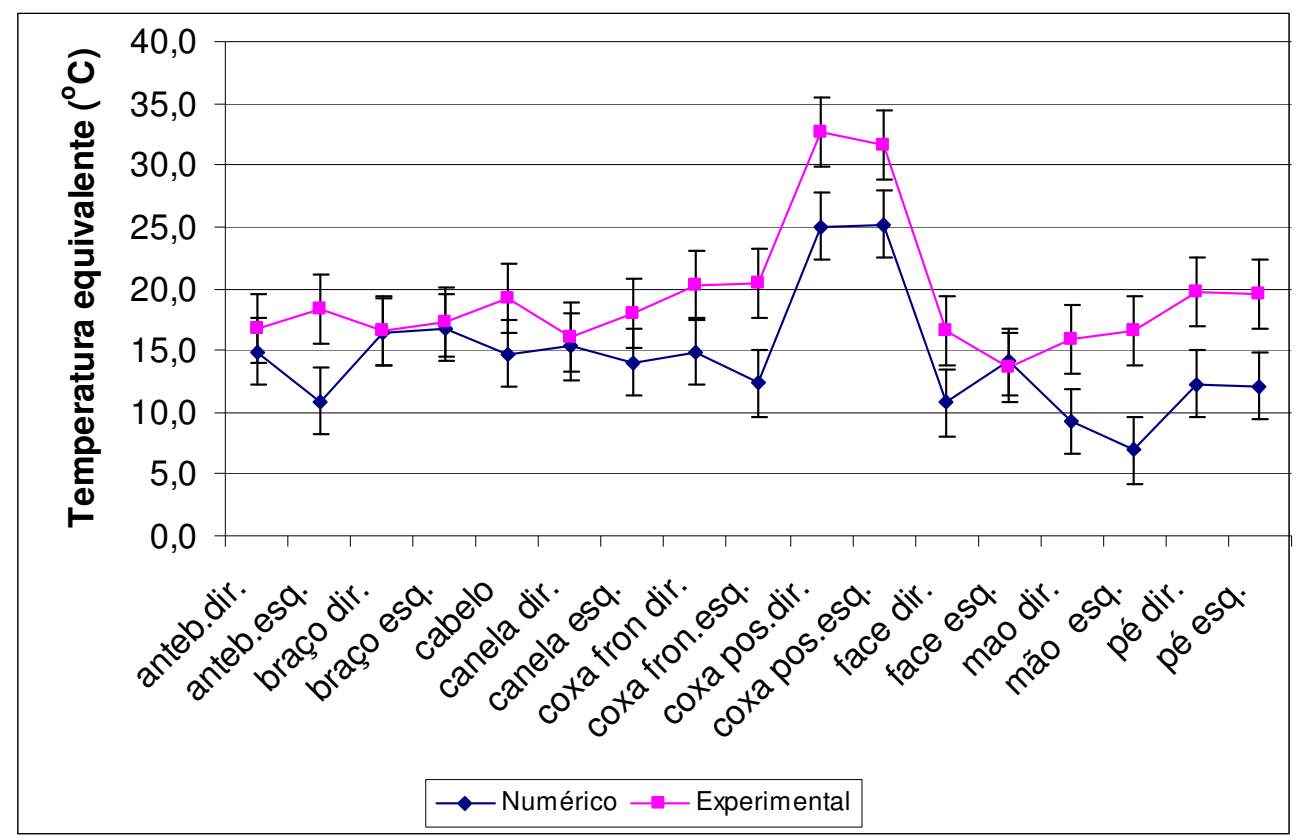

Figura 7.27 Temperaturas equivalente experimentais e numérica com manequim posicionado na janela com simuladores com dissipação de $0 \mathrm{~W} / \mathrm{m}^{2}$.

Em todos os três experimentos ambos manequins térmicos (experimental e digital 2) foram capazes de captar a mudança de temperatura média das cabines se compararmos as médias das temperaturas equivalentes da tabela $7.22 \mathrm{com}$ as temperaturas do ar e superfícies das cabines da tabela 7.21.

São apresentas na tabela 7.23 as médias das diferenças entre as teqs numéricas.

Tabela 7.23 Média das diferenças entre as $t_{\text {eqs }}$ experimentas e numéricas

\begin{tabular}{cc}
\hline Casos & Média $\left(\mathrm{t}_{\text {eq }} \underset{{ }^{\circ} \mathrm{C}}{\exp }-\mathrm{t}_{\text {eq }}\right.$ num.) \\
\hline $70 \mathrm{~W} / \mathrm{m}^{2}$ & 1,8 \\
$50 \mathrm{~W} / \mathrm{m}^{2}$ & 4,3 \\
$0 \mathrm{~W} / \mathrm{m}^{2}$ & 4,9 \\
\hline
\end{tabular}

Percebe-se nos gráficos das figuras 7.25; 7.26; e 7.27 que as temperaturas equivalentes numéricas sempre estiveram abaixo das experimentais. Este diferença cresce quanto menor for a temperaturas interna da cabine, conforme apresentado na tabela 7.23.

Esta diferença é facilmente explicável, pois à medida que o ambiente fica mais quente, menores são os fluxos de calor e menores os erros. 
As $t_{\text {eqs }}$ experimentais para os lados esquerdo e direito (caso com dissipação térmica de $70 \mathrm{~W} / \mathrm{m}^{2}$ ) são apresentadas em gráfico de barras na figura 7.28.

Janela

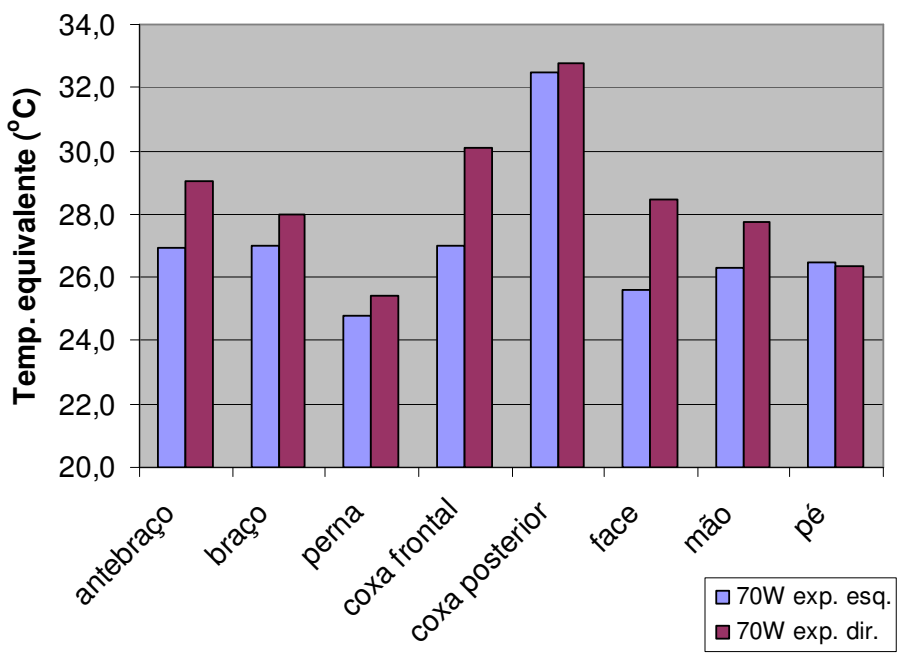

Figura 7.28 Valores de $t_{\text {eqs }}$ experimentais para os lados esquerdo e direito (caso com dissipação térmica de $70 \mathrm{~W} / \mathrm{m}^{2}$ ).

Os fluxos de calor no manequim digital 2 são apresentados nas fig. 7.29 e 7.30.

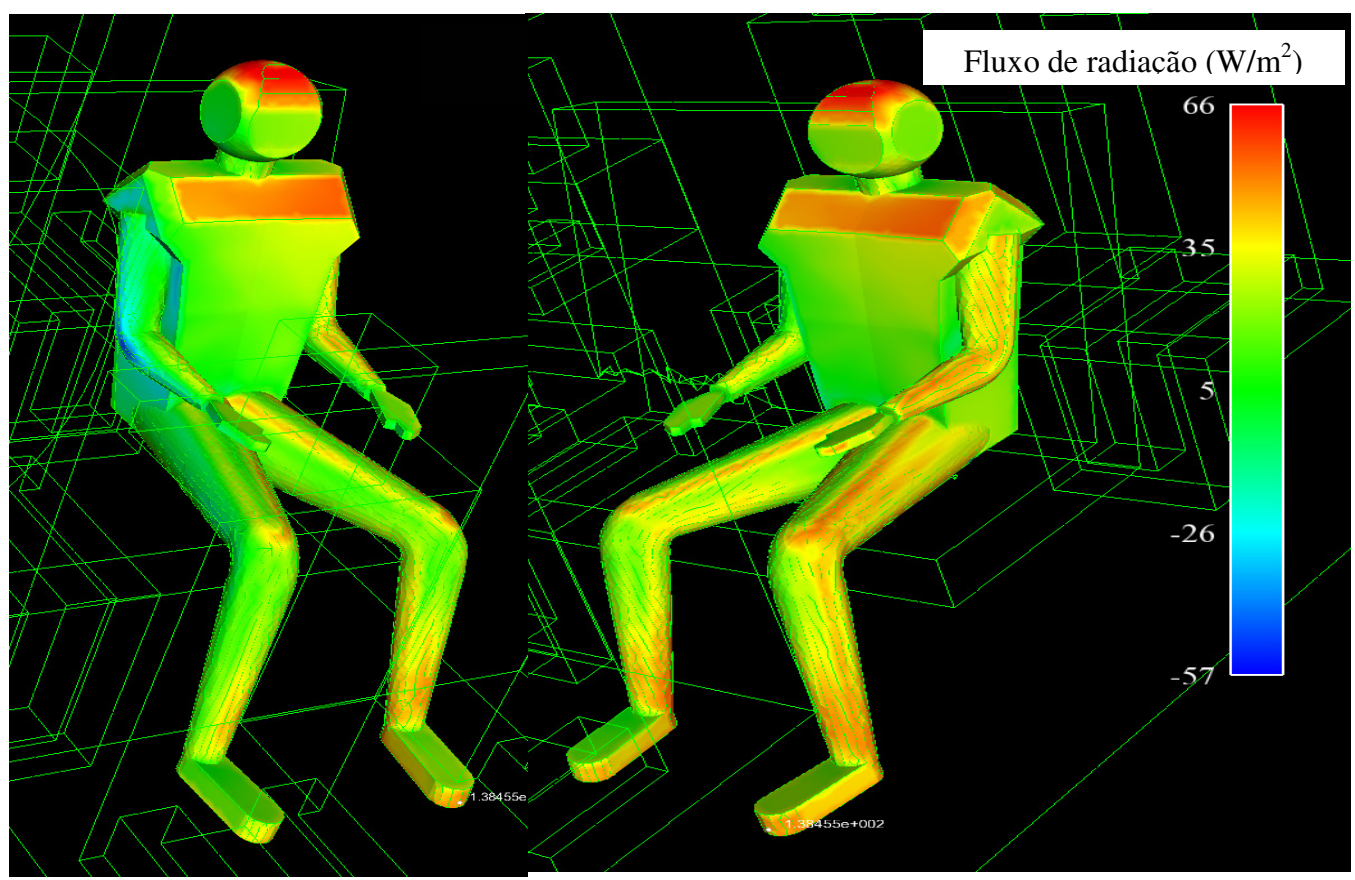

Figura 7.29 Fluxos de radiação do manequim no caso com dissipação de $70 \mathrm{~W} / \mathrm{m}^{2}$. 


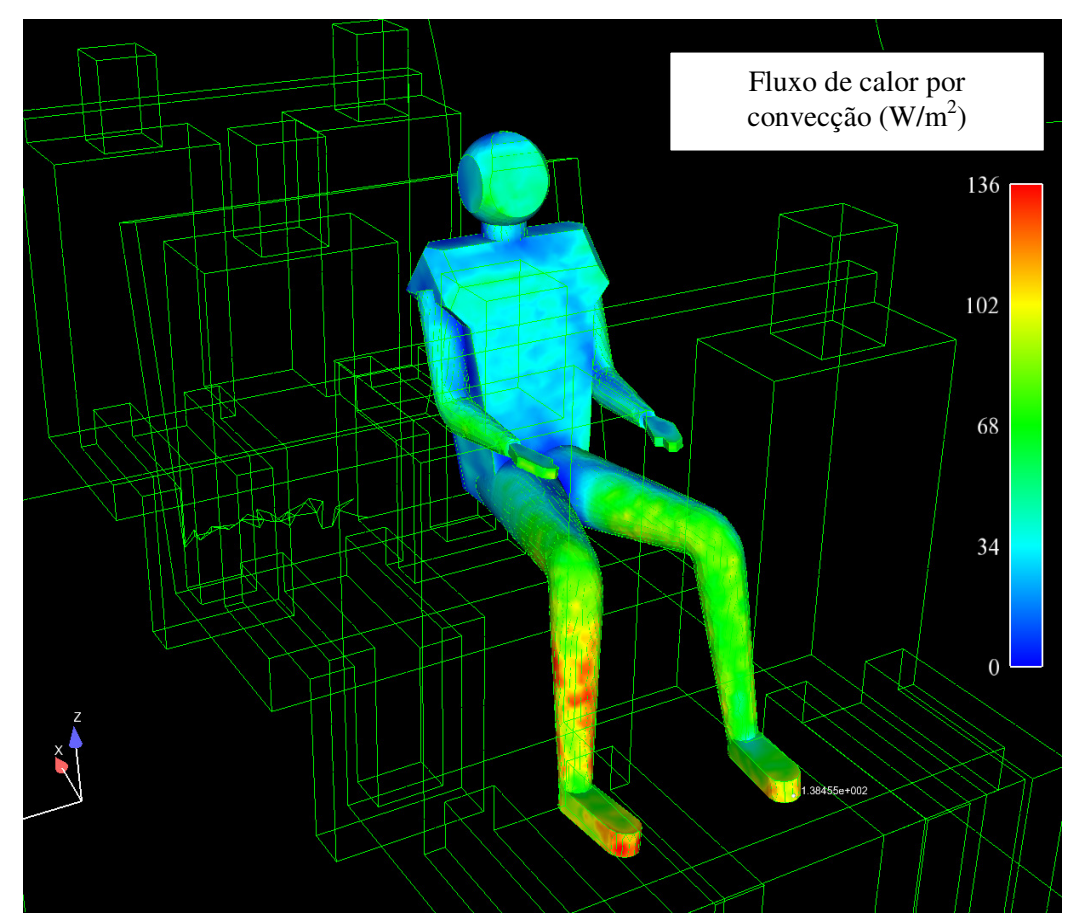

Figura 7.30 Fluxos de calor por convecção do manequim no caso com dissipação de 70

$$
\mathrm{W} / \mathrm{m}^{2} \text {. }
$$

Pode-se notar assimetrias térmicas laterais para os casos em que os manequins estavam com dissipação térmica $\left(70 \mathrm{~W} / \mathrm{m}^{2}\right.$ e $\left.50 \mathrm{~W} / \mathrm{m}^{2}\right)$ nos gráficos das figuras 7.25 e 7.26. Isto se verifica tanto experimentalmente como numericamente. As temperaturas equivalentes do lado direito foram mais altas do que do lado esquerdo. Este efeito é mais proeminente na face e coxa frontal, mas também pode ser observado em todos os outros segmentos com diferença média entre os lados de $1,9{ }^{\circ} \mathrm{C}$ para os dados numéricos e $1,4{ }^{\circ} \mathrm{C}$ para o experimental. É possível se observar na fig. 7.28 que a maioria dos segmentos do manequim térmico está com temperaturas equivalentes maiores do lado direito Isto se deve à menor troca de calor do lado próximo ao passageiro vizinho em função de menor troca de calor por radiação. Este fato foi possível se observar nas análises numéricas como é possível se verificar nas fig. 7.29 e 7.30. As assimetrias se devem a fluxos de radiação assimétricos, como se verifica na fig. 7.29. São pequenas as assimetrias nos fluxos convectivos, como se nota na fig. 7.30.

A posição dos pés e mãos do manequim térmico é apresentada na figura 7.31. 


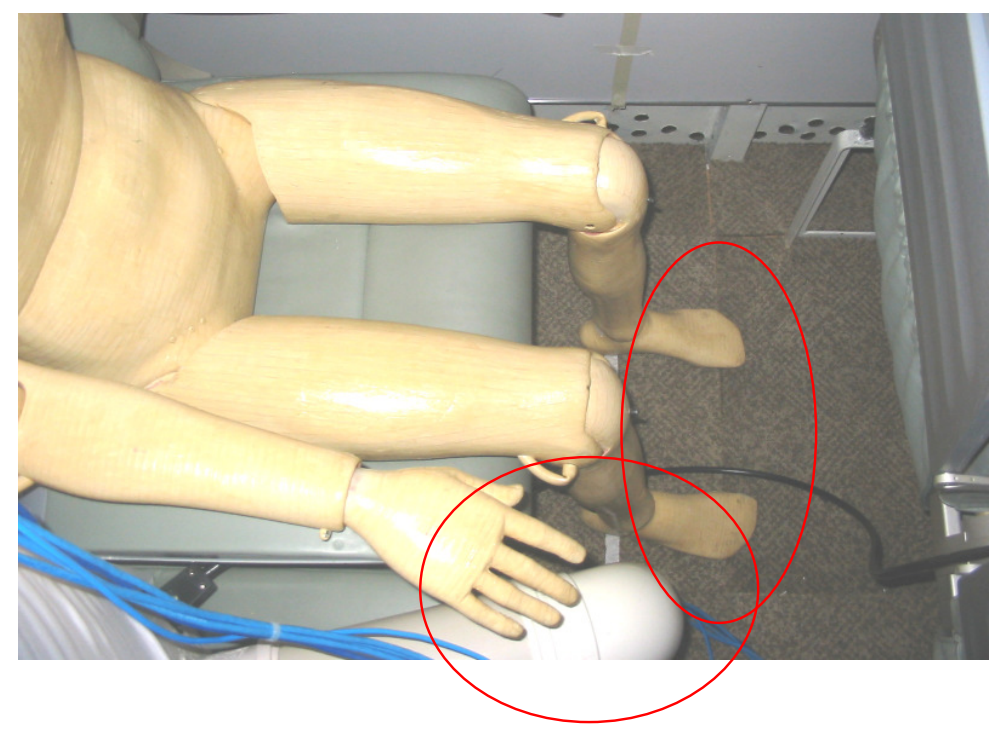

Figura 7.31 Mão do manequim apoiada no braço da poltrona e pés apoiados no piso.

Os segmentos que apresentaram maior discrepância entre os valores numéricos e experimentais foram as mão e pés como se pode verificar nas fig. 7.25; 7.26 e 7.27. Isto também pode ser facilmente explicado, pois são as regiões com menor semelhança geométrica. Os pés do modelo geométrico ficaram com a lateral muito espessa, sendo umas das áreas com maior fluxo de calor (Figura 7.29 e 7.30), o que explica as temperaturas equivalentes tão baixas. Existe também o fato de o pé do manequim experimental estar apoiado no piso (Figura 7.31) e o pé do manequim digital estar no ar. A mão do manequim experimental ficou apoiada no braço da cadeira conforme se pode notar na fig. 7.31 enquanto a mão do manequim digital ficou suspensa no ar.

Os segmentos que tiveram melhor correlação numérico-experimental foram as faces conforme se pode verificar nas fig. 7.25, 7.26 e 7.27.

\section{Temperaturas equivalentes experimentais e numéricas na posição próxima ao corredor.}

Neste item serão comentados os resultados numéricos e experimentais das temperaturas equivalentes do manequim junto ao corredor.

As temperaturas equivalentes numéricas e experimentais são apresentadas na tabela 7.24 e nos gráficos das figuras 7.32, 7.33 e 7.34 . 
Tabela 7.24 Temperaturas equivalentes experimentais e numéricas do manequim junto ao corredor.

\begin{tabular}{|c|c|c|c|c|c|c|}
\hline & 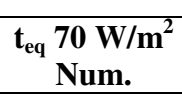 & $\begin{array}{l}t_{\text {eq }} 70 \mathrm{~W} / \mathrm{m}^{2} \\
\text { Exp. }\end{array}$ & $\begin{array}{c}\mathbf{t}_{\mathrm{eq}} \mathbf{5 0 W} / \mathrm{m}^{2} \\
\text { Num. }\end{array}$ & $\begin{array}{c}\text { teq__ }^{50} \mathrm{~W} / \mathrm{m}^{2} \\
\text { Exp. }\end{array}$ & $\begin{array}{c}\mathbf{t}_{\mathrm{eq}} 0 \mathbf{W} / \mathbf{m}^{2} \\
\text { Num. }\end{array}$ & $\begin{array}{l}\mathbf{t}_{\mathrm{eq}} 0 \mathrm{~W} / \mathbf{m}^{2} \\
\text { Exp. }\end{array}$ \\
\hline anteb.dir. & 26,3 & 23,7 & 20,8 & 20,2 & 14,3 & 14,7 \\
\hline anteb.esq. & 28,8 & 27,8 & 20,4 & 24,5 & 15,9 & 17,5 \\
\hline braço dir. & 28,8 & 23,2 & 24,7 & 22,3 & 15,9 & 15,9 \\
\hline braço esq. & 31,7 & 31,5 & 23,8 & 26,2 & 19,1 & 17,0 \\
\hline escalpo & 26,0 & 25,9 & 18,4 & 23,5 & 18,4 & 19,2 \\
\hline perna dir. & 26,0 & 23,2 & 19,2 & 18,7 & 15,0 & 15,3 \\
\hline perna esq. & 26,7 & 24,1 & 19,1 & 19,9 & 13,3 & 17,2 \\
\hline coxa fron dir. & 26,5 & 24,6 & 21,0 & 22,9 & 16,5 & 17,9 \\
\hline coxa fron.esq. & 27,8 & 27,6 & 21,7 & 24,3 & 16,8 & 19,4 \\
\hline coxa pos.dir. & 29,7 & 31,9 & 27,3 & 32,2 & 25,1 & 30,8 \\
\hline coxa pos.esq. & 30,1 & 32,1 & 27,4 & 31,6 & 25,1 & 28,9 \\
\hline face dir. & 27,1 & 24,5 & 22,0 & 21,3 & 15,4 & 14,0 \\
\hline face esq. & 28,9 & 27,9 & 20,9 & 22,9 & 15,3 & 15,4 \\
\hline mao dir. & 24,6 & 23,4 & 18,0 & 20,7 & 14,1 & 15,8 \\
\hline mão esq. & 28,4 & 27,7 & 18,8 & 24,7 & 13,6 & 17,2 \\
\hline pé dir. & 22,9 & 24,5 & 13,8 & 22,6 & 11,1 & 18,0 \\
\hline pé esq. & 24,1 & 25,4 & 15,3 & 23,0 & 10,9 & 18,1 \\
\hline Média & 27,3 & 26,4 & 20,7 & 23,6 & 16,2 & 18,4 \\
\hline
\end{tabular}
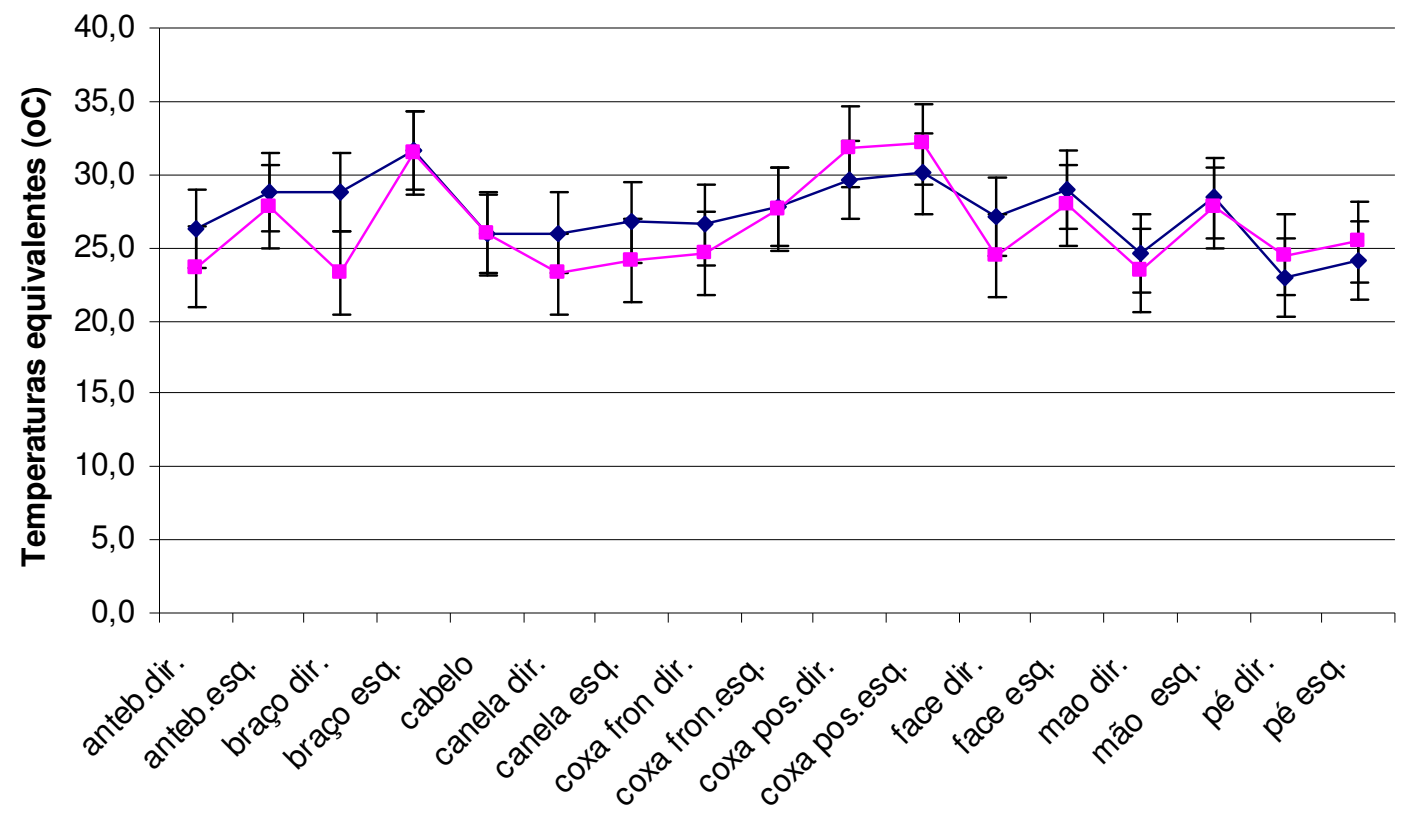

\section{$\multimap$ Numérico $\multimap-$ Experimental}

Figura 7.32 Temperaturas equivalentes experimentais e numéricas com manequim posicionado no corredor com simuladores com dissipação de $70 \mathrm{~W} / \mathrm{m}^{2}$. 


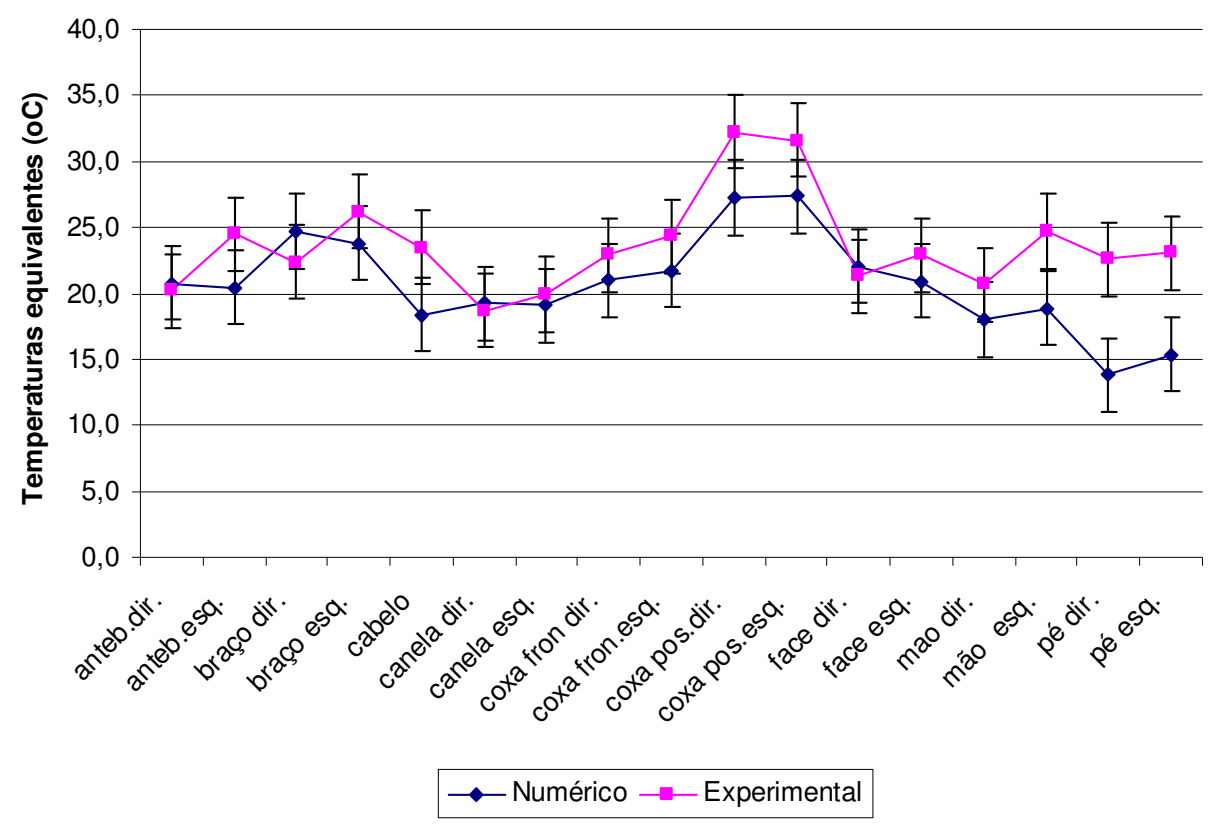

Figura 7.33 Temperaturas equivalentes experimentais e numéricas com manequim posicionado na janela com simuladores com dissipação de $50 \mathrm{~W} / \mathrm{m}^{2}$.

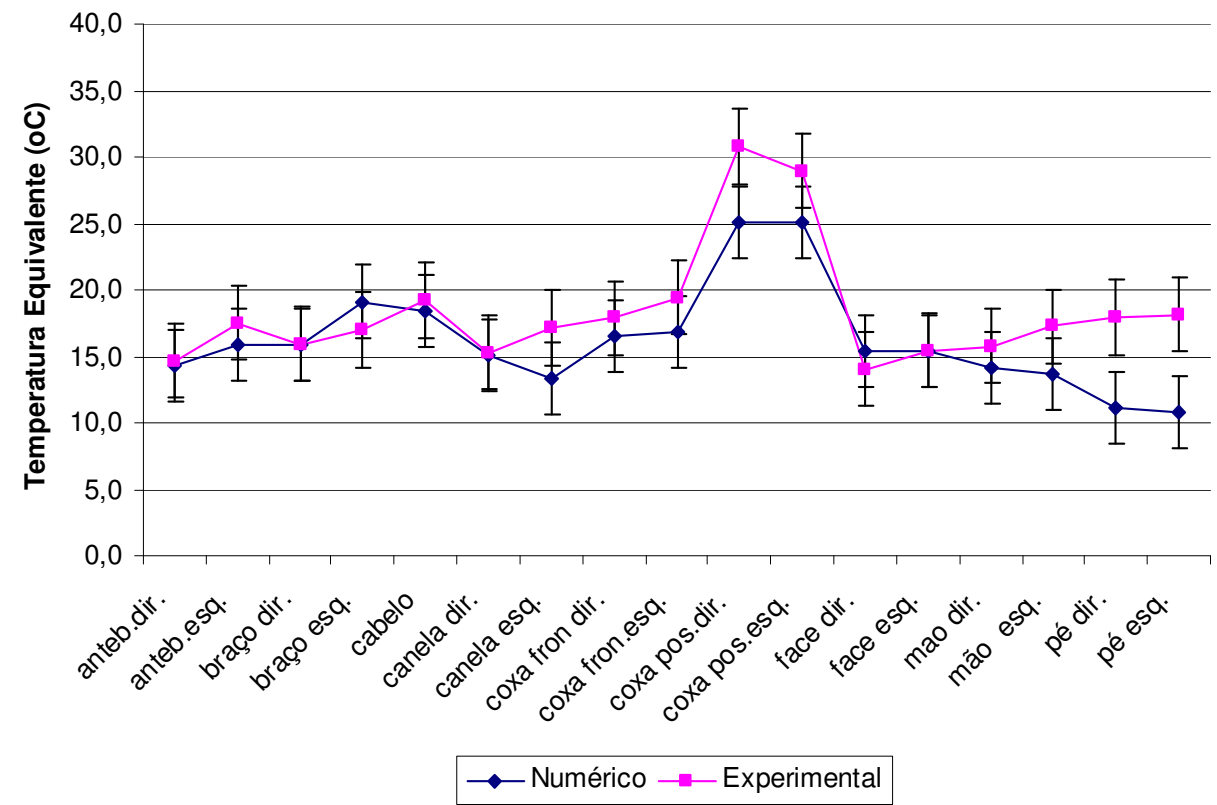

Figura 7.34 Temperaturas equivalente experimentais e numéricas com manequim posicionado na janela com simuladores com dissipação de $70 \mathrm{~W} / \mathrm{m}^{2}$.

Em todos os três experimentos ambos os manequins foram capazes de captar a mudança de temperatura média das cabines se compararmos as médias das temperaturas equivalentes da tabela 7.24 com as temperaturas do ar e superfícies das cabines da tabela 7.21. 
Percebe-se nos gráficos das fig. 7.32, 7.33, 7.34 que houve uma boa correlação para o caso da cabine mais quente e com diferenças maiores para os casos mais frios, como ocorreu no caso com o manequim próximo à fuselagem:

A média das diferenças entre as $t_{\text {eqs }}$ experimentas e numéricas é apresentada na tabela 7.25 .

Tabela 7.25 Média das diferenças entre as teqs experimentas e numéricas.

\begin{tabular}{cc}
\hline Casos & Média $\left(\mathrm{t}_{\mathrm{eq}} \underset{{ }^{\mathrm{O}} \mathrm{C}}{\exp }-\mathrm{t}_{\mathrm{eq}}\right.$ num. $)$ \\
\hline $70 \mathrm{~W} / \mathrm{m}^{2}$ & $-0,9$ \\
$50 \mathrm{~W} / \mathrm{m}^{2}$ & 2,9 \\
$0 \mathrm{~W} / \mathrm{m}^{2}$ & 2,1 \\
\hline
\end{tabular}

Nota-se na tabela 7.25 que também como no caso anterior (manequim junto à fuselagem, item 7.2.3) as diferenças médias entre as $t_{\text {eqs }}$ experimentas e numéricas aumentam com a diminuição das temperaturas do ar e das superfícies da cabine. Esta diferença é explicável, pois à medida que o ambiente fica mais quente, menores são os fluxos de calor e menores os erros.

As $t_{\text {eq }} \mathrm{s}$ experimentais para o lado esquerdo e direito (caso com dissipação térmica de $70 \mathrm{~W} / \mathrm{m}^{2}$ ) são apresentadas na fig. 7.35 .

\section{Corredor}

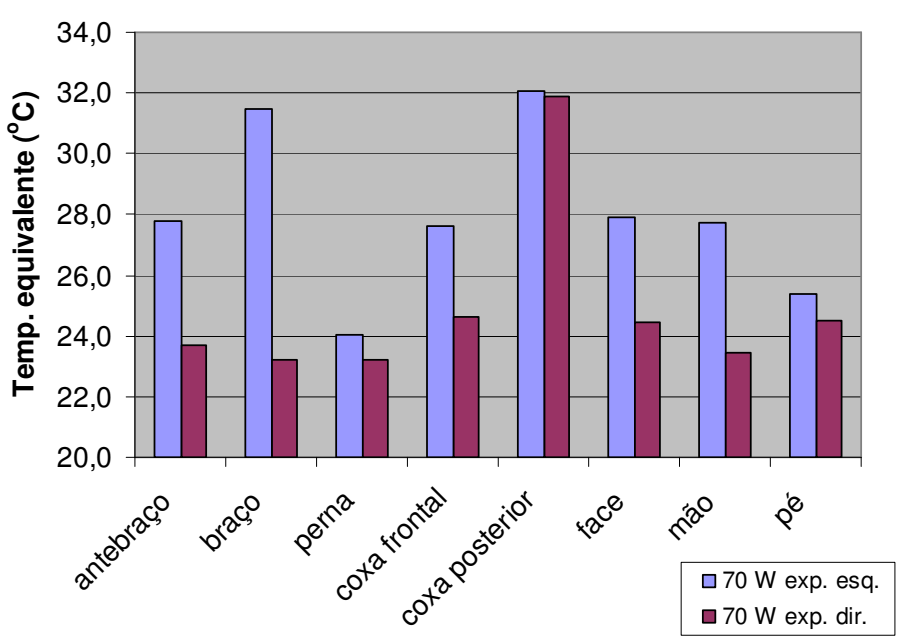

Figura 7.35 Valores de $t_{\mathrm{eq}} \mathrm{s}$ experimentais para o lado esquerdo e direito (caso com dissipação térmica de $70 \mathrm{~W} / \mathrm{m}^{2}$ ) 
Pode-se notar nos gráficos das fig. 7.32 e 7.33 assimetrias térmicas laterais para os casos que os manequins estavam com dissipação térmica $\left(70 \mathrm{~W} / \mathrm{m}^{2}\right.$ e $\left.50 \mathrm{~W} / \mathrm{m}^{2}\right)$. Isto pode ser observado nas fig. 7.32 e 7.33 tanto experimentalmente como numericamente. As temperaturas equivalentes do lado esquerdo foram mais altas do que do lado direito. Este efeito é mais proeminente no braço e mão como pode ser observado graficamente na fig. 7.35, mas também pode ser observado em todos os outros segmentos.

Os fluxos de troca de calor por radiação e convecção são apresentados nas fig. 7.36 e 7.37 .

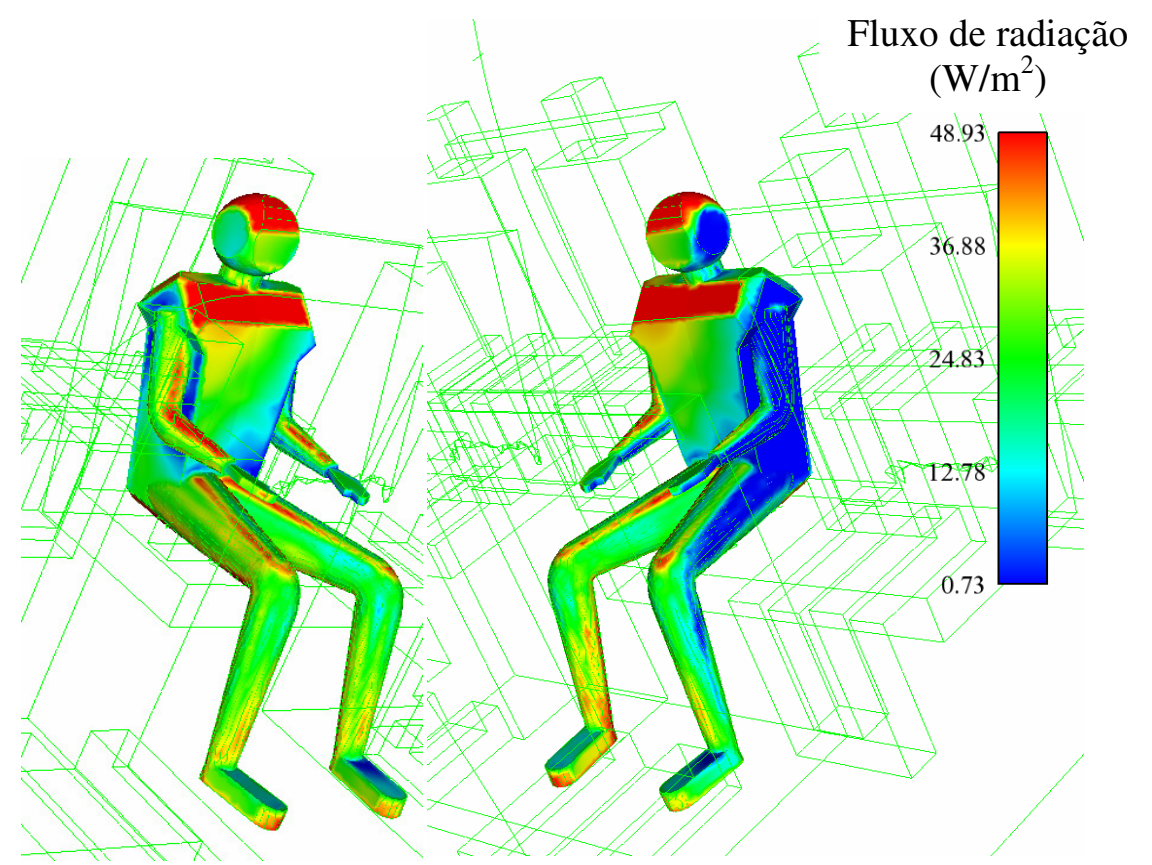

Figura 7.36 Fluxos de calor por radiação na posição próxima ao corredor. 


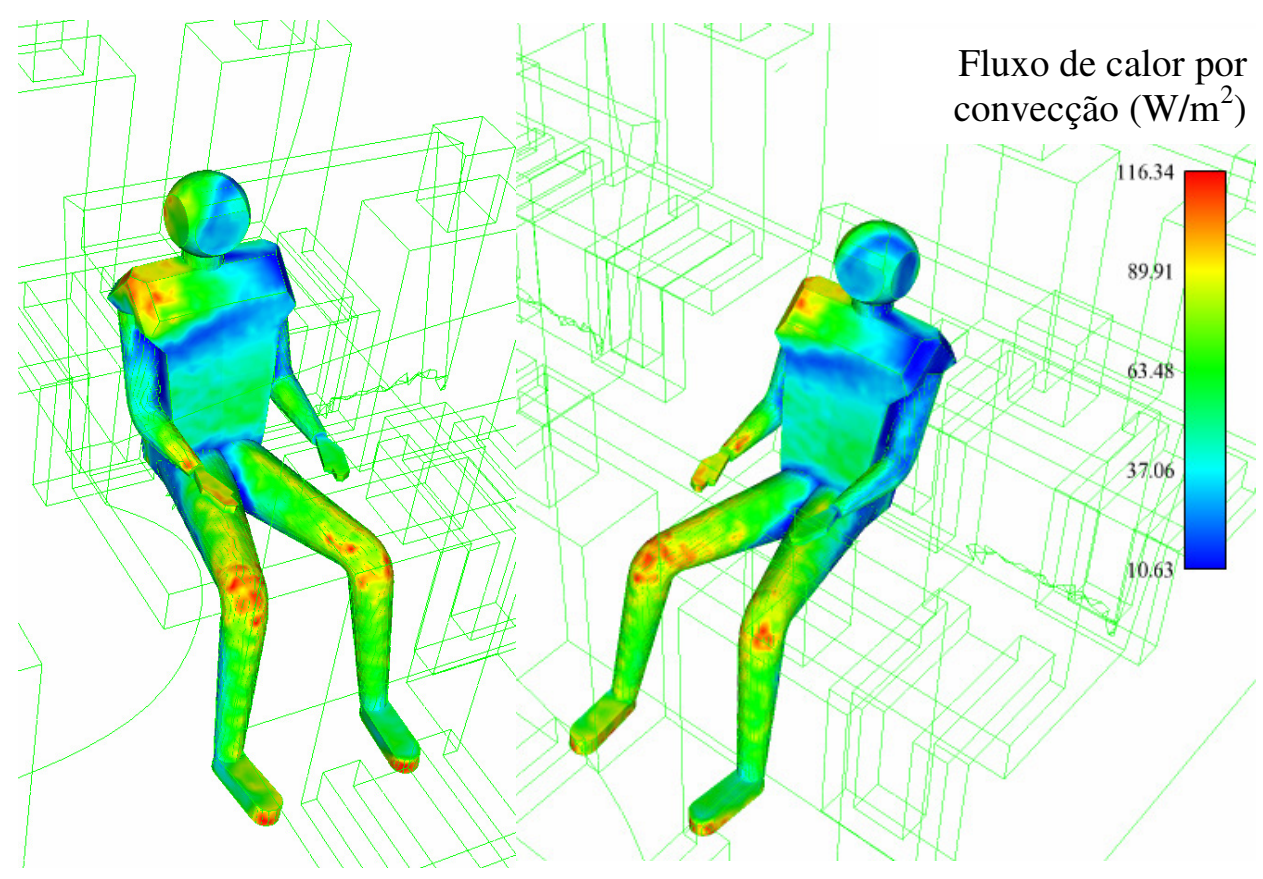

Figura 7.37 Fluxos de calor por convecção na posição próxima ao corredor.

Pode-se observar nas fig. 7.36 e 7.37 que as assimetrias dos fluxos de calor nas laterais são bem maiores nas trocas por radiação que por convecção. Portanto, assim como no caso do manequim próximo á fuselagem (item 7.2.3) assimetrias laterais nas $t_{\text {eqs }}$ se devem à fluxos de radiação assimétricos.

Também nesta posição, os segmentos que apresentaram maior discrepância entre os valores numéricos e experimentais foram as mãos e os pés, como pode ser observado nas fig. $7.32,7.33,7.34$.

Os segmentos que tiveram melhor correlação numérico-experimental foram a face esquerda e perna direita, como se pode observar nas fig. 7.32, 7.33, 7.34. Isto é um indicativo que a representação geométrica é bastante importante para se obter uma boa correlação numérico - experimental. Também serve de indicativo que as posições do corpo influenciam no conforto local.

\section{Diferenças Numérico-Experimentais das Temperaturas Equivalentes}

Os módulos das diferenças numérico-experimentais de cada segmento nas seis avaliações são apresentadas na tabela 7.26. 
Tabela 7.26 Módulos das diferenças numérico-experimentais de cada segmento nas seis avaliações.

\begin{tabular}{|c|c|c|c|c|c|c|c|}
\hline \multirow[b]{3}{*}{ Segmentos } & \multicolumn{7}{|c|}{ Módulo de $\left(\mathrm{t}_{\mathrm{eq}}\right.$ numérico $-\mathrm{t}_{\mathrm{eq}}$ experimental $)$} \\
\hline & \multicolumn{3}{|c|}{ Corredor } & \multicolumn{4}{|c|}{ Fuselagem } \\
\hline & $70 \mathrm{~W}$ & $50 \mathrm{~W}$ & $0 \mathrm{~W}$ & $70 \mathrm{~W}$ & $50 \mathrm{~W}$ & $0 \mathrm{~W}$ & Média \\
\hline anteb. dir. & 4,1 & 0,6 & 0,3 & 1,3 & 5,3 & 1,9 & 2,3 \\
\hline anteb. esq. & 1,0 & 4,0 & 1,6 & 3,7 & 5,1 & 7,6 & 3,8 \\
\hline braço dir. & 5,5 & 2,4 & 0,0 & 3,5 & 0,7 & 0,2 & 2,1 \\
\hline braço esq. & 0,2 & 2,4 & 2,2 & 0,4 & 2,9 & 0,5 & 1,4 \\
\hline escalpo & 0,1 & 5,1 & 0,8 & 0,7 & 5,6 & 4,4 & 2,8 \\
\hline perna dir. & 2,8 & 0,5 & 0,3 & 0,3 & 3,4 & 0,8 & 1,4 \\
\hline perna esq. & 2,6 & 0,8 & 3,9 & 1,1 & 3,1 & 4,0 & 2,6 \\
\hline coxa fron. dir. & 1,9 & 1,9 & 1,4 & 3,8 & 5,5 & 5,4 & 3,3 \\
\hline coxa fron. esq. & 0,2 & 2,6 & 2,6 & 2,5 & 4,4 & 8,0 & 3,4 \\
\hline coxa pos. dir. & 2,2 & 5,0 & 5,7 & 2,8 & 4,8 & 7,6 & 4,7 \\
\hline coxa. pos. esq. & 2,0 & 4,2 & 3,8 & 3,1 & 4,7 & 6,4 & 4,0 \\
\hline face dir. & 2,7 & 0,7 & 1,4 & 2,3 & 0,7 & 5,8 & 2,2 \\
\hline face esq. & 1,0 & 2,0 & 0,1 & 2,0 & 0,2 & 0,4 & 1,0 \\
\hline mão dir. & 1,2 & 2,7 & 1,7 & 1,7 & 4,8 & 6,6 & 3,1 \\
\hline mão esq. & 0,6 & 5,9 & 3,6 & 3,4 & 6,0 & 9,7 & 4,9 \\
\hline pé dir. & 1,6 & 8,8 & 6,9 & 5,7 & 8,5 & 7,4 & 6,5 \\
\hline pé esq. & 1,3 & 7,7 & 7,3 & 6,5 & 8,1 & 7,4 & 6,4 \\
\hline Medias & 1,8 & 3,4 & 2,6 & 2,6 & 4,3 & 4,9 & 3,3 \\
\hline
\end{tabular}

Admitindo uma incerteza nos valores experimentais de $\pm 2,8{ }^{\circ} \mathrm{C}$ e uma incerteza de $\pm 2,7{ }^{\circ} \mathrm{C}$ no cálculo numérico das temperaturas equivalentes, tem-se uma incerteza total de $\pm 5,5^{\circ} \mathrm{C}$. Analisando os dados na tabela 7.26 nota-se que os pés tiveram diferença maior que a incerteza total, sendo um indicativo que esta região necessita uma melhoria no modelamento. Como comentado anteriormente, mãos e pés necessitam uma representação geométrica melhor e um melhor detalhamento na geometria e condições de contorno. A inclusão do braço da poltrona com contato da mão e os pés tocando o piso poderão diminuir sensivelmente estas diferenças. Talvez a condutividade das espumas dos bancos, menor que a simulada $(0,04$ $\mathrm{W} / \mathrm{m}^{2} . \mathrm{K}$ ), seja uma das causas de temperaturas equivalentes numéricas menores que as medidas.

\section{Conclusão}

Foram calculadas as temperaturas equivalentes em duas posições de assentos em três condições térmicas. Ambos os manequins foram capazes de captar as mudanças térmicas ocorridas que impactam no conforto global. Ambos manequins captaram também as 
diferenças nos ambientes térmicos locais como a assimetria térmica lateral que os passageiros são submetidos. Houve uma boa concordância entre os valores das temperaturas equivalentes numéricas e experimentais com diferença média de $3,3{ }^{\circ} \mathrm{C}$. Notou-se que um melhor detalhamento geométrico e condições de contorno das regiões dos pés e mãos do manequim digital 2 são necessários. 


\section{Capítulo 8}

\section{Conclusões}

No presente trabalho foram feitas uma série de investigações do ambiente térmico em uma geometria de cabine de aeronave. Foram analisados quais os melhores modelos de turbulência e refinamento de malhas que possam fornecer os melhores resultados para os fluxos de calor dos passageiros. Medições experimentais e avaliações numéricas dos campos de temperatura, velocidade do ar e temperaturas equivalentes foram realizadas. Assim, todos os objetivos da tese foram amplamente cumpridos. Além disto, conseguiu-se uma boa correlação entre os valores numéricos e experimentais dos campos de temperatura do ar e temperaturas equivalente dos manequins. Verificou-se que passageiros estão submetidos a assimetrias térmicas laterais que contribuem para o desconforto térmico em vôo. Mostrou-se que estas assimetrias acorrem principalmente por assimetrias nas trocas térmicas por radiação. Consegui-se,assim, validar uma ferramenta numérica com resultados experimentais para avaliação do ambiente térmico de aeronaves. As conclusões abaixo listadas formam a base para a criação de uma metodologia numérica de avaliação de ambiente térmico de aeronaves e cabines em geral. A metodologia numérica e experimental aqui desenvolvida pode ser aplicada imediatamente para avaliação de conforto em cabines automotivas utilizando-se as cartas de conforto disponíveis em normas e literatura. Assim que cartas de conforto para aeronaves estiverem disponíveis, a metodologia numérica e experimental aqui descrita também poderá ser utilizada para avaliação de conforto térmico neste importante meio de transporte.

Espera-se assim que os fundamentos de metodologia aqui expostos sirvam para trabalhos futuros que venham a tratar de uma metodologia de avaliação de conforto térmico como próximo passo. Avaliações com pessoas utilizando como índice de conforto a temperatura equivalente está mostrando ser o caminho mais indicado para se obter as cartas de conforto. Assim, o desenvolvimento de um mock-up de aeronave com a possibilidade de simulação das temperaturas de fuselagem e piso mais realistas, com ambientação vibroacústica, fornecerá uma melhor percepção de vôo, fundamental para avaliações subjetivas com pessoas. Um mock-up que reproduza também de forma mais fidedigna a aeronave na sua forma e acabamento externos, ajudará também nesta percepção. Uma ambientação externa de 
aeroporto, balcões de $c h e c k$-in, e procedimentos de vôo que ajudem na percepção situacional da experiência de voo, ajudarão nesta ambientação psicológica.

Uma instrumentação mais adequada para medição dos campos de temperatura e velocidades do ar fornecerá dados para validar de forma ainda mais precisa os modelos numéricos. A retirada das placas de controle do manequim térmico experimental permitirá se medir as temperaturas equivalentes em todas as partes do tronco do manequim também. Um sistema de climatização que permita um correto balanceamento das vazões de ar na cabine tornará o ambiente térmico mais fiel ao do interior de aeronaves.

Este trabalho abre assim, o início de uma série de investigações sobre esta importante área da engenharia de conforto. Questões como a intercorrelação dos outros diversos aspectos do conforto humano com o conforto térmico serão exploradas em projeto em andamento entre a EMBRAER e a USP. Estes estudos servirão de fundamento para trabalhos mais aplicados visando prover os futuros ocupantes de aeronaves a possibilidade de ajuste personalizado de seu ambiente térmico. Espera-se, assim, que as principais conclusões e sugestões abaixo descritas sejam uma contribuição para os futuros trabalhos que se seguirão:

Chegou-se às seguintes principais conclusões:

1. Não houve grande influência dos modelos de turbulência estudados no cálculo das trocas térmicas por convecção. As variações nos fluxos de calor entre os modelos estão próximos de $10 \%$ dos valores médios, que corresponde aos erros experimentais normalmente encontrados.

2. Os melhores resultados dos fluxos de calor por convecção encontram-se com o uso de refinamento de malha sobre a superfície com y+ próximo de 4.

3. Obteve-se uma boa concordância do campo de temperatura numérico com o experimental com a diferença média entre os valores numérico-experimentais de $0,7{ }^{\circ} \mathrm{C}$.

4. Velocidades muito baixas do ar dificultaram uma melhor medição de campos de velocidades para validação com os resultados numéricos. As oscilações das velocidades nas entradas de ar dificultam uma medição precisa das condições de contorno para as simulações numéricas. A simulação numérica serviu como um indicativo do formato do campo de velocidades. Experimentalmente verificou-se que as plumas térmicas dos passageiros aumentam as velocidades em uma cabine com vazões típicas.

5. Foram calculadas as temperaturas equivalentes em duas posições de assentos e em três condições térmicas. Ambos os manequins térmicos (experimental e 
digital 2) foram capazes de perceber as mudanças térmicas ocorridas que impactam no conforto global e captaram também as diferenças nos ambientes térmicos locais como a assimetria térmica lateral que os passageiros são submetidos. Houve uma boa concordância entre os valores das temperaturas equivalentes numéricas e experimentais com diferença média de $3,3{ }^{\circ} \mathrm{C}$.

Concluiu-se assim que os modelos numéricos utilizados neste trabalho podem ser utilizados como uma boa ferramenta para predição do ambiente térmico em aeronaves. Sugerem-se, assim, as seguintes linhas de trabalho para desenvolvimento futuro:

1. Melhoria na geração da geometria do manequim virtual. Detalhar a geometria especialmente dos pés e mãos e das condições de contorno próximas, como o contato da mão com o braço da cadeira e do pé com o piso.

2. Construção de diagramas de sensação térmica para aeronaves. Foi utilizado nesta tese para se prever o conforto térmico local os diagramas de sensação térmica levantados para a indústria automobilística. Requerem-se dados específicos para a indústria aeronáutica, onde as condições térmicas e psicológicas são bastante diferentes.

3. Melhor avaliação dos campos de velocidade do ar dentro da cabine. Nota-se na literatura que o uso de velocimetria por imagens de partículas (PIV) tem sido uma ferramenta comum para validação de cálculos de CFD.

4. Verificou-se que as assimetrias térmicas são uma realidade para a disposição atual das poltronas em vôo comerciais. Um estudo de modificação do ambiente térmico por superfícies aquecidas/resfriadas e difusores localizados pode trazer soluções que poderiam minimizar este efeito.

5. Um estudo de criação de micro climas personalizados em aeronaves comerciais e privadas. Diversas arquiteturas de insuflamento e retorno do ar com aquecimento /resfriamento de assentos poderiam ser modeladas em CFD e posteriormente implementadas experimentalmente para validação/ajustes de parâmetros.

Vê-se assim que este complexo campo do conforto térmico em aeronaves está somente no início de seu desenvolvimento. Esta tese foi o primeiro passo para outros que se seguirão para o aprimoramento da complexidade do bem estar humano. 


\section{Capítulo 9}

\section{Referências bibliográficas}

IMM (1997). Proceedings of a European Seminar on Thermal Manikin Testing (eds. Nilsson H., Holmér I.) Arbetslivsinstitutet, Department of Ergonomics. Arbetslivsrapport 1997:9 (ISSN 1401-2928).

3IMM (1999). Proceedings of the Third International Meeting on Thermal Manikin Testing (eds. Nilsson H., Holmér I.) Arbete \& Hälsa 2000:4 (ISBN-7045-554-6. ISSN 0346-7821).

4IMM (2001). Proceedings of the Fourth International Meeting on Thermal Manikins. 27 28th September 2001. Hosted by EMPA in St. Gallen, Switzerland.

5I3M (2003). Proceedings of the 5th International Meeting on Thermal Manikin and Modelling, trasbourg, 29 - 30th September 2003.

6I3M (2006). Proceedings of the 6th International Thermal Manikin and Modeling Meeting at The Hong Kong Polytechnic University, Hong Kong SAR. 16 - 18th October 2006.

ABOOSAIDI, F.; WARFIELD, M. J.; CHOUDHURY, D. (1992). Computational fluid dynamics application in airplane cabin ventilation system design. Proceedings - Society of Automotive Engineers. 246: 249-258. SAE Paper 911992.

ALFAHAID, A.F.; CHATURVEDI, S. K.; TIWARI, S. N. (1999). Evaluation of Aerospace Environmental Control Systems Using an Objective Thermal Stress Index (OTSI). $33^{\text {rd }}$ Thermophysics Conference. Norfolk, USA. AIAA 99 - 3502, A99-33902.

ASHRAE Thermal Environmental Conditions for Human Occupancy. (ANSI/ASHRAE Standard 55-2004), American Society of Heating, Refrigerating, and Air-Conditioning Engineers, Inc., Atlanta - USA, 2004.

ASHRAE. ASHRAE Handbook of Fundamentals. American Society of Heating, Refrigerating, and Air-Conditioning Engineers, Inc., Atlanta - USA, 2005.

BEDFORD, T. (1936) The warmth factor in comfort at work. MRC Industrial Health Board Report HMSO, London, UK, v. 76. 
BELDING, H. (1949) Protection against dry cold. Physiology of heat regulation and the science of clothing, WB Saunders Company, p. 351-367.

BENZINGER, T. H.; A. W. PRATT et al. (1961). The Thermostatic Control of Human Metabolic Heat Production. Proc. Natl. Acad. Sci. 47: 730.

BJØRN, E. (2000) Simulation of human respiration with breathing thermal manikin. Proceedings of the Third International Meeting on Thermal Manikin Testing, 3IMM (eds. Nilsson H., Holmér I.), Arbete \& Hälsa 2000:4, arbetslivsinstitutet.se, p. 78-82.

BOHM, M.; NOREM, O.; HOLMÉR I.; NILSSON, H. O. (1999). Factors affecting the equivalent temperature measured with thermal manikins. Proceedings of the Third International Meeting on Thermal Maninikin Testing, 3IMM, ISBN 91-7045-554-6.

BOHM, M.M.; BROWEN, M.; HOMÉR, I.; NILSSON, H.; NOREN, O. Evaluation of vehicle climate with a thermal manikin - The relationship between human temperature experience and the local heat loss, Swedish Institute of Agricultural Engineeing. JTI- Report $123,1990$.

BROHUS, H.; NIELSEN P. (1996). CFD Models of Persons Evaluated by Full-Scale Wind Channel Experiments. Proceedings of the 5th International Conference on Air Distribution in Rooms (ROOMVENT 96). Yokohama, Japão, p. 137-144.

BUXON, A., ZHUBRIN, S.; DAANEN, H. (2003) The QinetiQ virtual manikin Incorporation of a thermophysiological model. Proceedings of the 5th International meeting on thermal manikins and modelling, 5I3M, Strasbourg, França, CD cepa.c-strasbourg.fr.

CABCLI Consortium (1999) Assessment of thermal climate in operator's cabs. Relatório JTI 270. Florença, Itália. ISSN 1401-4963.

CHEN, X.; CHEN, Q. Y. (2007) Numerical investigation of decontaminant delivery strategies in commercial aircraft cabin. Proceedings of Roomvent 2007. Helsink,.

COLEMAN, H. W.; STEELE, W. G (1989). Experimentation and uncertainty analysis for engineers. John Wiley \& Son. New York.

CONCEIÇÃO, E. Z. E.; SILVA, M.C.G.; VIEGAS, D.X. (1997) Airflow around a passenger seated in a bus. HVAC\&R Research, October 1997, v. 3, n. 4.

DE DEAR, R. J.; ARENS, E.; ZHANG, H. M. O.(1997). Convective and radiative heat transfer coefficients for individual human body segments. Int J. Biometeorol, v. 40, 141-156. 
FANGER, P. O.; MELIKOV,A. K.; HANZAWA,H. ; RING, J. (1988). Air turbulence and

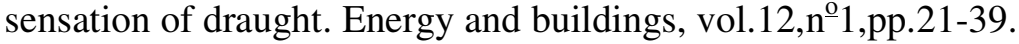

FANGER, P. O. (1972). Thermal Comfort, Analysis and Application in Environmental Engineering. McGraw-Hill, New York, 245 p.

FERREIRA, M. S. Um Modelo do Sistema Termorregulador do Corpo Humano: Exposição a Ambientes Quentes. Dissertação de Mestrado, Escola Politécnica da Universidade de São Paulo, São Paulo. 130 p., 1997.

FERREIRA, M. S. Um Modelo do Sistema Térmico do Corpo Humano. Tese de Doutorado, Escola Politécnica da Universidade de São Paulo, São Paulo, 166 p., 2001.

FLUENT (2006). FLUENT User's Guide. Fluent Inc., Lebanon

FORBES (2006). http://www.forbes.com/2006/05/23/unsolicited-advice-advertisingcx_meb_0524boeing.html. Site visitado em 15/06/2008.

GAN, G. (1994) Numerical method for a full assessment of indoor thermal comfort. Indoor Air, 4: 154-168.

GAO, N. P.; NIU, J. L. (2007). Personalized ventilation for commercial aircraft cabins. $45^{\text {th }}$ AIAA Aerospace Sciences Meeting and Exhibit. Reno, Nevada, EUA.

GAO, N. P.; ZHANG, H.; NIU, J. L. (2006). Investigating Indoor Air Quality and Thermal Comfort Using a Numerical Thermal Manikin. Indoor and Built Environment 2007; 16; 1:717.

GLOBO (2007) http://g1.globo.com/Noticias/Brasil/0,,MUL87144-5598,00.html. Site visitado em 15/03/2008.

GRUN, G.; HELLWIG, R. T.; TRIMMEL M.; HOLM, A. H. (2008). Interrrelations of comfort parameters in a simulated aircraft cabin. Proccedings of Indoor air 2008. Copenhagen, Dinamarca.

HAGHIGHAT, F.; ALLARD F.; MEGRI, A. C.; BLONDEAU, P.; SHIMOTAKAHARA R. (1999). Measurement of thermal comfort and indoor air quality aboard 43 flights on commercial airlines. Indoor-Built Environmet; 8:58-66. 
HAILONG, M.; HOSNI, M. H.; JONES B. W. (2003). Application of particle image velocimetry for the measurement of the airflow characteristics in aircraft cabin. ASHRAE Transactions 2003; 109 (2): 101-110.

HAN, T.; HUANG, L.; KELLY, S.; HUIZENGA, C.; HUI, Z. (2001) Virtual thermal comfort engineering. SAE 2001, World Congress, Detroit, USA, 2001-01-0588.

HAN, T.; HUANG, L. (2004) A model for relating a thermal comfort scale to EHT comfort index. SAE 2004, World Congress, Detroit, USA, 2004-01-0919.

HAN, T.; HUANG, L. (2005) A sensitivity study of occupant thermal comfort in a cabin using virtual thermal comfort engineering. SAE 2005, World Congress, Detroit, USA, 200501-1509.

HOLMÉR, I.; NILSSON, H.; BOHM, M.; BROWÉN, A.; NOREN, O. (1992). Evaluation of thermal environment in automotive vehicles. 2nd ATA Int Conf. on Vehicle Comfort Ergonomic, Vibrational, Noice and Thermal Aspects, Italy, p. 295-302.

HUIZENGA, C.;HUI, Z.; ARENS, E. (2001). A model of human physiology and comfort for assesing complex thermal environments. Building and Environment, n. 36, 691-699.

INMETRO, (1998). Guia para expressão da incerteza de medição. 2a . ed. Instituto Nacional de Metrologia e Associação Brasileira de Normas Técnicas.

IRGENS, S.; MELIKOV, A.; (2004) Assessment of the thermal environment in an aircraft cabin. Proceedings of Roomvent 2004, Coimbra.

ISO 14505-1 (2006) - Ergonomic of the thermal environment - Evaluation of thermal environment in vehicles. Part 1: Principles and methods for assessment of thermal stress. International Organization for Standardization, Genebra.

ISO 14505-2 (2006) - Ergonomic of the thermal environment - Evaluation of thermal environment in vehicles. Part 2: Determination of equivalent temperature. International Organization for Standardization. Genebra.

ISO 14505-3 (2006) - Ergonomic of the thermal environment - Evaluation of thermal environment in vehicles . Part 3: Evaluation of thermal comfort using human subjects. International Organization for Standardization, Genebra.

ISO 7726 (1998) - Ergonomics of the thermal environment - Instruments for measuring physical quantities. International Organization for Standardization. Genebra. 
ISO 7730 (1994) - Moderate thermal environments - Determination of the PMV and PPD indices and specification of the conditions for thermal comfort. International Organization for Standardization, Genebra.

KANG (2002) An Occupant-Coupled CFD Model for Local WBGT Analysis in a ventilated enclosure. Journal of the Human-Environment System, Society of Human Environment System, v. 5, n. 2, p. 79-86.

KATO, S. (1996) Numerical analysis of contaminant distribution around a human body. Proceedings of the 5th International conference on air distribution in rooms (ROOMVENT 96), Yokohama, Japan, v. 2, p. 129-136.

KELLER, A. D.; HARE, W.K. (1932). Proceedings of Soc. Exptl. Biol. Med. 29: 1069.

KOHRI, I.; KATAOKA, T. et al. (1995). Evaluation Method of Thermal Comfort in a Vehicle by SET* Using Thermal Manikin and Theoretical Thermoregulation Model in Man. IMechEC 496(022): 357 - 363.

LEBBIN, P. A.; HOSNI, M. H. (2005). Automobile climate measurements using two thermal observation manikins. Digital Human Modeling for Design and Engineering Symposium, Iowa City, Iowa. 14-16, Junho, 2005. SAE Technical Paper Series nº 2005-01-2732

LIN, C. H.; HORSTMAN, R. H.; AHLERS, M. F.; SEDGWICK, L. M. (2005a) Numerical simulation of airflow and airborne pathogen transport in aircraft cabins. Part I - numerical simulation of the flow field. ASHRAE Transactions 2005, v. III (1), p. 755 - 763.

LIN, C. H.; HORSTMAN, R. H.; AHLERS, M. F.; SEDGWICK, L. M. (2005b) Numerical simulation of airflow and airborne pathogen transport in aircraft cabins. Part II - numerical simulation of airborne pathogen transport. ASHRAE Transactions 2005, v. III (1), p. 764-768.

LOOMANS, M.; JACOGBS, P.; TISSOT, A.; MILES, S. (2004). In-flight measurement and simulation of aircraft environment. Proceedings of Roomvent 2004. Coimbra.

MADSEN, T. L.; OLESEN, B. W.; READ, K. (1986). A new method for evaluation of the thermal environment in automotive vehicles. ASHRAE Trans. 92. 38-54.

MADSEN, T.; OLESEN, B.; KRISTENSEN, N. (1984) Comparison between operative and equivalent temperature under typical indoor conditions. ASHRAE Transactions, Ashrae. Org., v. 90 , part 1, p. 1077-1090.

MARTINHO, N. A. G.; SILVA, M. C. G.; RAMOS J. A. E. (2004). Evaluation of thermal comfort in vehicle cabin; J. Automobile Engineering, v. 1, 218, Part. D. 
MATSUNAGA, K.; SUDOU, F.; TANABE, S. I (1997) Evaluation of comfort of thermal environment in vehicle occupant compartment. Technical Notes/JSAE Review 18 (1997) 5783.

MAUÉ, J.; WAHL, D.; CURRLE, J. (1997). Computation of the Thermal Environment in Passanger Compartments and Evaluation of Thermal Comfort. Proceedings of comfort in the automotive industry - Recent development and achievements. Bologna, Italy, ATA v. 1, p. 147-155.

MAZUMDAR, S.; CHEN, Q. Y. (2007). Impact of moving bodies on airflow and contaminant transport inside aircraft cabins. Proceedings of Roomvent 2007. Helsink

MCINTYRE, D. A. (1980). Indoor Climate. London, Applied Science Publishers LTD.

MELIKOV A.; ZHOU, H. (1999) Comparison of the methods for determining $t_{\mathrm{eq}}$ under welldefined conditions. Assesment of thermal climate in operators cabs. Seminar in Florence 18 19 November 1999. CABCLI Consortium. JTI-rapport Lantbruk \& Industri 270. ISSN 14014963.

MOURA, D. (2009) Condições do escoamento e de conforto térmico em cabine de aeronave. Dissertação de Mestrado. Departamento de Engenharia Mecânica. Escola Politécnica da Universidade de São Paulo, São Paulo, 74p., 2009.

MURAKAMI, S. (2004) Analysis and design of micro-climate around the human body with respiration by CFD, Indoor Air, 14 (Suppl 7): 144-156.

MURAKAMI, S.; KATO, S.; KIM, T. (2001). Indoor climate design based on CFD coupled simulation of convection, radiation, and HVAC control for attaining a given PMV value. Building and Environment, v. 36, p. 701-709.

MURAKAMI, S.; KATO, S.; ZENG, J. (1998) Numerical Simulation of Contaminant Distribution Around a Modelled Human Body: CFD Study on Computational Thermal Manikin - Part II. ASHRAE Transactions, ashrae.org, v. 104, part 2, p. 226-233.

MURAKAMI, S.; KATO, S.; ZENG, J. (1997) Flow and Temperature Fields Around Human Body with Various Room Air Distribution: CFD Study on Computational Thermal Manikin Part I. ASHRAE Transactions, ashrae.org, v. 103, part 1, p. 3-15.

NILSSON, H. O.; BROHUS, H.; NIELSEN, P. V. (2007) CFD modeling of thermal manikin heat loss in a comfort evaluation benchmark test. Proceedings of Roomvent 2007. Helsink. 
NILSSON, H. O. (2005) Thermal comfort evaluation with virtual manikin methods. Proceedings Indoor Air 2005, Beijing, China.

NILSSON, H. O. (2004) Comfort Climate Evaluations with Thermal Manikin Methods and Computer Simulation Models. Doutorado no Department for Work and Health, National Institute for Working Life, Estocolmo. ISBN 91-7045-703-4.

NILSSON, H. O.; HOLMÉR, I. (2002). Definitions and Measurements of Equivalent temperature. EQUIV Report n.1, European Commission Cost contract No SMT4 CT95-2017 (registrator@arbetslivsinstitutet.se): Dnr 2002-0213 National Institute for Working Life.

NILSSON, H.; HOLMÉR, I.; BOHM, M.; NORÉN, O. (1997). Equivalent temperature and thermal sensation - Comparison with subjective responses. Proceedings of comfort in the automotive industry - Recent development and achievements, Bologna, Italy, ATA v.1, p. 157-162, 97A3018.

ROY, D.; PETITJEAN, P.; CLODIC, D. (2003). Influence of various heat transfer on passenger thermal confort. 2003 SAE World Congress, Detroit, Michigan. 3-6, Março, 2003. SAE Technical Paper Series 2003-01-1075.

RUGH, J. P.; BHARATHAN, D. (2005) Predicting human thermal comfort in automobiles. Vehicle Thermal Management Systems Conference and Exhibition. Toronto, Canada. 10-12 de Maio, 2005. SAE Technical Paper Series 2005-01-2008.

SINGH, A.; HOSNI, M. H.; HORSTMAN, R. H. (2002) Numerical simulation in an aircraft cabin section. ASHRAE Transaction, v. 108 (1), p. 1005-1013.

SMACNA (1990). SHEET METAL AND AIR CONDITIONING CONTRACTOR'S NATIONAL ASSOCIATION (U.S.). 1990 HVAC - System Duct Design. Terceira edição, Vienna, Va., EUA.

STANCATO, F.; FERREIRA, T. A.; ARAÚJO, G. S.; CRUZ, D. A.; TRIBESS, A.; PUSTELNIK, M.; SANTOS, L. C. C. (2006) Aircraft cabin thermal comfort evaluation using numerical manikins. Congresso SAE Brasil 2006. São Paulo, Brasil. SAE paper 2006-012562.

STROM-TEJSEN, P. S.; ZUKOWSJA, D.; JAMA, A.; WYON, D. P. (2007) Assesment of the thermal environment in a simulated aircraft using thermal manikin exposure, Proceedings of Roomvent 2007. Helsink, Finlândia.

STROM-TEJSEN, P.S; WYON, D. P.; ZUKOWSJA, D.; JAMA, A.; FANG, L. (2005) Occupant evaluation of 7-hours exposures in a simulated aircraft cabin. Part 2: thermal effects. Proceedings Indoor Air 2005. Beijing, China. 
SUN, Y.; ZHANG, Y.; WANG, A.; TOPMILLER, J. L.; BENNET, J. S. (2005a). Experimental characterizing of airflow in aircraft cabins. Part I - experimental system and measurement procedure. ASHRAE Transaction 2005, 111(2): 45-52

SUN, Y.; ZHANG, Y.; WANG, A.; TOPMILLER, J. L.; BENNET, J. S. (2005b). Experimental characterizing of airflow in aircraft cabins. Part II - results and research recommendations. ASHRAE Transaction 2005, 111(2): 53-59

TANABE, S.; OZEKI, Y.; TAKABAYASHI, T. (2002) Numerical Comfort Simulator for Evaluating Thermal Environment. Proceedings of the 10th International Conference on Environmental Ergonomics, Fukuoka, Japan, p. 435-438.

VUOLO, J. H. (1996). Fundamentos da teoria de erros, $2^{\circ}$ ed., Edgard Blücher Ltda, São Paulo.

WAHL, D. (1995). Rechnerische Untersuchungen Zum Thermischen Komfort in Fahrzeugkabinen.

WYON, D. P.; TENNSTEDT, C.; LUNDGREN, I.; LARSSON, S. (1985). A new method for the detailed assessment of human heat balance in vehicles - Volvo's Thermal Manikin, Voltman. SAE Technical Paper Series 850042, 1985.

WYON, D. P.; S. LARSSON et al (1989). Standard Procedures for Assessing Vehicle Climate with a Thermal Manikin. SAE Technical Paper Series 890049: 1-11.

YAGLOU, C. P. (1947). A method for improving the effective temperature index. ASHVE Trans. 53:307, 1947.

ZHANG, H. (2003) Human thermal sensation and comfort in transient and non-uniform thermal environment. Tese. Universidade da California, Berkley.

ZHANG, T,; CHEN, Q. Y.; LIN, C. H. (2007a) Optimizing contaminant sensor locations in a twin-aile aircraft cabin. Proceedings of Roomvent 2007, Helsink, Finlândia.

ZHANG, T.; CHEN, T. Z. (2007). Novel air distribuition systems for commercial aircraft cabins. Building and Environment 42, 165-1684.

ZHANG, Z.; CHEN, X.; MAZUNDAR, S.; ZHANG, T.; CHEN, Q. (2007b). Experimental and numerical investigation of airflow and contaminant transport in an airliner cabin mockup. Proceedings of Roomvent 2007, Helsink, Finlândia. 
ZHIHUA, J.; YUHANG, S. (1999). Standardization of measuring clothing thermal resistance with thermal manikin. Proceedings of the Third International Meeting on Thermal Maninikin Testing, 3IMM, ISBN 91-7045-554-6. 